\title{
Design of Phosphorus Centered JanUs HEAD LIgANDS
}

\author{
Dissertation zur Erlangung des \\ mathematisch-naturwissenschaftlichen Doktorgrades \\ "Doctor rerum naturalium" \\ der Georg-August-Universität Göttingen
}

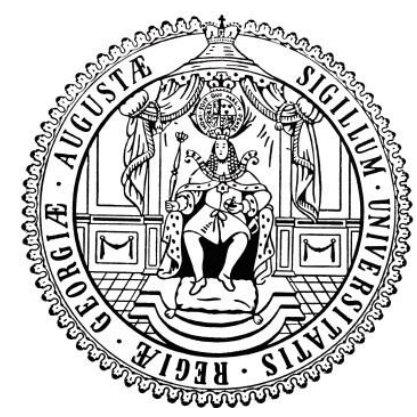

vorgelegt von

Dipl.-Chem. Ina Objartel aus Kiel

Göttingen 2011 
Referent: Prof. Dr. D. Stalke

Korreferent: Prof. Dr. Dr. h.c. mult. H. W. Roesky

Tag der mündlichen Prüfung: 31.10.2011 


\section{DANKSAgUNG}

Die vorliegende Arbeit wurde in der Zeit von November 2007 bis Oktober $2011 \mathrm{im}$ Arbeitskreis von Herrn Prof. Dr. Dietmar Stalke am Institut für Anorganische Chemie der Universität Göttingen angefertigt. An dieser Stelle möchte ich allen danken, die zum Gelingen dieser Arbeit beigetragen haben.

An erster Stelle möchte ich meinem Doktorvater Prof. Dr. Dietmar Stalke für die interessante Themenstellung und für das Vertrauen, dass er in mich gesetzt hat, danken.

Herrn Prof. Dr. Dr. h.c. mult. Herbert W. Roesky danke ich für die Übernahme meines Korreferats.

Dem gesamten Arbeitskreis Stalke bin ich dankbar für die fantastische Arbeitsatmosphäre. Ich habe zu schätzen gelernt, dass in diesem Arbeitskreis immer jemand da war, der mir mit Rat und Tat zur Seite gestanden hat, wenn es nötig war. Und auch wenn es mal nicht so gut lief, wurden schnell tröstende Worte oder ein blöder Spruch, der einen auf jeden Fall zum Lachen gebracht hat, gefunden.

Im speziellen danken möchte ich...

... meinen Korrektur-Lesern Dirk Leusser, Jakob Hey, Markus Granitzka, Manuel Wittenberg, Hilke Wolf und Reent Michel, die mir sehr geholfen haben und im Wesentlichen zum Gelingen dieser Arbeit beigetragen haben.

... Hilke Wolf, die mir mehr geholfen hat als das selbstverständlich wäre und die auch am Wochenende und nach Feierabend immer prompt korrigiert hat, damit ich alles in der vorgegebenen Zeit schaffe. Ganz nebenbei hat sie es auch geschafft mich immer wieder aufs Neue zu motivieren. Vielen Dank dafür!

... Dirk Leusser, der mir in einem Crash-Kurs experimentelle Elektronendichte Analyse näher gebracht hat. Und der, obwohl er eigentlich nicht mehr in Göttingen ist, mich während des Zusammenschreibens so hervorragend unterstützt hat.

... meinen Laborkollegen in alten Zeiten Thomas Schulz und Gerald Schwab. Wenn wir denn mal alle drei gleichzeitig im Labor gestanden haben, war es immer lustig. ... Ann-Christin Pöppler, die mich aus der Einsamkeit in Labor $2 / 3$ befreit hat. ... Arne Visscher und Sebastian Wandtke, die ganz zum Schluss meiner Laborzeit noch dazu gestoßen sind und mich im Labor gut unterhalten haben. Ich sage nur: „Arne du bewegst dich auf waffeldünnem Eis!“

... meiner Mitleidensgenossin Vera Kruse (na gut, Konstanzer), die mir eine große moralische Stütze während der Zeit des Zusammenschreibens war. Jetzt weiß ich wirklich was der Spruch „Geteiltes Leid ist halbes Leid“ heißt. Vera, du bist mir mehr wert als 1000 Kamele! 
... der alten Würzburger Truppe (Ulli Flierler, Holger Ott, Thomas Schulz, Stephan Deuerlein) und den zwei Südschweden (Christian Kling und Daniel Stern), die mich damals so herzlich im Arbeitskreis aufgenommen haben. Und ich bin immer noch stolz darauf als Würzburgerin ehrenhalber ernannt worden zu sein! Am meisten freue ich mich aber darüber, dass wir alle immer noch in Kontakt stehen!

... Sandra Altmannshofer, die aus dem noch viel südlicheren Bayern zu uns gestoßen ist, für die Unterstützung beim Erstellen der ED-Bildchen und für die immer guten Gespräche.

... Felix Engelhardt, dafür dass er mich davor bewahrt hat durchzudrehen und stattdessen am Sonntagabend bei Wind und Wetter in die Uni gekommen ist, um meine Daten zu retten.

... den drei Maschinen-Schraubern Markus Granitzka, Jakob Hey und Daniel Kratzert, dafür dass ihr die Maschinen für uns so gut in Schuss gehalten habt, aber auch für die viele Hilfe und dass mit euch albern sein am meisten Spaß macht.

... Heike Tappe, die mir immer mit Rat und Tat zur Seite stand, für die vielen guten Gespräche.

... Regine Herbst-Irmer, die wirklich jedes, und damit meine ich jedes, kristallographische Problem im Nu lösen kann. Vielen Dank für die Hilfe bei kniffeligen Datensätzen!

... Martin Schlote für das Bereitstellen jeglicher Chemikalien und Laborgeräte, sowie der NMR- und Analytik-Abteilung für das Messen meiner Proben.

... meinen Göttinger Kollegen, Vera Konstanzer, Magret Meinholz, Susanne Kohlmajer, Henning Böckemeier und Manuel Wittenberg, die mich von Anfang an hier in Göttingen begleitet haben.

... meine ehemaligen AC-F Praktikanten Julia Matussek, Felix Engelhardt, Stefan Koppermann und Harish Potukuchi für die tatkräftige Unterstützung im Labor.

... allen, denen der Dank gebührt, die ich aber hier vergessen habe aufzulisten. Seht es mir nach!

... meinen Freunden, meiner Familie und vor allem meinen Eltern, die mich immer unterstützt und mir Mut gemacht haben.

... Jörg Gründer für seine Liebe und sein Vertrauen in mich. 


\section{CONTENTS}

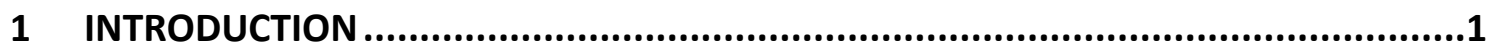

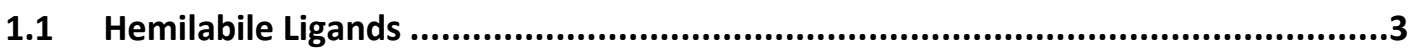

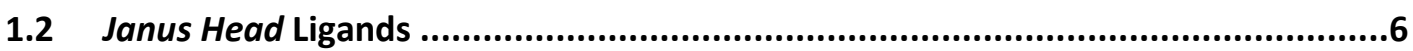

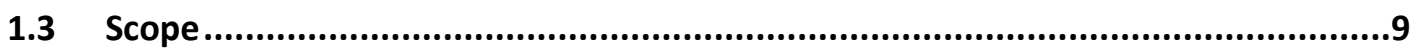

2 EXPERIMENTAL ELECTRON DENSITY STUDIES ON DI-2-PICOLYLPHENYLPHOSPHANE11

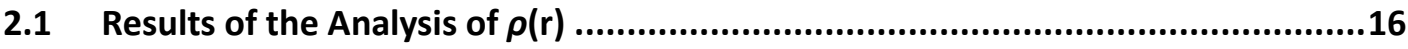

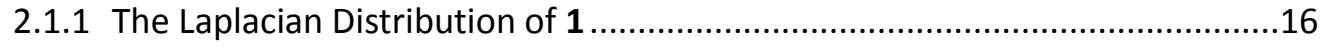

2.1.2 The Electrostatic Potential of 1.............................................................18

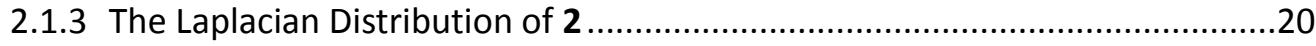

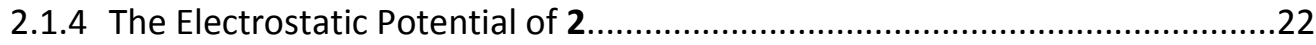

3 DEPROTONATION OF DI-2-PICOLYLPHENYLPHOSPHANE ...................................25

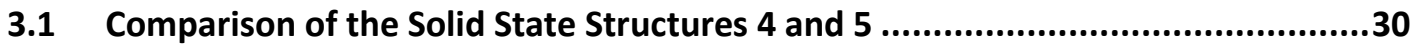

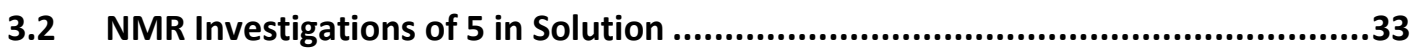

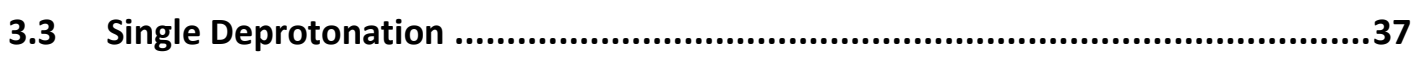

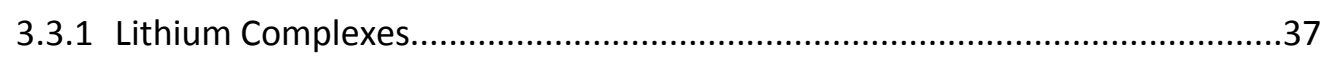

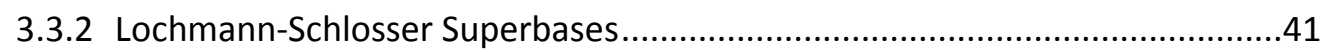

3.3.3 Solid State Structure of a Superbase $\mathrm{Li}_{4} \mathrm{~K}_{4}$ Adduct......................................48

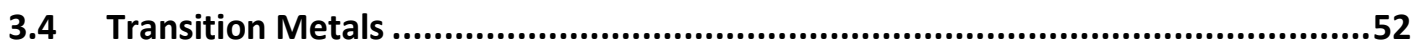

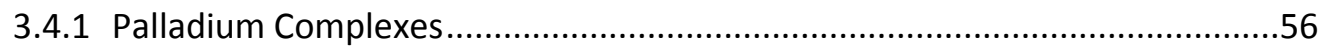

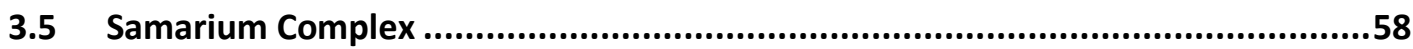

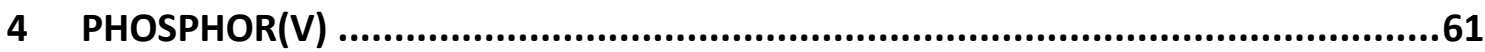

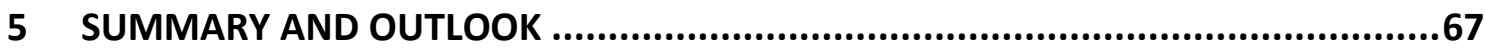




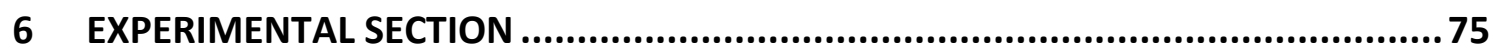

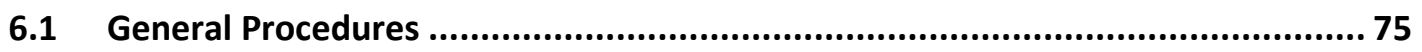

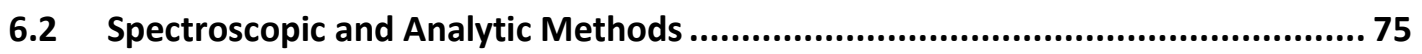

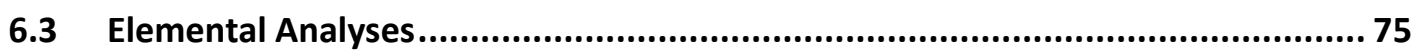

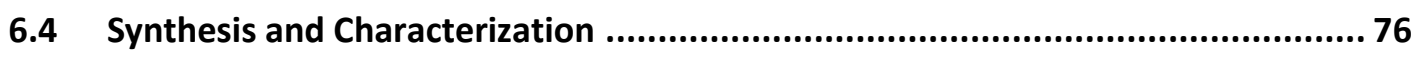

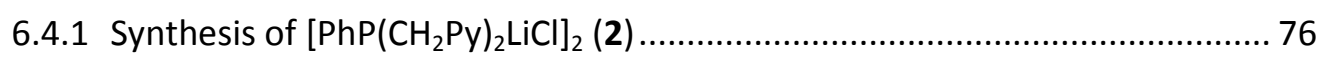

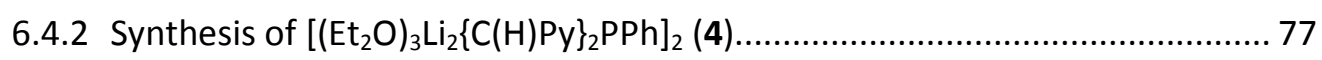

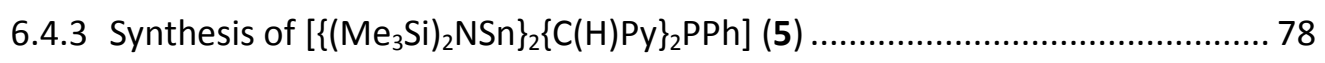

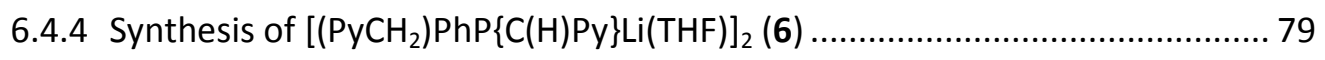

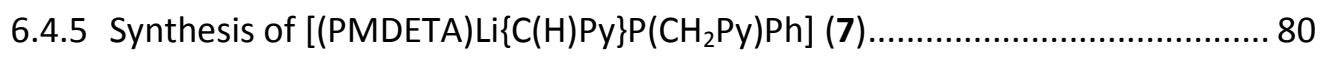

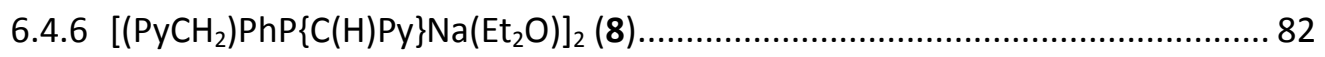

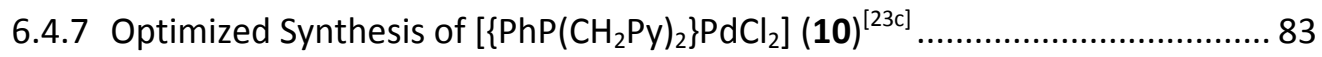

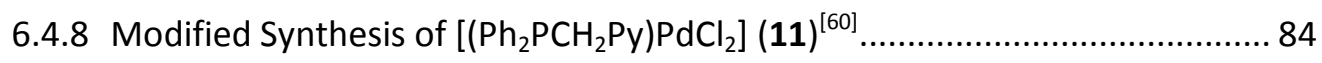

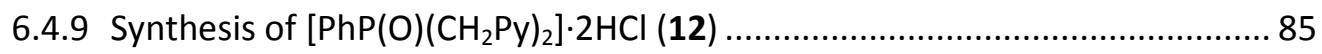

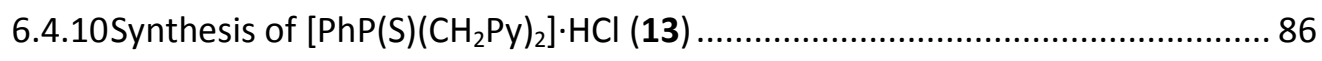

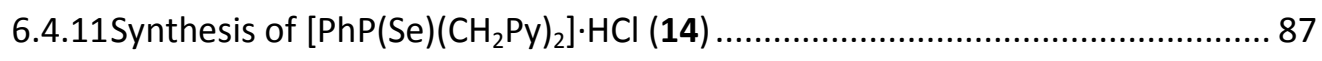

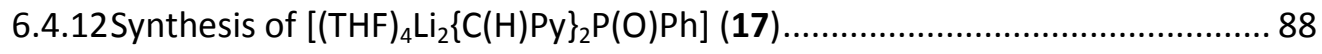

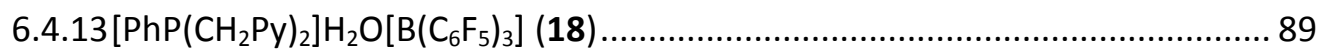

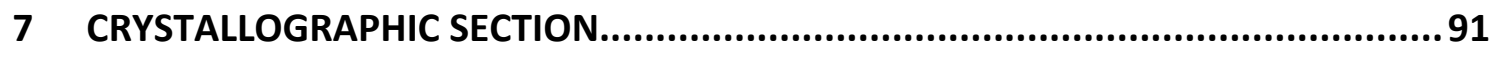

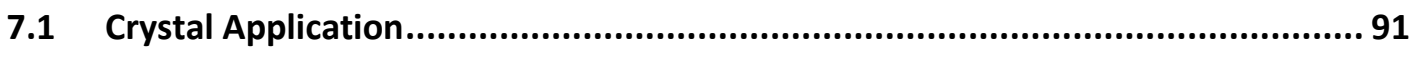

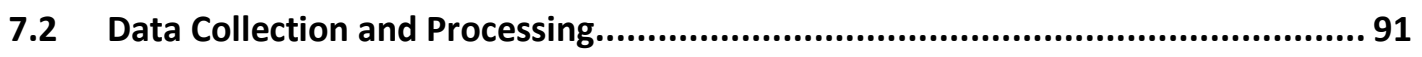

$7.3 \quad$ Structure Solution and Refinement ............................................................... 92

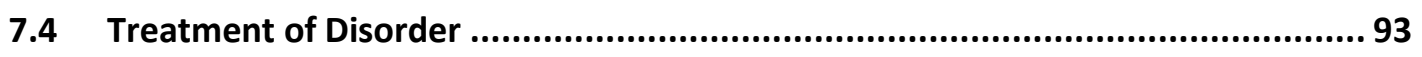

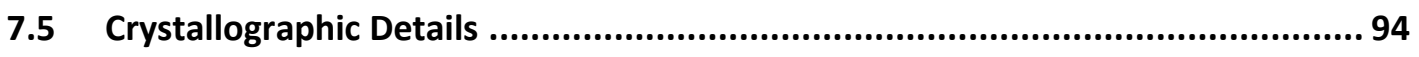

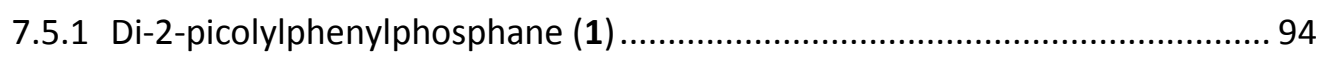

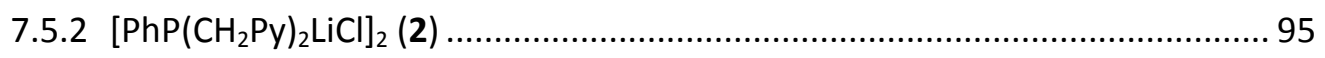




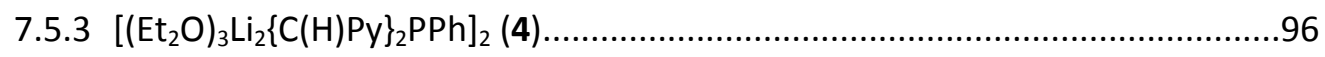

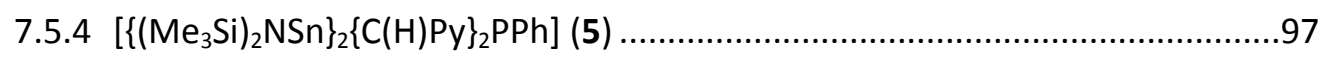

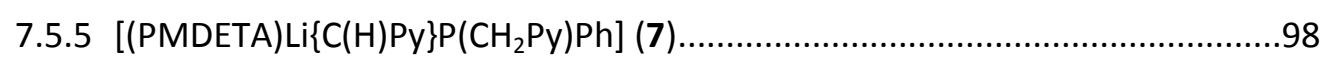

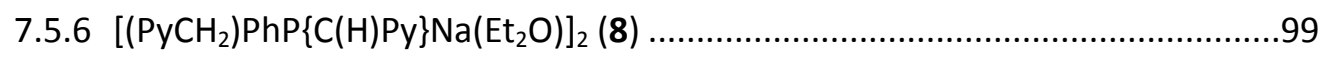

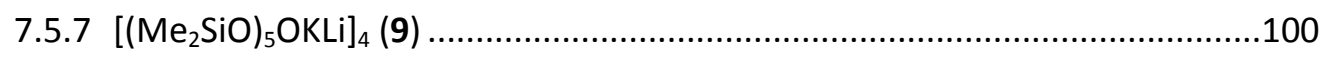

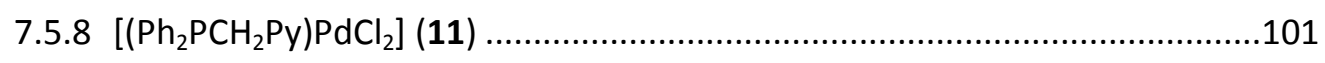

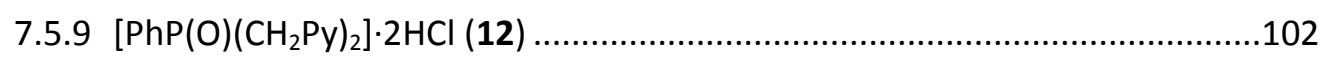

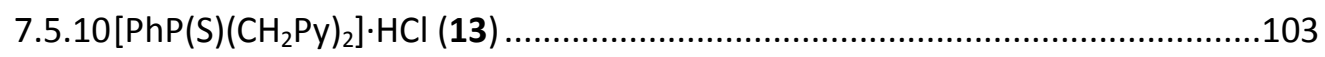

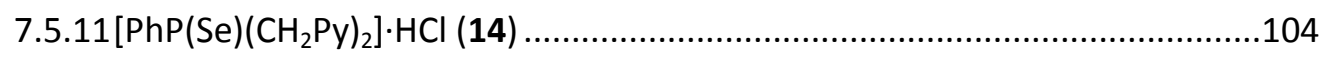

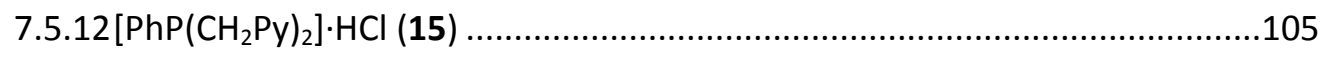

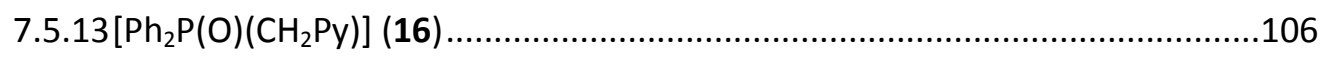

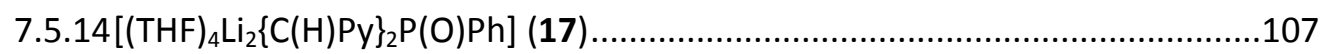

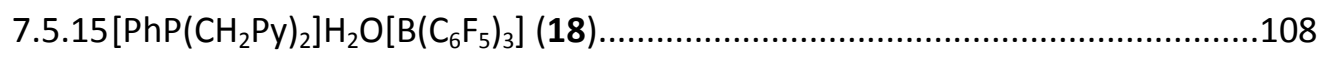

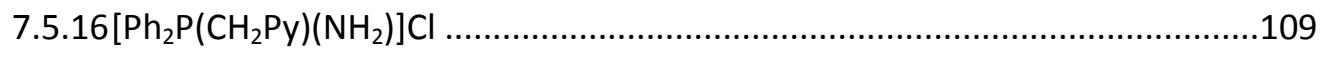

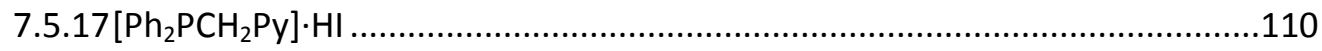

7.6 Crystallographic Cooperation..................................................................111

7.6.1 Structures measured for Dipl.-Chem. Julia Matussek .................................111

7.6.2 Structures measured for Dipl.-Chem. Christian Maaß................................114

7.6.3 Structures measured for Dipl.-Chem. Simone Dietz ...................................117

7.6.4 Structures measured for Dipl.-Chem. Tim Hungerland ...............................118

7.6.5 Structures measured for Dr. Sankaranarayana P. Sarish ..............................120

7.6.6 Structures measured for Dr. Anukul Jana ...................................................124

7.6.7 Structure measured for Dr. Monika Heinz...............................................142

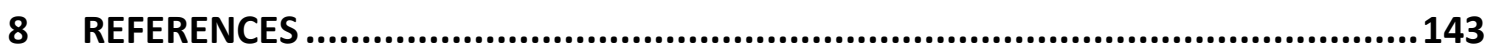




\section{AbBreviations}

\begin{tabular}{|c|c|}
\hline$\AA$ & ÅNGSTROM \\
\hline acac & acetylacetonate \\
\hline ADP & anisotropic displacement parameters \\
\hline $\mathrm{BCP}$ & bond critical point \\
\hline $\mathrm{BP}$ & bond path \\
\hline bth & 2-benzothiazolyl \\
\hline $\mathrm{Bu}$ & butyl \\
\hline calcd & calculated \\
\hline $\mathrm{CC}$ & charge concentration \\
\hline COD & cycloocta-1,5-diene \\
\hline $\mathrm{CP}$ & critical point \\
\hline $\mathrm{Cp}$ & cyclopentadienyl \\
\hline CSD & Cambridge Structural Database \\
\hline DCM & dichloromethane \\
\hline DME & dimethoxyethane \\
\hline e & electron \\
\hline e.g. & exempli gratia; for example \\
\hline Eq. & Equation \\
\hline eq. & equivalents \\
\hline ESP & electrostatic potential \\
\hline Et & ethyl \\
\hline et al. & et alii; and others \\
\hline FLP & frustrated Lewis pair \\
\hline GoF & goodness of fit \\
\hline$i$ & iso \\
\hline i.e. & id est; that is \\
\hline IAM & independent atom model \\
\hline LICKOR & mixture of alkyllithium and potassium alkoxides \\
\hline LP & lone pair \\
\hline M & metal atom \\
\hline $\max$. & maximal \\
\hline M & molar \\
\hline $\mathrm{Me}$ & methyl \\
\hline Mes & mesityl \\
\hline $\min$. & minimal \\
\hline MS & mass spectrometry \\
\hline$n$ & normal \\
\hline NMR & nuclear magnetic resonance \\
\hline $\mathrm{Ph}$ & phenyl \\
\hline
\end{tabular}




$\begin{array}{ll}\text { pm } & \text { picometer } \\ \text { PMDETA } & N, N, N^{\prime}, N^{\prime}, N^{\prime \prime} \text {-pentamethyldiethylenetriamine } \\ \text { ppm } & \text { parts per million } \\ \operatorname{Pr} & \text { propyl } \\ \text { Py } & \text { pyridyl } \\ \text { QTAIM } & \text { quantum theory of atoms in molecules } \\ \text { R } & \text { hydrogen atom or alkyl or aryl group } \\ \text { rt } & \text { room temperature } \\ t & \text { tertiary } \\ \text { THF } & \text { tetrahydrofuran } \\ \text { TMEDA } & \text { tetramethylethylenediamine } \\ \text { TMS } & \text { trimethylsilyl } \\ \text { VSCC } & \text { valence shell charge concentration }\end{array}$




\section{LIST OF COMPOUNDS}

$1 \mathrm{PhP}\left(\mathrm{CH}_{2} \mathrm{Py}\right)_{2}$

$2\left[\mathrm{PhP}\left(\mathrm{CH}_{2} \mathrm{Py}\right)_{2} \mathrm{LiCl}\right]_{2}$

$3 \quad\left[\mathrm{PhP}(\mathrm{Se})\left(\mathrm{CH}_{2} \mathrm{Py}\right)_{2} \mathrm{LiCl}\right]_{2}$

$4 \quad\left[\left(\mathrm{Et}_{2} \mathrm{O}\right)_{3} \mathrm{Li}_{2}\{\mathrm{C}(\mathrm{H}) \mathrm{Py}\}_{2} \mathrm{PPh}\right]_{2}$

$5 \quad\left[\left\{\left(\mathrm{Me}_{3} \mathrm{Si}\right)_{2} \mathrm{NSn}\right\}_{2}\{\mathrm{C}(\mathrm{H}) \mathrm{Py}\}_{2} \mathrm{PPh}\right]$

$6 \quad\left[\left(\mathrm{PyCH}_{2}\right) \operatorname{PhP}\{\mathrm{C}(\mathrm{H}) \mathrm{Py}\} \mathrm{Li}(\mathrm{THF})\right]_{2}$

7 [(PMDETA)Li $\left.\{\mathrm{C}(\mathrm{H}) \mathrm{Py}\} \mathrm{P}\left(\mathrm{CH}_{2} \mathrm{Py}\right) \mathrm{Ph}\right]$

$8\left[\left(\mathrm{PyCH}_{2}\right) \mathrm{PhP}\{\mathrm{C}(\mathrm{H}) \mathrm{Py}\} \mathrm{Na}\left(\mathrm{Et}_{2} \mathrm{O}\right)\right]_{2}$

$9 \quad\left[\left(\mathrm{Me}_{2} \mathrm{SiO}\right)_{5} \mathrm{OKLi}\right]_{4}$

$10\left[\left\{\mathrm{PhP}\left(\mathrm{CH}_{2} \mathrm{Py}\right)_{2}\right\} \mathrm{PdCl}_{2}\right]$

$11\left[\left(\mathrm{Ph}_{2} \mathrm{PCH}_{2} \mathrm{Py}\right) \mathrm{PdCl}_{2}\right]$

$12\left[\mathrm{PhP}(\mathrm{O})\left(\mathrm{CH}_{2} \mathrm{Py}\right)_{2}\right] \cdot 2 \mathrm{HCl}$

$13\left[\mathrm{PhP}(\mathrm{S})\left(\mathrm{CH}_{2} \mathrm{Py}\right)_{2}\right] \cdot \mathrm{HCl}$

$14\left[\mathrm{PhP}(\mathrm{Se})\left(\mathrm{CH}_{2} \mathrm{Py}\right)_{2}\right] \cdot \mathrm{HCl}$

$15\left[\mathrm{PhP}\left(\mathrm{CH}_{2} \mathrm{Py}\right)_{2}\right] \cdot \mathrm{HCl}$

$16\left[\mathrm{Ph}_{2} \mathrm{P}(\mathrm{O})\left(\mathrm{CH}_{2} \mathrm{Py}\right)\right]$

$17\left[(\mathrm{THF})_{4} \mathrm{Li}_{2}\{\mathrm{C}(\mathrm{H}) \mathrm{Py}\}_{2} \mathrm{P}(\mathrm{O}) \mathrm{Ph}\right]$

$18\left[\mathrm{PhP}\left(\mathrm{CH}_{2} \mathrm{Py}\right)_{2}\right] \mathrm{H}_{2} \mathrm{O}\left[\mathrm{B}\left(\mathrm{C}_{6} \mathrm{~F}_{5}\right)_{3}\right]$ 


\section{INTRODUCTION}

Ligand design is an inevitably important area in the development of efficient, profitable and sustainable catalysts in industrial processes, knowing well that even small changes in the periphery of a ligand can dramatically alter yields, selectivities and turn over numbers. ${ }^{[1]}$ The importance of the synthesis and optimization of new ligands should be clarified by the following examples.

One of the biggest homogenous catalysis in industrial production, in terms of quantity and value, is the hydroformylation with an annual turnover of more than eight million tons. Hydroformylation is the catalytic addition of $\mathrm{CO}$ and $\mathrm{H}_{2}$ (also known as syngas) to an olefin in which the formation of terminal ( $n$-aldehyde) and also branched aldehydes (iso-aldehydes) is possible. Most of the obtained aldehydes are reduced to alcohols like nbutanol, which is often used in the synthesis of softeners, or are oxidized to obtain carboxylic acids. ${ }^{[2]}$ Although the first used catalysts for this process contained cobalt as metal atom, rhodium plays a major role in present developments in particular the modified Wilkinson catalyst (Scheme 1-1). ${ }^{[3]}$

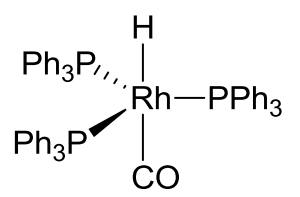

Scheme 1-1. Modified Wilkinson catalyst.

The rhodium metal of the modified Wilkinson catalyst is coordinated by three triphenyl phosphane ligands. The weak coordination of such soft donor bases to the metal atom is characteristic for triphenyl phosphane. Being able to generate a free coordination site for the reaction with a substrate by cleavage of a metal-phosphor bond is clearly an advantage. However, this rhodium catalyst is not selective towards $n$ - or iso-aldehydes and a high excess of the phosphane ligand is also needed. Another disadvantage is the complicated separation of the resulting product from the catalyst without any loss of the expensive rhodium complex. For this reason the phosphorus ligands were optimized to achieve higher selectivities. In the following example two $P$ ligands are displayed which increase the selectivity towards $n$-aldehydes in hydroformylation reactions caused by the steric demand of the aryl moieties (Scheme 1-2). ${ }^{[4]}$ Furthermore, the substitution of the phenyl rings with sodium sulfate leads to 
water-soluble rhodium complexes which enable a two-phase catalysis and hence also a simple separation of product and catalyst. Another advantage of these two-phase systems is the much smaller ratio of rhodium to phosphorus ligand (ca. 1:7) which of course is economically of much interest. Besides this, the BISBIS ligand with two phosphorus atoms chelates the metal atom and therefore stabilizes the complex.<smiles>CS(=O)(=O)c1cccc(-c2ccc(S(=O)(=O)O)cc2-c2cc(S(=O)(=O)O[Na])ccc2CP(c2ccccc2)c2cccc(S(C)(=O)=O)c2)c1</smiles>

BISBIS<smiles>CC12CC(C)(C(c3ccc(S(=O)(=O)O[Na])cc3)=C1c1ccc(S(=O)(=O)O[Na])cc1)P2c1ccc(S(=O)(=O)O[Na])cc1</smiles>

NORBOS

Scheme 1-2. The two steric demanding $P$ ligands BISBIS and NORBOS used in the hydroformylation of olefins.

Chiral molecules are of great importance in chemical synthesis. Not least because of the huge demand of optically active aldehydes in pharmaceutical industry, chiral $P$ ligands for the hydroformylation process are requested. ${ }^{[5]}$ Scheme 1-3 shows the chiral ligand (R,S)-BINAPHOS which was tested in a rhodium catalyzed hydroformylation of styrene and resulted in a highly enantioselective conversion to 2-phenylpropanal which is employed in synthesis of pharmacologically active amines.

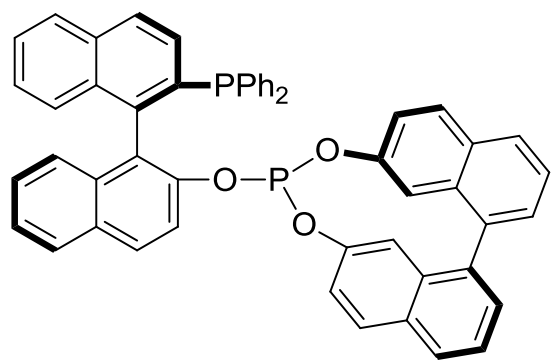

(R,S)-BINAPHOS

Scheme 1-3. Chiral phosphorus ligand (R,S)-BINAPHOS used in enantioselective hydroformylation. ${ }^{[5 c]}$

The examples mentioned above demonstrate that ligand design is a very important field of chemistry and that phosphorus ligands play a leading role therein. Despite the successful design of phosphorus ligands for different demands one should keep in 
mind that $P^{I I I}$ ligands tend to oxidize and scramble. The introduced complexes are also partially sensitive to air and uncontrolled $C-P$ bond cleavage can result in the formation of inactive phosphorus bridged rhodium complexes. Nevertheless, the huge diversity of phosphor containing starting materials and the flexibility of the coordination patterns of $P$ ligands outnumber the cons.

\subsection{Hemilabile Ligands}

The coordination sphere of phosphorus ligands can be broadened by the insertion of another donor atom, for example nitrogen. The resulting $P, N$ ligands have a common use in organometallic chemistry ${ }^{[6]}$ and form the class of the so called hemilabile ligands. Using such ligands is an elegant way to create more stability in metal complexes, e.g. in catalysis. Hemilabile ligands must bind strong enough to the active center to prevent the decomposition of the catalyst but must not block this center so that the catalyst becomes inactive. This can be achieved by using hemilabile ligands. ${ }^{[7]}$ The concept of hemilability was introduced for the first time by Jeffrey and Rauchfuss in the context of $P, N$ and $P, O$ ligands. ${ }^{[8]} \mathrm{A}$ hemilabile ligand consists of at least two coordination sites, which differ in the Pearson hardness ${ }^{[9]}$ of the donor atoms.

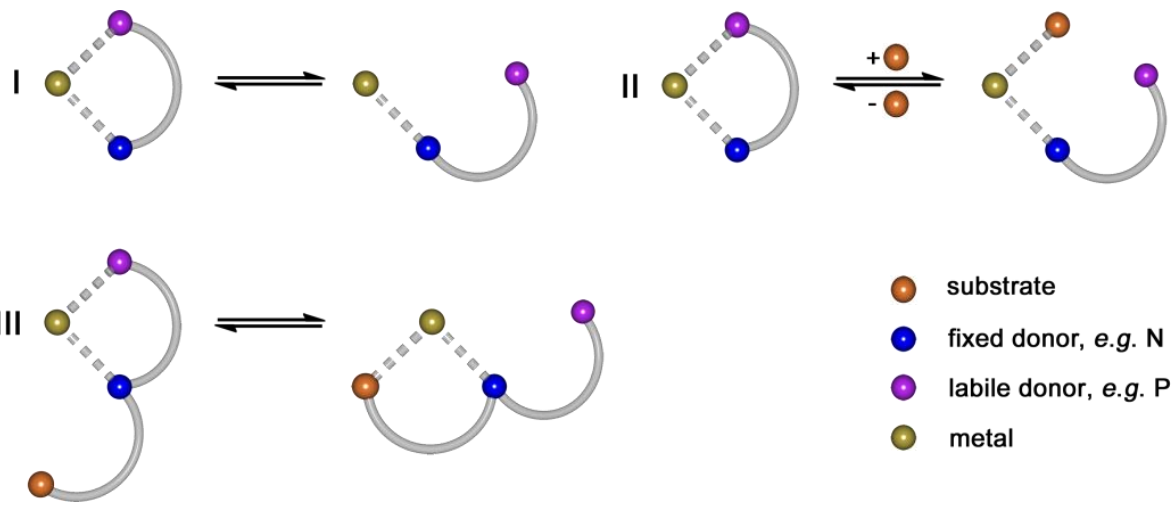

Figure 1-1. Possible bonding modes of hemilabile ligands to a metal atom.

One ligand donor atom must strongly bind to a metal atom and the second one only weakly. A catalyst can thus be masked until an appropriate substrate replaces the ligand side arm in the coordination sphere of the metal (hemilability type II). Once the substrate has reacted and left the proximity of the metal atom, the vacated coordination site will be occupied by the weak donor atom again. Hemilabile ligands 
are therefore ideal for the stabilization of metal complexes in lower oxidation states which can easily be deactivated by strong donors. Even highly reactive intermediates can be stabilized by multifunctional donor molecules. Three types of hemilability can be distinguished: the spontaneous metal-donor atom bond cleavage (type I), the one described above (type II) and the substitution with another ligand side arm (type III) (Figure 1-1). ${ }^{[10]}$

In my diploma thesis I synthesized the tin complex $\left[\left(\mathrm{Ph}_{2} \mathrm{PCH}_{2} \mathrm{Py}\right) \mathrm{Sn}(\mathrm{Cl})\right]\left[\mathrm{SnCl}_{3}\right](\mathrm{D})$ in which the $\left(\mathrm{Ph}_{2} \mathrm{PCH}_{2} \mathrm{Py}\right)$ moiety turned out to be a temperature dependent type II hemilabile ligand. ${ }^{[11]}$ While the solid state structure of $\left[\left(\mathrm{Ph}_{2} \mathrm{PCH}_{2} \mathrm{Py}\right) \mathrm{Sn}(\mathrm{Cl})\right]\left[\mathrm{SnCl}_{3}\right]$ has the same coordination mode like complex $\mathbf{D}$ at low temperatures in solution, the coordination of the tin atom at higher temperatures is different (Figure 1-2, left). At room temperature the metal atom is only coordinated by the hard nitrogen atom. This is also visible in the ${ }^{119} \mathrm{Sn}\left\{{ }^{1} \mathrm{H}\right\}$ NMR spectra of $\left[\left(\mathrm{Ph}_{2} \mathrm{PCH}_{2} \mathrm{Py}\right) \mathrm{Sn}(\mathrm{Cl})\right]\left[\mathrm{SnCl}_{3}\right]$ which displays only one broad singlet without any coupling to a ${ }^{31} \mathrm{P}$ atom (Figure 1-2, right). Only at low temperatures the coordination mode of the tin complex is changed. At $173 \mathrm{~K}$ the coordination by the soft phosphorus atom takes place and a $\mathrm{SnCl}_{3}$ counter ion is formed (C). This is in accordance with the measured ${ }^{119} \mathrm{Sn}\left\{{ }^{1} \mathrm{H}\right\}$ NMR spectra at $173 \mathrm{~K}$ where two other signals at $-83.71 \mathrm{ppm}$ and $-330.5 \mathrm{ppm}$ appear besides complex $\mathbf{C}$ (-286.9 ppm). The downfield shifted singlet can be assigned to the counter ion and the second signal is a doublet with a coupling constant of $915 \mathrm{~Hz}$ caused by the interaction to the now bonded phosphorus atom. This example has shown that hemilability is not only caused by the coordination of a substrate but can also be temperature dependently modulated.

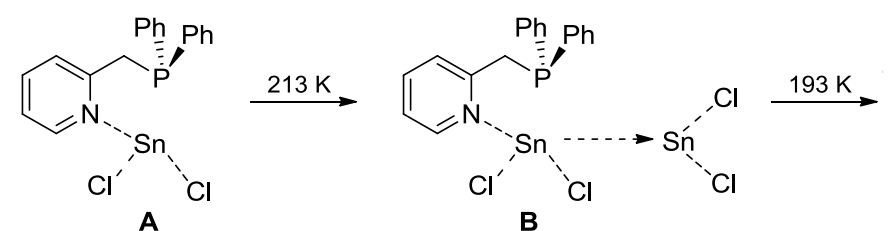<smiles>Cc1ccc(P(c2ccccc2)c2ccccc2)n1[Si](C)Cl</smiles>

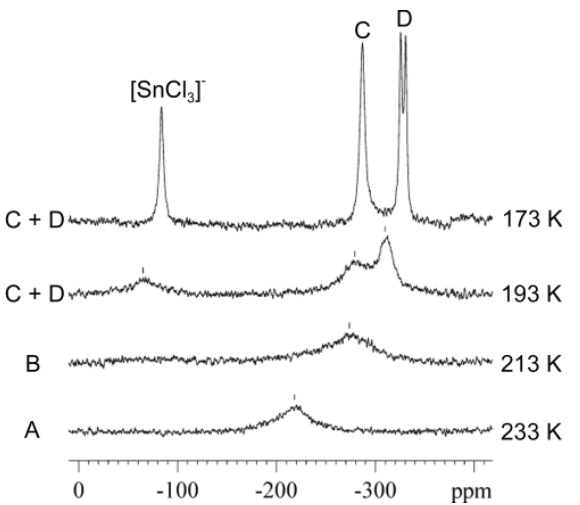

Figure 1-2. Temperature dependent coordination modes of $\left[\left(\mathrm{Ph}_{2} \mathrm{PCH}_{2} \mathrm{Py}\right) \mathrm{Sn}(\mathrm{Cl})\right]\left[\mathrm{SnCl}_{3}\right](\mathrm{left})$ and the ${ }^{119} \mathrm{Sn}\left\{{ }^{1} \mathrm{H}\right\}$ NMR spectra of the tin complex (right). 
Particularly, with regard to the advantage of a hemilabile ligand to equilibrate reactivity and stability of a metal complex, the pincer-type ligand of Milstein et al. is a good example to illustrate this. In addition to the typical coordination of the metal atom by a soft phosphorus and a hard nitrogen donor, a carbon-platinum bond is formed (Scheme 1-4, E). ${ }^{[12]}$ The reaction of the threefold coordinated platinum(II) complex $\mathbf{E}$ with methyllithium results in the formation of the methylated anionic complex $\mathbf{F}$ in which the labile nitrogen-platinum bond is cleaved. The reaction of the anionic complex $\mathbf{F}$ with the electrophile iodobenzene yields in the formation of toluene and the reconstitution of the complex $\mathbf{E}$ and thus the re-coordination of the nitrogen atom to platinum. As normally expected such anionic complexes should only be stable with strong $\pi$-acceptors which however would decrease the nucleophilic reactivity. For this reason the pincer-type ligand is a good solution to realize both, reactivity and stability.<smiles>CCCCP1Cc2cccc3c2P1(C)(C)CC3</smiles>

E

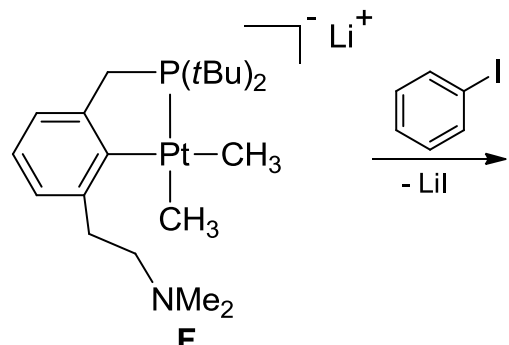

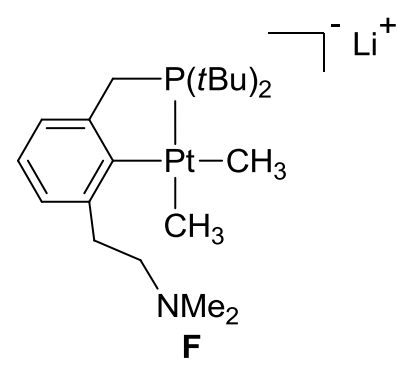<smiles>Cc1ccccc1</smiles>

E

Scheme 1-4. Pincer-type platinum complex $\mathbf{E}$ and its reaction with methyllithium and electrophiles. 


\subsection{Janus Head Ligands}

Janus is the roman god of the beginnings and transitions who is always portrayed with to faces that point, symbolically, into the future and the past (picture right). Janus is derived from the Latin word ianus (door) and is thus also the god of gates and doorways and was the patron saint of the romans. Janus Head ligands are a special form of hemilabile ligands. ${ }^{[13]}$ They contain also

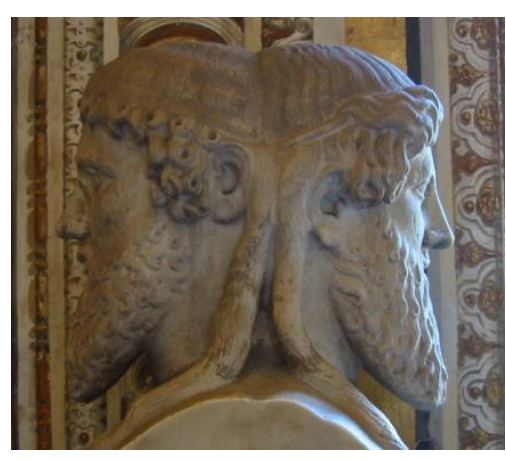
at least two different Lewis bases as donors but the characteristic of these compounds is the spatial orientation of these donors. The possible coordination sites point to opposite directions.

Scheme 1-5 shows four different examples for anionic Janus Head ligands. The Janus-type ligands $\left[\mathrm{PPy}_{2}\right]^{-}(\mathbf{G})$ and $\left[\mathrm{P}(\mathrm{bth})_{2}\right]^{-}(\mathbf{H})$ have one coordination site that is formed by two hard nitrogen donor atoms and the opposite one by a soft phosphorus atom. ${ }^{[14]}$ Both ligands are phosphanides and therefore can theoretically coordinate two different metal atoms. In addition, ligand $\mathbf{H}$ has a double heteroaromatic ring system where the sulfur atoms could also be potential donors. The other two examples $(\mathbf{I}, \mathbf{J})$ are known as modified scorpionate ${ }^{[15]}$ ligands. Unlike the $\mathrm{N}, \mathrm{N}$-chelates $\mathbf{G}$ and $\mathbf{H}$, aromatic ring nitrogen atoms perform a $\mathrm{k}^{3}-N, N, N$ coordination site. In the higher homologue of the tris(3,5-dimethylpyrazolyl)methanide anion (I) the second coordination site is supplied by a silyl anion. The characteristic of the last Janus-type ligand $(\mathrm{J})$ is the Lewis acid boron as core atom while the actual opposite coordination site is formed by the tripodal sulfur donors of the mercaptothiadiazolyl aromatic rings.<smiles></smiles>

G

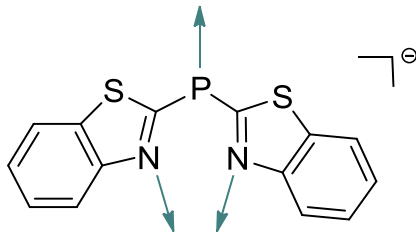

H
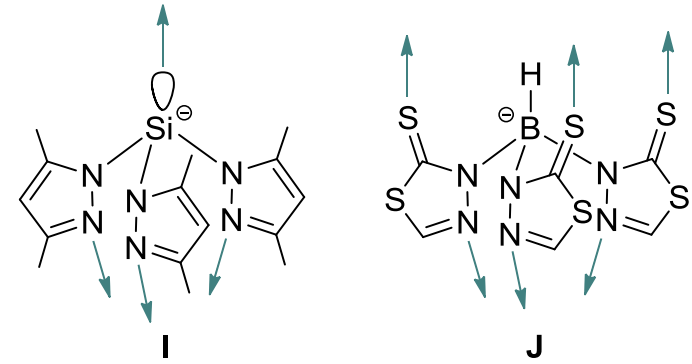

J 
The advantage of Janus Head ligands is that in one molecule two different active sites are available. Thus, they can serve as a molecular staple in bi- or heterobimetallic compounds ${ }^{[14,16]}$ and might turn out to be useful catalysts. ${ }^{[17]}$ With the right choice of ligand even a communication of the metal atoms in close proximity is possible. ${ }^{[18]}$ The following Scheme 1-6 shows two selected examples for heterobimetallic complexes. ${ }^{[19]}$ The di(2-benzothiazolyl)phosphanide complex (K) is a dimer in which the zinc atom is chelated by the ring nitrogen atoms of both ligands. On the opposite site manganese atoms are coordinated asymmetrically by the phosphorus donors, while one $P$ donor only bonds to one manganese moiety, the other one coordinates two metal atoms via both lone pairs. ${ }^{[19 c]}$ The second example is a tris(pyrazolyl-1-yl) methanide complex (L) with the two transition metals tungsten and gold. ${ }^{[19 a]}$

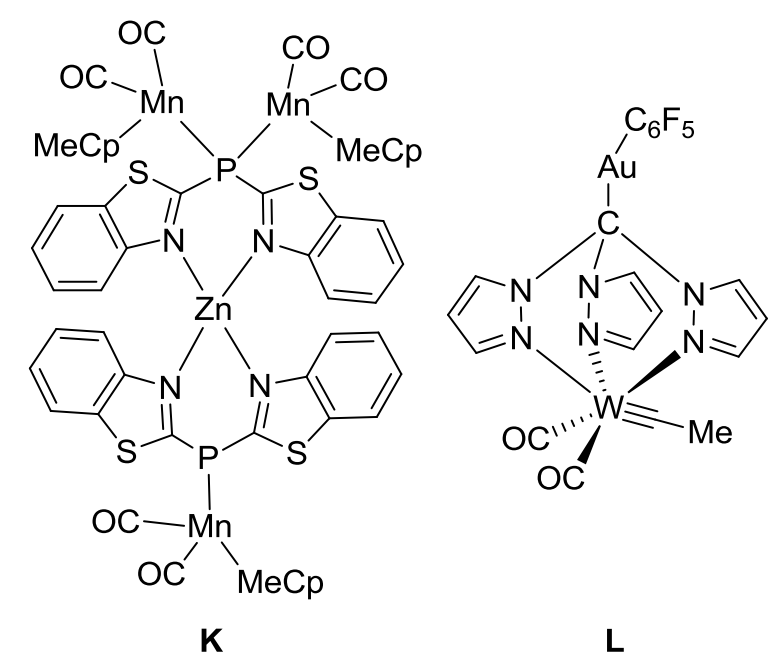

Scheme 1-6. Heterobimetallic Janus Head complexes.

The $N, P, N$ ligand di-2-picolylphenylphosphane (1) which is subject of this PhD thesis, is on first sight very similar to $\mathrm{PPy}{ }_{2} \mathrm{H}(\mathbf{G})$ mentioned in Scheme 1-5. But $\mathrm{PPy}_{2} \mathrm{H}$ behaves coordinatively as a phosphanide, thus has a divalent phosphorus atom which enables coordination in the opposite direction. Ligand $\mathbf{1}$ has a normal trivalent phosphorus atom which makes Janus-type coordination less probable because a chelating coordination with one or two of the nitrogen atoms is more likely. Another difference to $\mathrm{PPy}_{2} \mathrm{H}$ is the higher flexibility of the pyridine rings caused by the methylene bridges that are linked to the phosphorus atom. So, the complexation of metal ions of variable size is feasible. 
The synthesis of 1 was first mentioned by Lindner et al. in $1983 .{ }^{[20]}$ The reaction of 2 eq. of 2-picolyllithium with 1 eq. of dichlorophenylphosphane results in the formation of $\mathrm{PhP}\left(\mathrm{CH}_{2} \mathrm{Py}\right)_{2}$ (1) and lithium chloride as byproduct, which has to be separated from the phosphane by an aqueous work-up (Scheme 1-7). It was tested for the catalytic synthesis of ethanol but turned out to be unselective. ${ }^{[21]}$

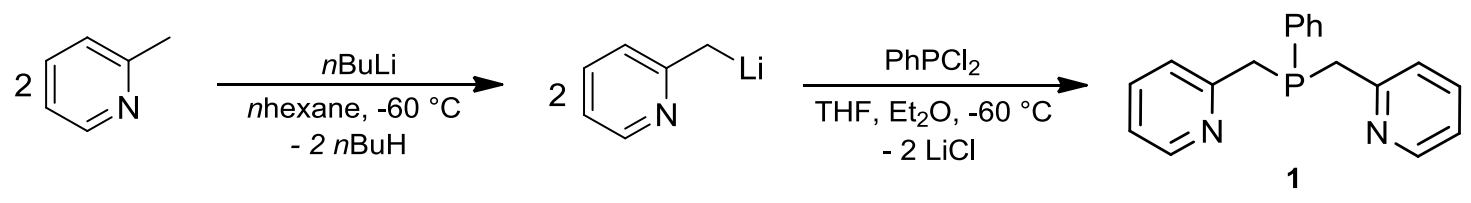

Scheme 1-7. Preparation of $\mathrm{PhP}\left(\mathrm{CH}_{2} \mathrm{Py}\right)_{2}(\mathbf{1})$ published by Lindner et al..

A more efficient reaction pathway to 1 was published by Braunstein et al. in $2008 .{ }^{[22]}$ It includes an additional step in which 2-picolyllithium is reacted with trimethylsilyl chloride to eliminate lithium chloride. The resulting product is a colorless liquid which can be separated from the formed lithium chloride by distillation under reduced pressure. The reaction of pure trimethylsilyl-2-picoline with dichlorophenylphosphane results in the formation of di-2-picolylphenylphosphane (1). A further purification of $\mathbf{1}$ is not necessary because the volatile byproduct $\mathrm{Me}_{3} \mathrm{SiCl}$ has a very low boiling point and can be removed in vacuum (Scheme 1-8).

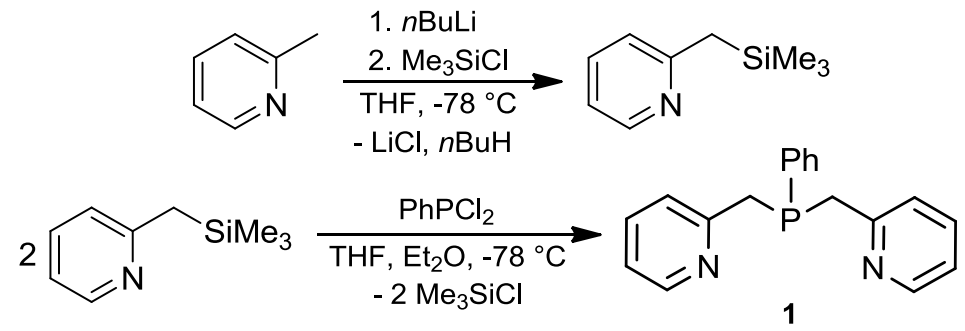

Scheme 1-8. Preparation of $\mathrm{PhP}\left(\mathrm{CH}_{2} \mathrm{Py}\right)_{2}$ (1) published by Braunstein et al..

Hitherto, the synthesized compounds containing $\mathbf{1}$ are monomeric or dimeric, mono- or bimetallic transition metal complexes (e. g. $\mathrm{Fe}, \mathrm{Cr}, \mathrm{Pd}, \mathrm{Ag}, \mathrm{Cu}$ ) in which the metal atom is mostly coordinated via the $P, N$ or $N, P, N$ claw. ${ }^{[20,22-23]}$ However, the coordination of the metal atoms takes place from just one site and therefore none of these complexes are Janus Head ligands. Nevertheless, all these compounds reflect the high flexibility of $\mathrm{PhP}\left(\mathrm{CH}_{2} \mathrm{Py}\right)_{2}$ (1). Scheme 1-9 displays the various coordination modes. Selected transition metal complexes were used in catalytic studies. ${ }^{[21-22,23 e]}$ 

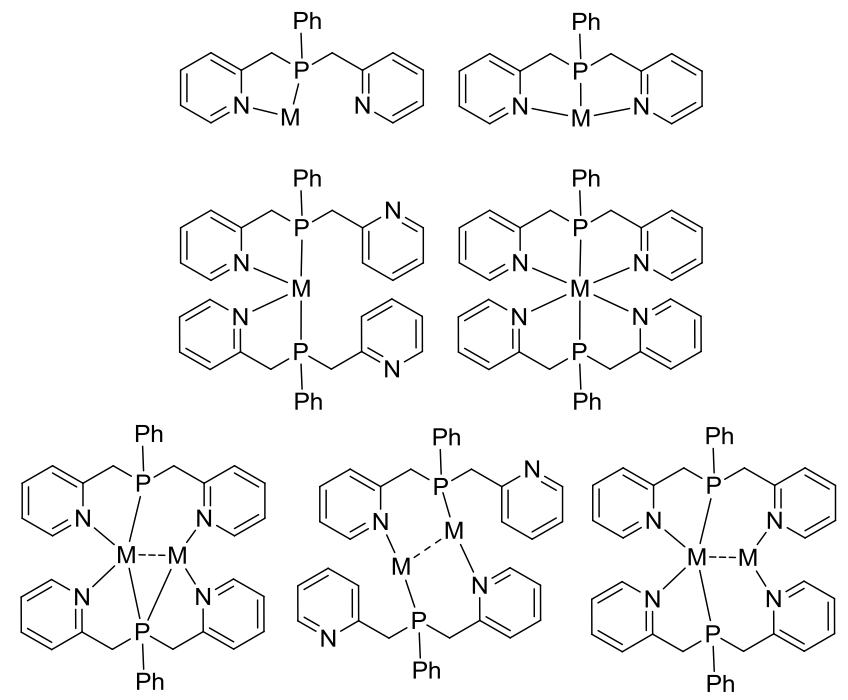

Scheme 1-9. Coordination modes of the neutral $\mathrm{PhP}\left(\mathrm{CH}_{2} \mathrm{Py}\right)_{2}(\mathbf{1})$.

\subsection{Scope}

The scope of this PhD thesis is the design of a new Janus Head ligand based on the $N, P, N$ donor di-2-picolylphenylphosphane (1).

It has already been mentioned in the introduction that metal atoms can be chelated by ligand $\mathbf{1}$ in a facial manner via the nitrogen and phosphorus donor atoms. Further coordination sites in opposite direction yielding a Janus Head ligand can in principle be achieved by the deprotonation of one or two methylene bridges of compound 1 . Therefore, the

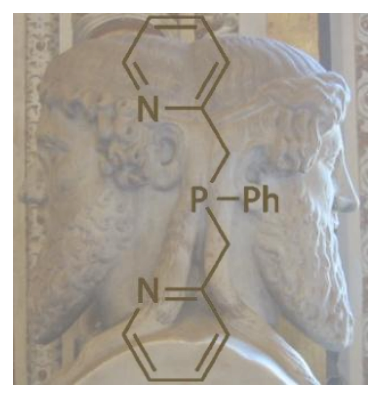
reactivity of phosphane 1 towards organolithium compounds was to be examined. The reaction of a deprotonating reagent with ligand $\mathbf{1}$ was expected to result in the formation of a metal complex containing a Janus Head ligand. Due to the flexibility of the picolyl units, different coordination patterns were feasible. The coordination behavior of the resulting Janus Head ligands were to be investigated in the solid state as well as in solution by X-ray diffraction and NMR experiments, respectively. Furthermore, it had to be proven if transmetalation reactions of the obtained lithium complexes with transition or main group metal salts could be used to synthesize new Janus Head metal complexes. 
At the beginning of this thesis, only few metal complexes with the neutral phosphane ligand $\mathbf{1}$ had been reported. For this reason, transition metal complexes with the neutral ligand were to be prepared, too.

It also had not been investigated if new phosphorane ligands could be achieved by treatment of di-2-picolylphenylphosphane (1) with group 16 oxidants. The products of these reactions are anticipated to exhibit a dissimilar coordination behavior compared to their parent phosphorus(III) compound due to the loss of the phosphorus lone pair.

It has been observed that the reactivity of the dimeric lithium chloride complex of di-2-picolylphenylphosphane (1) is significantly decreased in comparison to the lithium chloride-free ligand. It was desirable to investigate if the difference in reaction behavior could be explained by means of experimental electron density studies. 


\section{EXPERIMENTAL Electron Density Studies ON DI-2-PICOLYLPHENYLPHOSPHANE}

The synthesis of di-2-picolylphenylphosphane (1) was first mentioned by Lindner et al. in 1983, as already pointed out in the introduction. ${ }^{[20]}$ The reaction of 2 eq. of 2-picolyllithium with 1 eq. of dichlorophenylphosphane results in the formation of $\mathrm{PhP}\left(\mathrm{CH}_{2} \mathrm{Py}\right)_{2}(\mathbf{1})$ and lithium chloride as byproduct which has to be separated from the phosphane by hydrolysis (Scheme 1-7). The organic phases are subsequently dried with $\mathrm{Na}\left(\mathrm{SO}_{4}\right)_{2}$. The difficulties of the described reaction pathway are the increasing formation of byproducts during hydrolysis and the remaining water which can become a problem in subsequent reactions with organolithium compounds. For these reasons, Christian Kling of our work group developed a modified reaction pathway in his diploma thesis in which he has carried out the synthesis without the aqueous work up; adding 2-picolyllithium over a long period to the precooled dichlorophenylphosphane increases the yield. ${ }^{[24]}$ The observation he made was that although recrystallizing the crude product in DCM several times, he could not remove the lithium chloride completely, despite the poor solubility of $\mathrm{LiCl}$ in DCM. The observed product is a dimer with two bridging $\mathrm{LiCl}$ molecules $\left[\mathrm{PhP}\left(\mathrm{CH}_{2} \mathrm{Py}\right)_{2} \mathrm{LiCl}\right]_{2}$ (2) (Scheme 2-1).

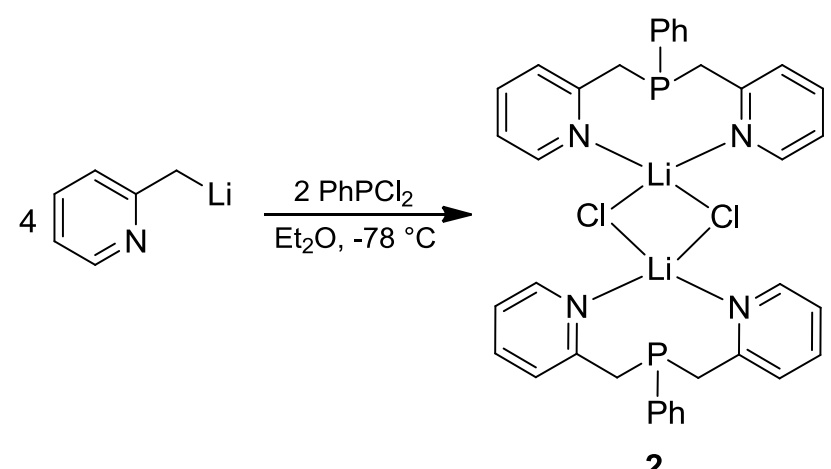

2

Scheme 2-1. Synthesis of $\left[\mathrm{PhP}\left(\mathrm{CH}_{2} \mathrm{Py}\right)_{2} \mathrm{LiCl}\right]_{2}$ (2).

This dimer is stable in solution proven by the oxidation of $\mathbf{2}$ with selenium resulting in the formation of the phosphorus(V) species, which also occurs as a LiCl-containing dimer (3) (Scheme 2-2). Whereas the oxidation of the phosphorus atom is feasible, Nils $A$. Pott has investigated in his thesis that the deprotonation of $\mathbf{2}$ and consequential coordination by the nitrogen atoms seem to be inhibited by the bonded $\mathrm{LiCl}^{[25]}$ These facts indicate that the reactivity of di-2-picolylphenylphosphane (1) is decreased by the 
blocking complexation of lithium chloride. This behavior is unexpected because the substitution of metal halides or metal amides in polar solvents to $\mathbf{2}$ should displace the lithium salt. Since this reactivity behavior cannot be explaind by straightforward chemical concepts we expected the reason to root in the electronic situation of 2 . Therefore we decided to study the experimental electron density distribution of 1 and 2 in detail by $X$-ray diffraction experiments. ${ }^{[26]}$<smiles></smiles>

2

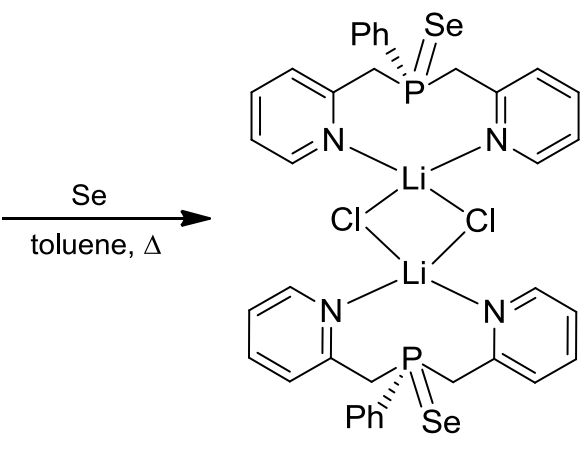

3

Scheme 2-2. Synthesis of $\left[\mathrm{PhP}(\mathrm{Se})\left(\mathrm{CH}_{2} \mathrm{Py}\right)_{2} \mathrm{LiCl}\right]_{2}(\mathbf{3}) \cdot{ }^{[24]}$

We collected two high-resolution data sets $\left(d_{\min }=0.42 \AA(\mathbf{1}), 0.45 \AA(2)\right)$ at low temperature $(100 \mathrm{~K})$ for di-2-picolylphenylphosphane (1) and $\left[\mathrm{PhP}\left(\mathrm{CH}_{2} \mathrm{Py}\right)_{2} \mathrm{LiCl}\right]_{2}$ (2). The datasets were collected on an Incoatec microfocus source (I $\mathrm{SS}$ ) (1) and on a rotating anode turbo X-ray source (TXS) (2) both equipped with mirror optics. Subsequent to a standard structure refinement (IAM - independent atom model) ${ }^{[27]}$ a multipole model was refined for both molecules. The resulting electron density distributions were topologically analyzed following R. W. F. Bader's Quantum Theory of Atoms in Molecules (QTAIM). ${ }^{[28]}$ In addition, reactivity-related physical properties like the electrostatic potential (ESP) were calculated from $\rho(\mathbf{r})$ (electron density) with the program XD. ${ }^{[29]}$ In Table 2-1 the crystallographic data for the two compounds are listed. We focused our analysis on electronic properties which can be related to the question of the reactivity. Even though a comprehensive topological analysis was done (e.g. all critical points, i.e. BCPs and RCPs were determined and their main features like the eigenvalues of the Hessian documented) only those properties are discussed and presented here that are needed to clarify the reactivity behavior of $\mathbf{1}$ and $\mathbf{2}$. 
Table 2-1. Crystallographic data for $\mathbf{1}$ (left) and $\mathbf{2}$ (right).

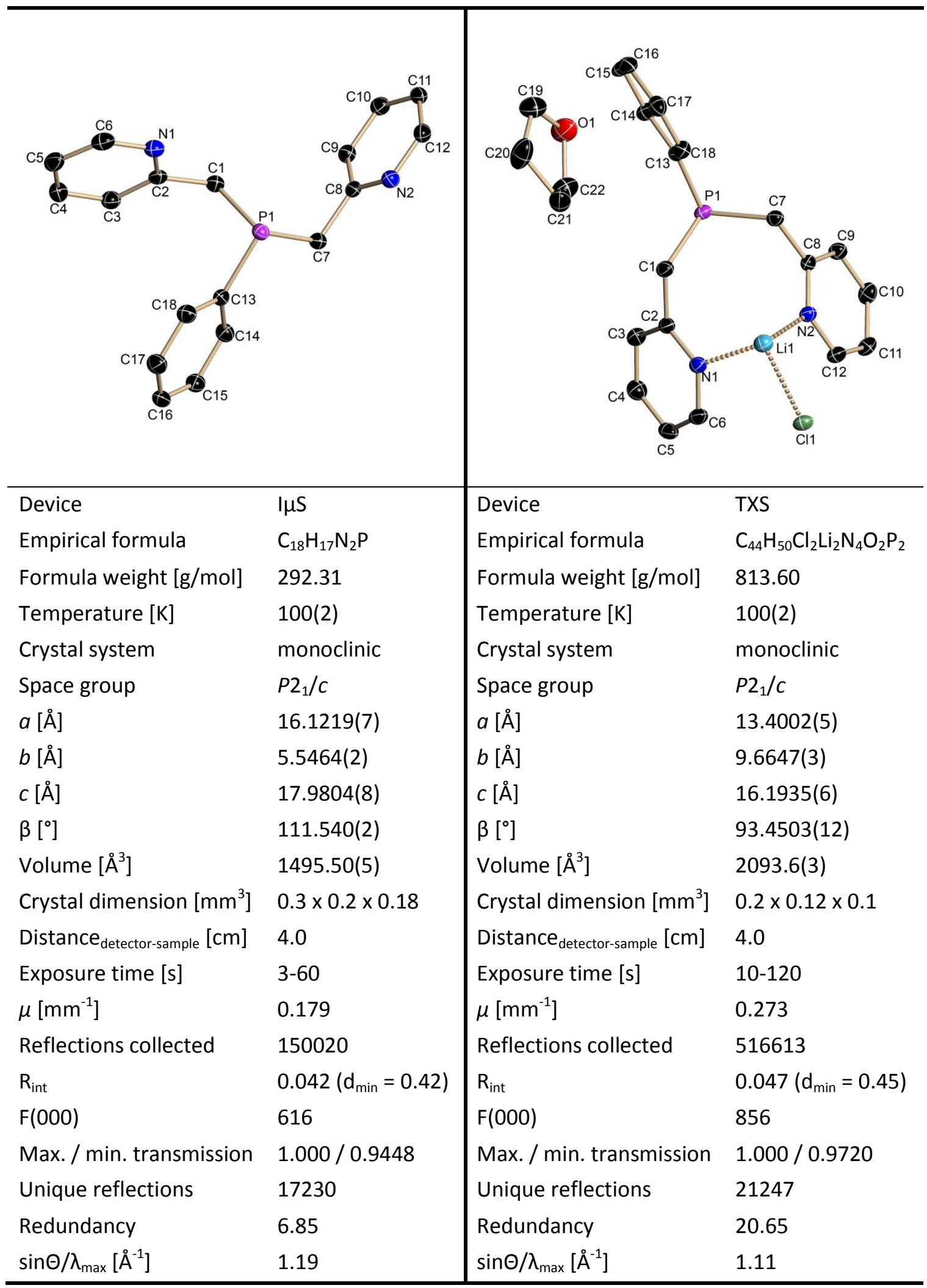


The electrostatic potential (ESP) is directly linked to the explanation for the observed reactivity. It can be calculated directly from the experimental electron density distribution. The ESP at a given point in space is defined as the potential energy required for bringing a positive charge from infinite distance to this point. ${ }^{[30]}$ Consequently, it is possible to determine the regions of a molecule where nucleophilic and electrophilic attack of a reagent is likely to happen. Sites for potential nucleophilic attack show positive, sites for electrophilic attack are those with negative ESP. Therefore, the ESP enables the prediction of an electrophilic attack by a metal ion and the reactivity of complex 2 .

Another way to interpret the charge density distribution to gain insight into chemical properties of the molecules under investigation, is application of the Quantum Theory of Atoms in Molecules (QTAIM) of Bader. ${ }^{[28]}$ This method was originally developed to examine theoretical charge density distributions but can also be used for experimentally derived density distributions. The advantage of QTAIM is that it is based on a physical, measurable variable, the electron density $\rho(\mathbf{r})$. This method provides a topological visualization of a molecule and can be compared to results from grid-based methods. To make a statement about the constitution of a bond the determination of the gradient of the density, $\nabla \rho(\mathbf{r})$ is necessary (Eq. 1-1):

\section{Eq. 1-1.}

$$
\nabla \rho(\boldsymbol{r})=\boldsymbol{i} \frac{\partial \rho}{\partial x}+\boldsymbol{j} \frac{\partial \rho}{\partial y}+\boldsymbol{k} \frac{\partial \rho}{\partial z}
$$

The vectors $\mathbf{i}, \mathbf{j}$, and $\mathbf{k}$ are the unit vectors of the Cartesian coordinate system. The gradient path between two atoms which follows the maximum density $\rho(\mathbf{r})$ is called bond bath (BP). The length and curvature of the BP and especially the point of minimum density in the $\mathrm{BP}$, the so called bond critical point ( $\mathrm{BCP})$, can give a hint to the characteristic of the bonding situation. The shift of the BCP towards the electropositive bonding partner is a consequence of bond polarization. Critical points (CP) occur, in general, where the gradient vanishes. They can be divided into bond-, core, ring- or cage-critical points characterized by the three eigenvalues of the Hessian Matrix $\lambda_{1}, \lambda_{2}$, and $\lambda_{3}$. These eigenvalues can be obtained by the second-order derivative of the density, the Laplacian $\nabla^{2} \rho(\mathbf{r})$, at this point (r) (Eq. 1-2).

Eq. 1-2. $\quad \nabla^{2} \rho(\boldsymbol{r})=\frac{\partial^{2} \rho}{\partial x^{2}}+\frac{\partial^{2} \rho}{\partial y^{2}}+\frac{\partial^{2} \rho}{\partial z^{2}}=\lambda_{1}+\lambda_{2}+\lambda_{3}$ 
The CPs can be classified by the rank $m$ and the signature $n$, whereas $m$ is the number of non-zero eigenvalues $\left(\lambda_{i}\right)$ and $n$ the algebraic sum of the signs of $\lambda_{\mathrm{i}}$. For example the $(3,-3) \mathrm{CP}$ (with $\mathrm{m}=3$ and $\mathrm{n}=-3$ ) is a local maximum in $\rho(\mathbf{r}$ ).

The value of the Laplacian displays charge concentration $\left(\nabla^{2} \rho(\mathbf{r})<0\right)$ or charge depletion $\left(\nabla^{2} \rho(\mathbf{r})>0\right)$. A positive Laplacian at the BCP is typical for closed shell interaction (strongly polarized bond) and a negative one for shared shell interaction (covalent bond). The spatial distribution of $\nabla^{2} \rho(\mathbf{r})$ around the atoms shows the structure of the valence shell. The regions around an atom with negative values of the Laplacian are called valence shell charge concentration (VSCC) and therefore indicate a local charge concentration like for example lone pairs. The maximum of the negative Laplacian is a $(3,-3)$ critical point. The spatial orientations of such VSCCs can give a hint to the density-related bonding geometry of an atom. 


\subsection{Results of the Analysis of $\rho(r)$}

\subsubsection{The Laplacian Distribution of 1}

The Laplacian distribution gives a very detailed picture of the charge concentration in the examined molecules. For this thesis, the distributions around the nitrogen atoms and the phosphorus atom were especially of interest, since these determine the reactivity behavior by means of potential lone pair coordination.

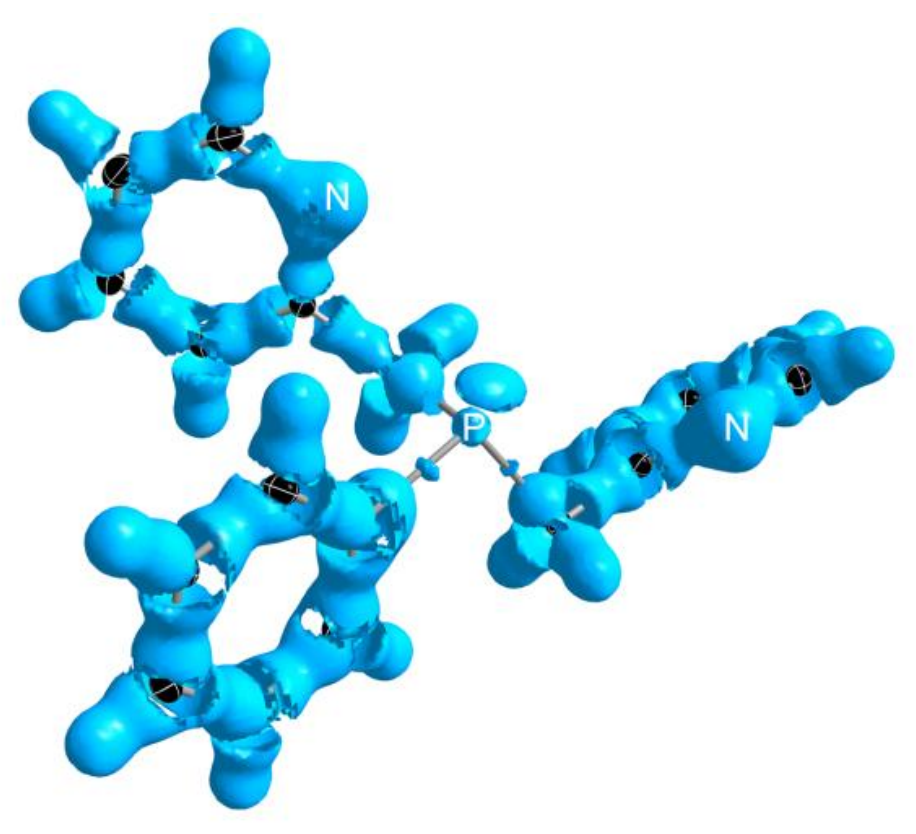

a

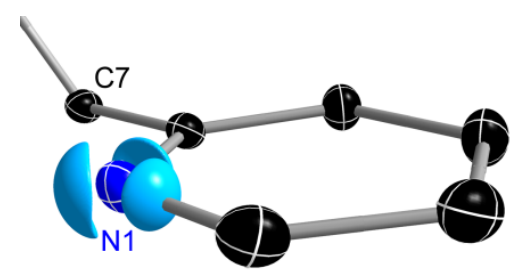

b

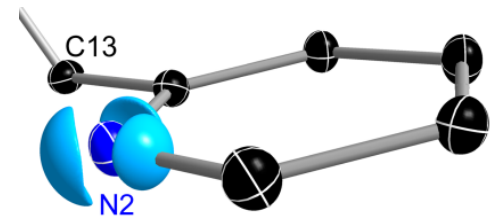

C

Figure 2-1. Isosurface representation of the Laplacian of 1 at a level of -4.0 e/ $/ \AA^{5}$ (a) and -35.0 e/ $\AA^{5}$ around N1 (b) and N2 (c).

The examination of the Laplacian reveals the expected features for 1 . Figure 2-1 a displays the Laplacian for the whole molecule. The distributions of the ring atoms are typical for covalent bonded atoms with distinct charge concentration in the interatomic region. The charge concentration which originates from the lone pair of the phosphorus atom is well defined and oriented in the direction anticipated for a valence shell with distorted tetrahedral geometry. In contrast to the aromatic bonds of the ring systems the charge concentrations in the three C-P bonds are separated and shifted close to the atoms which is typical for strongly polarized bonds. The depictions 
of the two aromatic rings show typical $\mathrm{sp}^{2}$ hybridized nitrogen atoms (Figure 2-1 b, c). The lone pair regions of both nitrogen atoms are well defined and oriented exactly coplanar to the rings.

A better insight into the donor capability of a molecule can be gained by the determination of the local maxima in the VSCCs. Especially, the value of the maximum of the lone pairs is a hint for the donor capability of the respective lone pair. In this context, the more negative the VSCC is, the better a donor the atom is. ${ }^{[31]}$

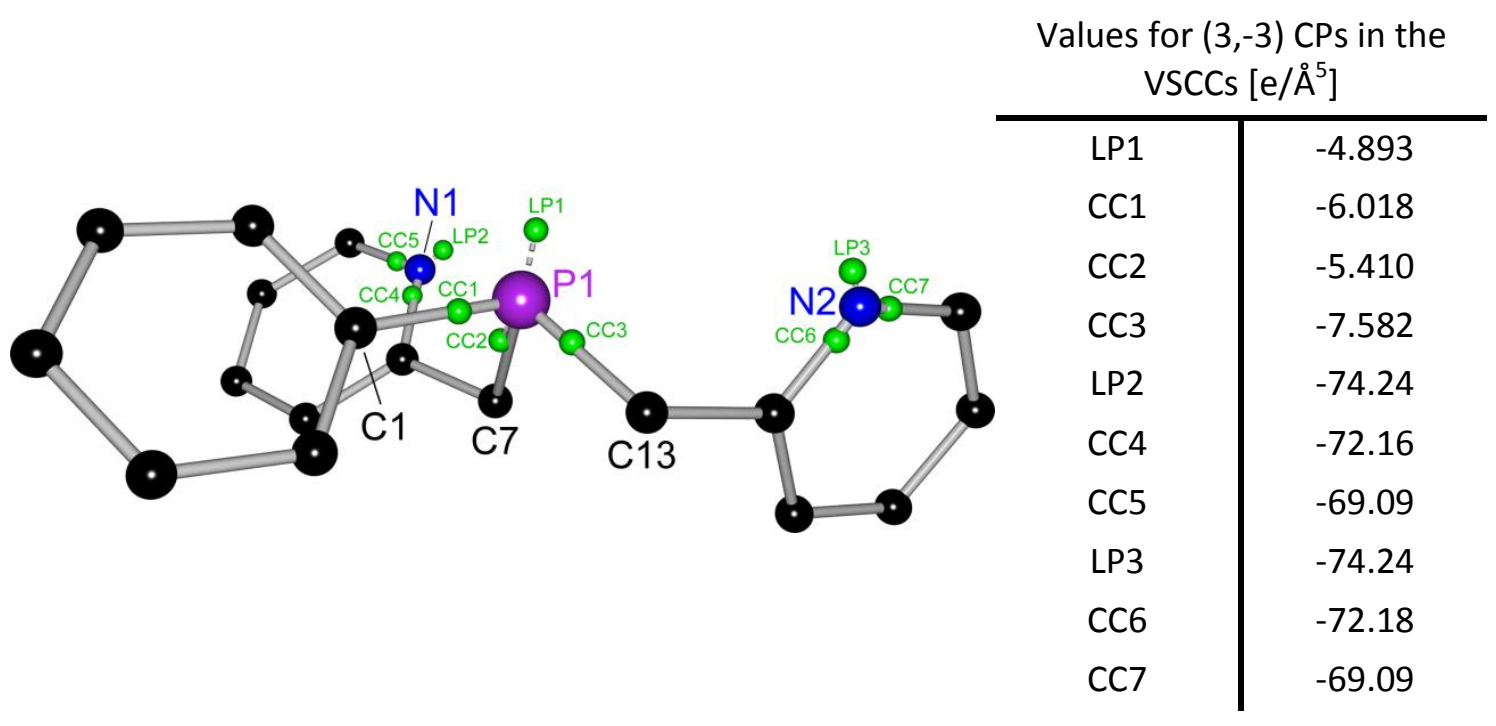

Figure 2-2. Orientations of the VSCCs in $\mathbf{1}$ (left) and their maximum values (right).

For ligand 1, the VSCCs of the two nitrogen atoms are almost equal concerning their absolute value (Figure 2-2). The concentration in the lone pair is higher than in the bonding VSCCs, among which the one directed to the ipso carbon atom of the ring is more distinct. The difference in values of the bonding VSCCs is the electronic response to the electron-donating effect of the methylene bridge. Despite small differences in the ESP, the distribution around the two nitrogen atoms are equal concerning the VSCCs. The absolute value of the lone pair-related VSCC at P1 is lower and its position further away from the atom center than in the case of the nitrogen atoms, which indicates that the lone pair of $\mathrm{P} 1$ is more diffuse and has less donor capacity. 


\subsubsection{The Electrostatic Potential of 1}

The analysis of the ESP in 1 leads to some unexpected results. From simple chemical concepts one could of course assume the nitrogen atoms to be the origin for a negative potential, expecting two identical distributions around the nitrogen atoms.

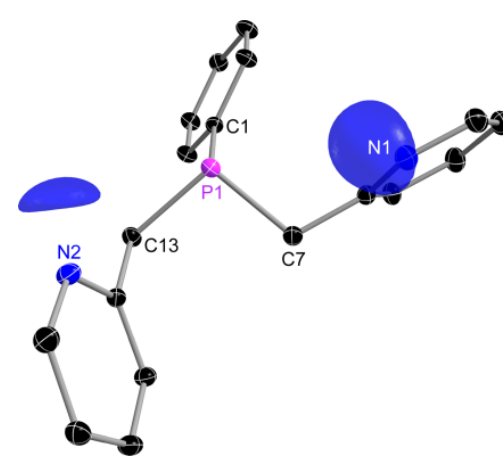

a

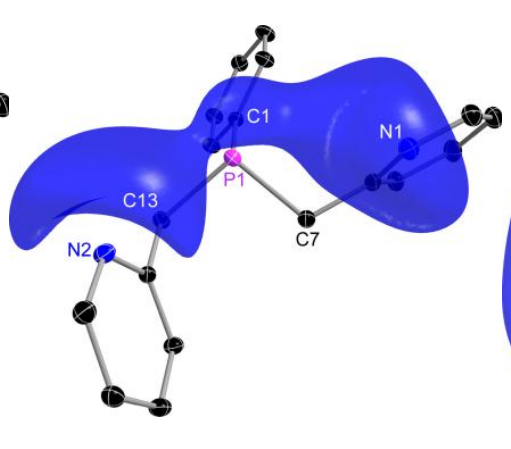

b

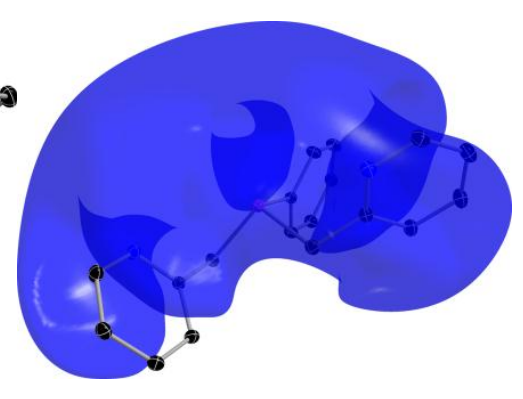

C

Figure 2-3. Isosurface representation of the electrostatic potential of 1 at the level of -0.2 e/Å (a), -0.13 e/Å (b) and -0.05 e/Å (c).

Figure 2-3 shows isosurfaces of the ESP of 1 at different levels. At first sight the difference in size of representations of the potential of N1 and N2 is obvious (Figure 2-3 a). Since the spatial distribution of a potential is correlated with the maximum value, N1 is more attractive to a positive charge (metal ion) than N2. This is remarkable, because the two picolyl moieties should be identical. Also the orientation of the two maxima in the ESP relative to the pyridine rings is different: while it is located above the pyridine ring plain at N1, it is in-plane for N2. At a lower level, the potential induced by the lone pair of P1 is also visible (Figure 2-3 b). The distribution of the potential of P1 has a preferred orientation towards N1. This points to a favored complexation of metal atoms via the $N, P$ and not the $N, P, N$ claw which matches with the complexes that can be found in literature and in this thesis where the coordination sphere of a metal atom is often filled with an additional ligand molecule. Figure 2-3 c displays that an electrophilic attack is only possible at one face of the molecule. In summary it can be stated that 1 has, as expected, three possible coordination sites, the nitrogen atoms are more attractive for a positive charge than the phosphorus atom but the ESP gives the explanation for the preferred $N, P$ complexation. 


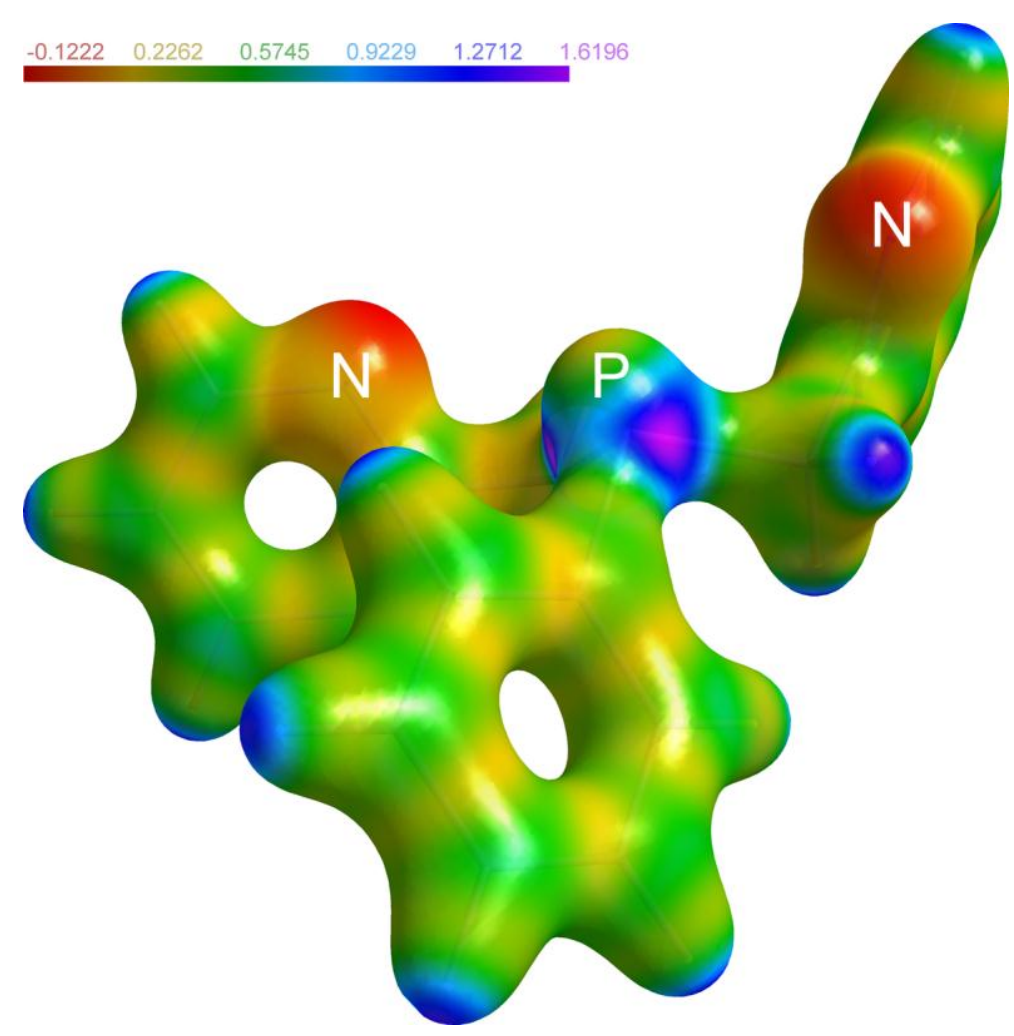

Figure 2-4. Isosurface representation of the electrostatic potential of 1 ranging from -0.12 to +1.62 e/A mapped on $\rho(\mathbf{r})=0.5 \mathrm{e} / \AA^{3}{ }^{[32]}$

The color-code of the electrostatic potential in Figure 2-4 indicates the reactive sites for a nucleophile or electrophile. The two nitrogen atoms with red colored isosurfaces are attractive for electrophiles while a nucleophilic attack could take place via the $\mathrm{C}-\mathrm{P}-\mathrm{C}$ angle bisector, indicated by the blue/magenta coded area at the phosphorus atom. 


\subsubsection{The Laplacian Distribution of 2}

A geometrical characteristic of $\left[\mathrm{PhP}\left(\mathrm{CH}_{2} \mathrm{Py}\right)_{2} \mathrm{LiCl}\right]_{2}(2)$ is the variably bonded lithium atom. While Li1 is in-plane with the pyridyl ring containing N1 (Figure 2-5a), it is located slightly out of the ring plane of N2 (Figure 2-5 c). Different hybridization states of the two nitrogen atoms would explain this geometry.

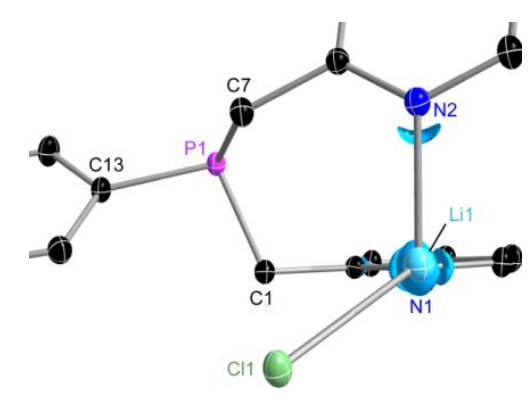

a

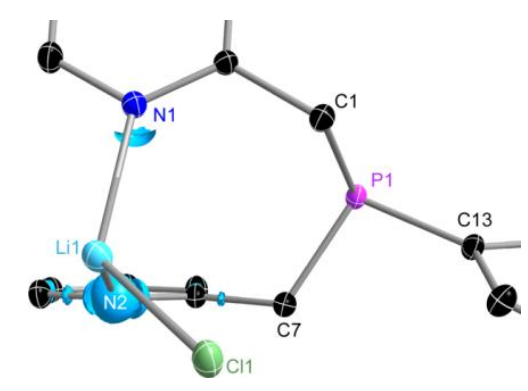

C

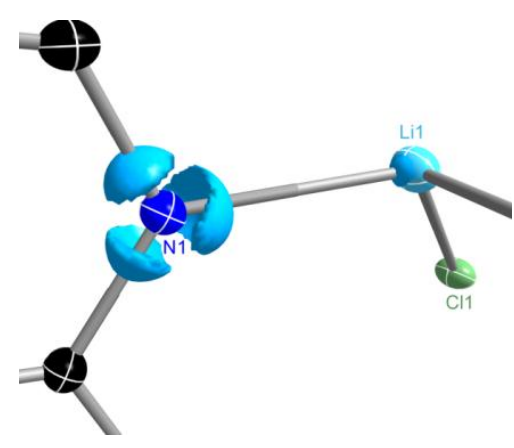

b

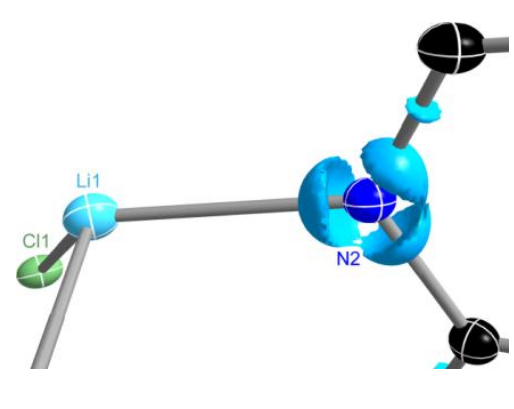

d

Figure 2-5. Isosurface representation of the Laplacian of $\mathbf{2}$ at a level of $-30 \mathrm{e} / \AA^{5}$ around N1 $(\mathbf{a}, \mathbf{b})$ and $\mathrm{N} 2$ (c, d).

Thus, it had to be assumed that $\mathrm{N} 1$ is $\mathrm{sp}^{2}$ hybridized as expected for an aromatic system whereas $\mathrm{N} 2$ is at least partially re-hybridized to $\mathrm{sp}^{3}$. However, this cannot be deduced from inspection of the electron density distribution. As the Laplacian distributions of $\mathrm{N} 1$ and $\mathrm{N} 2$ show, both reveal just one single lone pair related VSCC and therefore have to be classified as $\mathrm{N}_{\mathrm{sp}}{ }^{2}$ atoms (Figure 2-5 b, d). However, the dissimilarity between N1 and N2 that was also observed for the nitrogen atoms of $\mathbf{1}$ seems to hold equally for the lithium complex 2 . The lone pair distribution in the Laplacian of N2 is of bowl-like shape while N1 shows a slight banana shape. 


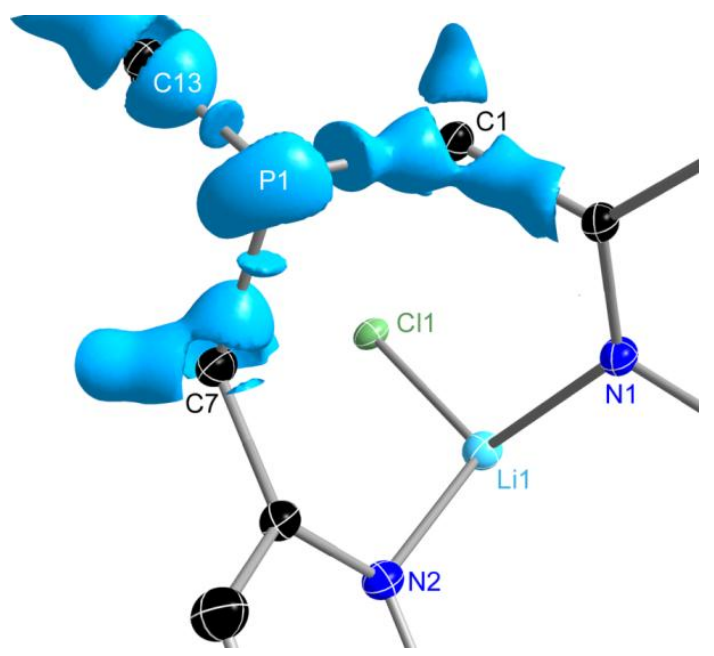

Figure 2-6. Isosurface representation of the Laplacian of $\mathbf{2}$ at a level of -5.0 e/ $\AA^{5}$ around the phosphorus atom.

The Laplacian at the phosphorus atom displays a banana-shaped lone pair and three bonding VSCCs to the carbon atoms (Figure 2-6). The two $\mathrm{P}-\mathrm{C}$ bonds to the picolyl moieties differ. While the P1-C1 bond shows the distribution of a typical covalent shared interaction, the $\mathrm{P} 1-\mathrm{C} 7$ bond is strongly polarized and, regarding its qualitative distribution, identical to the chemically different $\mathrm{P} 1-\mathrm{C} 13$ bond. $\mathrm{P} 1-\mathrm{C} 1$ is unique in its Laplacian distribution. The other two $\mathrm{P}-\mathrm{C}$ bonds show features comparable to those in ligand 1. The more 'classical' covalent shape of the P1-C1 bond corresponds to the spatial distribution of the phosphorus lone pair. This might be the origin. The lone pair possibly contributes to this bond, while relative to the two other bonds it is oriented towards the bisector.

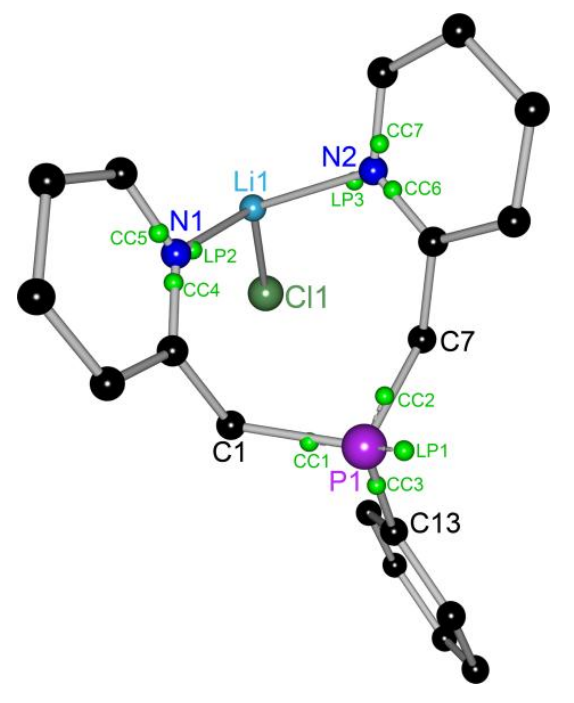

\begin{tabular}{c|c} 
Values for $(3,-3)$ CPs in the VSCCs $\left[\mathrm{e} / \AA^{5}\right]$ \\
\hline LP1 & -7.943 \\
CC1 & -10.91 \\
CC2 & -7.037 \\
CC3 & -7.554 \\
LP2 & -70.11 \\
CC4 & -72.41 \\
CC5 & -68.52 \\
LP3 & -82.91 \\
CC6 & -68.80 \\
CC7 & -61.70
\end{tabular}

Figure 2-7. Orientations of the VSCCs in $\mathbf{2}$ (left) and their maximum values (right). 
In comparison to the VSCCs of $\mathbf{1}$, the concentration values of N1 in $\mathbf{2}$ are different (Figure 2-7). The concentration at the lone pair is no longer the highest but the VSCC pointing towards a methylene bridge. This indicates that the density in the lone pair of $\mathrm{N} 1$ is decreased by the coordination of the lithium atom. In contrast, the VSCCs of N2 have the same tendency as in the free ligand but on a higher absolute level. The lone pair reveals a much higher concentration in comparison to the other two VSCCs around N2 and all other VSCCs in the molecule. The valence shell of N2 is obviously distorted by the coordination of the lithium cation. No direct hint for a re-hybridization was found, but the difference of the valence shell is consistent with the observed coordination asymmetry of the lithium atom in $\mathbf{2}$. From this it can be deduced that the observed coordination geometry is not determined by the 'geometrical' argument leading to assumed re-hybridization.

\subsubsection{The Electrostatic Potential of 2}

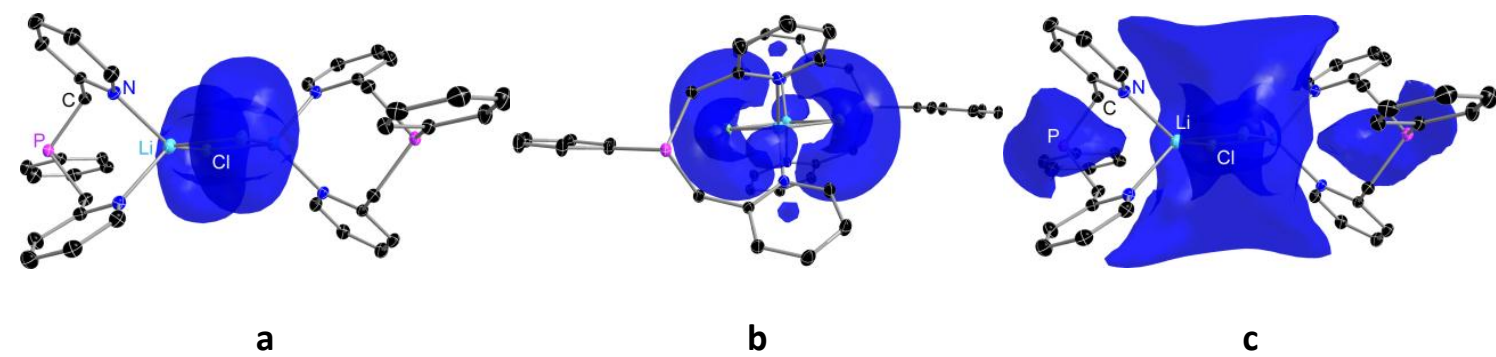

Figure 2-8. Isosurface representation of the electrostatic potential of $\mathbf{2}$ at the level of -0.3 e/Å (a), -0.25 e/Å (b) and -0.2 e/Å (c).

The electrostatic potential of $\left[\mathrm{PhP}\left(\mathrm{CH}_{2} \mathrm{Py}\right)_{2} \mathrm{LiCl}\right]_{2}(2)$ is dominated by the chloride atoms (Figure 2-8 a). But surprisingly, at a level of -0.25 e/Å, which refers to a quite remarkable ESP (compared for example to values around the nitrogen atoms in 1), an additional contribution originating from the nitrogen atoms is observed. The ESP is not located directly in-plane, as observed for one nitrogen atom in ligand 1, but above and below the ring system (Figure 2-8 b) effected by the coordination of the lithium atom.

An electrophilic attack of a metal ion should thus be feasible. Nevertheless, an attack is inhibited by the steric demand of the ligand. This steric effect can be 
quantitatively rationalized by the displayed ESP. The nitrogen atoms are completely shielded by the overwhelming ESP of the chlorine atoms. On a lower level for the ESP, the accessible potential for the phosphorus atom is displayed (Figure 2-8c). This explains why the phosphorus atom is the only potential donor even though from their local electronic distribution the nitrogen atoms have a much higher charge concentration at their lone pairs. If at all, a reaction with $\mathbf{2}$ is possible via the phosphorus atom.

In summary, it can be concluded from the experimental charge density distribution that the reduced reactivity of $\mathbf{2}$ is related to the predominantly shielding of the nitrogen atoms by the chlorine atoms. The electrostatic potential induced by the chlorine atoms dominates the ESP distribution of the whole molecule and inhibits an electrophilic attack of any metal ion at the nitrogen atoms. The only possible reactive site is the relative diffuse phosphorus lone pair which reduces the selection of potential acceptors to very soft metal ions.

The coordination behavior of 1 can be explained by the aid of experimental charge density studies. From the distribution of the ESP it is now understandable that 1 often coordinates metal ions via the $\mathrm{P}, \mathrm{N}$ claw and an additional nitrogen atom of another ligand molecule instead of the coordination by the $N, P, N$ claw.

Finally, the density distribution gave no indication for a potential partial $\mathrm{sp}^{3}$ hybridization of one of the nitrogen atoms in $\mathbf{2}$ as might be assumed from simple geometrical considerations. It is therefore another example ${ }^{[31 a-c]}$ in which a detailed topological analysis helps avoiding wrong electronic predictions which seem chemically reasonable at the first glance. 



\section{DEPROTONATION OF DI-2-PICOLYLPHENYLPHOSPHANE}

Di-2-picolylphenylphosphane (1) was prepared according to the published method as described earlier in the introduction (Scheme 3-1). ${ }^{[22]}$ However, the yield reported therein could be increased by the filtration of the reaction mixture of trimethylsilyl-2-picoline and lithium chloride before distillation. Further work-up after the final step is not required. Crystallization of the desired product is usally achieved by storing the resulting oil in a glove box. These crystals can be used easily for following reactions.

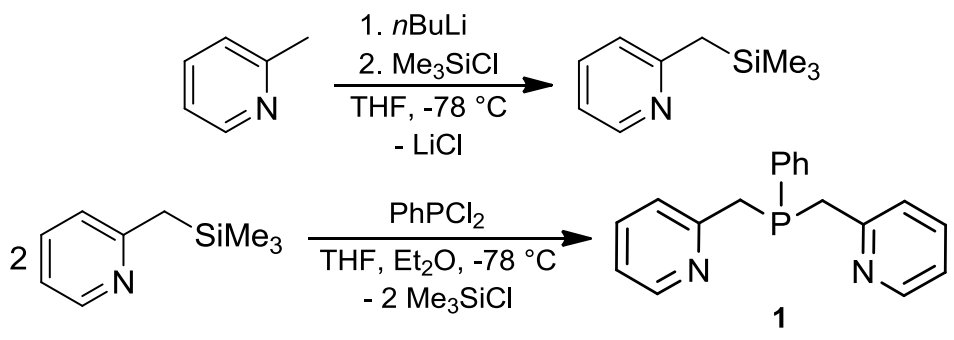

Scheme 3-1. Preparation of $\mathrm{PhP}\left(\mathrm{CH}_{2} \mathrm{Py}\right)_{2}$ (1).

However, it has to be mentioned that $\mathbf{1}$ is highly sensitive to air and the tendency to form insoluble side products during the reaction. Unfortunately, within some batches the formation of a white solid could be observed. After filtration of this solid and subsequent NMR investigation of 1 no noteworthy impurities could be detected. Nevertheless, this orange oil did not crystallize as readily as the afore mentioned compound in the glove box; it even hardened due to the loss of solvent molecules. However, further reactions with these batches were possible although the insolubility in solvents like $\mathrm{Et}_{2} \mathrm{O}$ was increased. The change of solvents, temperature or sequence of adding the starting materials did not result in an improvement to avoid the undesirable side reaction.

As already pointed out in the introduction the uncharged $N, P$ or $N, P, N$ claw of $\mathrm{PhP}\left(\mathrm{CH}_{2} \mathrm{Py}\right)_{2}(\mathbf{1})$ is only one coordination site of the ligand and therefore cannot be classified as a Janus Head ligand. As A. Murso has already shown it is possible to deprotonate similar ligands at the methylene bridge with for example organolithium compounds or amides. ${ }^{[33]}$ In analogy Leung et al. reported main group metal complexes of $i \mathrm{Pr}_{2} \mathrm{P}\left(\mathrm{CH}_{2} \mathrm{Py}\right)\left(\mathrm{NSiMe}_{3}\right)$ and $\left[2,6-\left(\mathrm{Me}_{3} \mathrm{SiNPiPr}{ }_{2} \mathrm{CH}_{2}\right)_{2}\left(c y-\mathrm{C}_{5} \mathrm{H}_{3} \mathrm{~N}\right)\right]$, obtained by 
deprotonation with organolithium compounds, alkyl magnesium or group 14 amides. Metathesis with group 14 halides gave 1,3-dimetallacyclobutanes. ${ }^{\text {[34] }}$

The deprotonation at an acidic methylene bridge opens the coordination sphere of 1 and gives a new hemilabile anionic ligand that can coordinate metal atoms at two opposite binding sites and hence can be designated as Janus head ligand. Scheme 3-2 illustrates the possible coordination patterns for the dianionic form $\left[\mathrm{PhP}(\mathrm{CHPy})_{2}\right]^{2-}$. The two complexes depict the second coordination site in the opposite direction of the ring nitrogen atoms each. They would thus serve as a bidirectional molecular staple between two different metal residues.

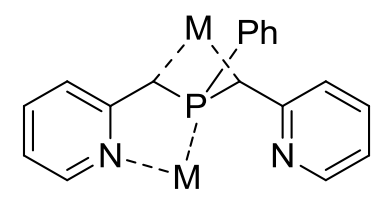

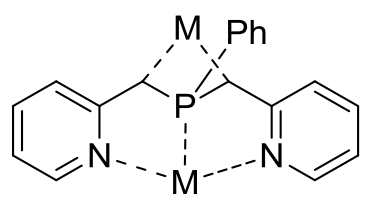

Scheme 3-2. Coordination mode of the dianionic ligand $\left[\mathrm{PhP}(\mathrm{CHPy})_{2}\right]^{2-}$.

$\mathrm{PhP}\left(\mathrm{CH}_{2} \mathrm{Py}\right)_{2}$ (1) was crystallized and structurally determined as it is especially interesting because the bond lengths in the pyridyl rings and the $\mathrm{CH}$ bridges serve as bench mark distances in the comparison to the metalated species. 1 crystallizes from dichloromethane at $-20^{\circ} \mathrm{C}$ in the monoclinic space group $P 2_{1} / c$. The asymmetric unit contains one molecule of the phosphane ligand (Figure 3-1). The coordination sphere of the phosphorus atom is trigonal pyramidal with the stereochemically active lonepair on top.

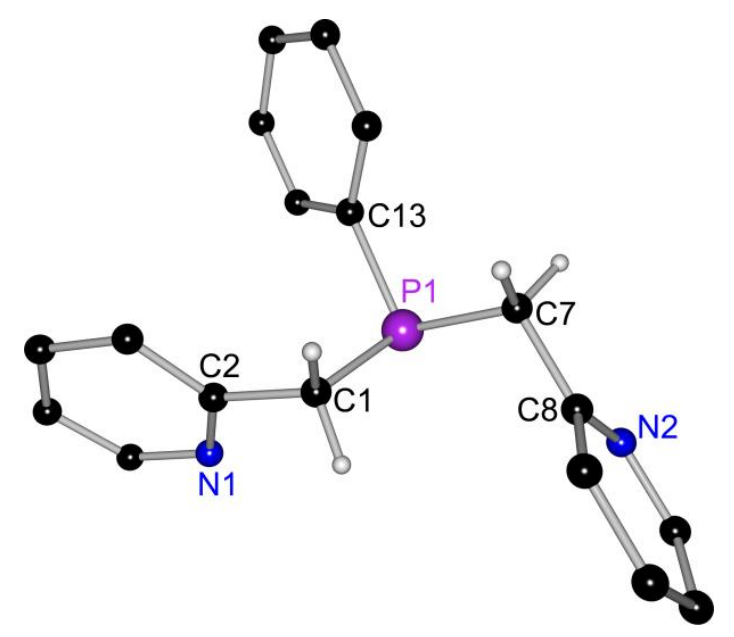

Figure 3-1. Solid state structure of $\mathrm{PhP}\left(\mathrm{CH}_{2} \mathrm{Py}\right)_{2}$ (1). Hydrogen atoms, expect those of $\mathrm{C} 1$ and $\mathrm{C7}$, are omitted for clarity. Selected bond lengths and angles are listed in Table 3-1. 
Dual deprotonation of $\mathrm{PhP}\left(\mathrm{CH}_{2} \mathrm{Py}\right)_{2}$ (1) can be achieved with $n$ butyllithium in diethyl ether solution at $-20^{\circ} \mathrm{C}$ (Scheme 3-3). The dimeric lithium complex $\left[\left(\mathrm{Et}_{2} \mathrm{O}\right)_{3} \mathrm{Li}_{2}\{\mathrm{C}(\mathrm{H}) \mathrm{Py}\}_{2} \mathrm{PPh}\right]_{2}(4)$ was obtained as yellow crystals of the triclinic space group $P \overline{1}$ (Figure 3-2). The asymmetric unit contains half the molecule. One lithium atom (Li1) is coordinated by one nitrogen and the phosphorus atom of the ligand and two diethyl ether molecules. The second lithium atom (Li2) is coordinated by the two carbanionic $\mathrm{CH}$ bridges, a single nitrogen atom of a second ligand and one diethyl ether molecule.

2<smiles>c1ccc(CP(Cc2ccccn2)c2ccccc2)cc1</smiles>

1
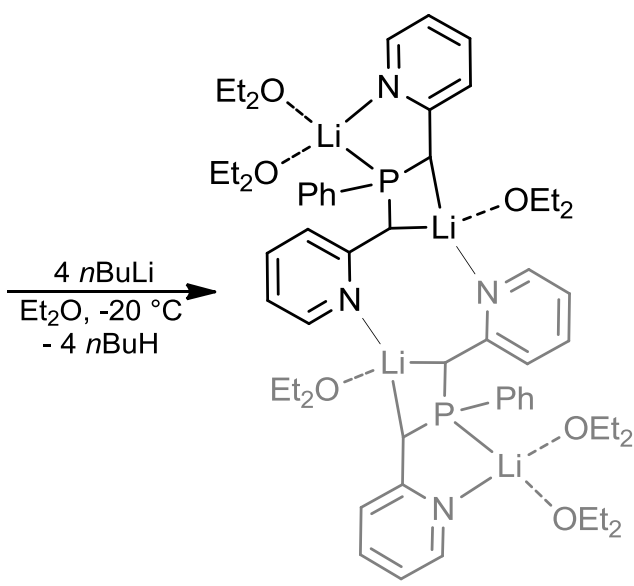

4

Scheme 3-3. Preparation of $\left[\left(\mathrm{Et}_{2} \mathrm{O}\right)_{3} \mathrm{Li}_{2}\{\mathrm{C}(\mathrm{H}) \mathrm{Py}\}_{2} \mathrm{PPh}\right]_{2}(4)$.

The $\mathrm{N}_{(\mathrm{py})}-\mathrm{Li}$ coordination provides the link in this head-to-tail dimer and gives rise to an eight membered $\left(\mathrm{LiNC}_{2}\right)_{2}$ ring. The deprotonation of the two methylene bridges affords a shortening of the $\mathrm{C} 1-\mathrm{C} 2$ and $\mathrm{C} 7-\mathrm{C} 8$ bond lengths by ca. $10 \mathrm{pm}$, compared to the free ligand 1 (140.0(3) and $141.0(3) \mathrm{pm}$, respectively). The literature value of a $\mathrm{P}-\mathrm{C}_{\mathrm{sp}}$ single bond is about $185 \mathrm{pm} .{ }^{[35]}$ The $\mathrm{P}-\mathrm{C}$ bond length in the neutral ligand 1 matches with this value. Due to the deprotonation of the ligand and the resulting rehybridization of the related carbon atoms from $\mathrm{sp}^{3}$ to $\mathrm{sp}^{2}$, one would expect a shortening of the P1-C1 and P1-C7 bond lengths in 4 by ca. $4 \mathrm{pm}$ caused by the smaller valence radius of the carbon atom. Indeed, the shortening of the P1-C1 (178.2(2) pm) and the P1-C7 (177.9(2) pm, respectively) bond is about $8 \mathrm{pm}$ which might be taken as a hint toward $\mathrm{P}=\mathrm{C}$ ylenic double bonding. However, our previous charge density work on $\mathrm{HP}(\text { bth })_{2}$, (bth = benzothiazol-2-yl, $\left.\mathrm{C}_{7} \mathrm{H}_{4} \mathrm{NS}\right)^{\left[{ }^{[13 c]}\right.}$ and $\left.\left[\mathrm{Me}_{2} \mathrm{Al}(\mu-\mathrm{Py})_{2} \mathrm{P}\right]\right]^{[36]}$ has already shown that a $\mathrm{P}-\mathrm{C}$ bond of around $178 \mathrm{pm}$ is not a double bond but a short, very polar, single bond. 


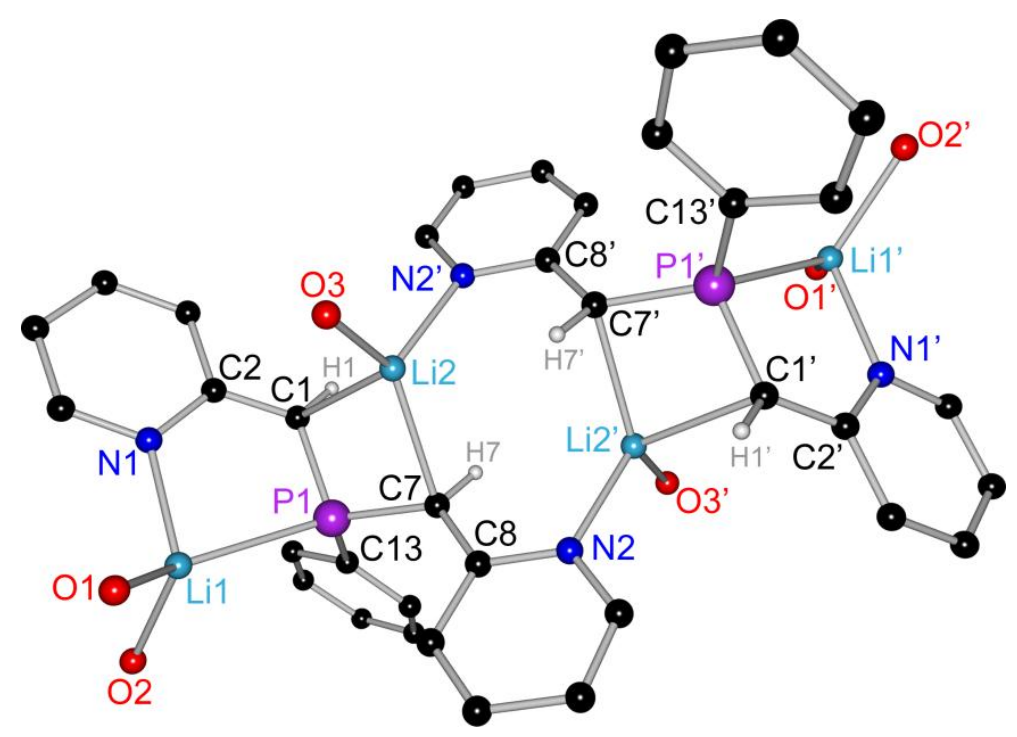

Figure 3-2. Solid state structure of $\left[\left(\mathrm{Et}_{2} \mathrm{O}\right)_{3} \mathrm{Li}_{2}\{\mathrm{C}(\mathrm{H}) \mathrm{Py}\}_{2} \mathrm{PPh}\right]_{2}$ (4). Hydrogen atoms, expect those of $\mathrm{C} 1$ and $\mathrm{C7}$, and ethyl groups of the diethyl ether molecules are omitted for clarity. Selected bond lengths and angles are listed in Table 3-1.

The deprotonation of $\mathrm{PhP}\left(\mathrm{CH}_{2} \mathrm{Py}\right)_{2}$ (1) can also be achieved by employing metal silylamides as nucleophilic bases. To generate the Sn(II) complex 5 a solution of $\mathbf{1}$ in diethyl ether was added dropwise to a solution of $\left[\mathrm{Sn}\left\{\mathrm{N}\left(\mathrm{SiMe}_{3}\right)_{2}\right\}_{2}\right]$ in THF at room temperature (Scheme 3-4).

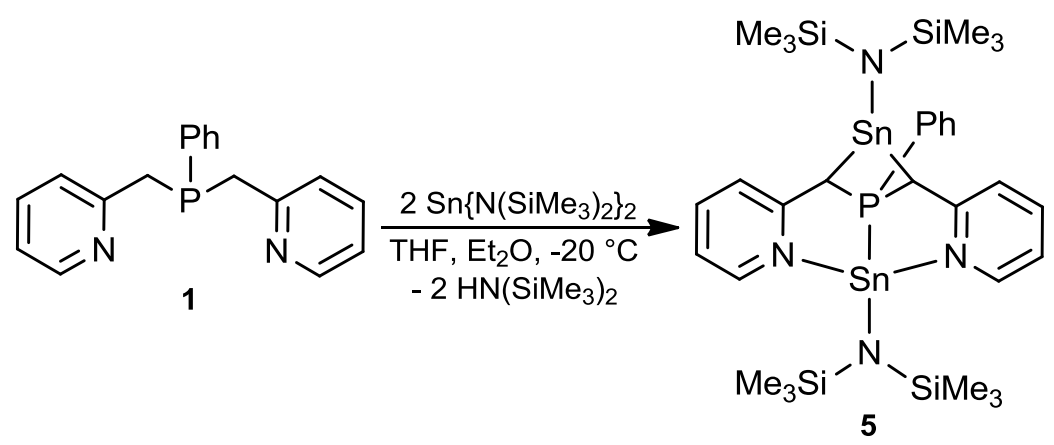

Scheme 3-4. Preparation of $\left[\left\{\left(\mathrm{Me}_{3} \mathrm{Si}\right)_{2} \mathrm{NSn}\right\}_{2}\{\mathrm{C}(\mathrm{H}) \mathrm{Py}\}_{2} \mathrm{PPh}\right](\mathbf{5})$.

The synthesis yielded yellow crystals made up from $\left[\left\{\left(\mathrm{Me}_{3} \mathrm{Si}\right)_{2} \mathrm{NSn}\right\}_{2}\{\mathrm{C}(\mathrm{H}) \mathrm{Py}\}_{2} \mathrm{PPh}\right](\mathbf{5})$, suitable for $\mathrm{X}$-ray structural analysis (Figure 3-3). 5 crystallizes in the triclinic space group $P \overline{1}$ and the asymmetric unit contains the tin complex and one non-coordinating THF molecule together with a nhexane molecule disordered on a special lattice position (inversion centre). Although the coordination pattern is similar to that of the lithium complex 4, the tin compound is a monomer, because each tin atom is coordinated by one hexamethylsilylamide ligand each. Apart 
from the amide contact Sn1 is exclusively $(N, P, N)$ chelated by the lower part of the ligand like in other transition metal complexes. ${ }^{[20-23]}$ The second tin atom Sn2 is addressed by the two carbanionic $\mathrm{CH}$ bridges of the ligand, remaining only threecoordinate. The coordination polyhedron of Sn1 can be described as a distorted trigonal bipyramide with the two pyridyl ring nitrogen atoms N1 and N2 located in the axial positions and the amide nitrogen atom $\mathrm{N} 3$, the phosphorus atom $\mathrm{P} 1$ and the stereochemically active lone-pair in the equatorial positions. Hence, the tin lone-pair points away from the electronically depleted phosphorus atom. Sn2 displays a distorted trigonal pyramidal coordination environment with the carbanionic C1 and C7 as well as the amide nitrogen atom N4 in the basal positions. Again, the metal lone pair points away from the phosphorus atom. However, a comparison of all published Sn-P bond lengths in the CSD shows a mean value of 262.5 pm. ${ }^{[37]}$ Hence the Sn1-P1 distance with 264.56(5) pm can be classified as a bond while the distance between Sn2 and P1 (299 pm) is too long to be regarded a bond. The deprotonation of the two methylene bridges affords a shortening of the $\mathrm{C} 1-\mathrm{C} 2$ and $\mathrm{C} 7-\mathrm{C} 8$ bond lengths, (147.3(2) and 146.3(2) pm, respectively). As already observed for the lithium complex 4 the P1-C1 (178.75(19) pm) and the P1-C7 (178.53(18) pm) bond lengths in 5 are also shortened by about $8 \mathrm{pm}$. For the previously reported reasons these bonds can also be classified as short, polar single bonds.

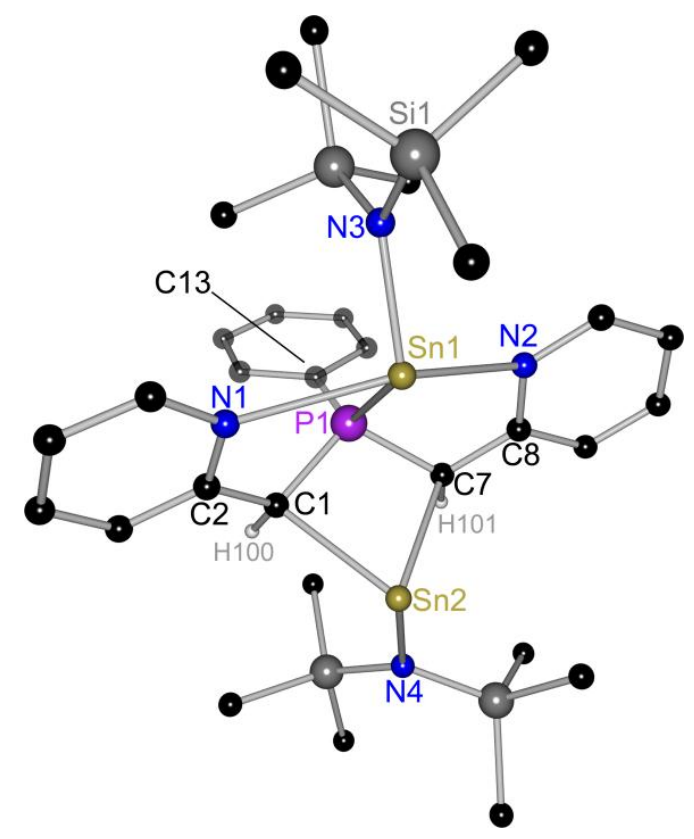

Figure 3-3. Solid state structure of $\left[\left\{\left(\mathrm{Me}_{3} \mathrm{Si}\right)_{2} \mathrm{NSn}\right\}_{2}\{\mathrm{C}(\mathrm{H}) \mathrm{Py}\}_{2} \mathrm{PPh}\right](5)$. Hydrogen atoms, expect those of $\mathrm{C} 1$ and C7, and the solvent molecules are omitted for clarity. Selected bond lengths and angles are listed in Table 3-1. 
Table 3-1. Selected bond lengths (pm) and angles (deg) for 1, 4 and $\mathbf{5 .}$

\begin{tabular}{l|ccc|lc|lc} 
& $\mathbf{1}$ & $\mathbf{4}$ & $\mathbf{5}$ & & $\mathbf{4}$ & & $\mathbf{5}$ \\
\hline P1-C1 & $186.86(13)$ & $178.2(2)$ & $178.75(19)$ & Li1-N1 & $202.4(4)$ & Sn1-N1 & $253.38(16)$ \\
P1-C7 & $185.28(13)$ & $177.9(2)$ & $178.53(18)$ & Li1-P1 & $254.9(4)$ & Sn1-N2 & $247.89(16)$ \\
P1-C13 & $184.10(13)$ & $184.2(2)$ & $182.02(18)$ & Li1-O1 & $195.3(4)$ & Sn1-P1 & $264.56(5)$ \\
N1-C2 & $134.28(18)$ & $138.3(3)$ & $135.0(2)$ & Li1-O2 & $197.8(4)$ & Sn1-N3 & $209.75(15)$ \\
N2-C8 & $134.38(17)$ & $137.8(3)$ & $135.7(2)$ & Li2-C1 & $234.3(5)$ & Sn2-N4 & $214.38(14)$ \\
C1-C2 & $150.17(17)$ & $140.0(3)$ & $147.3(2)$ & Li2-C7 & $227.9(5)$ & Sn2-C1 & $242.99(18)$ \\
C7-C8 & $150.52(16)$ & $141.0(3)$ & $146.3(2)$ & Li2-N2 & $201.7(4)$ & Sn2-C7 & $244.51(18)$ \\
C1-P1-C7 & $98.35(6)$ & $106.15(11)$ & $104.61(8)$ & P1-C1-C2 & $122.17(17)$ & P1-C1-C2 & $115.55(13)$ \\
C1-P1-C13 & $99.53(6)$ & $103.64(10)$ & $109.97(8)$ & C2-C1-H1 & $118.7(15)$ & C2-C1-H100 & $111.5(11)$ \\
C7-P1-C13 & $101.46(6)$ & $105.82(11)$ & $110.75(8)$ & P1-C1-H1 & $117.8(15)$ & P1-C1-H100 & $116.4(12)$
\end{tabular}

\subsection{Comparison of the Solid State Structures 4 and 5}

We recently showed by means of experimental and theoretical electron density studies that the deprotonation of 2-picoline with organolithium compounds leads to a distinct change in the bonding situation of the aromatic heterocycle. ${ }^{[31 b]}$ The question was whether the metalated species should best be regarded as an enamide ( $a$ in Scheme 3-5) or as a carbanion (b in Scheme 3-5).

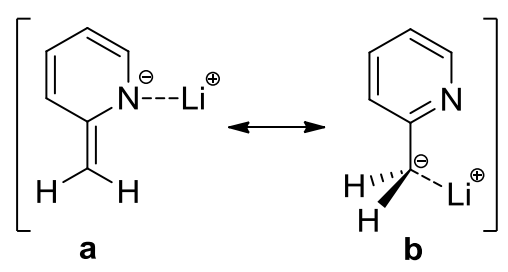

Scheme 3-5. Resonance formulas of deprotonated 2-picoline.

Due to the similar coordination mode of the metals lithium and tin in the complexes 4 and 5, a related analysis of the bonding situation should be feasible, based on distance considerations. By comparison of the bond lengths in the two metal complexes 4 and 5 relative to those in the neutral ligand 1, it should be possible to judge on the electron density distribution and the coordination behavior to get some insight into the probable fluctuation in solution.

In the neutral ligand $\mathrm{PhP}\left(\mathrm{CH}_{2} \mathrm{Py}\right)_{2}(\mathbf{1})$ the $\mathrm{C}-\mathrm{C}$ bond lengths in the aromatic ring vary only from $138.2(3)$ to $139.1(3) \mathrm{pm}$ (mean value $138.6 \mathrm{pm}$, Figure 3-4 a). The two $\mathrm{N}-\mathrm{C}$ 
bond lengths are almost equal (134.1(3) and 134.3(3) pm) and range between a $\mathrm{N}_{\mathrm{sp}^{2}}-\mathrm{C}_{\mathrm{sp}^{2}}$ single and double bond (140 and $129 \mathrm{pm}$, respectively) ${ }^{[35]}$. These bond lengths prove that the electron density of the heteroaromatic substituent is delocalized in the ring. The exocyclic $\mathrm{C} 1 / 7-\mathrm{C} 2 / 8$ bond lengths of $150.3(4) \mathrm{pm}$ are close to a standard $\mathrm{C}_{\mathrm{sp}^{3}}-\mathrm{C}_{\mathrm{sp}^{2}}$ single bond $(151 \mathrm{pm})^{[35]}$. The deprotonation of 1 causes an appreciable alteration of the bonding in the aromatic rings. Due to the differently coordinated two metal atoms, two different bonding situations can be observed in the complexes $\mathbf{4}$ and 5. The change in complex 4 is very similar to the results found in the study of 2picolyllithium (Figure 3-4 a). ${ }^{[31 b]}$ The $\mathrm{C} 1 / 7-\mathrm{C} 2 / 8$ bond lengths are shortened by ca. $10 \mathrm{pm}(140.5(8) \mathrm{pm})$ in comparison to the neutral ligand 1 and range between a $\mathrm{C}_{\mathrm{sp}^{2}}-$ $\mathrm{C}_{\mathrm{sp}^{2}}$ single and double bond (146.6 and $133.5 \mathrm{pm}$, respectively) ${ }^{[35]}$. Also the bond lengths in the aromatic ring differ from those of the neutral ligand. The $\mathrm{N} 1 / 2-\mathrm{C} 2 / 8$ bonds are elongated to $138.1(6) \mathrm{pm}$ while the second N1/2-C6/12 (135.1(8) pm) bonds adopt similar values like in the neutral ligand. The $\mathrm{C} 2 / 8-\mathrm{C} 3 / 9$ bonds are elongated to $143.9(9) \mathrm{pm}$ just as the $\mathrm{C} 4 / 10-\mathrm{C} 5 / 11$ bonds (139.9(4) pm) while the $\mathrm{C} 3 / 9-\mathrm{C} 4 / 10$ and $\mathrm{C} 5 / 11-\mathrm{C} 6 / 12$ bond lengths are shortened. This altered bonding situation is associated with more localized double bond character. The localization of the electron density in the shortened exocyclic $\mathrm{C} 1 / 7-\mathrm{C} 2 / 8$ bonds points toward an enamidic resonance formula $a$ in Scheme 3-5 to best describe the bonding in the pyridyl ring. This implies the carbon atoms $\mathrm{C} 1 / 7$ to be predominantly $\mathrm{sp}^{2}$ hybridized. The interaction of the lithium atom Li2 is consequently maintained by the nonhybridized p-orbital to the delocalized $\pi$-density (Figure $3-5$, left) ${ }^{[31 d]}$ rather than to an directed $\mathrm{sp}^{3}$-hybrid orbital (Figure 3-5, right). 


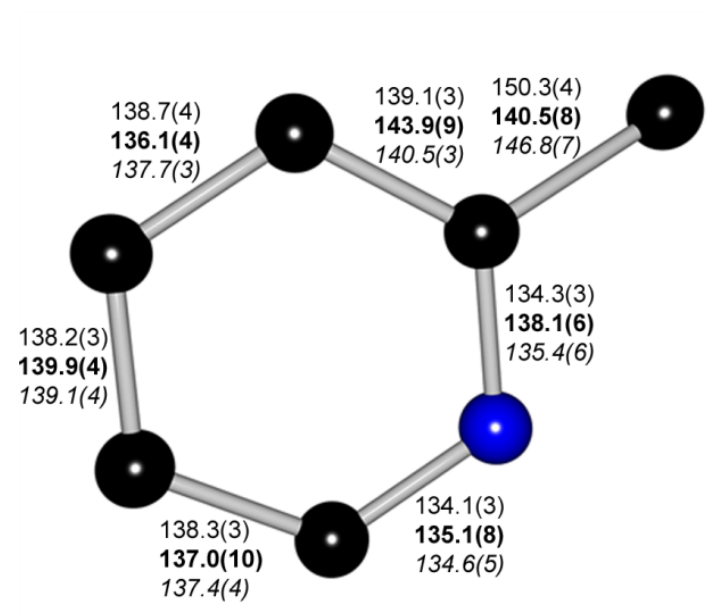

a

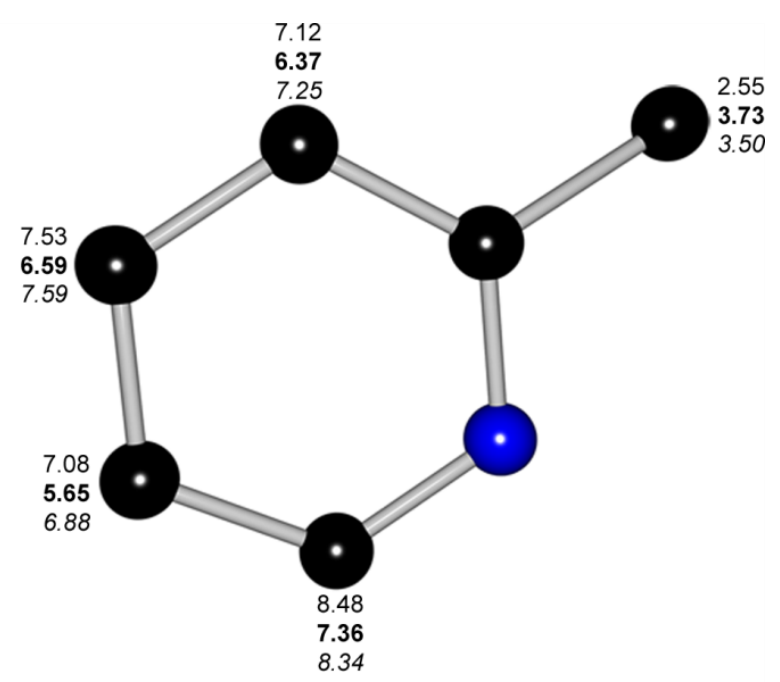

b

Figure 3-4. Picolyl fragment of the ligand with the bond lengths of the neutral complex $\mathbf{1}$ (standard), the lithium complex $\mathbf{4}$ (bold) and the tin complex $\mathbf{5}$ (italics). The bond length values of the two picolyl moieties of the ligand have been averaged ( $a$, left). The chemical shifts of the pyridyl protons in the neutral 2-picoline (standard), 4 (bold) and 5 (italics) (b, right).

The bonding in the tin complex 5 is different (Figure 3-4 a). The first distinction which has to be mentioned is the bond lengths of $\mathrm{C} 1 / 7-\mathrm{C} 2 / 8$ (146.8(7) pm) which are only marginally shortened by $4 \mathrm{pm}$ compared to the related bonds in the neutral ligand $1(150.3(4) \mathrm{pm})$ but considerably longer than in the lithiated complex 4 (140.5(8) pm). From those lengths alone it cannot be classified as a classical $\mathrm{C}_{\mathrm{sp}^{3}}-\mathrm{C}_{\mathrm{sp}^{2}}$ single bond, because the distance is shortened in comparison to the parent ligand, however the coordination geometry suggests $C 1 / 7$ to be predominantly sp ${ }^{3}$ hybridized (Figure $3-5$, right). The pyridyl rings show less pronounced bond lengths alternation than in the lithium complex 4. All bond lengths are similar to those of the neutral ligand 1. $\mathrm{C} 2 / 8-\mathrm{C} 3 / 9$ and C4/10-C5/11 are only slightly longer and C3/9-C4/10 and C5/11-C6/12 only marginally shorter. In contrast to the $\mathrm{C}-\mathrm{N}$ bonds in 4 these bonds (N1/2-C2/8 and $\mathrm{N} 1 / 2-\mathrm{C6} / 12$ ) are almost equal at values of $135.4(6)$ and $134.6(5) \mathrm{pm}$. For the tin complex 5 the carbanionic resonance formula $\mathbf{b}$ in Scheme 3-5, in which the C1/C7 carbon atom is $\mathrm{sp}^{3}$ hybridized and the lone-pair density stays at the deprotonated center while the $\pi$ electron density of the heteroaromatic ring remains almost unchanged, would best describe the bonding. In this case the interaction between the metal and the carbon atom is more of the covalent $\sigma$-type, operated from the directed carbanionic lone-pair. 


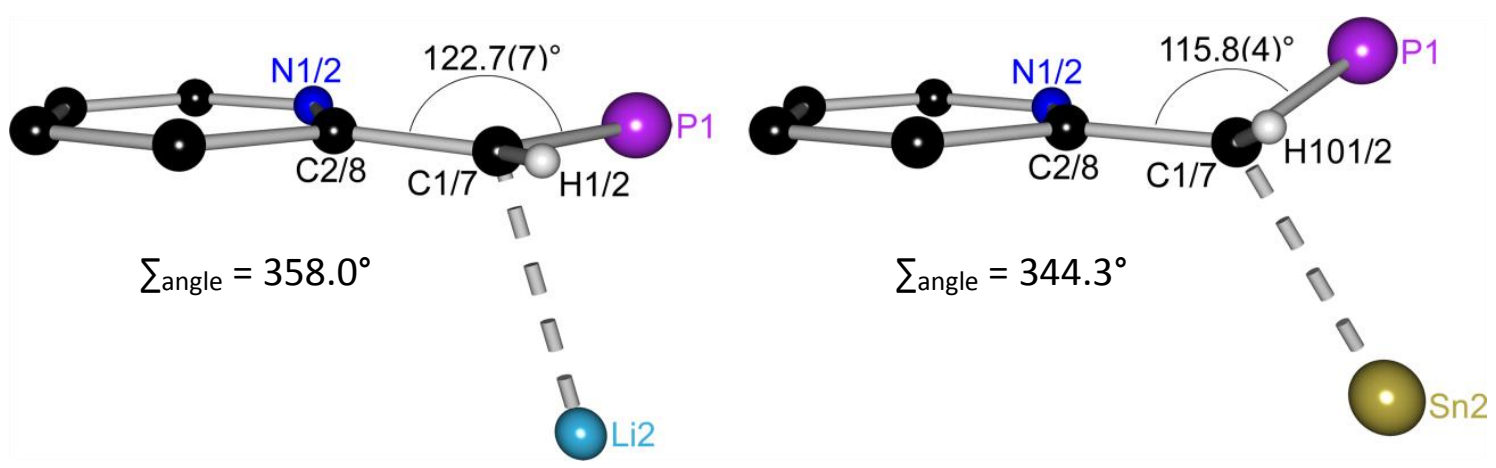

Figure 3-5. Fragments of the metal complexes 4 (left) and 5 (right) which show the different metal coordination, indicating the changed hybridization of the $\mathrm{C} 1 / 7$ carbon atom. The values of the bond angles of the two picolyl moieties are averaged.

Figure 3-5 shows the structural moieties of the two metal complexes $\mathbf{4}$ and $\mathbf{5}$ in which the coordination spheres and the angular sums ( $\left.\sum_{\text {angle }}\right)$ of the deprotonated methylene bridges $(\mathrm{C} 1 / 7)$ are displayed. It is obvious that the non-metallic coordination sphere of $\mathrm{C} 1 / 7$ in 4 is rather trigonal planar whereas it is more tetrahedral in 5 . This is mirrored in the $\mathrm{C} 1 / 7-\mathrm{C} 2 / 8$ bond lengths of $140.5(8) \mathrm{pm}$ in 4 and the $\mathrm{C} 1 / 7-\mathrm{C} 2 / 8$ bond lengths of $146.8(7) \mathrm{pm}$ in 5 , accounting to the different hybridization of the metalated carbon atoms in $\mathbf{4}$ and $\mathbf{5}$.

Even the chemical shifts of the pyridyl protons of $\mathbf{4}$ and $\mathbf{5}$ in comparison with the chemical shifts of those in the neutral 2-picoline reflect the bonding situation that was already discussed by the analysis of the bond lengths and angles (Figure 3-4 b). While the chemical shifts of $\mathbf{5}$ are almost similar to those of the neutral 2-picoline, those of the lithium complex 4 are upfield shifted due to the additional negative charge accumulated in the pyridyl ring. In summary, the picolyl moiety in $\mathbf{4}$ is best described by an enamidic coordination pattern while in the tin complex $\mathbf{5}$ the charge is mainly accumulated at the carbanionic sites.

\subsection{NMR Investigations of 5 in Solution}

To make a statement about the reactivity of a homogenous catalyst it is not only necessary to examine the solid state structure of a metal complex, but also to analyze the coordination behavior in solution. The question is whether $\left[\left\{\left(\mathrm{Me}_{3} \mathrm{Si}\right)_{2} \mathrm{NSn}\right\}_{2}\{\mathrm{C}(\mathrm{H}) \mathrm{Py}\}_{2} \mathrm{PPh}\right](5)$ is stable in solution and maintains the coordination mode of a Janus head. For this reason NMR investigations of $\mathbf{5}$ were conducted, 
especially because it contains no less than 6 spins $-1 / 2$ nuclei: ${ }^{1} \mathrm{H},{ }^{13} \mathrm{C},{ }^{15} \mathrm{~N}(0.37 \%$ natural abundance), ${ }^{29} \mathrm{Si}(4.67 \%),{ }^{31} \mathrm{P},{ }^{117} \mathrm{Sn}(7.68 \%)$, and ${ }^{119} \mathrm{Sn}(8.58 \%)$. In the solid state structure of $\mathbf{5}$ the two tin atoms are coordinated differently to the ligand: One tin moiety (Sn2) is coordinated to the two carbanionic $\mathrm{CH}$ bridges and the other (Sn1) is chelated by the $(N, P, N)$ tripod. The ${ }^{31} \mathrm{P}\left\{{ }^{1} \mathrm{H}\right\}$ NMR spectrum of $\mathbf{5}$ displays a singlet at $6.04 \mathrm{ppm}$ and two sets of satellites due to the presence of two non-equivalent tin atoms, each set splitting into two peaks due to the two NMR active tin isotopes (Figure 3-6). The coupling constants of one satellite set $\left({ }^{1} J_{\mathrm{p}-1175 n}=1698 \mathrm{~Hz},{ }^{1} J_{\mathrm{p}-119 \mathrm{Sn}}=1775 \mathrm{~Hz}\right)$ are much larger than those of the other set $\left({ }^{2} J_{\mathrm{P}-117 \mathrm{Sn}}=199 \mathrm{~Hz},{ }^{2} J_{\mathrm{P}-1195 \mathrm{~S}}=207 \mathrm{~Hz}\right)$.

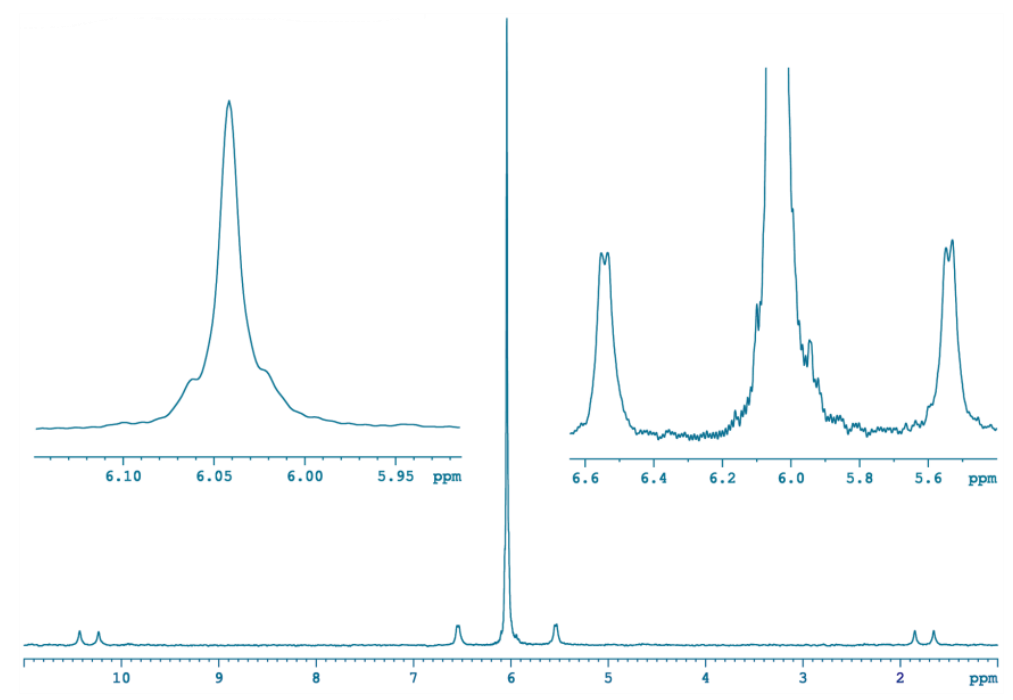

Figure 3-6. ${ }^{31} \mathrm{P}\left\{{ }^{1} \mathrm{H}\right\}$ NMR spectrum of $\mathbf{5}$.

In the ${ }^{29} \mathrm{Si}\left\{{ }^{1} \mathrm{H}\right\}$ NMR spectrum of 5 two different signals can be detected (Figure 3-7). Because of the different couplings of the two signals an assignment to the two silicon moieties in the complex is possible. The signal at $-3.5 \mathrm{ppm}$ is a singlet with satellites due to the coupling with the tin atom Sn2 which is not directly bonded to the phosphorus atom $\left({ }^{2} J_{\mathrm{Si}-\mathrm{Sn}}=10 \mathrm{~Hz}\right)$. The second signal at $1.5 \mathrm{ppm}$, a doublet also with satellites $\left({ }^{2} J_{\mathrm{Si}-\mathrm{Sn}}=32 \mathrm{~Hz}\right)$, can be assigned to the silicon moiety at $\mathrm{Sn} 1$ because of the additional coupling to the phosphorus atom $\left({ }^{3} J_{\mathrm{Si}-\mathrm{P}}=8 \mathrm{~Hz}\right)$. 


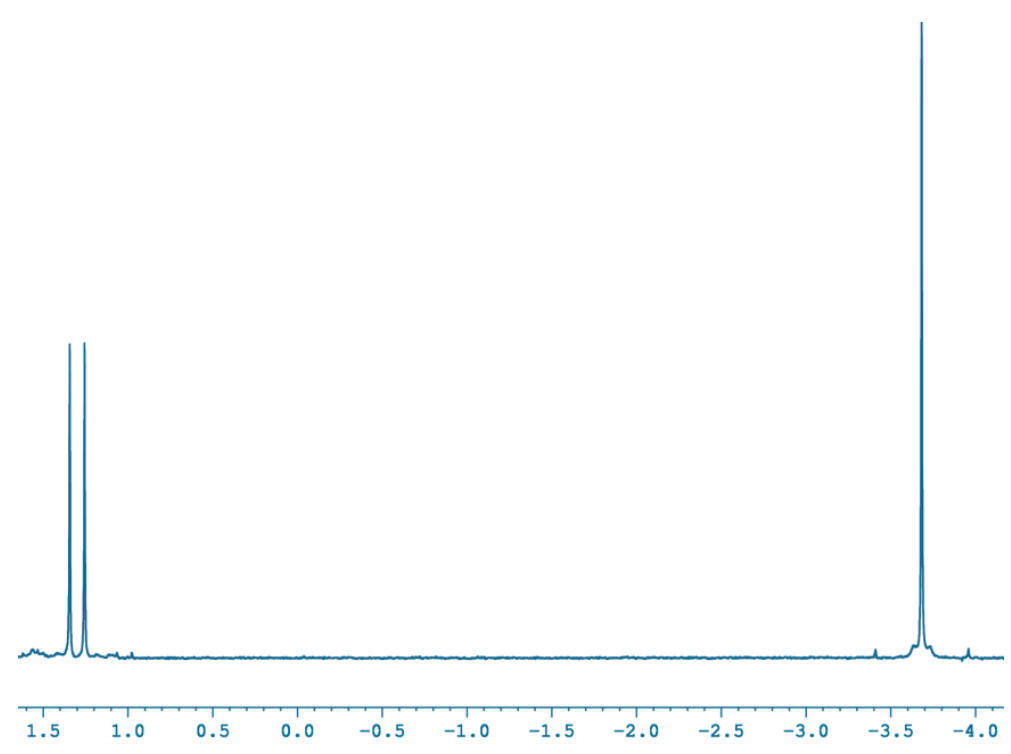

Figure 3-7. ${ }^{29} \mathrm{Si}\left\{{ }^{1} \mathrm{H}\right\}$ NMR spectrum of 5.

The ${ }^{119} \mathrm{Sn}\left\{{ }^{1} \mathrm{H}\right\}$ NMR spectrum of 5 consists of two doublets at $114.9\left({ }^{2} J_{\mathrm{P}-\mathrm{Sn}}=207 \mathrm{~Hz}\right)$ and $-219.5\left({ }^{1} J_{\mathrm{P}-\mathrm{Sn}}=1775 \mathrm{~Hz}\right) \mathrm{ppm}$ (Figure 3-8). Additionally the doublet at $114.9 \mathrm{ppm}$ shows satellites splitting into two peaks with a coupling constant of about $5400 \mathrm{~Hz}$ which can be assigned to the coupling with the second tin atom. With this information and the solid state structure it is possible to assign the two tin atoms unambiguously. The signal in the ${ }^{119} \mathrm{Sn}\left\{{ }^{1} \mathrm{H}\right\}$ NMR spectrum at $114.9 \mathrm{ppm}$ has the smaller ${ }^{2} J_{\mathrm{P}-\mathrm{Sn}}$ coupling constant with $207 \mathrm{~Hz}$ and can therefore be assigned to the tin atom that is coordinated by the two carbanionic $\mathrm{CH}$ bridges of the ligand ( $\mathrm{Sn} 2$ of the solid state structure, Figure 3-3). The second doublet in the ${ }^{119} \mathrm{Sn}\left\{{ }^{1} \mathrm{H}\right\}$ NMR spectrum at $-219.5 \mathrm{ppm}$ with a ${ }^{1} \mathrm{~J}-\mathrm{Sn}$ coupling $1775 \mathrm{~Hz}$ can be related to the tin atom which is directly coordinated by the phosphorus atom and the two pyridyl ring nitrogen atoms (Sn1 of the solid state structure, Figure 3-3). 


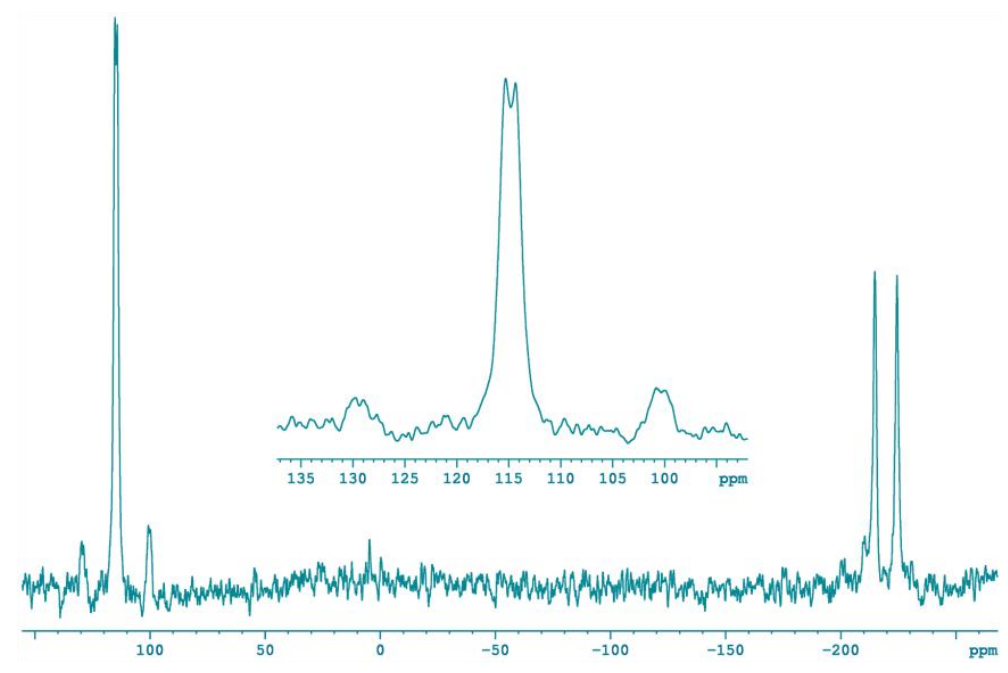

Figure 3-8. ${ }^{119} \mathrm{Sn}\left\{{ }^{1} \mathrm{H}\right\}$ NMR spectrum of $\mathbf{5}$.

In order to verify the coordination of the pyridyl ring to Sn1, we recorded a ${ }^{15} \mathrm{~N}-\mathrm{HMBC}$ spectrum of 5 and found the pyridyl resonance at $-104.6 \mathrm{ppm}$, which is shifted about $40 \mathrm{ppm}$ upfield from the free phosphane ligand. ${ }^{[38]}$ Furthermore, a strong cross peak in the 2D NOESY spectrum of 5 between the proton on the pyridyl carbon $\mathrm{C} 6\left(\mathrm{H}_{\mathrm{f}}\right)$ and the $\mathrm{N}\left(\mathrm{SiMe}_{3}\right)_{2}$ group on $\mathrm{Sn} 1$ indicates the pyridyl nitrogen atoms must coordinate Sn1 and not Sn2.

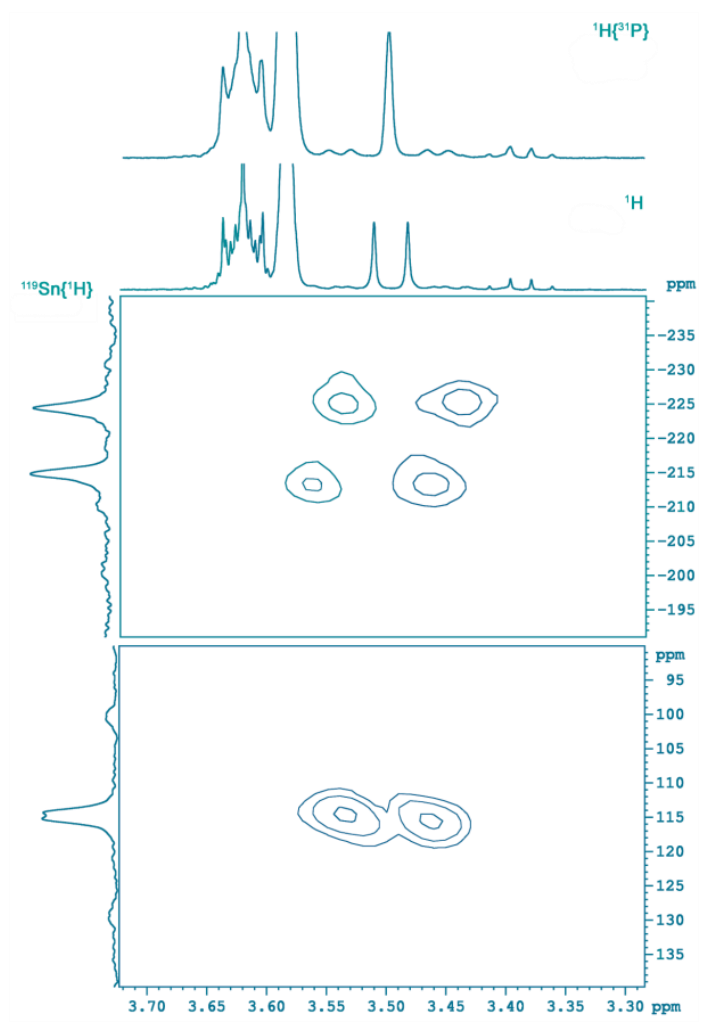

Figure 3-9. ${ }^{119}$ Sn HMBC spectrum of 5. 
The NOESY spectrum also shows a strong correlation between the other $\mathrm{N}\left(\mathrm{SiMe}_{3}\right)_{2}$ group (on $\mathrm{Sn} 2$ ) and the (anionic) $\mathrm{CH}$ group which points away from the tripodal pocket. This proton appears at $3.50 \mathrm{ppm}$ as a doublet $\left({ }^{2} J_{\mathrm{H}-\mathrm{P}}=-11.3 \mathrm{~Hz}\right)$ but again with two pairs of satellites $\left({ }^{2} J_{\mathrm{H}-\mathrm{Sn}}=25 \mathrm{~Hz},{ }^{3} \mathrm{~J}_{\mathrm{H}-\mathrm{Sn}}=40 \mathrm{~Hz}\right)$, where again the larger coupling constant is related to Sn1 (Figure 3-9).

With the aid of these NMR investigations it could be proved with absolute certainty that the coordination mode of the tin complex $\mathbf{5}$ in the solid state structure is identical with the one in solution.

\subsection{Single Deprotonation}

\subsubsection{Lithium Complexes}

As has been shown in the previous part, the double deprotonation of di-2-picolylphenylphosphane (1) with $n \mathrm{BuLi}$ is feasible. The question is whether a single deprotonated species is also possible. For this reason the reaction of phosphane $\mathbf{1}$ with $n$ BuLi was repeated with only one equivalent of the organolithium compound. The reaction was carried out under similar reaction conditions in THF at $-20{ }^{\circ} \mathrm{C}$ (Scheme 3-6). As for the lithium compound 4 the red solution was layered with nhexane and stored in the freezer to grow crystals.

2<smiles>c1ccc(CP(Cc2ccccn2)c2ccccc2)cc1</smiles>

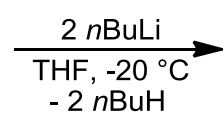

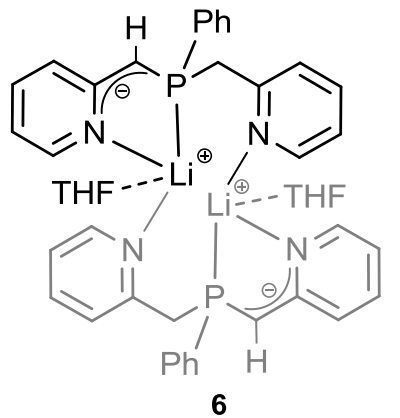

6

Scheme 3-6. Preparation of $\left[\left(\mathrm{PyCH}_{2}\right) \mathrm{PhP}\{\mathrm{C}(\mathrm{H}) \mathrm{Py}\} \mathrm{Li}(\mathrm{THF})\right]_{2}(6)$.

After two weeks yellow crystals of 6 could be obtained. Unfortunately, the obtained crystals were seriously twinned so that the resulting data set of the X-ray measurement was of poor quality. Because of the high air-sensitivity of $\mathbf{6}$ all crystals decomposed during the mounting process and no further characterization could be 
made. Subsequent crystallization approaches, also with other solvents, were inconclusive. The quality of the measured data set is not good enough to discuss the bond lengths and angles of this lithium complex but it is good enough to describe the atom connectivities and to get an insight of the coordination mode of the $N, P, N$ ligand. 6 crystallizes in the monoclinic space group $P 2_{1} / n$, the asymmetric unit contains the whole dimer (Figure 3-10).

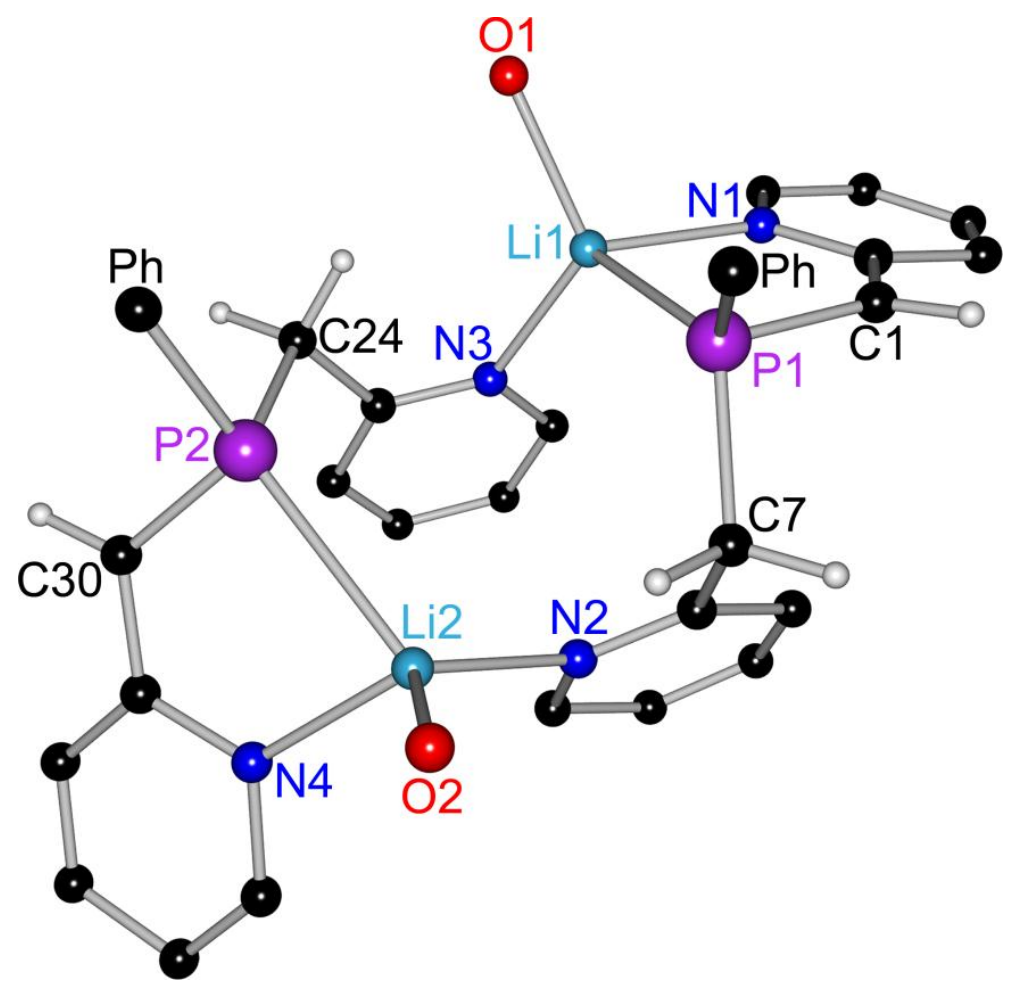

Figure 3-10. Solid state structure of $\left[\left(\mathrm{PyCH}_{2}\right) \mathrm{PhP}\{\mathrm{C}(\mathrm{H}) \mathrm{Py}\} \mathrm{Li}(\mathrm{THF})\right]_{2}(6)$. Hydrogen atoms, expect those of methylene bridges, the phenyl rings and carbon atoms of the THF molecules are omitted for clarity.

Each phosphanide ligand of the dimer 6 is only deprotonated at one methylene bridge. The two lithium atoms Li1 and Li2 are coordinated by the phosphorus atom and the nitrogen atom of the pyridine ring each linked to the phosphorus atom via the deprotonated methylene bridge. The tetrahedral coordination sphere of both lithium atoms is each completed by a donating THF molecule and the nitrogen atom of the neutral picolyl moiety of the second ligand. A coordination of the lithium atom by the carbanion is not observed. ${ }^{[33 a]}$ Presumably the negative charge is delocalized throughout the whole pyridine ring.

Through X-ray diffraction experiments as well as NMR investigations it could be verified that by addition of donor bases the aggregation grade of organolithium 
compounds could be decreased. ${ }^{[39]}$ Examples for common donor solvents are oxygen bases like $\mathrm{THF}, \mathrm{Et}_{2} \mathrm{O}$ or DME and nitrogen bases like TMEDA or PMDETA. The aggregation grade is often depending on the denticity of the donor molecule. The more donor sites a solvent has, the lower the observed aggregation grade is. Deaggregation studies of organolithiums are of great interest, not only because new coordination patterns for lithium can often be observed but mostly because dimeric and monomeric compounds show higher reactivity. ${ }^{[40]}$ In Scheme 3-7 the dimeric structure of tbutyllithium $(a)^{[41]}$ and the monomeric structure of trimethylsilyllithium (b) ${ }^{[42]}$ are displayed.

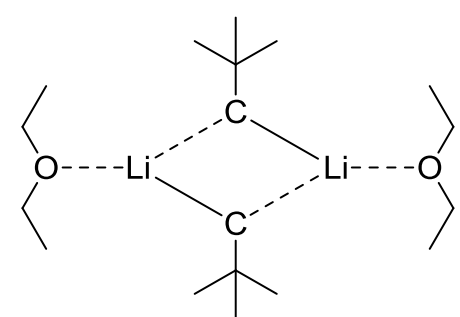

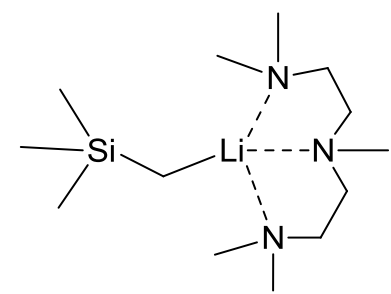

b

Scheme 3-7. Structures of the dimer $\left[\mathrm{Et}_{2} \mathrm{O} \cdot \mathrm{tBuLi}_{2}(\mathbf{a})\right.$ and monomer $\left[(\mathrm{PMDETA}) \cdot \mathrm{LiCH}_{2} \mathrm{SiMe}_{3}\right](\mathbf{b})$.

Therefore, 1 added the donor base PMDETA to the deprotonated compound in order to confirm deaggregation. Phosphane 1 and PMDETA were dissolved in a 1 to 1.05 ratio in toluene and after cooling the solution to $0{ }^{\circ} \mathrm{C} 1.1$ eq. of $n$ BuLi were added dropwise (Scheme 3-8). Subsequently, the volume of the red solution was reduced and again a few drops of PMDETA and THF were added. The mixture was stored in the freezer. Warming the solution to room temperature yielded crystals suitable for X-ray diffraction analysis.<smiles>c1ccc(CP(Cc2ccccn2)c2ccccc2)cc1</smiles>

1

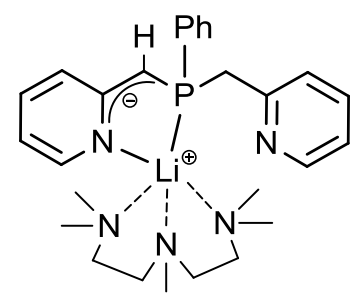

7

Scheme 3-8. Preparation of [(PMDETA)Li\{C(H)Py\}P(CH $\left.\left.{ }_{2} \mathrm{Py}\right) \mathrm{Ph}\right](\mathbf{7})$. 
7 crystallizes in the monoclinic space group $C c$ with one molecule in the asymmetric unit. The lithium complex is a monomer in which now only one coordination site of the ligand is occupied (Figure 3-11). Only one picolyl moiety is deprotonated and no further coordination of the carbanion takes place. The lithium atom is chelated by the phosphorus atom and the nitrogen atom N1 of the deprotonated picolyl moiety. Additionally, all three nitrogen atoms of the PMDETA donor base coordinate Li1. That implies a trigonal bipyramidal coordination polyhedron for Li1 which is quite unusual as lithium prefers a tetrahedral geometry. The axial positions of the polyhedron are occupied by N1 of the ligand and N3 of the PMDETA molecule while in the equatorial positions P1, N4 and N5 of the donor solvent are located. The P1-C1 and C1-C2 bond lengths are shortened to $175.03(19) \mathrm{pm}$ and $139.6(3) \mathrm{pm}$, respectively, due to the deprotonation of $\mathrm{C} 1$. It stands out that the shortening of these two bonds is stronger in comparison to the bond shortening of the dilithium complex 4 . This could be explained by the additional bonding of the carbanion with a second lithium atom in complex 4 while $\mathrm{C} 1$ in 7 remains without any further coordination.

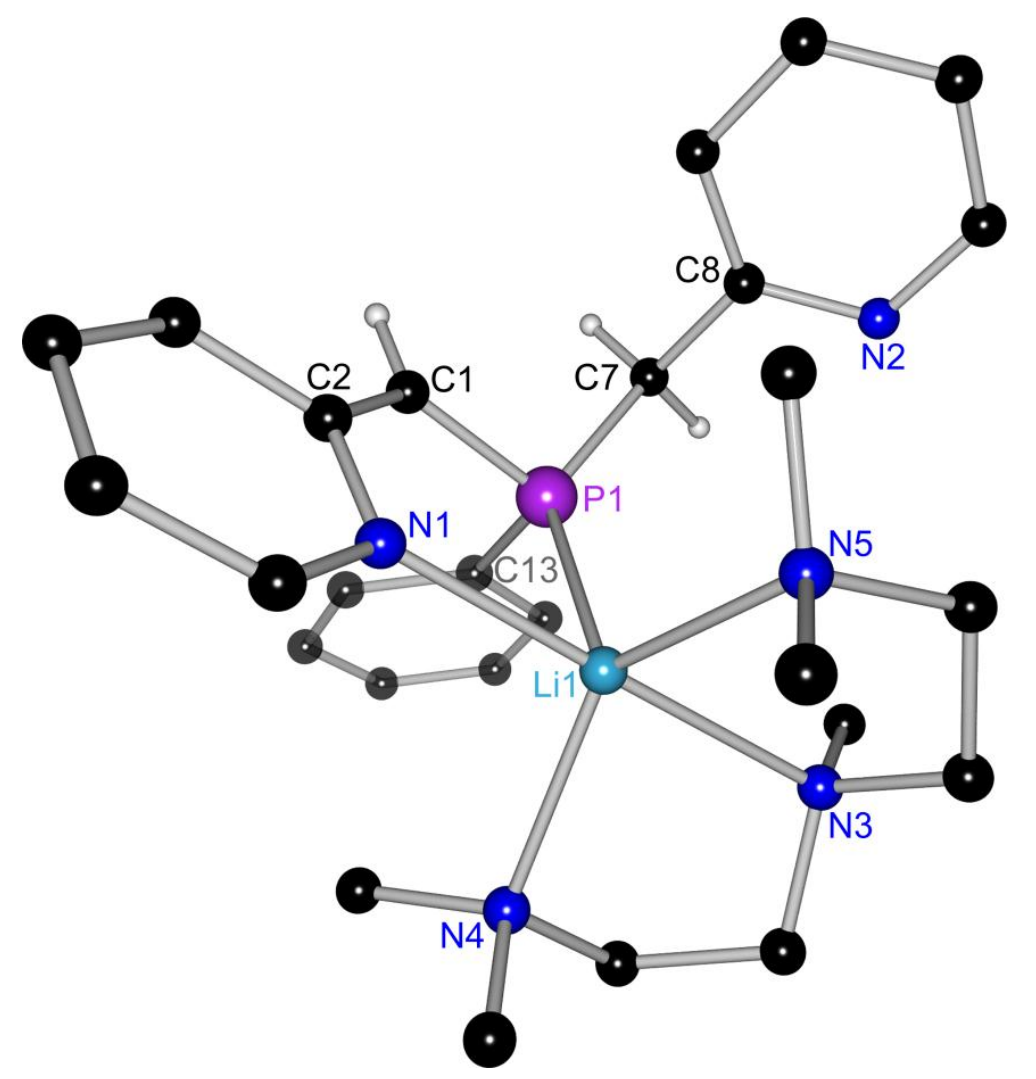

Figure 3-11. Solid state structure of [(PMDETA)Li\{C(H)Py\}P( $\left.\left.\mathrm{CH}_{2} \mathrm{Py}\right) \mathrm{Ph}\right](7)$. Hydrogen atoms, expect those of methylene bridges are omitted for clarity. Selected bond lengths and angles are listed in Table 3-2. 
The bond lengths in the pyridine ring of the deprotonated picolyl moiety are the same as in complex $\mathbf{4}$ and thus the double bond character is more or less localized. The N1-Li1 and the P1-Li1 bond lengths are elongated (by about 12 and $8 \mathrm{pm}$, respectively) in comparison to $\mathbf{4}$, which can be explained by the unusual fivefold coordination pattern of Li1 in 7. This trend is also obvious for the three lithiumnitrogen bonds to PMDETA (N3-Li1 231.5(9), N4-Li1 220.6(6) and N5-Li1 216.5(5) pm, respectively) that are elongated approximately $12-20 \mathrm{pm}$ compared to that of the lithium monomer in Scheme 3-7, b.

The same reaction as for the mono lithiated species was also repeated with the dilithiated compound using two equivalents of PMDETA. Unfortunately, no crystals could be obtained until know. The dilithiated species already forming a bulky aggregate, the steric demand of PMDETA cannot be satisfied when coordination takes place. This might explain the hampered crystallization so far.

Table 3-2. Selected bond lengths (pm) and angles (deg) for $\mathbf{7}$ and 8.

\begin{tabular}{l|cc|lc|lc} 
& $\mathbf{7}$ & $\mathbf{8}$ & & $\mathbf{7}$ & & $\mathbf{8}$ \\
\hline P1-C1 & $175.03(19)$ & $176.7(2)$ & Li1-P1 & $263.0(3)$ & Na1-P1 & $298.76(11)$ \\
P1-C7 & $187.0(2)$ & $186.5(3)$ & Li1-N1 & $214.5(3)$ & Na1-N1 & $244.3(2)$ \\
P1-C13 & $185.42(19)$ & $185.8(2)$ & Li1-N3 & $231.5(9)$ & Na1-N2' & $248.9(2)$ \\
N1-C2 & $138.1(2)$ & $137.2(3)$ & Li1-N4 & $220.6(6)$ & Na1-C1' & $276.9(3)$ \\
N2-C8 & $134.0(3)$ & $134.9(3)$ & Li1-N5 & $216.5(5)$ & Na1-O1 & $241.28(18)$ \\
C1-C2 & $139.6(3)$ & $142.2(3)$ & N1-Li1-N3 & $178.8(2)$ & P1-Na1-N2' & $162.02(6)$ \\
C2-C3 & $143.5(2)$ & $142.5(3)$ & N4-Li1-N5 & $132.1(2)$ & N1-Na1-O1 & $120.21(7)$ \\
C7-C8 & $149.8(3)$ & $149.8(3)$ & P1-Li1-N4 & $111.46(15)$ & O1-Na1-C1' & $120.76(7)$ \\
C8-C9 & $140.2(3)$ & $139.3(3)$ & P1-Li1-N5 & $114.77(16)$ & C1'-Na1-N1 & $118.64(8)$
\end{tabular}

\subsubsection{Lochmann-Schlosser Superbases}

At about the same time Lochmann and Schlosser discovered independently that the combination of organolithium compounds and alkali metal alkoxides results in the formation of very reactive adducts. The so called superbases opened up a new synthetic method to obtain heavier alkali metal organic compounds. ${ }^{[43]}$ Lochmann observed that the treatment of an alkyllithium compound with sodium tbutoxide results in an exchange of the metal ions and in the formation of the alkyl sodium compound in high yields. By further adding an organic compound like 
tri-phenylmethane the formation of the corresponding tri-phenylmethylsodium compound is observed. Schlosser discovered that not only the addition of a polar donor like DME, but also the addition of KOtBu increases the reactivity of organolithium compounds towards low acidic hydrocarbons. Schlosser used the name LICKOR for such superbases, meaning LithiumCarbonK=potassiumOR=alkoxide. The assumed intermediate of such LICKOR bases is displayed in Scheme 3-9.

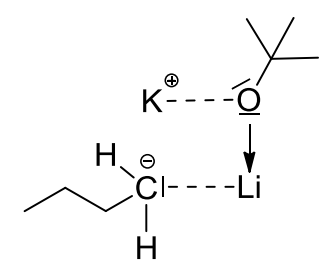

Scheme 3-9. Supposed intermediate by Schlosser. ${ }^{[43 b]}$

As an example, the reaction of benzene with $n$ BuLi to obtain phenyl lithium gives much better yields if potassium butoxide is added. This was also observed for aromatic hydrocarbons treated with $n \mathrm{BuLi}$ and TMEDA. ${ }^{[40]}$ The advantage of the LICKOR base is that the mixture can be quenched with $\mathrm{LiBr}$ after the reaction to give the lithium organyle free of any donor bases. ${ }^{[44]}$ Another difference is, that in contrast to organolithium compounds which tend to make additional reactions with olefins, superbases are regioselective to deprotonation of olefins only. ${ }^{[45]}$

To obtain further metal complexes of 1 the classical metal exchange reactions were tried first; i.e. adding metal salts to the lithium complexes trying to eliminate lithium chloride. However, all transmetalation reactions were inconclusive which could be explained by the strong lithium-nitrogen bond and the solid lattice of the metal salts. For this reasons the Lochmann-Schlosser superbases were used to introduce further alkali metal ions. After exploring several different adding sequences the following showed promising results and was applied in further coming experiments. The reaction was carried out in nhexane in which phosphane 1 and $\mathrm{NaOtBu}$ were suspended. After cooling of the mixture to $-20^{\circ} \mathrm{C} n$ BuLi was added slowly and a pale orange solid precipitated overnight (Scheme 3-10). Because of the good solubility of the resulting $\mathrm{LiOtBu}$ in nhexane only filtration and washing of the orange sodium precipitate was needed. For crystallization the crude product was dissolved in $\mathrm{Et}_{2} \mathrm{O}$ and stored in the freezer. Yellow colored crystals of $\mathbf{8}$ could be obtained and single crystal X-ray analysis was performed. 
2<smiles>c1ccc(CP(Cc2ccccn2)c2ccccc2)cc1</smiles>

$2 n \mathrm{BuLi}, 2 \mathrm{NaOtBu}$

nhexane, $\mathrm{Et}_{2} \mathrm{O},-20^{\circ} \mathrm{C}$

$-2 n \mathrm{BuH},-2 \mathrm{LiOtBu}$

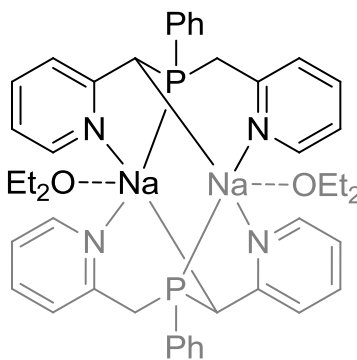

8

Scheme 3-10. Preparation of $\left[\left(\mathrm{PyCH}_{2}\right) \mathrm{PhP}\{\mathrm{C}(\mathrm{H}) \mathrm{Py}\} \mathrm{Na}\left(\mathrm{Et}_{2} \mathrm{O}\right)\right]_{2}(\mathbf{8})$.

8 crystallizes in the triclinic space group $P \overline{1}$ with half of the dimer in the asymmetric unit. Although 2 eq. of the sodium alkoxide were used for the reaction phosphane $\mathbf{1}$ is only single deprotonated (Figure 3-12). The coordination polyhedron of the sodium metal Na1 can be described as distorted trigonal bipyramidal with the phosphorus atom P1 and the nitrogen atom N2' of the second ligand located in the axial positions. The pyridine nitrogen atom N1, the carbanion $\mathrm{C}^{\prime}$ of the second ligand and the oxygen atom of an $\mathrm{Et}_{2} \mathrm{O}$ molecule occupy the equatorial positions. The first coordination site of the ligand is occupied by the phosphorus atom P1 and N1 of the deprotonated picolyl moiety which chelated one sodium atom. The carbanion C1 is bonded to a second sodium atom Na1'.

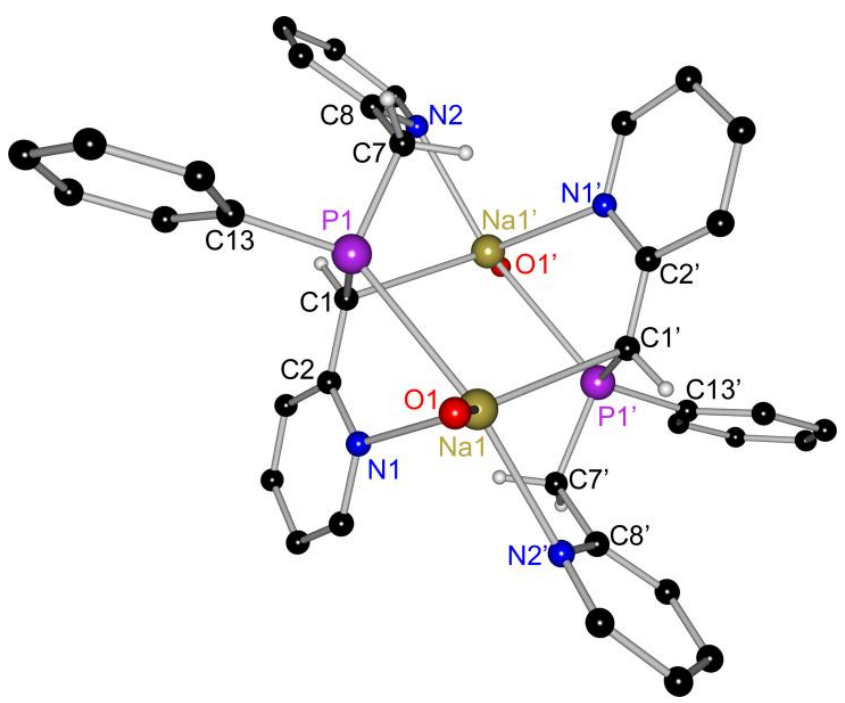

Figure 3-12. Solid state structure of $\left[\left(\mathrm{PyCH}_{2}\right) \mathrm{PhP}\{\mathrm{C}(\mathrm{H}) \mathrm{Py}\} \mathrm{Na}\left(\mathrm{Et}_{2} \mathrm{O}\right)\right]_{2}(\mathbf{8})$. Hydrogen atoms, expect those of methylene bridges and the carbon atoms of the $\mathrm{Et}_{2} \mathrm{O}$ donors are omitted for clarity. Selected bond lengths and angles are listed in Table 3-2. 
In comparison to the dilithium complex 4 and the tin complex $\mathbf{5}$, the carbanion $\mathrm{C} 1$ in $\mathbf{8}$, with a C2-C1-P1 angle of $117.90(18)^{\circ}$, forms a geometry somewhere in between the two cases. While the geometry can be described rather as tetrahedral than trigonal planar and is similar to the tin compound $\mathbf{5}$ the bonding situation of the metal atom is very different to $\mathbf{5}$. In $\mathbf{8}$ the second sodium atom is not placed above the carbanion as in 5 but in-plane with the latter (C1-Na1' 276.9(3) pm). Therefore, a trigonal planar geometry of $\mathrm{C} 1$ would be more or less impossible. The shortening of the $\mathrm{C} 1-\mathrm{C} 2$ bond $(142.2(3) \mathrm{pm})$ of about $8 \mathrm{pm}$ and the bond lengths of the pyridine ring which indicate a localization of the double bonds in the ring, predict a more enamidic form as for the lithium complex 4.

However, a comparison of all published $\mathrm{Na}-\mathrm{N}$ bond lengths in the CSD shows a mean value of $252.6 \mathrm{pm} .{ }^{[46]}$ The Na1-N1 and the Na1-N2' bond lengths (244.3(2), 248.9(2) pm, respectively) are slightly shorter than this value, but the Na1-O1 bond length $(241.28(18) \mathrm{pm})$ matches with the mean value of the CSD $(243.5 \mathrm{pm}){ }^{[46]}$ Searching the CSD for all structures with a Na-P bond only 61 references could be found, indicating that such a bond seems very uncommon. However the Na1-P1 bond length $(298.76(11) \mathrm{pm})$ is in accord with the mean value of $294.2 \mathrm{pm} .{ }^{[46]}$ The two sodium atoms of the complexes show a distance of $416.30(18) \mathrm{pm}$.

As already mentioned the double deprotonation with sodium alkoxide was not feasible despite the use of 2 eq. of NaOtBu. However, during the NMR investigations of 8 an unusual behavior of the sodium complex in solution was observed. While the ${ }^{1} \mathrm{H}$ NMR spectrum of the obtained crystals shows two sets of signals each per the deprotonated and neutral picolyl moiety as expected, the ${ }^{1} \mathrm{H}$ NMR spectrum of the crude product of $\mathbf{8}$ displays only one set of signals. Both spectra were measured in the same solvent, THF- $\mathrm{d}_{8}$. It is noteworthy that not only the sets of signals have changed but also the integrals of the signals and even the singlet in the ${ }^{31} \mathrm{P}\left\{{ }^{1} \mathrm{H}\right\} \mathrm{NMR}$ spectrum has shifted to lower field. Figure 3-13 displays sections of the ${ }^{1} \mathrm{H}$ (left) and ${ }^{31} \mathrm{P}\left\{{ }^{1} \mathrm{H}\right\}$ (right) NMR spectra of $\mathbf{8}$. While the blue spectra represent the NMR signals collected for the crystals in solution, the red spectra display the NMR signals for the crude product. The ${ }^{1} \mathrm{H}$ NMR spectrum presents the area of chemical shift assigned to the $\mathrm{CH}_{2}$ bridges of the ligand. The blue spectrum implies two signals with integrals of one and two protons which can be assigned to the deprotonated and neutral methylene bridge. The red spectrum displays only one broad signal with an integral of two protons which 
means that, keeping in mind the composition of the ligand, two chemically identical protons can be associated to this signal. The presence of only one set of signals for the picolyl moiety, their integrals and the up-field shifted peak in the ${ }^{31} \mathrm{P}\left\{{ }^{1} \mathrm{H}\right\} N M R$ spectrum point to the formation of the double deprotonated species. A possible explanation for this behavior could be that the excess of the formed superbase was also insoluble in nhexane and therefore was isolated together with the product. Furthermore, the reactivity of the remaining base might have been low in $\mathrm{Et}_{2} \mathrm{O}$ which was used as solvent for the crystallization but high in the deuterated THF. Additional crystallization of the crude product in $\mathrm{Et}_{2} \mathrm{O}$ also results in the formation of the single deprotonated species $\mathbf{8}$. Unfortunately no crystals of $\mathbf{8}$ in THF could be obtained, so until this point the questions could not be clarified.

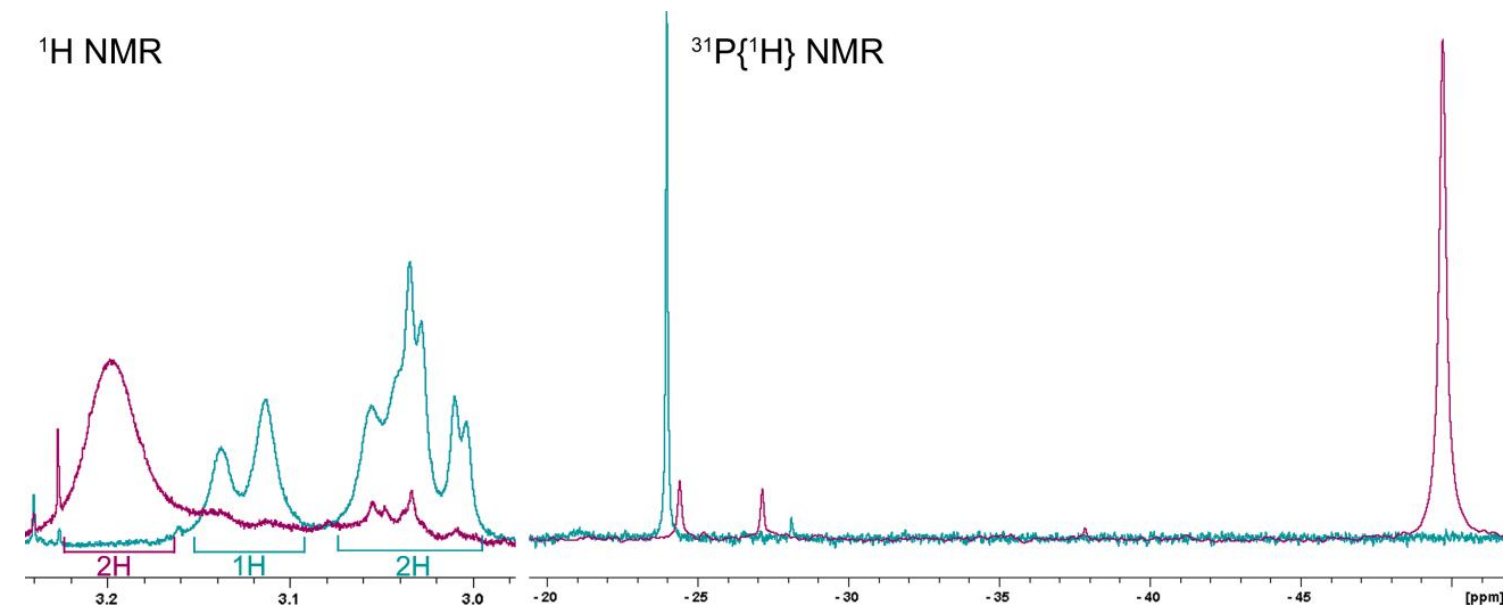

Figure 3-13. ${ }^{1} \mathrm{H}$ NMR spectrum (left) and ${ }^{31} \mathrm{P}\left\{{ }^{1} \mathrm{H}\right\}$ NMR spectrum of 8 as crystals (blue) and crude product (red).

After the successful synthesis of the sodium complex $\mathbf{8}$ the reaction was repeated using the LiCKOR base nbutyllithium and potassium alkoxide. However, the synthesis of a potassium complex turned out to be difficult due to the high reactivity of potassium compounds. For this reason several reaction pathways were tested. An overview of the applied adding sequences is displayed in Scheme 3-11. Firstly, the lithiated species was generated using THF as solvent, afterwards sodium alkoxide was added dissolved in nhexane (sequence a) or THF (sequence b). Secondly, the mixture of $n$ butyllithium and potassium alkoxide in toluene was pre-generated and added to a cooled toluene/nheptane suspension of phosphane $\mathbf{1}$ (sequence $\mathbf{c}$ ). Thirdly, a mixture of the two solids phosphane 1 and potassium alkoxide was suspended in nhexane and cooled to $-20^{\circ} \mathrm{C}$ before $n$ BuLi was added dropwise (sequence d). Last, a solution of 
phosphane 1 was added to the pre-generated, cooled LiCKOR base in nheptane (sequence e). Additionally, the amount of LiCKOR base was varied between one and two equivalents.

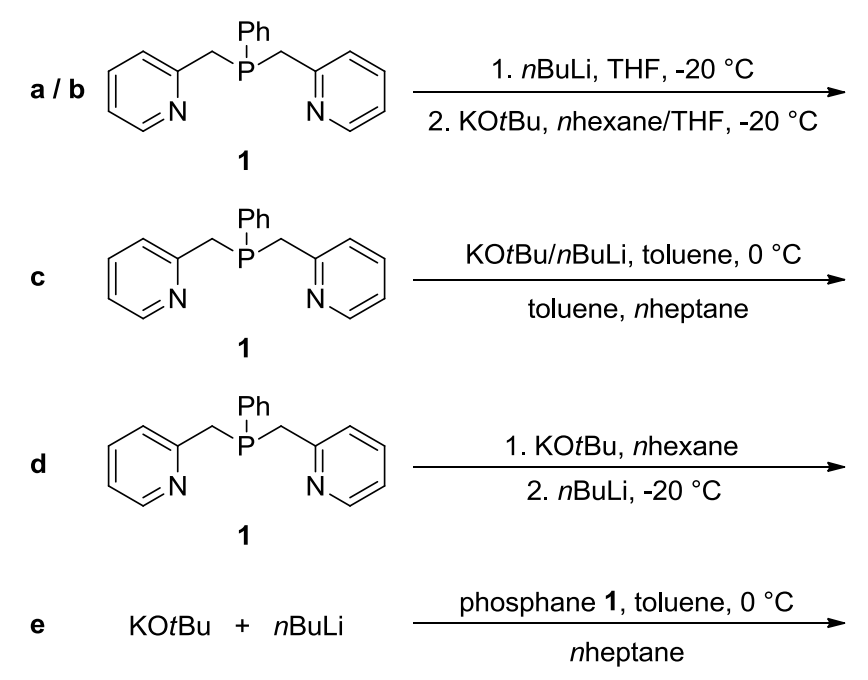

Scheme 3-11. Different adding sequences for the reaction of 1 with KOtBu.

The investigations of the obtained orange to brown solids were performed by ${ }^{31} \mathrm{P}$ NMR studies. ${ }^{31} \mathrm{P}$ NMR spectroscopy is ideal for this purpose due to the fact that there are not only significantly lesser signals than i.e. ${ }^{1} \mathrm{H}$ NMR spectra but also because it is easy to distinguish between starting material and product. The resonance of the neutral phosphane 1 is located around $-13 \mathrm{ppm}$ while the coordination of an alkali metal ion results in an up-field shift of the ${ }^{31} \mathrm{P}$ signal. The various reactions resulted in very different products. In Figure 3-14 four different ${ }^{31} \mathrm{P}\left\{{ }^{1} \mathrm{H}\right\}$ NMR spectra measured in deuterated THF are displayed. It is obvious that the different adding sequences have a considerable influence on the formation of products. While for the reaction with 1 eq. potassium alkoxide and sequence $\mathbf{c}$ only phosphane $1(-11.2 \mathrm{ppm})$ could be isolated (green spectrum, Figure 3-14), the reaction of 2 eq. potassium alkoxide following the same reaction pathway results in the formation of starting material $(-13.9 \mathrm{ppm})$ and two additional products with chemical shifts of -19.1 and $-21.6 \mathrm{ppm}$ (blue spectrum, Figure 3-14). The use of 2 eq. potassium alkoxide following the adding sequence $\mathbf{d}$ gave no starting material but again two products visible as signals at -16.1 and $-19.1 \mathrm{ppm}$ (red spectrum, Figure 3-14). The latter is identical to the one observed in the blue spectrum. A promising reaction pathway is displayed in Scheme 3-11, e in which 2 eq. of the LiCKOR base are pre-generated and phosphane 1 is added. The ${ }^{31} \mathrm{P}\left\{{ }^{1} \mathrm{H}\right\} \mathrm{NMR}$ 
spectrum reveals only one broad signal at $-22.6 \mathrm{ppm}$ (red spectrum, Figure 3-15) which ranges in the same field like the ${ }^{31} \mathrm{P}\left\{{ }^{1} \mathrm{H}\right\}$ NMR signal for the sodium complex 8 . Thus it can be assumed that a complex of 1 containing potassium was formed.

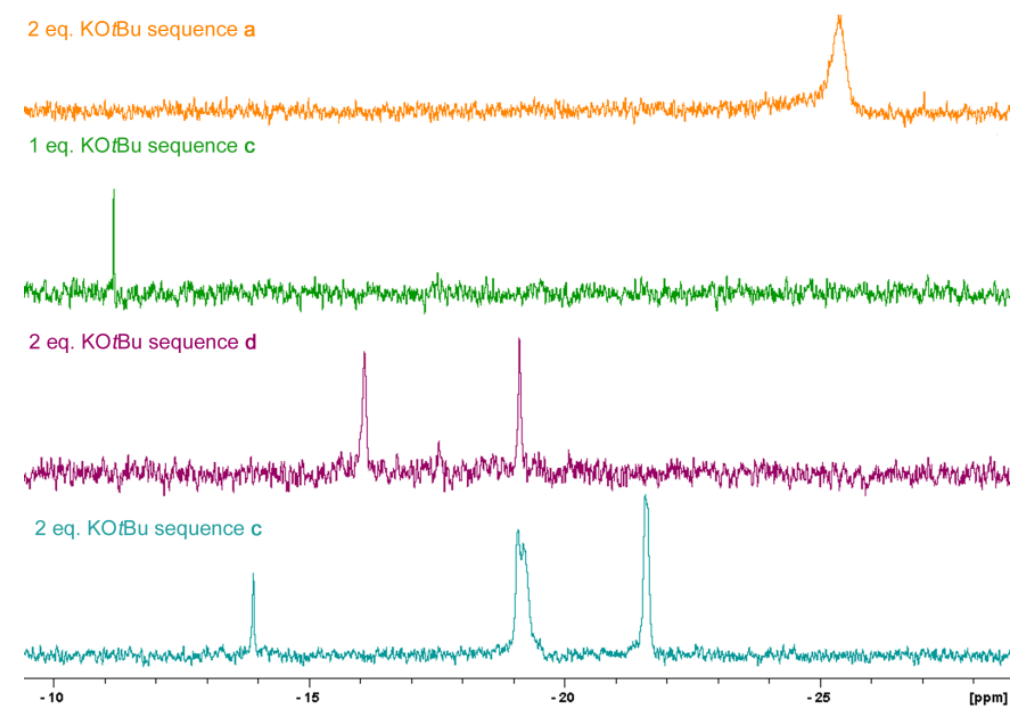

Figure 3-14. ${ }^{31} \mathrm{P}\left\{{ }^{1} \mathrm{H}\right\}$ NMR spectra measured for the reaction of 1 with LICKOR base in THF- $\mathrm{d}_{8}$.

The reaction with 2 eq. potassium alkoxide also following adding sequence a results in the formation of only one product containing phosphorus (yellow spectrum, Figure 3-14). The broad singlet at $-25.45 \mathrm{ppm}$ is located in the same region as the signal reported before. Adding sequence $\mathbf{b}$ which is almost identical to $\mathbf{a}$, except the used solvent, results in the formation of a product arising as a broad singlet at $-30.1 \mathrm{ppm}$ and remaining starting material at -13.9 ppm (blue spectrum, Figure 3-15).

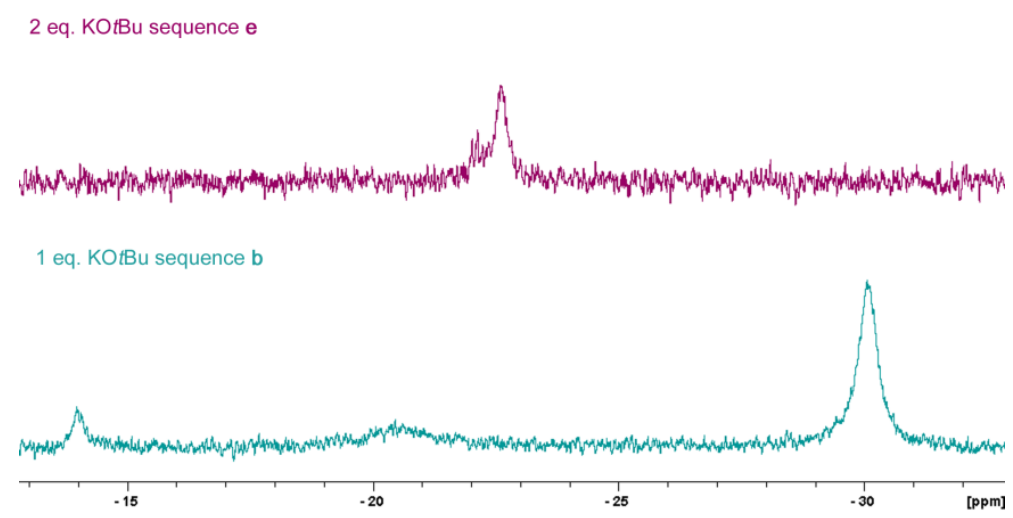

Figure 3-15. ${ }^{31} \mathrm{P}\left\{{ }^{1} \mathrm{H}\right\}$ NMR spectra measured for the reaction of 1 with LICKOR base in $\mathrm{C}_{6} \mathrm{D}_{6}$.

It can be concluded that the reaction pathways a and $\mathbf{e}$ (Scheme 3-11) are the most promissing ones to obtain the desired potassium complexes. Also, the pyridine proton 
signals in the ${ }^{1} \mathrm{H}$ NMR spectrum of both compounds are shifted up-field and therefore give a hint of additional coordination of the nitrogen atoms to the metal ion.

On the one hand, the pre-generation of the LiCKOR base before adding the substrate gave full conversion to one product. On the other hand, the pre-generation of the lithiated species and afterwards addition of the alkoxide also unexpectedly results in the formation of only one product. This could be explained with the pre-coordination of the ligand thus a complexation of the potassium ion is more feasible. Likewise, it could be observed that the amount of the alkoxide can also play a role. The conversion of reaction a with 2 eq. alkoxide was completed while in reaction b with 1 eq. of alkoxide starting material remained although the adding sequences are almost equal. Although, crystallization of the yielded crude products were performed in several donor bases like $\mathrm{THF}$ or $\mathrm{Et}_{2} \mathrm{O}$ in and without combination with hydrocarbon solvents no crystals suitable for X-ray diffraction experiments could be obtained. Therefore, up until now the constitution of the obtained potassium compounds could not be clarified. Ultimately, it cannot be precluded that the obtained products contain lithium and not potassium due to the similarity of the ${ }^{31} \mathrm{P}\left\{{ }^{1} \mathrm{H}\right\}$ NMR chemical shift of both compounds. Elemental analysis could clarify this but is not feasible due to the high reactivity of potassium compounds.

The attempt to use group 13 alkoxides to introduce boron and aluminum as metal ions failed. This might have been due to the steric demand of three tbutoxide moieties and unstable lithium group 13 metal intermediates inhibiting the formation of complexes.

\subsubsection{Solid State Structure of a Superbase $\mathrm{Li}_{4} \mathrm{~K}_{4}$ Adduct}

It is a matter of common knowledge that the combination of organolithium compounds with heavier alkali metal alkoxides increases the reactivity, and sometimes even selectivity, of deprotonating reactions. ${ }^{[45,47]}$ While the application of such superbases is well investigated, the structural determination of the hetero alkali metal adducts is less examined. The prediction of theses adducts is rather difficult because many factors like aggregation, bonding of donor solvents or substrates must be considered. The work group of R. E. Mulvey studies the structural behavior of mixed alkali metal compounds, in particular the combination of lithium amides with heavier 
alkali metal alkoxides. ${ }^{[48]}$ One example that should be highlighted is the reaction of lithium tbutylamide and potassium tbutoxide which results in $\left[\left\{[t \mathrm{BuN}(\mathrm{H})]_{4}(t \mathrm{BuO}) \mathrm{Li}_{4} \mathrm{~K}_{4}\left(\mathrm{C}_{6} \mathrm{H}_{6}\right)_{3}\right\}\left(\mathrm{C}_{6} \mathrm{H}_{6}\right)\right]$ (Scheme 3-12). ${ }^{[49]}$ The reaction of the $\mathrm{Li}_{4} \mathrm{~K}_{4}$ adduct with toluene results in the formation of benzylpotassium and thus is the first structural verified $\mathrm{Li}_{4} \mathrm{~K}_{4}$ superbase.

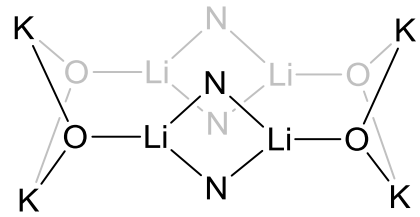

Scheme 3-12. $\mathrm{Li}_{4} \mathrm{~K}_{4} \mathrm{O}_{4} \mathrm{~N}_{4}$ core of $\left[\left\{[t \mathrm{BuN}(\mathrm{H})]_{4}(t \mathrm{BuO}) \mathrm{Li}_{4} \mathrm{~K}_{4}\left(\mathrm{C}_{6} \mathrm{H}_{6}\right)_{3}\right\}\left(\mathrm{C}_{6} \mathrm{H}_{6}\right)\right]$.

A reaction similar to the synthesis for the sodium complex 8 was prepared by using potassium alkoxide instead of $\mathrm{NaOtBu}$. However, the adding sequence of the reactants was modified. While in the synthesis of $8 \mathrm{PhP}\left(\mathrm{CH}_{2} \mathrm{Py}\right)_{2}(\mathbf{1})$ and $\mathrm{NaOtBu}$ were dissolved together before $n \mathrm{BuLi}$ was added, KOtBu was first mixed with $n \mathrm{BuLi}$ and then transferred to a toluene solution of $\mathbf{1}$. The work-up was identical to $\mathbf{8}$. The storage of a toluene solution of the crude product in the freezer yielded small colorless crystals. Single crystal X-ray analysis revealed the unexpected formation of a compound containing lithium and potassium being chelated by decamethylpentasiloxane. While this was not the desired product it provided an interesting insight into the still unexplored structural conformation and reactivity of LiCKOR bases. The siloxane ligand is probably based on silicon grease which might have been eluted from the ground of the flask. $\left[\left(\mathrm{Me}_{2} \mathrm{SiO}\right)_{5} \mathrm{OKLi}\right]_{4}(9)$ crystallizes in the tetragonal space group $\overline{14}$ and contains one siloxane ligand, one lithium and potassium metal ion, respectively, in the asymmetric unit (Figure 3-16). The siloxane ligand is twisted like an opened crown ether and chelates the potassium ion with six oxygen atoms. In contrast the lithium atom is only bonded to 01 . The averaged $\mathrm{Si}-\mathrm{O}$ bond lengths of the bridged oxygen atoms are, with value of $162.9 \mathrm{pm}$, a bit shorter than a standard Si-O bond (164 pm). ${ }^{[35]}$ The terminal Si-O bonds are shortened (Si1-O1 157.69(13) pm and Si5-06 158.35(13) pm, respectively) about by $5 \mathrm{pm}$ due to the anionic character of the oxygen atoms. 


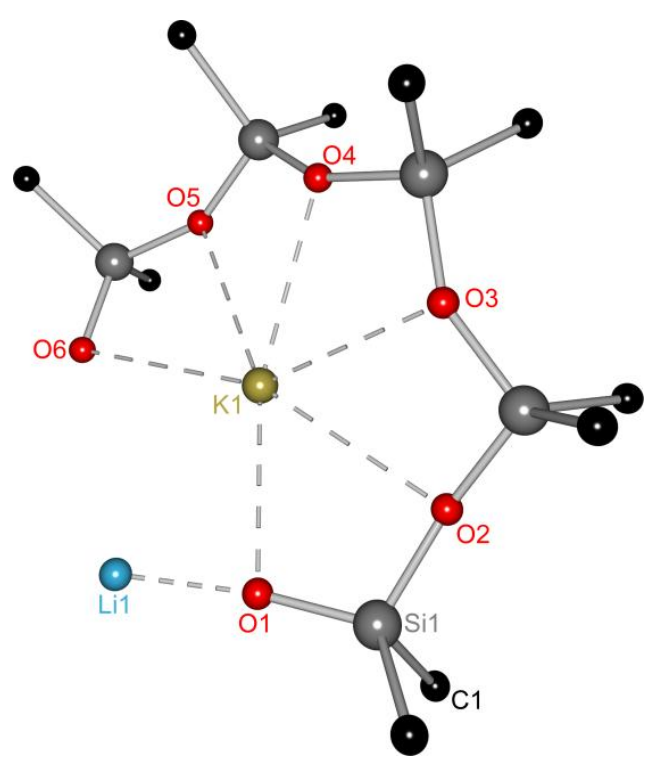

Figure 3-16. Solid state structure of $\left[\left(\mathrm{Me}_{2} \mathrm{SiO}\right)_{5} \mathrm{OKLi}\right]_{4}$ (9). Hydrogen atoms and solvent molecules are omitted for clarity.

Considering the whole molecule an unusual motive of a hetero alkali metal complex is observed. In Figure 3-17, a only the conformation of the two metal ions is displayed. The inner core is formed by a slightly distorted lithium tetrahedron. Every face of the tetrahedron is capped by a potassium atom with the position being slightly shifted to the edges. The distances between Li and K vary from 314.9(3) up to 339.7(3) pm. This mixed alkali metal core is bridged by the two oxygen atoms 01 and 06 (Figure 3-17, b). Two different structural motives can be distinguished: 01 bridges two potassium atoms and is bonded to one lithium atom on the corner of the tetrahedron (Table $3-3, c)$, while 06 bridges two lithium atoms above the edge as well as two potassium atoms (Table 3-3, d).

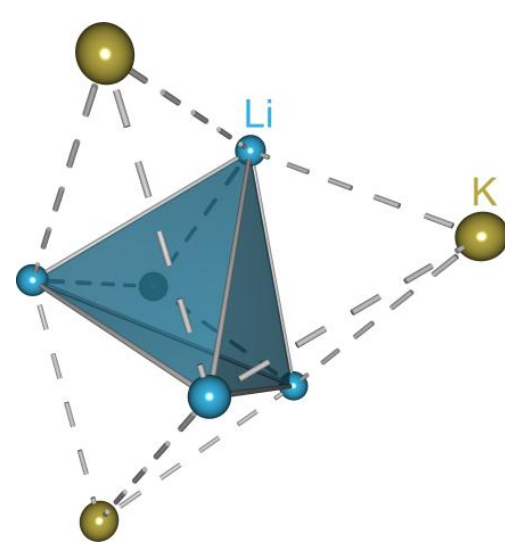

a

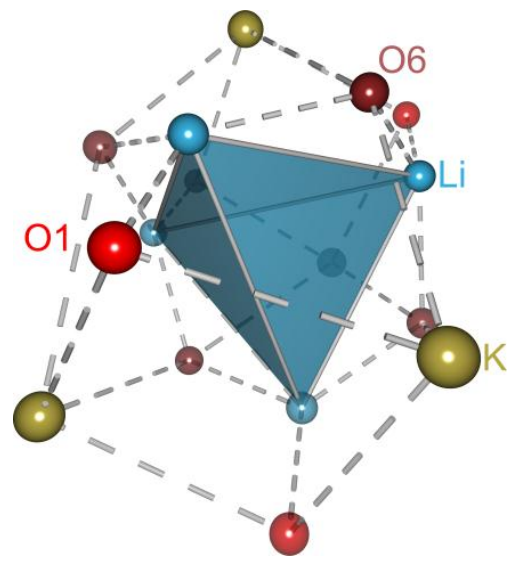

b

Figure 3-17. Mixed alkali metal core of 9. 
However, a comparison of all published $\mathrm{Li}-\mathrm{O}$ and $\mathrm{K}-\mathrm{O}$ bond lengths in the CSD shows mean values of $199.3 \mathrm{pm}$ and $282.2 \mathrm{pm}$, respectively. ${ }^{[46]}$ The $\mathrm{Li}-\mathrm{O}$ and $\mathrm{K}-\mathrm{O}$ bond lengths listed in Table 3-3 are somewhat shorter than their mean values, except 06-K1 which is $32 \mathrm{pm}$ longer but still in the given range (min. $170 \mathrm{pm} / \max .466 \mathrm{pm}$ ). ${ }^{[46]}$ The remaining oxygen atoms that are only bonded to the potassium ion have an averaged $\mathrm{K}-\mathrm{O}$ bond length of $298.8 \mathrm{pm}$.

Table 3-3. Bond lengths (pm) for the two structure motives $\mathbf{c}$ and $\mathbf{d}$ in $\mathbf{9}$.

\begin{tabular}{|c|c|c|c|c|}
\hline & \multicolumn{2}{|c|}{ c } & \multicolumn{2}{|c|}{ d } \\
\hline Li1 & O1-Li1 & 181.1(3) & O6-Li1A & 189.1(3) \\
\hline C & O1-K1 & $277.9(2)$ & O6-Li1C & $189.2(4)$ \\
\hline Li1A & O1-K1C & $266.5(2)$ & O6-K1 & $314.2(2)$ \\
\hline d & & & O6-K1A & $282.9(2)$ \\
\hline
\end{tabular}

In all probability, the formation of $\left[\left(\mathrm{Me}_{2} \mathrm{SiO}\right)_{5} \mathrm{OKLi}\right]_{4}$ (9) was encouraged by the sequence of adding the starting materials to the reaction mixture. Since in the first step $n$ BuLi and potassium alkoxide were mixed before the substrate was added, a stable $\mathrm{Li}_{4} \mathrm{~K}_{4}$ complex could be formed. Up until today only two structural motives of sodium or potassium with a cyclic siloxane are reported in literature (Scheme 3-13). ${ }^{\text {[50] }}$
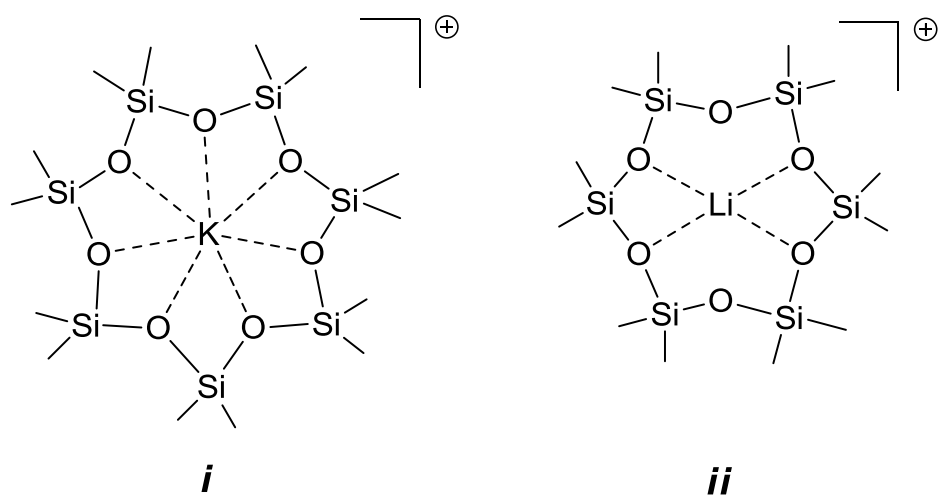

Scheme 3-13. Potassium (i) and lithium (ii) cation chelated by cyclic siloxanes.

The coordination pattern of $\boldsymbol{i}$ is very similar to the one observed in complex $\mathbf{9}$ and was obtained from reaction of a potassium indium salt with silicon grease. In structure ii the lithium atom is chelated by four oxygen atoms. To the best of my knowledge 9 is the first mixed alkali metal complex in which a siloxane and lithium tetrahedron is involved which is normally observed in organolithium compounds like 
methyllithium. ${ }^{[51]}$ Equally unexpected for this class of compounds is the absence of the organic moieties of the used alkali metals. Nearly all measured structures of mixed lithium organyle heavier alkali metal alkoxides have heteroatoms of their anions as bridging ligand. In this case they are replaced by a siloxane, possibly caused by the energetically favorable fivefold chelating ligand.

\subsection{Transition Metals}

Transition metals of the fourth period are widely used for the development of new catalysts. ${ }^{[52]}$ They support various different reactions in chemistry. A Co(acac) ${ }_{3}$ complex enables the direct cross-coupling of $\mathrm{C}-\mathrm{H}$ bonds with Grignard reagents, for example. ${ }^{[53]}$ A Cu' complex with spirobisoxazoline ligands is used for the enantioselective insertion of metal carbenes into $\mathrm{N}-\mathrm{H}$ bonds. ${ }^{[54]}$ Additionally, a complex containing Fe" carbonyl and a $P, N, N, P$ ligand catalyzes the asymmetric transfer hydrogenation of ketones. ${ }^{[55]}$ With regard to diverse applications of these metals in catalysis they were used to synthesize metal complexes with the deprotonated ligand $\left[\mathrm{PhP}\{\mathrm{C}(\mathrm{H}) \mathrm{Py}\}_{2}\right]^{2-}$.

As already mentioned in this chapter the synthesis of metal complexes via transmetallation of the dilithiated species with metal salts yielded in no results. For this reason the introduction of transition metals was performed using silylamides which have already proved to work in the synthesis towards the tin complex $\mathbf{5}$. The availability of various metal amides is also an advantage. Three different transition metal silylamides were used: $\mathrm{Co}\left[\mathrm{N}\left(\mathrm{SiMe}_{3}\right)_{2}\right]_{2}, \mathrm{Fe}\left[\mathrm{N}\left(\mathrm{SiMe}_{3}\right)_{2}\right]_{2}$ and $\mathrm{Cu}\left[\mathrm{N}\left(\mathrm{SiMe}_{3}\right)_{2}\right]$. In Scheme 3-14 the reaction pathway for all three metals is summarized, the adding sequence being identical for all three compounds. Both starting materials were dissolved in toluene and the metal silylamides were added dropwise to phosphane 1 at room temperature.

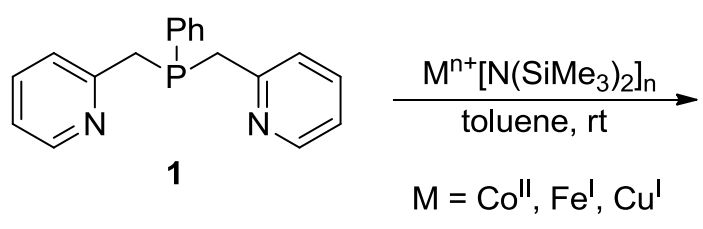

Scheme 3-14. Reaction of 1 with transition metal silylamides. 

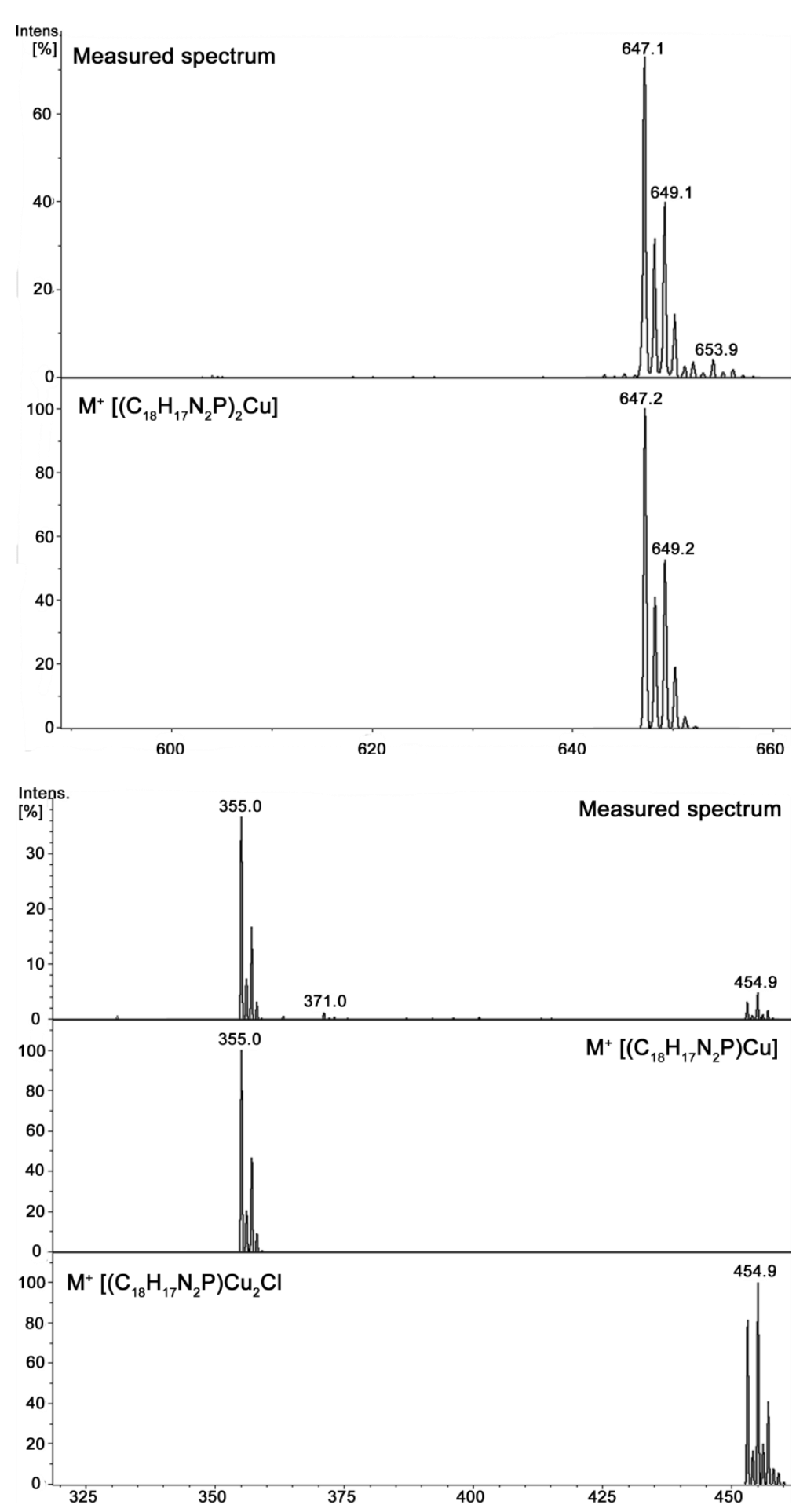

Figure 3-18. ESI-MS spectra ( $\mathrm{MeCN})$ of the reaction of 1 with $\mathrm{Cu}\left[\mathrm{N}\left(\mathrm{SiMe}_{3}\right)_{2}\right]$.

The reaction of the copper silylamide with phosphane 1 results in the formation of a yellow solution with an also yellow precipitate which was filtered out. Afterwards the solvent of the filtrate was removed in vacuum. By adding cobalt silylamide to 1 a bluegreen solid was formed while the solution completely discolored. The precipitate was 
filtered out and the filtrate was discarded. The resulting solids of both reactions have been investigated by NMR studies. However, due to the poor solubility in common deuterated solvents it was impossible to comment on the outcome of the experiment. It was further not possible to learn something about the composition of the formed precipitate.

In order to analyze whether transition metal complexes were formed ESI-MS spectra were measured on a Bruker HTC Ultra Spectrometer connected with a glove box for sample injection. Both solids resulting from the reaction with copper silylamide show almost identical peaks in the mass spectra, therefore only sections of one spectrum are shown in Figure 3-18 exemplarily. Besides the measured peaks also simulated peaks are displayed to compare their isotope patterns with the ones observed. The mass spectrometric analysis of the copper compound reveals three signals which can be assigned to copper complexes including phosphane 1 (Figure 3-18). The peak with a mass-to-charge ratio $(\mathrm{m} / \mathrm{z}) 647.1$ is comparable with a dimeric copper complex. Two other fragments in the spectrum at $355.0 \mathrm{~m} / \mathrm{z}$ and $454.9 \mathrm{~m} / \mathrm{z}$, respectively, can be assigned to a monomeric copper complex of 1 and the monomeric complex with additional $\mathrm{CuCl}$ which probably originates from polluted silylamide as copper chloride is used within the synthesis of the metal amine.

The mass spectrum obtained from the reaction of cobalt silylamide with $\mathbf{1}$ is displayed in Figure 3-19. Equally, this spectrum shows fragments that give a hint for the formation of a cobalt complex with phosphane 1 . The fragment at $641.1 \mathrm{~m} / \mathrm{z}$ can be assigned to a dimeric cobalt complex of 1 and the one at 321.6 is the same complex but with a charge of $2+$. However, there is one fragment present which has also been observed in the spectrum of the copper compound. This fragment shows an isotope pattern typical for copper which can only be explained by some impurities on the spectrometer. As the copper compound was measured before the cobalt compound some copper might have been stuck.

Although no clear statement of the composition of the measured solids can be made using the mass spectral analysis it is unambiguous that copper and cobalt compounds containing 1 have been formed. Crystallization of these compounds was not possible due to their poor solubility even in very polar solvents. The reaction of di-2-picolylphenylphosphane (1) with $\mathrm{Fe}\left[\mathrm{N}\left(\mathrm{SiMe}_{3}\right)_{2}\right]_{2}$ gave no measurable result. Although a dark green solution was formed during the reaction, the mixture 
decomposed very soon due to the enormous air sensitivity, even when handled with great care under inert gas atmosphere.
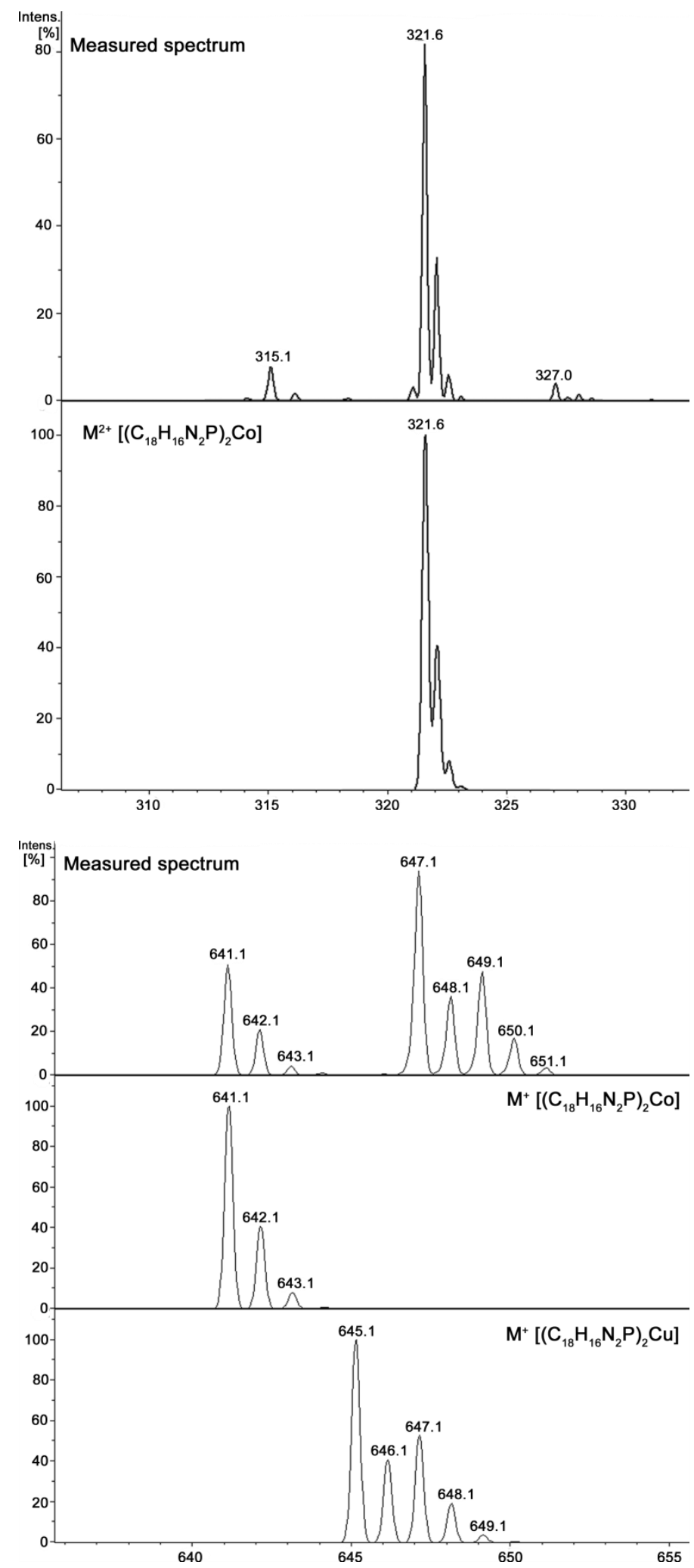

Figure 3-19. ESI-MS spectra (MeCN) of the reaction of 1 with $\mathrm{Co}\left[\mathrm{N}\left(\mathrm{SiMe}_{3}\right)_{2}\right]_{2}$. 


\subsubsection{Palladium Complexes}

Palladium catalysts are an indispensable tool for the syntheses of various compounds particularly in organic chemistry. An outstanding development in palladium catalysis was the so called Heck reaction in which palladium in oxidation state zero and plus two, respectively, catalyzes the arylation and alkenylation of olefins in the broadest sense. ${ }^{[56]}$ Often phosphane ligands are used to stabilize the metal ion in the oxidation state zero. An equally huge achievement in organic chemistry was the development of carbon-carbon bond forming reactions named cross coupling reactions, in general. ${ }^{[57]}$ An example is the Suzuki coupling in which aryl or alkenyl halides are reacted with organoboron compounds. ${ }^{[58]}$

Before preparation of a palladium complex containing di-2-picolylphenylphosphane (1), the $\mathrm{Pd}^{\prime \prime}$ species $\mathrm{PdCl}_{2}(\mathrm{COD})$ was synthesized as reported previously in literature. ${ }^{[59]}$ Because of the fourfold pre-coordination of the palladium ion a complexation of the metal atom by phosphane 1 should be more feasible. The reaction of 1 with $\mathrm{PdCl}_{2}(\mathrm{COD})$ in $\mathrm{DCM}$ at room temperature resulted in the formation of a yellow solution (Scheme 3-15). After removal of the solvent the residue was dissolved in $\mathrm{Et}_{2} \mathrm{O}$. A yellow precipitate was obtained which, after filtration, was resolved in a mixture of DCM and $\mathrm{MeOH}$. After storage in the freezer yellow crystals could be obtained which were suitable for X-ray structural analysis.

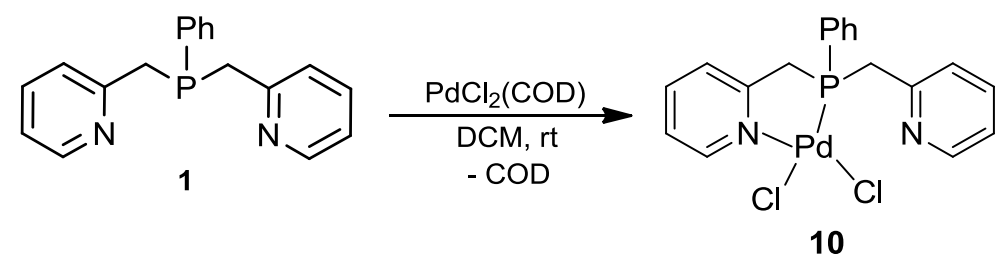

Scheme 3-15. Synthesis of $\left[\left\{\mathrm{PhP}\left(\mathrm{CH}_{2} \mathrm{Py}\right)_{2}\right\} \mathrm{PdCl}_{2}\right](\mathbf{1 0})$.

10 crystallizes in the monoclinic space group $C 2 / c$ with one molecule in the asymmetric unit (Figure 3-20). The palladium ion is chelated by one nitrogen atom and the phosphorus atom. In combination with the two chloride atoms the coordination geometry of palladium is square planar. The mean values of all published $\mathrm{Pd}-\mathrm{P}$ $(228.7 \mathrm{pm})$ and $\mathrm{Pd}-\mathrm{N}(205.6 \mathrm{pm})$ bond lengths in the $\mathrm{CSD}^{[46]}$ are in accordance with those of the palladium complex 10 (Pd-P 219.52(14) pm, Pd-N 206.5(4) pm, respectively). Regrettably, the work group of $P$. Braunstein who are also working with 
di-2-picolylphenylphsophane (1) have published a preparation of the palladium complex 10 shortly after I synthesized the compound. ${ }^{[23 c]}$ Within this publication the crystal structure of $\mathbf{1 0}$ is also introduced. The space group and cell parameters are identical with the one I measured. However, the preparation I used to synthesize the palladium complex resulted in a higher yield.

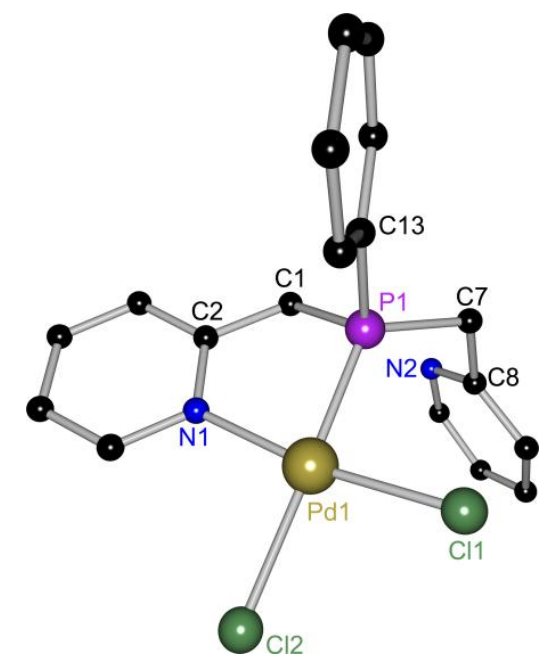

Figure 3-20. Solid state structure of $\left[\left\{\mathrm{PhP}\left(\mathrm{CH}_{2} \mathrm{Py}\right)_{2}\right\} \mathrm{PdCl}_{2}\right](10)$. Hydrogen atoms are omitted for clarity.

Due to the successful preparation and crystallization of $\left[\left\{\mathrm{PhP}\left(\mathrm{CH}_{2} \mathrm{Py}\right)_{2}\right\} \mathrm{PdCl}_{2}\right](10)$ the same reaction pathway was used to obtain a palladium complex containing the $P, N$ ligand diphenyl-2-picolylphosphane. Even though there already exists a preparation method in literature, I decided to use the one already proven to work which is mentioned above. ${ }^{[60]}$ The pale green solid which results from the reaction of $\mathrm{PdCl}_{2}(\mathrm{COD})$ and diphenyl-2-picolylphosphane was dissolved in a mixture of $\mathrm{THF}, \mathrm{Et}_{2} \mathrm{O}$ and DCM to grow crystals of the palladium complex $\left[\left(\mathrm{Ph}_{2} \mathrm{PCH}_{2} \mathrm{Py}\right) \mathrm{PdCl}_{2}\right]$ (11). After storage of the solution for one day in the freezer crystals of $\mathbf{1 1}$ were obtained (Figure 3-21).

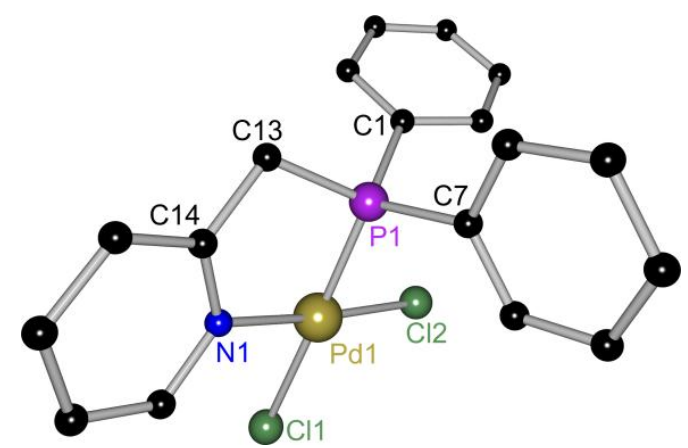

Figure 3-21. Solid state structure of $\left[\left(\mathrm{Ph}_{2} \mathrm{PCH}_{2} \mathrm{Py}\right) \mathrm{PdCl}_{2}\right](\mathbf{1 1})$. Hydrogen atoms are omitted for clarity. 
11 crystallizes in the monoclinic space group $P 2_{1} / c$ with one molecule in the asymmetric unit. The coordination sphere of the palladium atom is square planar. The $\mathrm{Pd}-\mathrm{P}$ (220.0(1) pm) and $\mathrm{Pd}-\mathrm{N}$ (207.3(3) pm) bond lengths, respectively, are comparable to those found for the previously reported complex and are thus within the expected range for a palladium complex.

\subsection{Samarium Complex}

Although transition metals are well established in the field of various catalytic processes there are some reactions in which the use of lanthanide complexes gives better results or enables the formation of desired products in the first place. ${ }^{[61]}$ An organolanthanide complex containing samarium as active site is $\mathrm{Cp}_{2}{ }^{*} \mathrm{SmCH}(\mathrm{TMS})_{2}$. This complex is used for the catalytic cyclization of phosphinoalkenes and phosphinoalkynes yielding stable tertiary phospholanes. ${ }^{[62]}$ The lanthanide complex $\left[\left\{\mathrm{CH}\left(\mathrm{PPh}_{2} \mathrm{NSiMe}_{3}\right)_{2}\right\} \mathrm{Sm}\left(\eta^{8}-\mathrm{C}_{8} \mathrm{H}_{8}\right)\right]$ containing a phosphinimino ligand catalyzes, similar to the previously mentioned process, a cyclization of terminal aminoolefins. ${ }^{[63]}$

To the best of my knowledge, up until today only two samarium complexes are reported in which the metal atom is chelated by a $N, P, N$ claw. This is a) the anionic ligand $\left[\mathrm{PhP}\left\{\mathrm{CH}_{2} \mathrm{SiMe}_{2} \mathrm{NPh}\right\}_{2}\right]^{-[64]}$ and b) the fourfold coordinating ligand $\mathrm{PhP}\left(\mathrm{CH}_{2} \mathrm{SiMe}_{2} \mathrm{NSiMe}_{2} \mathrm{CH}_{2}\right)_{2} \mathrm{PPh}^{[65]}$ synthesized by the work group of $M$. D. Fryzuk. With regard to the coordination pattern of the tin complex 5 in which the tin ion is coordinated by both nitrogen and the phosphorus atom a similar coordination pattern for samarium should be feasible.

To synthesize a samarium complex with phosphane 1 different reaction strategies were tested. During this investigation it turned out that the adding sequence and the solvents used play an important role for the formation of a samarium complex, similar to the results obtained for reactions with potassium alkoxide. Firstly, phosphane 1 was dissolved in THF and a solution of the samarium amide in $\mathrm{Et}_{2} \mathrm{O}$ was added at room temperature (sequence $\mathbf{A}$ ). 


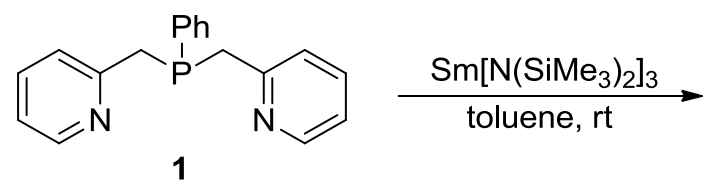

Scheme 3-16. Reaction pathway $\mathbf{C}$ with samarium silylamide.

Although the reactants were well soluble in the solvents used it seemed that the product is insoluble because the ${ }^{31} \mathrm{P}\left\{{ }^{1} \mathrm{H}\right\}$ NMR spectrum of the crude product reveals only one signal at $-13.9 \mathrm{ppm}$ which can be assigned to staring material (Figure 3-22, reaction A). Due to this the more nonpolar solvent toluene was used for further reactions. Because of the insolubility of the samarium silylamide in toluene both reagents were neatly mixed in the glove box and afterwards toluene was added at room temperature (reaction B). As displayed in the ${ }^{31} \mathrm{P}\left\{{ }^{1} \mathrm{H}\right\}$ NMR spectrum of the reaction mixture again most of the starting material is still present (Figure 3-22, reaction B). For this reason the reaction was repeated dissolving both reagents separately with toluene. Subsequently, the suspension of the samarium amide was transferred to phosphane 1 (Scheme 3-16). The resulting dark red solution was dried in vacuum and the yielded solid was investigated by NMR studies.

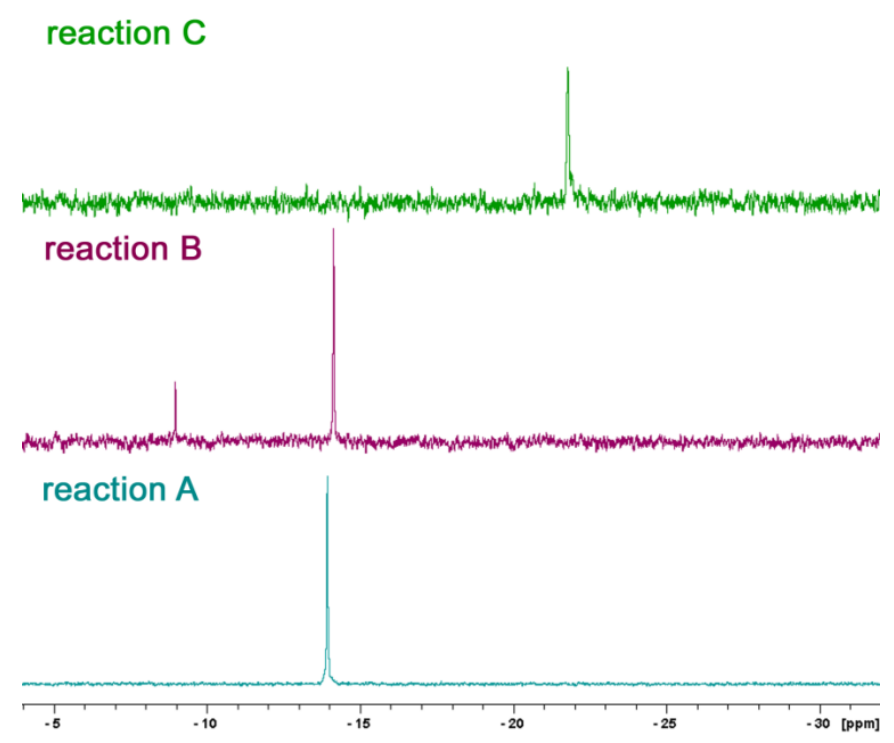

Figure 3-22. ${ }^{31} \mathrm{P}\left\{{ }^{1} \mathrm{H}\right\} \mathrm{NMR}$ spectra of the different reactions of 1 with $\mathrm{Sm}\left[\mathrm{N}\left(\mathrm{SiMe}_{3}\right)_{2}\right]_{3}$ measured in THF- $d_{8}(A)$ and $C_{6} D_{6}(B, C)$.

The ${ }^{31} \mathrm{P}\left\{{ }^{1} \mathrm{H}\right\}$ NMR spectrum reveals only one singlet at $-21.79 \mathrm{ppm}$ indicating a full conversion of 1 to a samarium complex. Additionally, the ${ }^{1} \mathrm{H}$ NMR spectrum displays an up-field shift of the pyridine proton signals indicating a bonding of the nitrogen atom 
to the samarium atom. Due to the presence of two sets of signals in the proton spectrum a dissimilar coordination of the pyridine rings can be assumed. Several solutions containing this compound were prepared for crystallization in order to gain structural proof for the samarium complex. Unfortunately, no crystals suitable for X-ray diffraction experiments have been obtained yet. 


\section{PHOSPHOR(V)}

Oxidation of the phosphorus atom in di-2-picolylphenylphosphane (1) generates a new coordination site and changes the coordination behavior due to the loss of the phosphorus lone pair. The introduction of different group 16 elements enables possible coordination of metal ions with differing Pearson hardness. An additional benefit of these $P^{V}$ ligands is their increased stability. The work group of $R$. Ziessel has synthesized a ligand similar to 1 in which the oxidized phosphane has two substituted bipyridine moieties (Scheme 4-1). ${ }^{[66]}$ The ligand can coordinate transition metals as well as lanthanides. While a $\mathrm{Cu}^{\prime}$ ion is only coordinated by the four nitrogen atoms of the bipyridine moieties, ${ }^{[66]}$ the lanthanide ion $\mathrm{Eu}^{\text {III }}$ is additionally coordinated by the oxygen atom. ${ }^{[67]}$ Due to the incompletely saturated fivefold coordination sphere of the europium atom, this lanthanide complex can serve as a luminescence sensor for anions. $^{[68]}$<smiles>Cc1cccc(CP(=O)(Cc2cccc(-c3cccc(C)n3)n2)c2ccccc2)n1</smiles>

Scheme 4-1. Structure of (6-methylene-6'-methyl-2,2'-bipyridyl)phenylphosphane oxide.

The following Scheme 4-2 displays the reactions of phosphane 1 with group 16 oxidants oxygen, sulfur and selenium ${ }^{[24]}$, respectively, resulting in the formation of the phosphorus species $\left[\mathrm{PhP}(\mathrm{O})\left(\mathrm{CH}_{2} \mathrm{Py}\right)_{2}\right] \cdot 2 \mathrm{HCl}(12), \quad\left[\mathrm{PhP}(\mathrm{S})\left(\mathrm{CH}_{2} \mathrm{Py}\right)_{2}\right] \cdot \mathrm{HCl}(13) \quad$ and $\left[\mathrm{PhP}(\mathrm{Se})\left(\mathrm{CH}_{2} \mathrm{Py}\right)_{2}\right] \cdot \mathrm{HCl}(\mathbf{1 4})$. To synthesize the phosphane oxide 12 an aqueous hydrogen peroxide solution was added carefully to a cooled solution of $\mathbf{1}$ in DCM and $\mathrm{MeOH}$. Following the completion of the reaction all volatile components of the discolored solution were removed in vacuum and the precipitate was dissolved in a mixture of THF, nhexane and DCM for crystallization.

The addition of a toluene solution of elemental sulfur to a pre-cooled solution of ligand 1 results in the formation of a yellow suspension containing phosphane sulfide 13. After filtration the volume of the filtrate was reduced and a few drops of THF were added for crystallization. 
For the synthesis of the phosphane selenide 14 a suspension of grey selenium in toluene was added to a cooled solution of $\mathbf{1}$. The resulting pale green suspension was filtered and the volume of the filtrate was reduced for crystallization. Storage of the compounds at $-20^{\circ} \mathrm{C}(12,13)$ or at room temperature $(14)$ results in the formation of colorless crystals suitable for X-ray structural analysis.

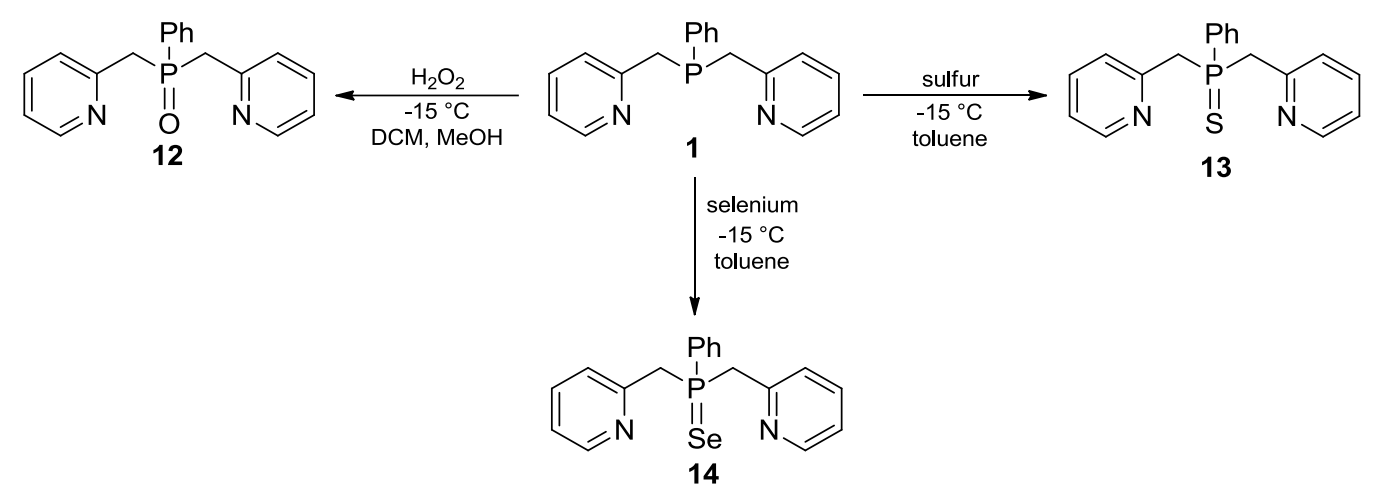

Scheme 4-2. Syntheses of the oxidized phosphanes 12, 13 and 14.

All measured solid state structures are hydrogen chloride adducts which can be explained in case of compound 12 (Figure 4-1, b) by the presence of DCM because it tends to form hydrochloric acid if the solvent is not absolutely water-free. In case of compounds 13 (Figure 4-1, c) and 14 (Figure 4-1, d) the hydrogen chloride cannot originate from the solvent due to the fact that only toluene and THF were used. For this reason the $\mathrm{HCl}$-adduct had to be formed before the oxidation and thus during the preparation of ligand $\mathbf{1}$. In the second step of the synthesis dichlorophenylphosphane is used, thus being a possible source for hydrogen chloride. As mentioned in the beginning of this chapter some batches of 1 had a lower solubility which can now be explained the formation of the hydrogen chloride adduct of 1 . The solid state structure of $\left[\mathrm{PhP}\left(\mathrm{CH}_{2} \mathrm{Py}\right)_{2}\right] \cdot \mathrm{HCl}$ (15) gave final proof for the proposal adduct (Figure 4-1, a). However, all these compounds form hydrogen...acceptor bonds which stabilize the ligands and thus support the crystallization process.

The phosphane oxide 12 crystallizes in the monoclinic space group $P 2_{1}$ with two molecules and four chloride counterions in the asymmetric unit (Figure 4-1, b). 12 is protonated at each nitrogen atom. The $\mathrm{P}-\mathrm{O}$ bond length with a value of 148.69 (19) pm is slightly longer than a $\mathrm{P}-\mathrm{O}$ double bond $(147 \mathrm{pm}) \cdot{ }^{[35]}$ Two types of hydrogen ...acceptor bonds are formed: one $\mathrm{H} \cdots \mathrm{Cl}$ and one $\mathrm{H} \cdots \mathrm{O}$ bond for each ligand. The two ligand molecules are linked via the hydrogen...oxygen bond. 


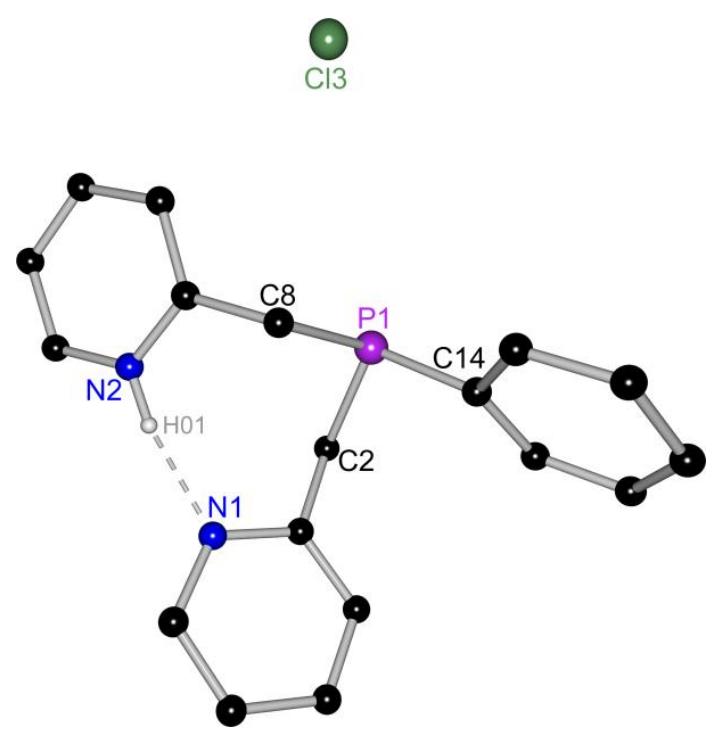

a

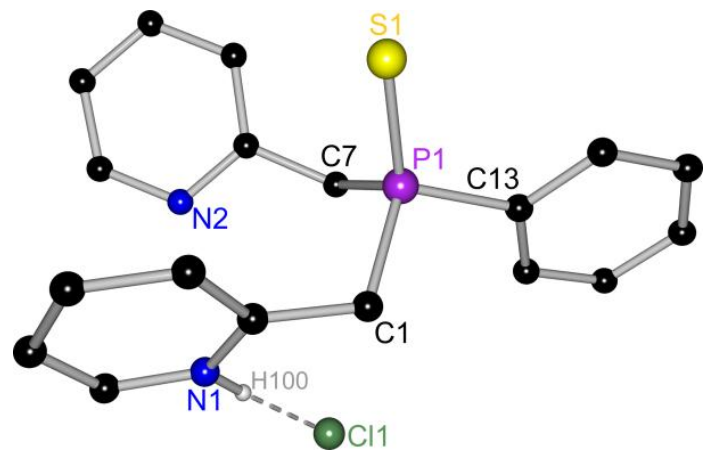

C

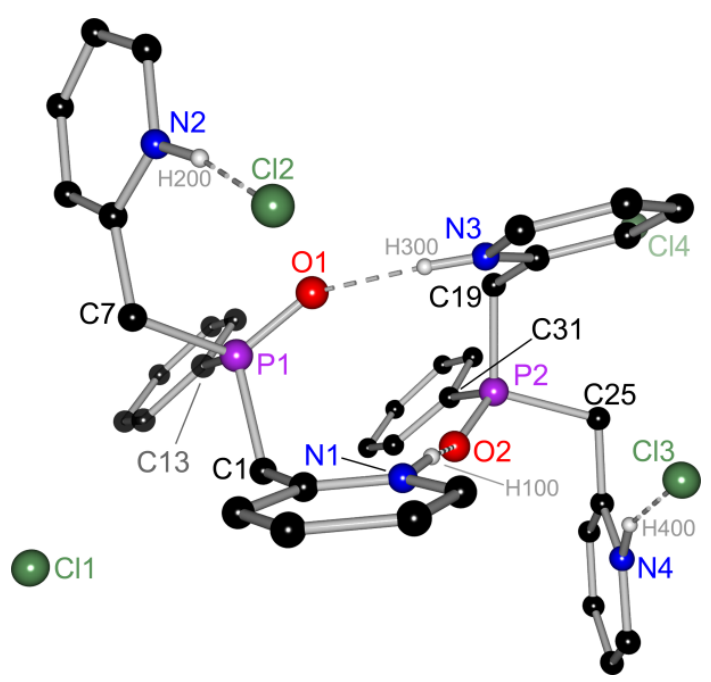

b

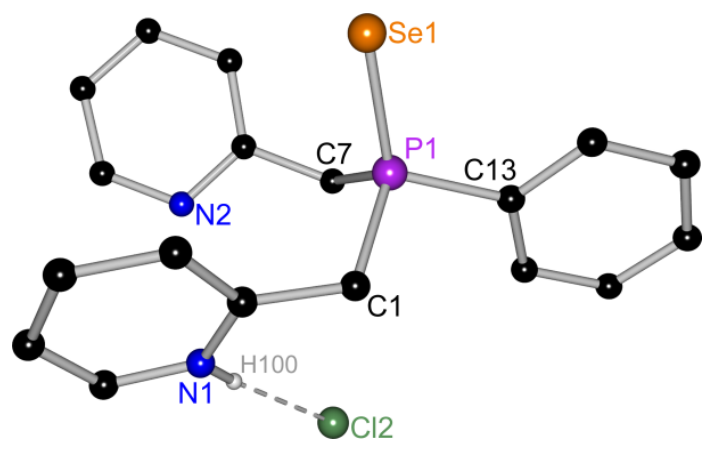

d

Figure 4-1. Solid state structure of $\left[\mathrm{PhP}\left(\mathrm{CH}_{2} \mathrm{Py}\right)_{2}\right] \cdot \mathrm{HCl}(\mathbf{1 5}) \mathbf{a},\left[\mathrm{PhP}(\mathrm{O})\left(\mathrm{CH}_{2} \mathrm{Py}\right)_{2}\right] \cdot 2 \mathrm{HCl}(\mathbf{1 2}) \mathbf{b}$, $\left[\mathrm{PhP}(\mathrm{S})\left(\mathrm{CH}_{2} \mathrm{Py}\right)_{2}\right] \cdot \mathrm{HCl}(\mathbf{1 3}) \mathrm{c}$ and $\left[\mathrm{PhP}(\mathrm{Se})\left(\mathrm{CH}_{2} \mathrm{Py}\right)_{2}\right] \cdot \mathrm{HCl}(\mathbf{1 4})$ d. Hydrogen atoms and non-coordinating solvent molecules are omitted for clarity.

In contrast, the phosphane sulfide 13 and selenide 14 (Figure 4-1, c, d) have solid state structures in which only one nitrogen atom of the ligand is protonated. Both compounds crystallize in the monoclinic space group $P 2_{1} / c$ and the asymmetric units contain two protonated phosphane ligands, two toluene molecules and two chloride counterions each. The P-S bond length $(194.32(12) \mathrm{pm})$ is about $2 \mathrm{pm}$ longer than a P-S double bond $(192 \mathrm{pm}) .^{[35]}$ Similarly, the P-Se bond length $(209.46(10) \mathrm{pm})$ is, in comparison to all measured structures reported in the CSD $(211.7 \mathrm{pm}),{ }^{[46]}$ comparable to a P-Se double bond. A hydrogen...chloride bond is formed for each structure. All hydrogen...acceptor bond lengths of the structures in Figure 4-1 are listed in Table 4-1. They are in the range of moderate bonds with mostly electrostatic interactions as reported in literature. ${ }^{[69]}$ 
Table 4-1. Hydrogen $\cdots$ acceptor bond lengths $[\AA ̊]$ for $12,13,14$ and 15 , respectively.

\begin{tabular}{|c|c|c|c|}
\hline \multicolumn{2}{|l|}{12} & \multicolumn{2}{|l|}{13} \\
\hline N1-H100…02 & $2.02(3)$ & N1-H100 …Cl1 & $2.16(3)$ \\
\hline $\mathrm{N} 2-\mathrm{H} 200 \cdots \mathrm{Cl} 2$ & $1.98(2)$ & $\mathrm{N} 4-\mathrm{H} 400 \cdots \mathrm{Cl} 2 \_\$ 1^{\mathrm{a}}$ & $2.12(3)$ \\
\hline N3-H300 ...O1 & $1.93(3)$ & & \\
\hline $\mathrm{N} 4-\mathrm{H} 400 \cdots \mathrm{Cl} 3$ & $1.98(2)$ & & \\
\hline 14 & & 15 & \\
\hline $\mathrm{N} 1-\mathrm{H} 100 \cdots \mathrm{Cl} 2 \_\$ 1^{a}$ & $2.22(4)$ & $\mathrm{N} 2-\mathrm{H} 01 \cdots \mathrm{N} 1$ & $1.81(3)$ \\
\hline N4-H101‥Cl1_\$2 & $2.18(4)$ & N4-H02 $\cdots \mathrm{N} 3$ & $1.80(2)$ \\
\hline
\end{tabular}

The K.K.Klausmeyer group is also working on the neutral di-2-picolylphenylphosphane (1). At about the same time than me, they have performed the oxidation of 1 in a similar way. The reaction of the prepared phosphane oxide with a $\mathrm{Cu}^{\prime \prime}$ salt results in the formation of a dimeric copper complex in which each ligand chelates the copper ion via the $O, N$ claw. ${ }^{[70]}$ However, they have not published a crystal structure of the phosphane oxide, yet. Their investigations also covered the diphenyl-2-picolylphosphane oxide ${ }^{[70-71]}$ which I have crystallized as a side product (Figure 4-2).

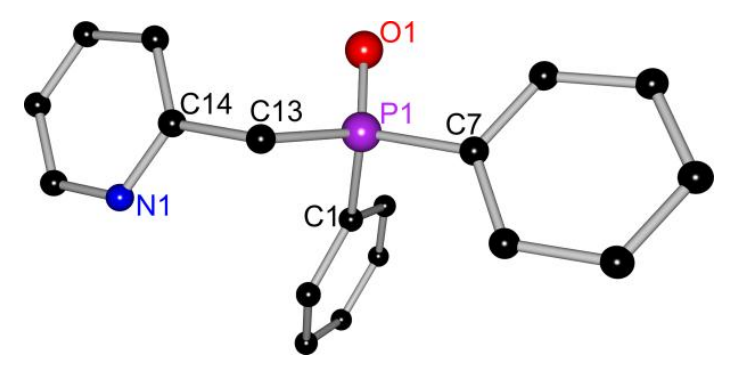

Figure 4-2. Solid state structure of $\left[\mathrm{Ph}_{2} \mathrm{P}(\mathrm{O})\left(\mathrm{CH}_{2} \mathrm{Py}\right)\right]$ (16). Hydrogen atoms are omitted for clarity.

Exposure of a THF solution of dilithium complex $\left[\left(\mathrm{Et}_{2} \mathrm{O}\right)_{3} \mathrm{Li}_{2}\{\mathrm{C}(\mathrm{H}) \mathrm{Py}\}_{2} \mathrm{PPh}\right]_{2}$ (4) to atmospheric oxygen results in the formation of the lithium phosphorane $\left[(\mathrm{THF})_{4} \mathrm{Li}_{2}\{\mathrm{C}(\mathrm{H}) \mathrm{Py}\}_{2} \mathrm{P}(\mathrm{O}) \mathrm{Ph}\right]($ (17) (Scheme 4-3). Reducing the volume of the solution and layering with nhexane gives orange cyrstals which were suitable for X-ray structural analysis. 17 crystallizes in the monoclinic space group $P 2_{1} / n$ and the asymmetric unit contains one phosphorane and additionally a non-coordinating THF molecule (Figure 4-3). In comparison with the dilithium complex 4, the lithium ions in complex 17 are only coordinated via one of the two possible coordination sites of the dianionic $\left[\mathrm{PhP}(\mathrm{CHPy})_{2}\right]^{2-}$ ligand. The two lithium cations Li1 and Li2 are coordinated by the $\mathrm{O}, \mathrm{N}$ 
claw of the ligand and two THF solvent molecules each and resulting in a distorted tetrahedral coordination geometry. It is feasible to say that coordination of a lithium atom by the oxygen atom of a phosphorane like $R_{3} P=O$ is unusual due to the fact that the search of this motive in the CSD results only in 28 hits. ${ }^{[46]}$ The exocyclic $\mathrm{C} 1 / \mathrm{C} 7-\mathrm{C} 2 / \mathrm{C} 8$ bonds are shortened to an averaged value of $139.8(4) \mathrm{pm}$ which is very similar to the value of the exocyclic bonds in $\mathbf{4}$ and thus range between a $\mathrm{C}_{\mathrm{sp}^{2}}-\mathrm{C}_{\mathrm{sp}^{2}}$ single and double bond (146.6 and 133.5 pm, respectively) ${ }^{[35]}$.

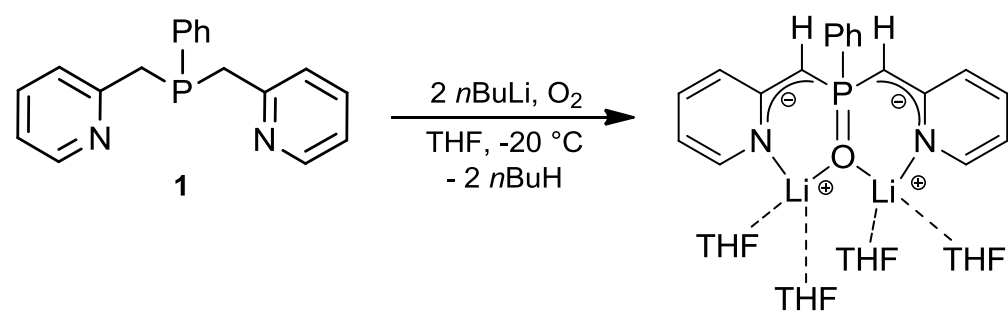

17

Scheme 4-3. Preparation of $\left[(\mathrm{THF})_{4} \mathrm{Li}_{2}\{\mathrm{C}(\mathrm{H}) \mathrm{Py}\}_{2} \mathrm{P}(\mathrm{O}) \mathrm{Ph}\right](\mathbf{1 7})$.

The deprotonation of 1 causes an appreciable alteration of the bonding in the aromatic rings which is even more considerable as in the dilithium complexes 4 . While the $\mathrm{C} 2 / \mathrm{C} 8-\mathrm{C} 3 / \mathrm{C} 9$ and the $\mathrm{C} 4 / \mathrm{C} 10-\mathrm{C} 5 / \mathrm{C} 11$ bond lengths are elongated to averaged values of $144.0(6)$ and $140.5(6) \mathrm{pm}$, respectively, the C3/C9-C4/C10, C5/C11-C6/C12 and N1/2-C6/C12 bonds are shortened (136.3(5), 137.1(7) and 134.7(6) pm, respectively). This altered bonding situation is associated with more localized double bond character on the pyridyl rings

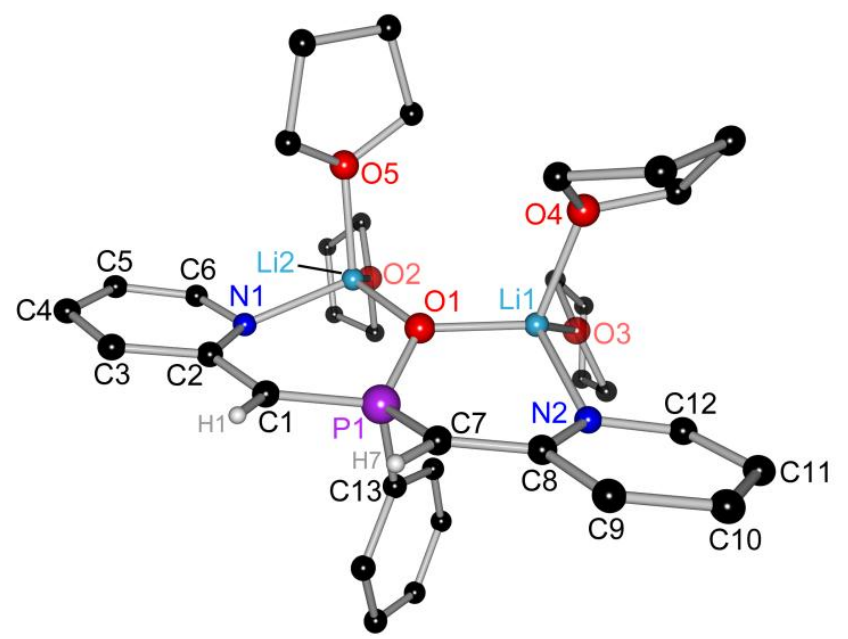

Figure 4-3. Solid state structure of $\left[(T H F)_{4} \mathrm{Li}_{2}\{\mathrm{C}(\mathrm{H}) \mathrm{Py}\}_{2} \mathrm{P}(\mathrm{O}) \mathrm{Ph}\right](\mathbf{1 7})$. Hydrogen atoms and non-coordinating THF are omitted for clarity. 
The localization of the electron density in the pyridine rings and the shortened exocyclic $\mathrm{C} 1 / 7-\mathrm{C} 2 / 8$ bonds point toward an enamidic resonance formula like displayed in Scheme 4-3. The $\mathrm{P}-\mathrm{O}$ bond length is $5 \mathrm{pm}$ longer $(153.87(13) \mathrm{pm})$ than in the corresponding neutral ligand $\mathbf{1 2}$ due to the additional bonding to the lithium atoms. The two lithium bonds to the terminal oxygen atom are $8 \mathrm{pm}$ shorter than the averaged values of all other lithium-oxygen donor bonds in this complex (196.3 pm). This could be explained by the more electron-rich oxygen atom which is bonded to the phosphorus atom.

After a feasible reaction pathway was discovered preparing lithium phosphorane 17, the heavier group 16 oxidants sulfur and selenium were dealt with. As sulfur and selenium are known to show different reaction behavior, two alternative pathways were tested. Firstly, the phosphane sulfide $\mathbf{1 3}$ and selenide $\mathbf{1 4}$ were pre-generated like reported earlier in this chapter. Afterwards 2 eq. of nbutyllithium were added dropwise to cooled solutions of the phosphoranes 13 and 14. In both cases an orange solution with a yellow-orange precipitate was formed. NMR spectroscopic analysis showed that a mixture of three products was obtained and additionally starting material remained.

In a second trial, the solvent used was changed from toluene to THF and furthermore the adding sequence was modified. As for the synthesis of 17, the dilithium complex 4 was prepared first. A toluene solution/suspension of elemental sulfur and selenium were added to pre-cooled solutions of 4 in THF. Both solutions changed their color to red. Unlike in the previous reaction, no solid could be observed. The volume of the red reaction mixtures were reduced and layered with nheptane. Storage of the solutions in the freezer did not result in the formation of crystals suitable for X-ray structural analysis, thus the formation of the lithium complex containing phosphoranes could not be clarified.

Because of the soft donor atoms the formation of palladium complexes with the phosphoranes 13 and 14 should be feasible. Thus 13 and 14 were treated with $\mathrm{PdCl}_{2}(\mathrm{COD})$ since the reaction of this palladium complex with $\mathrm{PhP}\left(\mathrm{CH}_{2} \mathrm{Py}\right)_{2}(\mathbf{1})$ and $\mathrm{Ph}_{2} \mathrm{PCH}_{2} \mathrm{Py}$ were successful. Unfortunately only crystals of $\mathrm{PdCl}_{2}(\mathrm{COD})$ could be obtained until today. 


\section{SUMMARY AND OUTLOOK}

The scope of this thesis was the preparation of a Janus Head ligand based on the $N, P, N$ ligand di-2-picolylphenylphosphane (1) and the synthesis of different metal complexes containing this Janus Head ligand. The resulting complexes were to be investigated by single crystal X-ray diffraction experiments.

The investigations based on experimental electron density studies could elucidate the hindered reactivity of $\left[\mathrm{PhP}\left(\mathrm{CH}_{2} \mathrm{Py}\right)_{2} \mathrm{LiCl}\right]_{2}(2)$ compared to the reactivity behavior of the lithium chloride-free phosphane ligand 1 . It can be concluded that the reduced reactivity of $\mathbf{2}$ is related to the predominant shielding of the nitrogen atoms by the chlorine atoms and therefore inhibiting an electrophilic attack of any metal ion at the nitrogen atoms. The only possible reactive site is the relatively diffuse phosphorus lone pair (Figure 5-1).

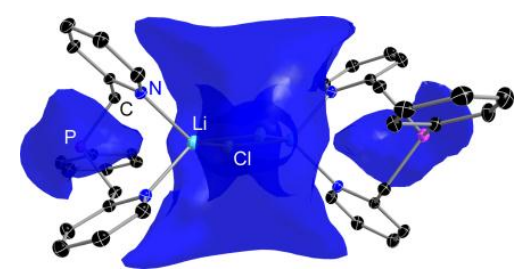

Figure 5-1. Electrostatic potential of $\left[\mathrm{PhP}\left(\mathrm{CH}_{2} \mathrm{Py}\right)_{2} \mathrm{LiCl}\right]_{2}(2)$.

By application of the organolithium compound nbutyllithium and the group 14 silylamide $\left[\mathrm{Sn}\left\{\mathrm{N}\left(\mathrm{SiMe}_{3}\right)_{2}\right\}_{2}\right]$ the dianionic Janus Head ligand $\left[\mathrm{PhP}(\mathrm{CHPy})_{2}\right]^{2-}$ could be generated in which one coordination site is allocated by the $N, P, N$ or $N, P$ claw, respectively, while in the opposite direction the metal ion is chelated by the two negative charged carbon atoms. The conformation of the resulting metal complexes $\left[\left(\mathrm{Et}_{2} \mathrm{O}\right)_{3} \mathrm{Li}_{2}\{\mathrm{C}(\mathrm{H}) \mathrm{Py}\}_{2} \mathrm{PPh}\right]_{2}(4)$ and $\left[\left\{\left(\mathrm{Me}_{3} \mathrm{Si}\right)_{2} \mathrm{NSn}\right\}_{2}\{\mathrm{C}(\mathrm{H}) \mathrm{Py}\}_{2} \mathrm{PPh}\right](5)$ could be verified by means of X-ray structural analysis (Figure 5-2). Due to the similar coordination pattern of the lithium and tin complexes the bonding situation in both molecules was investigated by comparison of bond lengths and angles of the solid state structures revealing two different bonding situations. The picolyl moieties of the lithium complex 4 are best described with an enamidic resonance formula in which the electron density in the aromatic ring is more or less localized and the negative charge is shifted to the nitrogen atoms. In contrast, the electron density of the pyridyl rings in the tin complex 5 remained almost completely delocalized and thus a resonance formula with 
carbanionic character of the picolyl moieties should be preferred. Due to the fact that 5 contains no less than 6 spins $-1 / 2$ nuclei NMR investigations were conducted which have proven with absolute certainty that the coordination mode of the tin complex 5 in the solid state structure is identical with the one in solution.
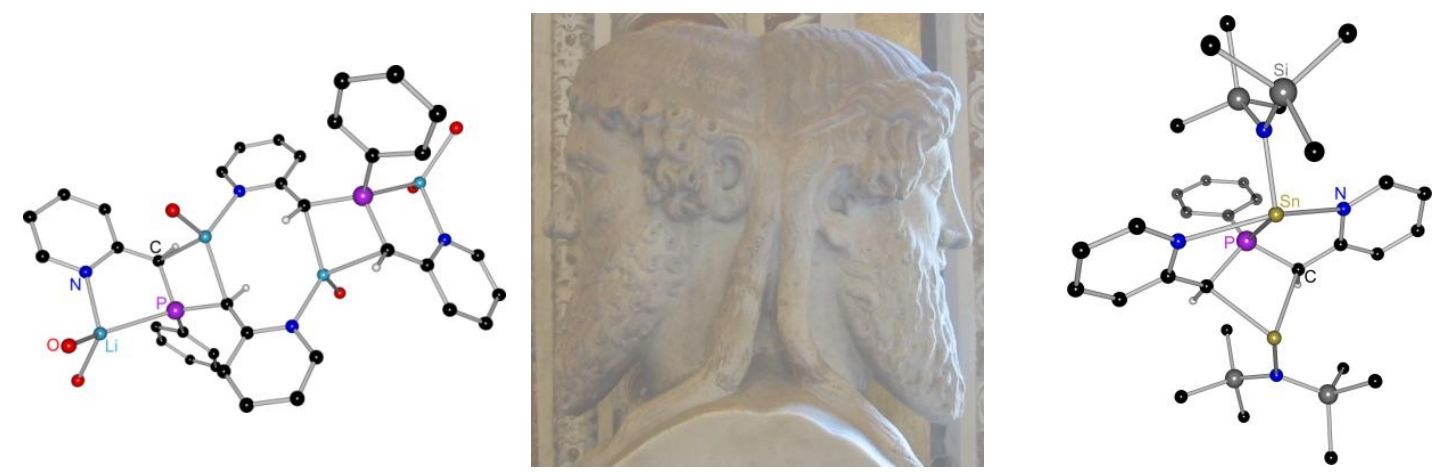

Figure 5-2. $\left[\left(\mathrm{Et}_{2} \mathrm{O}\right)_{3} \mathrm{Li}_{2}\{\mathrm{C}(\mathrm{H}) \mathrm{Py}\}_{2} \mathrm{PPh}\right]_{2}(4)$ (left) and $\left[\left\{\left(\mathrm{Me}_{3} \mathrm{Si}\right)_{2} \mathrm{NSn}\right\}_{2}\{\mathrm{C}(\mathrm{H}) \mathrm{Py}\}_{2} \mathrm{PPh}\right](5)$ (right).

Besides the dilithium complex $\mathbf{4}$ also two lithium complexes with the monoanionic ligand $\left[\mathrm{PhP}\{\mathrm{C}(\mathrm{H}) \mathrm{Py}\}\left(\mathrm{CH}_{2} \mathrm{Py}\right)\right]^{-}$could be prepared. In $\left[\left(\mathrm{PyCH}_{2}\right) \mathrm{PhP}\{\mathrm{C}(\mathrm{H}) \mathrm{Py}\} \mathrm{Li}(\mathrm{THF})\right]_{2}(6)$ as well as in [(PMDETA)Li\{C(H)Py\}P(CH $\left.\left(\mathrm{CH}_{2} \mathrm{Py}\right) \mathrm{Ph}\right]$ (7) the coordination of the lithium ion is only achieved by the $N, P$ claw of the ligand. By the use of the oxygen donor base THF a dimeric complex was formed, while addition of the threefold nitrogen donor base PMDETA resulted in deaggregation and the formation of a monomeric complex (Figure $5-3)$.

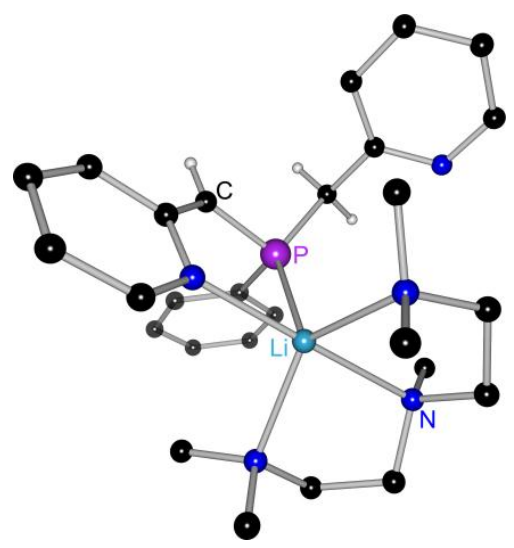

Figure 5-3. [(PMDETA)Li\{C(H)Py\}P( $\left.\left.\mathrm{CH}_{2} \mathrm{Py}\right) \mathrm{Ph}\right](\mathbf{7})$.

The preparation of further alkali metal complexes was realized by means of Lochmann-Schlosser superbase. The sodium complex $\left.\left[\left(\mathrm{PyCH}_{2}\right) \mathrm{PhP}\{\mathrm{C}(\mathrm{H}) \mathrm{Py}\} \mathrm{Na}_{(\mathrm{Et}} \mathrm{O}\right)\right]_{2}$ (8) was synthesized including the monoanionic ligand $\left[\mathrm{PhP}\{\mathrm{C}(\mathrm{H}) \mathrm{Py}\}\left(\mathrm{CH}_{2} \mathrm{Py}\right)\right]^{-}$. 
In contrast to the two lithium complexes $\mathbf{6}$ and $\mathbf{7}$ an additional coordination of the carbanion to the sodium atom was observed. The formation of a potassium compound could not ultimately be clarified but the NMR investigations strongly suggested a successful conversion. The LiCKOR base adduct $\left[\left(\mathrm{Me}_{2} \mathrm{SiO}\right)_{5} \mathrm{OKLi}\right]_{4}(9)$ was crystallized which revealed a hitherto unknown conformation of the $\mathrm{Li}_{4} \mathrm{~K}_{4}$ core (Figure 5-4). While nearly all measured structures of mixed lithium organyle heavier alkali metal alkoxides have heteroatoms of their anions as bridging ligand, they are replaced by a siloxane ligand in this complex.

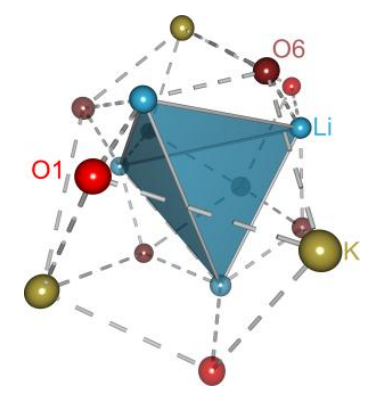

Figure 5-4. Mixed alkali metal core of $\left[\left(\mathrm{Me}_{2} \mathrm{SiO}\right)_{5} \mathrm{OKLi}\right]_{4}(9)$

The treatment of di-2-picolylphenylphosphane (1) with further transition metal silylamides did not yield in satisfactory results due to the poor solubility or stability, respectively, of the obtained products. However, mass spectrometric analysis gave a hint to the formation of complexes containing cobalt or copper as metal ion. The reaction with the lanthanide silylamide $\operatorname{Sm}\left[\mathrm{N}\left(\mathrm{SiMe}_{3}\right)_{2}\right]_{3}$ resulted in the formation of a samarium complex which could be clarified by NMR investigations. The conformation of the complex could not be characterized until today.

The reaction of the neutral phosphane 1 with $\mathrm{PdCl}_{2}(\mathrm{COD})$ resulted in the formation of the metal complex $\left[\left\{\mathrm{PhP}\left(\mathrm{CH}_{2} \mathrm{Py}\right)_{2}\right\} \mathrm{PdCl}_{2}\right]$ (10). The Palladium complex $\left[\left(\mathrm{Ph}_{2} \mathrm{PCH}_{2} \mathrm{Py}\right) \mathrm{PdCl}_{2}\right]$ (11) was obtained by similar preparation carried out with the $N, P$ ligand diphenyl-2-picolylphosphane (Figure 5-5). The solid state structures of $\mathbf{1 0}$ and $\mathbf{1 1}$ showed an identical coordination pattern of the metal ion. 


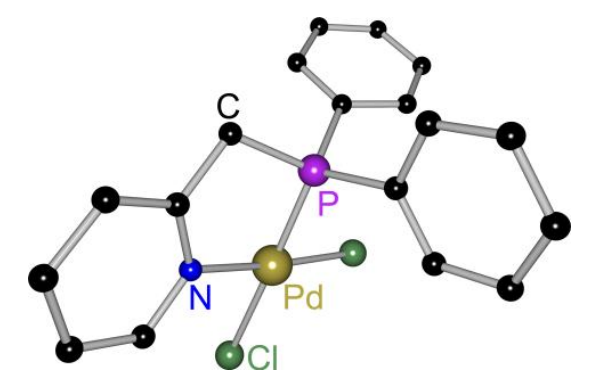

Figure 5-5. [( $\left.\left.\mathrm{Ph}_{2} \mathrm{PCH}_{2} \mathrm{Py}\right) \mathrm{PdCl}_{2}\right](\mathbf{1 1})$.

Within this work it was also possible to synthesize phosphoranes containing oxygen, sulfur or selenium as heteroatom. For all three phosphorus(V) species $\left.\mathrm{PhP}(\mathrm{O})\left(\mathrm{CH}_{2} \mathrm{Py}\right)_{2}\right] \cdot 2 \mathrm{HCl}$ (12), $\left[\mathrm{PhP}(\mathrm{S})\left(\mathrm{CH}_{2} \mathrm{Py}\right)_{2}\right] \cdot \mathrm{HCl}$ (13) and $\left[\mathrm{PhP}(\mathrm{Se})\left(\mathrm{CH}_{2} \mathrm{Py}\right)_{2}\right] \cdot \mathrm{HCl}$ (14) crystals were obtained which were analyzed with $\mathrm{X}$-ray diffraction experiments. All proved to be hydrogen chloride adducts. The exposure of the dilithium complex to atmospheric oxygen resulted in the formation of the lithium complex $\left[(\mathrm{THF})_{4} \mathrm{Li}_{2}\{\mathrm{C}(\mathrm{H}) \mathrm{Py}\}_{2} \mathrm{P}(\mathrm{O}) \mathrm{Ph}\right]$ (17) which shows a different coordination behavior in comparison with the dilithiated complex 4 (Figure 5-6).

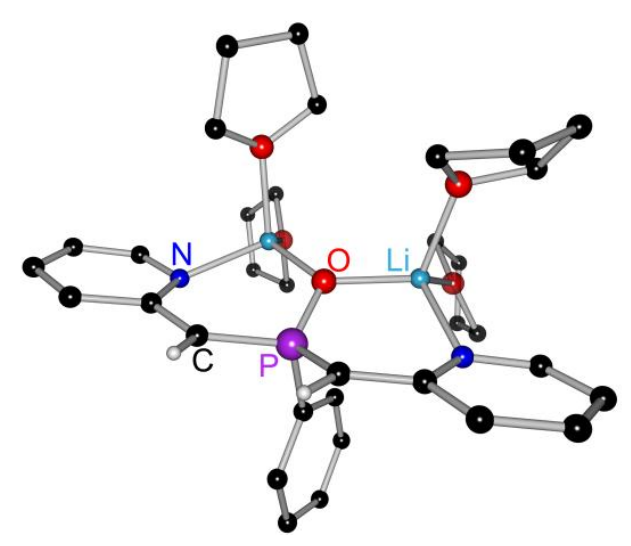

Figure 5-6. [(THF) $\left.{ }_{4} \mathrm{Li}_{2}\{\mathrm{C}(\mathrm{H}) \mathrm{Py}\}_{2} \mathrm{P}(\mathrm{O}) \mathrm{Ph}\right](17)$.

Regarding future objectives, the synthesis of a Frustrated Lewis pair (FLP) would be desirable. The definition $D$. W. Stephan made for the FLPs reads as follows:

"The combination of Lewis acids and bases that are sterically precluded from forming Lewis acid-base adducts, termed Frustrated Lewis pairs provide a unique route to the activation of small molecules and applications in catalysis." 
During their investigations the work group of $D$. W. Stephan has synthesized the zwitterionic salt (Scheme 5-1, I) which is able to release $\mathrm{H}_{2}$ when heated. The formed species II includes a Lewis base as well as an acid which are separated by an aryl moiety. This system was the first non-transition metal compound which reversibly releases and bonds hydrogen. ${ }^{[73]}$ As the formation of Lewis acid-base adducts is not observed for the examined compounds, they can be designated as Frustrated Lewis pairs.

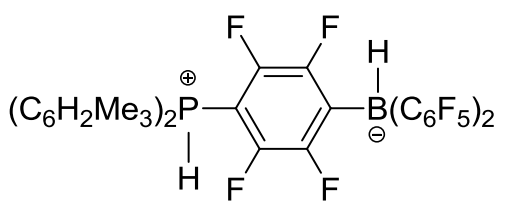

I

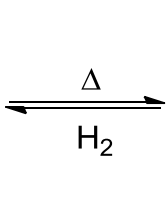

$\mathrm{H}_{2}$<smiles></smiles>

II

Scheme 5-1. Reversible activation of hydrogen.

At about the same time G. Erker et al. developed the alkylene-bridged phosphane/borane species [ $\mathrm{Mes}_{2} \mathrm{P}\left(\mathrm{CH}_{2} \mathrm{CH}_{2}\right) \mathrm{B}\left(\mathrm{C}_{6} \mathrm{~F}_{5}\right)_{2}$ ] which is also able to activate $\mathrm{H}_{2}$. The obtained zwitterionic salt is able to hydrogenate organic carbonyl compounds. ${ }^{[7]}$ Due to the unusual reaction behaviors of FLPs and the opening of a new field of chemistry several investigations were made during the last few years. ${ }^{[75]}$ The probably most important application of FLPs is the metal-free hydrogenation of small molecules like e.g. olefins or imines. ${ }^{[76]}$

Frequently, FLPs are built on bulky phosphanes and boranes. For this reason, it is conceivable to synthesize a Frustrated Lewis pair based on di-2-picolylphenylphosphane (1). Already, some preliminary work was done during this thesis. The combination of phosphane 1 with the Lewis acid $B\left(C_{6} F_{5}\right)_{3}$ did not result in the formation of a Lewis acid-base adduct. However, the solid state structure of the product revealed the formation of an oxygen-boron donor bond due to the presence of water (Figure 5-7). 


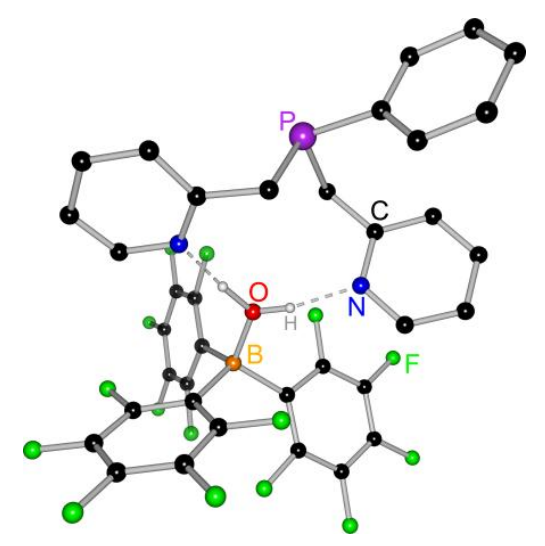

Figure 5-7. $\left[\mathrm{PhP}\left(\mathrm{CH}_{2} \mathrm{Py}\right)_{2}\right] \mathrm{H}_{2} \mathrm{O}\left[\mathrm{B}\left(\mathrm{C}_{6} \mathrm{~F}_{5}\right)_{3}\right](\mathbf{1 8})$.

The preparation of a Frustrated Lewis pair should be feasible by linking a $\mathrm{BR}_{2}$ unit with the methylene bridge of the ligand 1 . The synthesis of the desired phosphane/borane species could be performed by the reaction of the mono lithiated phosphane 6 with a borane halide by elimination of lithium chloride. In Scheme 5-2 the suggested FLP is displayed.<smiles>[R]B([R])C(c1ccccn1)P(c1ccccn1)P(c1ccccc1)c1ccccc1</smiles>

Scheme 5-2. Suggested FLP containing phosphane 1.

Due to this, three different chloro boranes were preliminarily tested in the reaction with 6 (Scheme 5-3). Borane III has two alkyl moieties, IV is a catechol borane and V an aminoborane. Compounds similar to these boranes were reported to form element-B bonds under elimination of alkali metal salts. ${ }^{[77]}$ First experiments with these chloro boranes gave no final results until today.<smiles>ClB(C1CCCCC1)C1CCCCC1</smiles>

III<smiles>ClB1Oc2ccccc2O1</smiles>

IV<smiles>CC(C)(C)N(B(Cl)Cl)C(C)(C)C</smiles>

$\mathbf{V}$

Scheme 5-3. Three different chloro boranes used for synthesis of a FLP. 
For further investigations it should be tested if the reaction of higher homologues of alkali metal complexes containing di-2-picolylphenylphosphane (1) with bromo boranes achieves better results due to the fact that the formed sodium or potassium bromides have less solubility in common organic solvents and do not tend to be chelate by the ligand. Furthermore, it should be verified if an alkyl or aryl linker between the methylene bridge and the borane would support the formation of an FLP. 



\section{EXPERIMENTAL SECTION}

\subsection{General Procedures}

All manipulations were carried out under dry argon inert gas atmosphere by using modified Schlenk techniques ${ }^{[78]}$ or in an argon glove box. Solvents were freshly distilled from sodium, potassium or sodium potassium alloy prior to use. The employed reactants were commercially available or synthesized according to literature procedures: $\mathrm{PhP}\left(\mathrm{CH}_{2} \mathrm{Py}\right)_{2}{ }^{[22]}\left[\mathrm{Sn}\left\{\mathrm{N}\left(\mathrm{SiMe}_{3}\right)_{2}\right\}_{2}\right],{ }^{[79]} \mathrm{PdCl}_{2}(\mathrm{COD}) .{ }^{[59]}$

\subsection{Spectroscopic and Analytic Methods}

NMR spectra were recorded on a Bruker Avance $500 \mathrm{MHz}$ or $300 \mathrm{MHz}$ spectrometer. Chemical shifts $\delta$ are given in ppm and were calibrated either to solvent signal $\left(\mathrm{C}_{6} \mathrm{D}_{6}: 7.15\left({ }^{1} \mathrm{H}\right), 128.0\left({ }^{13} \mathrm{C}\right)\right.$, THF- $d_{8}: 1.73\left({ }^{1} \mathrm{H}\right), 25.3\left({ }^{13} \mathrm{C}\right)$, DMSO- $\mathrm{d}_{6}: 2.50\left({ }^{1} \mathrm{H}\right)$, $\left.39.52\left({ }^{13} \mathrm{C}\right), \mathrm{CD}_{2} \mathrm{Cl}_{2}: 5.32\left({ }^{1} \mathrm{H}\right), 53.84\left({ }^{13} \mathrm{C}\right)\right)$ or to the unified $\Xi$-scale $\Xi\left({ }^{15} \mathrm{~N}\right.$, nitromethane $)=0.10136767, \Xi\left({ }^{29} \mathrm{Si}, \mathrm{TMS}\right)=0.19867187, \Xi\left({ }^{31} \mathrm{P}\right.$, phosphoric acid $)=$ $\left.\left.0.40480742, \Xi\left({ }^{119} \mathrm{Sn}, \mathrm{Me}_{4} \mathrm{Sn}\right)=0.37290632\right), \Xi\left({ }^{77} \mathrm{Se}, \mathrm{Me}_{2} \mathrm{Se}\right)=0.19071513\right), \Xi\left({ }^{7} \mathrm{Li}\right.$, LiCl) $=0.38863797) \cdot{ }^{[80]}$ The obtained chemical shifts were assigned according to Scheme 6-1.<smiles>CC(c1ccccc1)P(C)c1ccccc1</smiles>

Scheme 6-1. Labeling scheme of NMR signals.

\subsection{Elemental Analyses}

Elemental analyses were carried out by the Analytische Labor des Instituts für Anorganische Chemie der Georg-August-Universität Göttingen with an Elementar Vario EL3. Some of the determined values of the air and moisture sensitive compounds 
deviate more than $1.0 \%$ from the calculated ones. This can be explained by the instability of the compounds when handling outside of a Schlenk flask or glove box, the loss of solvent molecules during the drying of the sample in vacuum or the inclusion of argon from canning the samples in an argon glove box.

\subsection{Synthesis and Characterization}

\subsubsection{Synthesis of $\left[\mathrm{PhP}\left(\mathrm{CH}_{2} \mathrm{Py}\right)_{2} \mathrm{LiCl}\right]_{2}(2)$}

$\mathrm{PhP}\left(\mathrm{CH}_{2} \mathrm{Py}\right)_{2}$ (1) $(0.20 \mathrm{~g}, 0.67 \mathrm{mmol})$ and anhydrous lithium chloride $(0.03 \mathrm{mg}, 0.67 \mathrm{mmol})$ were dissolved in THF $(1.5 \mathrm{~mL})$. Storage of the solution at $-20^{\circ} \mathrm{C}$ results in the formation of colorless crystals of $\mathbf{2}$ after 5 days.

Yield: $0.15 \mathrm{~g}, 67 \% . \mathrm{M}=669.42 \mathrm{~g} / \mathrm{mol}$<smiles></smiles>

${ }^{1}$ H NMR (300.13 MHz, THF-d $\left.{ }_{8}\right): \quad \delta(p p m) 8.43-8.40\left(\mathrm{~m}, 2 \mathrm{H}, \mathrm{H}_{\mathrm{f}}\right), 7.48-7.42(\mathrm{~m}, 4 \mathrm{H}$, $\left.\mathrm{H}_{\mathrm{d}}, \mathrm{Ph}\right), 7.26-7.24\left(\mathrm{~m}, 3 \mathrm{H}, \mathrm{C}_{\mathrm{c}}, i-\mathrm{Ph}\right), 7.03-6.99(\mathrm{~m}$, $\left.4 \mathrm{H}, \mathrm{H}_{\mathrm{e}}, \mathrm{Ph}\right), 3.42\left(\mathrm{dd},{ }^{2} \mathrm{~J}_{\mathrm{H}-\mathrm{H}}=13.3 \mathrm{~Hz},{ }^{2} J_{\mathrm{H}-\mathrm{P}}=\right.$ $\left.2.03 \mathrm{~Hz}, 2 \mathrm{H}, \mathrm{H}_{\mathrm{a}}\right), 3.28\left(\mathrm{~d},{ }^{2} J_{\mathrm{H}-\mathrm{H}}=13.3 \mathrm{~Hz}, 2 \mathrm{H}, \mathrm{H}_{\mathrm{a}}\right)$.

${ }^{13}$ C NMR (75.48 MHz, THF- $\left.d_{8}\right): \quad \delta(p p m) 159.8\left(d, C_{b}\right), 149.9\left(s, C_{f}\right), 139.1\left(d,{ }^{1} J_{C-P}=\right.$ $20.4 \mathrm{~Hz}, \quad i-P h), 136.3\left(\mathrm{~s}, \mathrm{C}_{\mathrm{d}}\right), 133.4\left(\mathrm{~d},{ }^{2} \mathrm{~J}_{\mathrm{C}-\mathrm{P}}=\right.$ $19.7 \mathrm{~Hz}, \mathrm{Ph}), 129.3(\mathrm{~s}, \mathrm{Ph}), 128.7$ (d, ${ }^{2} \mathrm{~J}_{\mathrm{C}-\mathrm{P}}=6.6 \mathrm{~Hz}$, $\left.\mathrm{C}_{\mathrm{c}}\right), 124.2\left(\mathrm{~d},{ }^{3} \mathrm{~J}_{\mathrm{C}-\mathrm{P}}=5.0 \mathrm{~Hz}, \mathrm{Ph}\right), 121.3\left(\mathrm{~d},{ }^{5} \mathrm{~J}_{\mathrm{C}-\mathrm{P}}=\right.$ $\left.1.9 \mathrm{~Hz}, \mathrm{C}_{\mathrm{e}}\right), 38.9\left(\mathrm{~d},{ }^{1} \mathrm{~J}_{\mathrm{C}-\mathrm{P}}=20.0 \mathrm{~Hz}, \mathrm{C}_{\mathrm{a}}\right)$.

${ }^{7}$ Li NMR (116.64 MHz, THF-d $\left.d_{8}\right): \quad \delta(p p m)-0.63(\mathrm{~s})$.

${ }^{31}$ P NMR (212.50 MHz, THF-d $\left.\mathrm{d}_{8}\right): \quad \delta(\mathrm{ppm})-13.7(\mathrm{~s})$.

${ }^{15}$ N NMR (30.42 MHz, THF-d 8 ) $\delta($ ppm) -63.7 (Py-N).

Anal. Calcd for $\mathrm{C}_{36} \mathrm{H}_{34} \mathrm{Cl}_{2} \mathrm{Li}_{2} \mathrm{~N}_{4} \mathrm{P}_{2}$ : $\quad$ C, 64.59; $\mathrm{H}, 5.12 ; \mathrm{N}, 8.37$. Found: $\mathrm{C}, 62.96 ; \mathrm{H}, 5.54$; N, 8.03 . 


\subsubsection{Synthesis of $\left[\left(E t_{2} \mathrm{O}\right)_{3} \mathrm{Li}_{2}\{\mathrm{C}(\mathrm{H}) \mathrm{Py}\}_{2} \mathrm{PPh}\right]_{2}(4)$}

A $1.6 \mathrm{M} n \mathrm{BuLi}$ solution in nhexane $(4.94 \mathrm{~mL}$, $7.90 \mathrm{mmol}$ ) was added dropwise to a suspension of $\mathrm{PhP}\left(\mathrm{CH}_{2} \mathrm{Py}\right)_{2}$ (1) $(1.05 \mathrm{~g}, 3.59 \mathrm{mmol})$ in $\mathrm{Et}_{2} \mathrm{O}(20 \mathrm{~mL})$ at $-20^{\circ} \mathrm{C}$ and stirred for one hour. The red solution was layered with $n$ hexane and stored for one week at $-20^{\circ} \mathrm{C}$. The lithium complex 4 was obtained as yellow crystals.

Yield: $1.44 \mathrm{~g}, 76 \% . \mathrm{M}=1053.12 \mathrm{~g} / \mathrm{mol}$

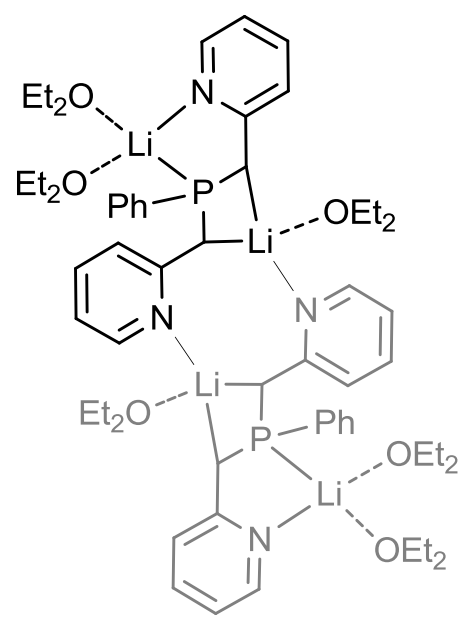

${ }^{1} \mathrm{H}$ NMR (500.13 MHz, $\left.\mathrm{C}_{6} \mathrm{D}_{6}\right)$ :

$\delta(\mathrm{ppm})$ 8.02-7.90 (m, 4H, Ph), 7.40-7.32 (m, 4H, $\left.\mathrm{H}_{\mathrm{f}}\right), 7.26-7.18(\mathrm{~m}, 4 \mathrm{H}, \mathrm{Ph}), 7.09-7.02(\mathrm{~m}, 2 \mathrm{H}, \mathrm{Ph})$, 6.63-6.54 (m, 4H, $\left.H_{d}\right), 6.41-6.33\left(m, 4 H, H_{c}\right), 5.69-$ $5.61\left(\mathrm{~m}, 4 \mathrm{H}, \mathrm{H}_{\mathrm{e}}\right), 3.77-3.68\left(\mathrm{~m}, 4 \mathrm{H}, \mathrm{H}_{\mathrm{a}}\right), 3.15(\mathrm{q}$, $\left.\mathrm{Et}_{2} \mathrm{O}\right), 0.99\left(\mathrm{t}, \mathrm{Et}_{2} \mathrm{O}\right)$.

${ }^{13} \mathrm{C}$ NMR (125.77 MHz, $\left.\mathrm{C}_{6} \mathrm{D}_{6}\right): \quad \delta(\mathrm{ppm})$ 167.20-166.57 (m, $\left.\mathrm{C}_{\mathrm{b}}\right), 148.35\left(\mathrm{~s}, \mathrm{C}_{\mathrm{f}}\right)$, 147.16-146.84 (m, Ph), $133.41\left(\mathrm{~s}, \mathrm{C}_{\mathrm{d}}\right), 130.76$ (d, $\left.{ }^{2} J_{C-P}=12.6 \mathrm{~Hz}, \mathrm{Ph}\right), 128.00(\mathrm{~s}, \mathrm{Ph}), 126.09(\mathrm{~s}, \mathrm{Ph})$, $118.74\left(\mathrm{~s}, \mathrm{C}_{\mathrm{c}}\right), 103.52\left(\mathrm{~s}, \mathrm{C}_{\mathrm{e}}\right), 65.83$ (s, $\left.\mathrm{Et}_{2} \mathrm{O}\right)$, 65.30-64.10 (m, $\left.\mathrm{C}_{\mathrm{a}}\right), 14.63\left(\mathrm{~s}, \mathrm{Et}_{2} \mathrm{O}\right)$.

${ }^{7}$ Li NMR (194.37 MHz, $\left.\mathrm{C}_{6} \mathrm{D}_{6}\right): \quad \delta(\mathrm{ppm}) 1.16(\mathrm{~s})$.

${ }^{31}$ P NMR (202.46 MHz, $\left.\mathrm{C}_{6} \mathrm{D}_{6}\right): \quad \delta(\mathrm{ppm})-46.93(\mathrm{~s})$.

Anal. Calcd for $\mathrm{C}_{60} \mathrm{H}_{90} \mathrm{Li}_{4} \mathrm{~N}_{4} \mathrm{O}_{6} \mathrm{P}_{2}: \quad \mathrm{C}, 68.43 ; \mathrm{H}, 8.61 ; \mathrm{N}, 5.32$. Found: $\mathrm{C}, 67.51 ; \mathrm{H}, 7.57$; $\mathrm{N}, 6.43$. 


\subsubsection{Synthesis of $\left[\left\{\left(\mathrm{Me}_{3} \mathrm{Si}\right)_{2} \mathrm{NSn}\right\}_{2}\{\mathrm{C}(\mathrm{H}) \mathrm{Py}\}_{2} \mathrm{PPh}\right](5)$}

A solution of $\left[\mathrm{Sn}\left\{\mathrm{N}\left(\mathrm{SiMe}_{3}\right)_{2}\right\}_{2}\right](3.00 \mathrm{~g}, 6.83 \mathrm{mmol})$ in $\mathrm{Et}_{2} \mathrm{O}$ $(25 \mathrm{~mL})$ was added dropwise to a solution of $\mathrm{PhP}\left(\mathrm{CH}_{2} \mathrm{Py}\right)_{2}$ (1) $(1.00 \mathrm{~g}, 3.42 \mathrm{mmol})$ in THF $(25 \mathrm{~mL})$ at room temperature. The solution was stirred overnight and all volatile components were removed in vacuo. The yellow residue was dissolved in toluene and stored for one week at $-20^{\circ} \mathrm{C}$. The tin complex 5 was obtained as yellow crystals.

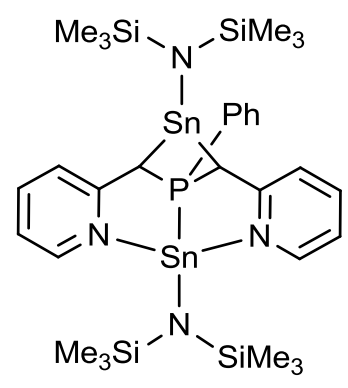

Yield: $2.49 \mathrm{~g}, 80 \% . \mathrm{M}=914.81 \mathrm{~g} / \mathrm{mol}$

${ }^{1} \mathrm{H}$ NMR (500.13 MHz, THF-d $\left.\mathbf{d}_{8}\right): \quad \delta(\mathrm{ppm}) 8.34\left(\mathrm{~d},{ }^{3} \mathrm{~J}_{\mathrm{H}-\mathrm{H}}=5.2 \mathrm{~Hz}, 2 \mathrm{H}, \mathrm{H}_{\mathrm{f}}\right), 7.61-7.56$ $\left(\mathrm{m}, 2 \mathrm{H}, \mathrm{H}_{\mathrm{d}}\right), 7.27-7.23\left(\mathrm{~m}, 5 \mathrm{H}, m-, p-\mathrm{Ph}, \mathrm{H}_{\mathrm{c}}\right), 7.14-$ $7.08(\mathrm{~m}, 2 \mathrm{H}, \mathrm{o}-\mathrm{Ph}), 6.90-6.86\left(\mathrm{~m}, 2 \mathrm{H}, \mathrm{H}_{\mathrm{e}}\right), 3.64-$ $3.60(\mathrm{~m}, \mathrm{THF}), 3.50\left(\mathrm{~d},{ }^{2} \mathrm{~J}_{\mathrm{P}-\mathrm{H}}=-11.3 \mathrm{~Hz}\right.$, satellites $\left.{ }^{3} J_{\mathrm{H}-\mathrm{Sn}}=40 \mathrm{~Hz},{ }^{2} J_{\mathrm{H}-\mathrm{Sn}}=25 \mathrm{~Hz}, 2 \mathrm{H}, \mathrm{H}_{\mathrm{a}}\right), 1.80-1.76(\mathrm{~m}$, THF), $0.12\left(\mathrm{~s}, 18 \mathrm{H}, \mathrm{SiMe}_{3}\right), 0.02\left(\mathrm{~d},{ }^{5} J_{\mathrm{H}-\mathrm{P}}=0.5 \mathrm{~Hz}\right.$, satellites $\left.{ }^{4} \mathrm{H}_{\mathrm{H}-\mathrm{Sn}}=5 \mathrm{~Hz}, 18 \mathrm{H}, \mathrm{SiMe}_{3}\right)$.

${ }^{13} \mathrm{C}$ NMR (125.76 MHz, THF-d $\left.)_{8}\right): \quad \delta(p p m) 166.4\left(\mathrm{~d},{ }^{2} \mathrm{~J}_{\mathrm{C}-\mathrm{P}}=3.8 \mathrm{~Hz}, \mathrm{C}_{\mathrm{b}}\right), 147.0\left(\mathrm{~d},{ }^{1} \mathrm{~J}_{\mathrm{C}-\mathrm{P}}\right.$ $=15.1 \mathrm{~Hz}, i-\mathrm{Ph}), 146.4\left(\mathrm{~s}, \mathrm{C}_{\mathrm{f}}\right), 138.2\left(\mathrm{~s}, \mathrm{C}_{\mathrm{d}}\right), 130.2$ $\left(d,{ }^{4} J_{C-P}=2.6 \mathrm{~Hz}, p-P h\right), 129.6\left(d,{ }^{2} J_{C-P}=11.0 \mathrm{~Hz}, o-\right.$ $\mathrm{Ph}), 128.7\left(\mathrm{~d},{ }^{3} \mathrm{~J}_{\mathrm{C}-\mathrm{P}}=8.8 \mathrm{~Hz}, \mathrm{~m}-\mathrm{Ph}\right), 123.3\left(\mathrm{~d},{ }^{3} \mathrm{~J}_{\mathrm{C}-\mathrm{P}}=\right.$ $\left.9.4 \mathrm{~Hz}, \mathrm{C}_{\mathrm{c}}\right), 117.5\left(\mathrm{~d},{ }^{5} \mathrm{~J}_{\mathrm{C}-\mathrm{P}}=3.1 \mathrm{~Hz}, \mathrm{C}_{\mathrm{e}}\right), 68.2(\mathrm{~s}$, THF), $37.0\left(\mathrm{~d},{ }^{1} J_{\mathrm{C}-\mathrm{P}}=31.7 \mathrm{~Hz}, \mathrm{C}_{\mathrm{a}}\right), 26.4(\mathrm{~s}, \mathrm{THF}), 6.2$ (s, $\left.\mathrm{SiMe}_{3}\right), 6.1\left(\mathrm{~d},{ }^{4} \mathrm{~J}_{\mathrm{C}-\mathrm{p}}=2.3 \mathrm{~Hz}, \mathrm{SiMe}_{3}\right)$.

${ }^{29}$ Si NMR (99.36 MHz, THF-d 8 ): $\quad \delta(\mathrm{ppm}) 1.5\left(\mathrm{~d},{ }^{3} J_{\mathrm{Si}-\mathrm{P}}=8 \mathrm{~Hz}\right.$, satellites ${ }^{2} J_{\mathrm{Si}-\mathrm{Sn}}=$ $32 \mathrm{~Hz}),-3.5\left(\mathrm{~s}\right.$, satellites $\left.{ }^{2} \mathrm{~J}_{\mathrm{Si}-\mathrm{Sn}}=10 \mathrm{~Hz}\right)$.

${ }^{31}$ P NMR (202.46 MHz, THF-d $\left.d_{8}\right): \quad \delta(p p m) 6.04\left(\mathrm{~s}\right.$, satellites ${ }^{1} J_{\mathrm{P}-119}{ }^{119} \mathrm{~S}=1775 \mathrm{~Hz},{ }^{1} J_{\mathrm{P} \_}{ }^{117} \mathrm{Sn}$

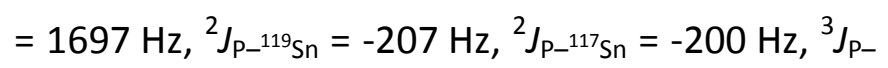
$\mathrm{si}=8 \mathrm{~Hz}$.

${ }^{119}$ Sn NMR (186.50 MHz, THF-d $\left.d_{8}\right): \quad \delta(p p m) 114.9\left(d^{2}{ }^{2} J_{S n-P}=-207 \mathrm{~Hz}\right.$, satellites ${ }^{3} J_{S n-S n}=$ $5400 \mathrm{~Hz}),-219.5\left(d,{ }^{1} J_{S n-P}=1775 \mathrm{~Hz}\right)$. 
${ }^{15}$ N NMR (50.70 MHz, THF-d $\left.\mathbf{d}_{8}\right): \quad \delta(\mathrm{ppm})-104.6$ (Py-N), -304.5 (NSiMe $\left.{ }_{3}\right),-316.7$ (NSiMe $)_{3}$.

Anal. Calcd for $\mathrm{C}_{30} \mathrm{H}_{51} \mathrm{~N}_{4} \mathrm{PSi}_{4} \mathrm{Sn}_{2}+0.8\left(\mathrm{C}_{4} \mathrm{H}_{8} \mathrm{O}\right)+0.1\left(\mathrm{C}_{6} \mathrm{H}_{14}\right)$ :

C, 44.38; $H, 6.48 ; N, 6.12$. Found: $C, 43.72 ; H, 6.74$;

$\mathrm{N}, 6.58$.

\subsubsection{Synthesis of $\left[\left(\mathrm{PyCH}_{2}\right) \mathrm{PhP}\{\mathrm{C}(\mathrm{H}) \mathrm{Py}\} \mathrm{Li}(\mathrm{THF})\right]_{2}(6)$}

A $1.86 \mathrm{M} n$ BuLi solution in $n$ hexane $(2.03 \mathrm{~mL}, 3.76 \mathrm{mmol})$ was added dropwise to a solution of $\mathrm{Ph}_{2} \mathrm{PCH}_{2} \mathrm{Py}$ (1) $(1.00 \mathrm{~g}, 3.42 \mathrm{mmol})$ in THF $(15 \mathrm{~mL})$ at $-20^{\circ} \mathrm{C}$ and stirred for one hour. The red solution was reduced, layered with nhexane and stored for two weeks at $-20^{\circ} \mathrm{C}$. The lithium complex 6 was obtained as yellow crystals. Unfortunately, the crystals decomposed before a characterization could be performed.

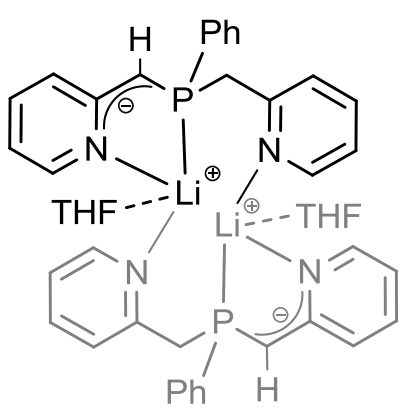

$M=740.36 \mathrm{~g} / \mathrm{mol}$ 


\subsubsection{Synthesis of [(PMDETA)Li\{C(H)Py\}P(CH $\left.\left.\mathrm{CH}_{2} \mathrm{Py}\right) \mathrm{Ph}\right](7)$}

A $1.6 \mathrm{M} \mathrm{nBuLi}$ solution in nhexane $(0.69 \mathrm{~mL}, 1.10 \mathrm{mmol})$ was added dropwise to a solution of $\mathrm{PhP}\left(\mathrm{CH}_{2} \mathrm{Py}\right)_{2}$ (1) $(0.29 \mathrm{~g}, 1.00 \mathrm{mmol})$ and PMDETA $(0.18 \mathrm{~g}, 0.22 \mathrm{~mL}$, $1.05 \mathrm{mmol})$ in toluene $(10 \mathrm{~mL})$ at $0{ }^{\circ} \mathrm{C}$ and stirred for $15 \mathrm{~min}$. Afterwards the pale red solution was stirred for one day at room temperature. The volume of the solution was reduced and $0.2 \mathrm{~mL}$ PMDETA and 30 drops THF were added. The reaction mixture was stored at $-20^{\circ} \mathrm{C}$. Crystals of the lithium complex 7 were

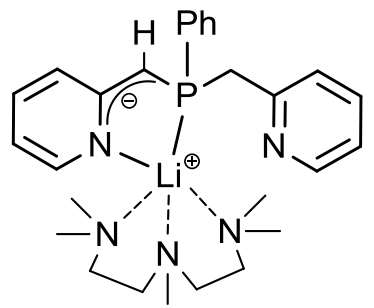
obtained by warming up the solution to room temperature.

Yield: $0.25 \mathrm{~g}, 53 \% . \mathrm{M}=471.55 \mathrm{~g} / \mathrm{mol}$

${ }^{1} \mathrm{H}$ NMR (500.13 MHz, $\left.\mathrm{C}_{6} \mathrm{D}_{6}\right)$ :

${ }^{13} \mathrm{C}$ NMR (125.77 MHz, $\left.\mathrm{C}_{6} \mathrm{D}_{6}\right)$ : $\delta(p p m) 8.44\left(\mathrm{~d}, 1 \mathrm{H},{ }^{3} \mathrm{~J}_{\mathrm{H}-\mathrm{H}}=4.63 \mathrm{~Hz}, \mathrm{H}_{\mathrm{f}}\right), 7.90-7.87$ $(\mathrm{m}, 2 \mathrm{H}, o-\mathrm{Ph}), 7.27-7.24\left(\mathrm{~m}, 3 \mathrm{H}, \mathrm{m}-\mathrm{Ph}, \mathrm{H}_{\mathrm{f}}\right), 7.16$ $\left(H_{c}, 1 H\right.$, overlaps with solvent), 7.11-7.09 (m, $1 \mathrm{H}$, $p-\mathrm{Ph}), 6.95\left(\mathrm{dd}, 1 \mathrm{H},{ }^{3} \mathrm{~J}_{\mathrm{H}-\mathrm{H}}=7.13 \mathrm{~Hz},{ }^{3} J_{\mathrm{H}-\mathrm{H}}=7.13 \mathrm{~Hz}\right.$, $\left.\mathrm{H}_{\mathrm{d}}\right), 6.83\left(\mathrm{ddd}, 1 \mathrm{H},{ }^{3} \mathrm{~J}_{\mathrm{H}-\mathrm{H}}=8.15 \mathrm{~Hz},{ }^{3} \mathrm{~J}_{\mathrm{H}-\mathrm{H}}=8.45 \mathrm{~Hz}\right.$, $\left.{ }^{4} J_{\mathrm{H}-\mathrm{H}}=1.50 \mathrm{~Hz}, \mathrm{H}_{\mathrm{d}^{\prime}}\right), 6.72\left(\mathrm{~d}, 1 \mathrm{H},{ }^{3} \mathrm{~J}_{\mathrm{H}-\mathrm{H}}=8.15 \mathrm{~Hz}\right.$, $\left.H_{c^{\prime}}\right)$, 6.59-6.57 $\left(m, 1 H, H_{e}\right), 5.74-5.72\left(m, 1 H, H_{e^{\prime}}\right)$, $3.65\left(d,{ }^{2} J_{H-P}=6.26 \mathrm{~Hz}, 1 \mathrm{H}, \mathrm{H}_{\mathrm{a}^{\prime}}\right), 3.61\left(\mathrm{~d},{ }^{2} J_{\mathrm{H}-\mathrm{H}}=\right.$ $\left.12.0 \mathrm{~Hz}, 1 \mathrm{H}, \mathrm{H}_{\mathrm{a}}\right), 3.35\left(\mathrm{dd},{ }^{2} J_{\mathrm{H}-\mathrm{H}}=12.0 \mathrm{~Hz},{ }^{2} J_{\mathrm{H}-\mathrm{P}}=\right.$ $\left.5.51 \mathrm{~Hz}, 1 \mathrm{H}, \mathrm{H}_{\mathrm{a}}\right), 2.36\left(\mathrm{br}, 3 \mathrm{H}, \mathrm{NCH}_{3}\right), 1.84(\mathrm{br}, 2 \mathrm{OH}$, $\mathrm{NCH}_{3}, \mathrm{NCH}_{2}$ ).

$\delta(p p m) 170.9\left(\mathrm{~d},{ }^{2} J_{C-p}=26.1 \mathrm{~Hz}, \mathrm{C}_{\mathrm{b}}\right), 161.4\left(\mathrm{~s}, \mathrm{C}_{\mathrm{b}^{\prime}}\right)$, $148.8\left(\mathrm{~s}, \mathrm{C}_{\mathrm{f}}\right), 147.5\left(\mathrm{~s}, \mathrm{C}_{\mathrm{f}^{\prime}}\right), 135.0\left(\mathrm{~s}, \mathrm{C}_{\mathrm{d}}\right), 132.9$ (s, $\left.\mathrm{C}_{\mathrm{d}^{\prime}}\right), 131.3\left(\mathrm{~d},{ }^{2} \mathrm{~J}_{\mathrm{C}-\mathrm{P}}=12.6 \mathrm{~Hz}, o-\mathrm{Ph}\right), 128.3(\mathrm{~m}-\mathrm{Ph}$, overlaps with solvent), 126.2 (s, p-Ph), 124.9 (s, $\left.\mathrm{C}_{\mathrm{c}}\right), 122.4\left(\mathrm{~d},{ }^{1} \mathrm{~J}_{\mathrm{C}-\mathrm{P}}=373 \mathrm{~Hz}, i-\mathrm{Ph}\right), 120.2\left(\mathrm{~s}, \mathrm{C}_{\mathrm{e}}\right.$ ), $118.4\left(d,{ }^{3} J_{C-P}=9.80 \mathrm{~Hz}, C_{c^{\prime}}\right), 100.7\left(s, C_{e^{\prime}}\right), 60.5(d$, 
$\left.{ }^{1} J_{\mathrm{C}-\mathrm{p}}=23.2 \mathrm{~Hz}, \mathrm{C}_{\mathrm{a}^{\prime}}\right), 57.8\left(\mathrm{~s}, \mathrm{NCH}_{2}\right), 54.7\left(\mathrm{~s}, \mathrm{NCH}_{2}\right)$, $45.4\left(\mathrm{~s}, \mathrm{NCH}_{3}\right), 43.3\left(\mathrm{~d},{ }^{1} J_{\mathrm{C}-\mathrm{P}}=5.82 \mathrm{~Hz}, \mathrm{C}_{\mathrm{a}}\right.$ ).

${ }^{7}$ Li NMR (194.37 MHz, $\mathrm{C}_{6} \mathrm{D}_{6}$ ): $\quad \delta$ (ppm) 0.93 (s).

${ }^{31}$ P NMR (202.46 MHz, $\left.\mathrm{C}_{6} \mathrm{D}_{6}\right): \quad \delta(\mathrm{ppm})-27.2(\mathrm{~s})$.

Anal. Calcd for $\mathrm{C}_{27} \mathrm{H}_{39} \mathrm{LiN}_{5} \mathrm{P}: \quad$ C, 68.77; $\mathrm{H}, 8.34 ; \mathrm{N}, 14.85$. Found: $\mathrm{C}, 67.39 ; \mathrm{H}$, 7.93; N, 14.32 . 


\subsection{6 $\left[\left(\mathrm{PyCH}_{2}\right) \mathrm{PhP}\{\mathrm{C}(\mathrm{H}) \mathrm{Py}\} \mathrm{Na}\left(\mathrm{Et}_{2} \mathrm{O}\right)\right]_{2}(8)$}

$\mathrm{PhP}\left(\mathrm{CH}_{2} \mathrm{Py}\right)_{2}$ (1) $(0.50 \mathrm{~g}, 1.70 \mathrm{mmol})$ and $\mathrm{NaOtBu}(0.32 \mathrm{~g}$, $3.40 \mathrm{mmol})$ were suspended in nhexane $(5 \mathrm{~mL})$ and $1.59 \mathrm{M} \mathrm{nBuLi}$ in $n$ hexane $(1.18 \mathrm{~mL}, 1.87 \mathrm{mmol})$ were added dropwise at $-20{ }^{\circ} \mathrm{C}$ and stirred for one day at room temperature. The resulting orange powder was filtrated and resolved in $\mathrm{Et}_{2} \mathrm{O}$ to obtain yellow crystals of 8 after two days storage at $-20^{\circ} \mathrm{C}$.

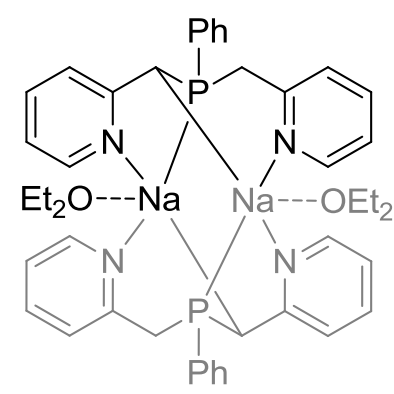

Yield (crude product): $0.59 \mathrm{~g}, 89 \% . \mathrm{M}=776.84 \mathrm{~g} / \mathrm{mol}$

${ }^{1} \mathbf{H}$ NMR (500.13 MHz, THF-d d $\left._{8}\right): \quad \delta(p p m) 8.34\left(\mathrm{~d}, 1 \mathrm{H},{ }^{3} J_{\mathrm{H}-\mathrm{H}}=4.36 \mathrm{~Hz}, \mathrm{H}_{\mathrm{f}}\right), 7.51-7.50$ (m, 2H,o-Ph), 7.41-7.38 (m, 1H, $\left.\mathrm{H}_{\mathrm{d}}\right), 7.15-7.12(\mathrm{~m}$, $\left.3 \mathrm{H}, \mathrm{H}_{\mathrm{f}^{\prime}}, m-\mathrm{Ph}\right), 7.04-6.99\left(\mathrm{~m}, 2 \mathrm{H}, p-\mathrm{Ph}, \mathrm{H}_{\mathrm{c}}\right), 6.93-$ $6.91\left(\mathrm{~m}, 1 \mathrm{H}, \mathrm{H}_{\mathrm{e}}\right), 6.30-6.28\left(\mathrm{~m}, 1 \mathrm{H}, \mathrm{H}_{\mathrm{d}^{\prime}}\right), 5.96-5.94$ $\left(\mathrm{m}, 1 \mathrm{H}, \mathrm{H}_{\mathrm{c}^{\prime}}\right), 5.17-5.14\left(\mathrm{~m}, 1 \mathrm{H}, \mathrm{H}_{\mathrm{e}^{\prime}}\right), 3.14-3.11(\mathrm{~m}$, $\left.1 \mathrm{H}, \mathrm{H}_{\mathrm{a}^{\prime}}\right), 3.06-3.00\left(\mathrm{~m}, 2 \mathrm{H}, \mathrm{H}_{\mathrm{a}}\right)$.

${ }^{13} \mathrm{C}$ NMR (125.77 MHz, THF-d $\left.\mathrm{d}_{8}\right): \quad \delta(\mathrm{ppm}) 170.0\left(\mathrm{~d},{ }^{2} \mathrm{~J}_{\mathrm{C}-\mathrm{P}}=26.0 \mathrm{~Hz}, \mathrm{C}_{\mathrm{b}}\right), 162.6\left(\mathrm{~s}, \mathrm{C}_{\mathrm{b}^{\prime}}\right)$, 149.3 (bs, $C_{f}$ ), 148.5 (bs, $\left.C_{f^{\prime}}\right), 148.4$ (d, ${ }^{1} J_{C-P}=$ $11.1 \mathrm{~Hz}, i-\mathrm{Ph}), 135.8\left(\mathrm{~s}, \mathrm{C}_{\mathrm{d}}\right.$ ), 132.2 (s, $\left.\mathrm{C}_{\mathrm{d}^{\prime}}\right), 131.7$ (d, $\left.{ }^{2} J_{C-P}=15.0 \mathrm{~Hz}, o-P h\right), 127.8\left(d,{ }^{3} J_{C-P}=5.10 \mathrm{~Hz}, m-\right.$ $\mathrm{Ph}), 126.2(\mathrm{~s}, p-\mathrm{Ph}), 124.7\left(\mathrm{~s}, \mathrm{C}_{\mathrm{c}}\right), 120.4\left(\mathrm{~d},{ }^{5} \mathrm{~J}_{\mathrm{C}-\mathrm{P}}=\right.$ $\left.1.93 \mathrm{~Hz}, \mathrm{C}_{\mathrm{e}}\right), 117.6\left(\mathrm{~d},{ }^{3} \mathrm{~J}_{\mathrm{C}-\mathrm{P}}=8.53 \mathrm{~Hz}, \mathrm{C}_{\mathrm{c}^{\prime}}\right), 100.6(\mathrm{~s}$, $\left.C_{e^{\prime}}\right), 60.45\left(d,{ }^{1} J_{C-P}=19.2 \mathrm{~Hz}, C_{a}\right), 44.89\left(d,{ }^{1} J_{C-}\right.$ $\mathrm{p}=12.7 \mathrm{~Hz}, \mathrm{C}_{\mathrm{a}^{\prime}}$ ).

${ }^{15}$ N NMR (30.42 MHz, THF-d d $_{8}: \quad \delta$ (ppm) -346.2 (Py-N).

${ }^{31}$ P NMR (202.46 MHz, THF-d d $_{8}: \quad \delta$ (ppm) -23.99 (s).

Anal. Calcd for $\mathrm{C}_{44} \mathrm{H}_{52} \mathrm{~N}_{4} \mathrm{Na}_{2} \mathrm{O}_{2} \mathrm{P}_{2}: \quad$ C, 68.03; $\mathrm{H}, 6.75 ; \mathrm{N}, 7.21$. Found: $\mathrm{C}, 67.45 ; \mathrm{H}, 7.03$; N, 7.37. 


\subsubsection{Optimized Synthesis of $\left[\left\{\mathrm{PhP}\left(\mathrm{CH}_{2} \mathrm{Py}\right)_{2}\right\} \mathrm{PdCl}_{2}\right](10)^{[23 \mathrm{c}]}$}

$\mathrm{PhP}\left(\mathrm{CH}_{2} \mathrm{Py}\right)_{2}(\mathbf{1})(0.58 \mathrm{~g}, 2.00 \mathrm{mmol})$ and $\mathrm{PdCl}_{2}(\mathrm{COD})(0.57 \mathrm{~g}$, $2.00 \mathrm{mmol}$ ) were mixed in an argon dry box and dissolved in $40 \mathrm{ml} \mathrm{DCM}$. The solution was stirred overnight at room temperature afterwards all volatile components were removed in vacuum. $20 \mathrm{~mL} \mathrm{Et}_{2} \mathrm{O}$ were added to the residue<smiles></smiles>
and the remaining yellow solid was filtered and dried.

Yield: $0.80 \mathrm{~g}, 85 \% . \mathrm{M}=469.64 \mathrm{~g} / \mathrm{mol}$

${ }^{1}$ H NMR (300.13 MHz, DMSO-d $\left.\mathbf{d}_{6}\right): \quad \delta(\mathrm{ppm}) 9.29\left(\mathrm{br}, 1 \mathrm{H}, \mathrm{H}_{\mathrm{f}^{\prime}}\right), 8.37\left(\mathrm{br}, 1 \mathrm{H}, \mathrm{H}_{\mathrm{f}}\right), 8.02$ (br, 1H, PyH), 7.79-7.72 (m, 4H, PhH, PyH), 7.59$7.54(\mathrm{~m}, 1 \mathrm{H}, \mathrm{p}-\mathrm{Ph}), 7.50-7.45(\mathrm{~m}, 4 \mathrm{H}, \mathrm{PhH}, \mathrm{PyH})$, 7.24 (br, 1H, PyH), 4.69 (br, $\left.1 \mathrm{H}, \mathrm{CH}_{2}\right), 4.30-4.20$ $\left(\mathrm{m}, 2 \mathrm{H}, \mathrm{CH}_{2}\right), 4.08\left(\mathrm{br}, 1 \mathrm{H} \mathrm{CH} \mathrm{CH}_{2}\right.$.

${ }^{13} \mathrm{C}$ NMR (75.50 MHz, DMSO-d $\left.\mathrm{d}_{6}\right): \quad \delta(\mathrm{ppm}) 161.9\left(\mathrm{~s}, \mathrm{C}_{\mathrm{b}^{\prime}}\right), 152.8\left(\mathrm{~s}, \mathrm{C}_{\mathrm{b}}\right), 151.7\left(\mathrm{~s}, \mathrm{C}_{\mathrm{f}^{\prime}}\right)$, 149.1 (s, C $\mathrm{f}_{\mathrm{f}}, 140.3$ (s, PyC), 137.1 (s, PyC), 132.1 (s, $p-\mathrm{Ph}), 131.6\left(\mathrm{~d},{ }^{3} \mathrm{~J}_{\mathrm{C}-\mathrm{P}}=10.0 \mathrm{~Hz}, m-\mathrm{Ph}\right), 129.0\left(\mathrm{~d},{ }^{2} \mathrm{~J}_{\mathrm{C}-}\right.$ $\mathrm{P}=11.3 \mathrm{~Hz}, o-\mathrm{Ph}), 127.2\left(\mathrm{~d},{ }^{1} J_{\mathrm{C}-\mathrm{P}}=52.4 \mathrm{~Hz}, i-\mathrm{Ph}\right)$, 125.2 (s, PyC), 124.2 (br, PyC), 123.6 (s, PyC), 122.4 $(\mathrm{s}, \mathrm{PyC}), 38.34\left(\mathrm{~s}, \mathrm{CH}_{2}\right), 34.21\left(\mathrm{~d},{ }^{1} \mathrm{~J}_{\mathrm{C}-\mathrm{P}}=28.8 \mathrm{~Hz}\right.$, $\mathrm{CH}_{2}$ ).

${ }^{31}$ P NMR (121.50 MHz, DMSO-d 6 ): $\delta$ (ppm) 48.42 (s).

Anal. Calcd for $\mathrm{C}_{18} \mathrm{H}_{16} \mathrm{Cl}_{2}$ NPPd: $\quad$ C, 46.03; $\mathrm{H}, 3.65 ; \mathrm{N}, 5.96$. Found: $\mathrm{C}, 45.20 ; \mathrm{H}, 3.53$; N, 6.04 . 


\subsubsection{Modified Synthesis of $\left[\left(\mathrm{Ph}_{2} \mathrm{PCH}_{2} \mathrm{Py}\right) \mathrm{PdCl}_{2}\right](11)^{[60]}$}

$\mathrm{Ph}_{2} \mathrm{PCH}_{2} \mathrm{Py}$ (1) $(0.55 \mathrm{~g}, 2.00 \mathrm{mmol})$ and $\mathrm{PdCl}_{2}(\mathrm{COD})$ (0.57 g, $2.00 \mathrm{mmol}$ ) were mixed in an argon dry box and dissolved in $90 \mathrm{ml}$ DCM. The solution was stirred overnight at room temperature afterwards all volatile components were removed in vacuum. The sparingly soluble pale green residue was dissolved in $\mathrm{THF}, \mathrm{Et}_{2} \mathrm{O}$ and $\mathrm{DCM}$ and stored for two days at $-20^{\circ} \mathrm{C}$. The palladium complex 11 was obtained as yellow crystals.

Yield: $0.76 \mathrm{~g}, 84 \% . \mathrm{M}=454.62 \mathrm{~g} / \mathrm{mol}$

${ }^{1} \mathrm{H}$ NMR (300.13 MHz, DMSO-d $\left.\mathrm{d}_{6}\right): \quad \delta(\mathrm{ppm}) 9.42\left(\mathrm{~d},{ }^{3} \mathrm{~J}_{\mathrm{H}-\mathrm{H}}=6.0 \mathrm{~Hz}, 1 \mathrm{H}, \mathrm{H}_{\mathrm{f}}\right), 8.11-8.05$ $\left(\mathrm{m}, 1 \mathrm{H}, \mathrm{H}_{\mathrm{d}}\right), 7.90-7.83(\mathrm{~m}, 4 \mathrm{H}, \mathrm{m}-\mathrm{Ph}), 7.78\left(\mathrm{~d},{ }^{3} \mathrm{~J}_{\mathrm{H}-}\right.$ $\left.\mathrm{H}=8.0 \mathrm{~Hz}, 1 \mathrm{H}, \mathrm{H}_{\mathrm{c}}\right), 7.67-7.61(\mathrm{~m}, 2 \mathrm{H}, p-\mathrm{Ph}), 7.59-$ $7.52\left(\mathrm{~m}, 5 \mathrm{H}, \mathrm{o}-\mathrm{Ph}, \mathrm{H}_{\mathrm{e}}\right), 4.70\left(\mathrm{~d},{ }^{2} \mathrm{~J}_{\mathrm{P}-\mathrm{H}}=14.9 \mathrm{~Hz}, 2 \mathrm{H}\right.$, $\left.\mathrm{H}_{\mathrm{a}}\right)$.

${ }^{13} \mathrm{C}$ NMR (75.50 MHz, DMSO-d $\left.)_{6}\right): \quad \delta(\mathrm{ppm}) 160.8\left(\mathrm{~d},{ }^{2} J_{\mathrm{C}-\mathrm{p}}=4.6 \mathrm{~Hz}, \mathrm{C}_{\mathrm{b}}\right), 152.1\left(\mathrm{~s}, \mathrm{C}_{\mathrm{f}}\right)$, $140.7\left(\mathrm{~s}, \mathrm{C}_{\mathrm{d}}\right), 132.9\left(\mathrm{~d},{ }^{3} \mathrm{~J}_{\mathrm{C}-\mathrm{P}}=10.9 \mathrm{~Hz}, \mathrm{~m}-\mathrm{Ph}\right), 132.4$ $\left(d,{ }^{4} J_{C-P}=3.1 \mathrm{~Hz}, p-P h\right), 129.1\left(d,{ }^{2} J_{C-P}=11.7 \mathrm{~Hz}, o-\right.$ $\mathrm{Ph}), 126.6\left(\mathrm{~d},{ }^{1} J_{\mathrm{C}-\mathrm{P}}=58.0 \mathrm{~Hz}, i-\mathrm{Ph}\right), 124.1\left(\mathrm{~d},{ }^{3} \mathrm{~J}_{\mathrm{C}-\mathrm{P}}=\right.$ $\left.13.3 \mathrm{~Hz}, \mathrm{C}_{\mathrm{c}}\right), 123.9\left(\mathrm{~s}, \mathrm{C}_{\mathrm{e}}\right), 40.4\left(\mathrm{~d},{ }^{1} \mathrm{~J}_{\mathrm{C}-\mathrm{P}}=32.9 \mathrm{~Hz}\right.$, $\left.\mathrm{C}_{\mathrm{a}}\right)$.

${ }^{31}$ P NMR (121.50 MHz, DMSO-d 6 ): $\delta(p p m) 44.05$ (s).

Anal. Calcd for $\mathrm{C}_{18} \mathrm{H}_{16} \mathrm{Cl}_{2} \mathrm{NPPd}: \quad \mathrm{C}, 47.55 ; \mathrm{H}, 3.55 ; \mathrm{N}, 3.08$. Found: $\mathrm{C}, 45.92 ; \mathrm{H}, 3.70$; N, 3.22 . 


\subsubsection{Synthesis of $\left[\mathrm{PhP}(\mathrm{O})\left(\mathrm{CH}_{2} \mathrm{Py}\right)_{2}\right] \cdot 2 \mathrm{HCl}(12)$}

$\mathrm{PhP}\left(\mathrm{CH}_{2} \mathrm{Py}\right)_{2}$ (1) $(0.36 \mathrm{~g}, 1.25 \mathrm{mmol})$ was dissolved in $10 \mathrm{~mL} \mathrm{DCM}$ and $10 \mathrm{~mL} \mathrm{MeOH}$. The pale yellow solution was cooled down to $-15{ }^{\circ} \mathrm{C}$ and aqueous $\mathrm{H}_{2} \mathrm{O}_{2}$ (35 wt \%, $0.13 \mathrm{~mL}, 1.38 \mathrm{mmol}$ ) was added dropwise over a period of $30 \mathrm{~min}$. The reaction mixture was stirred overnight at room temperature and all volatile components were removed in vacuum. The colorless residue was dissolved

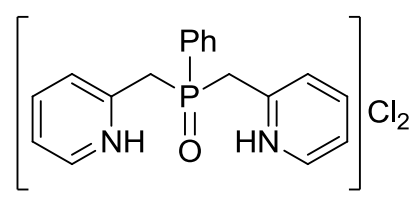
in DCM, MeOH and THF (1:1:0.5) and stored for two weeks at $-20^{\circ} \mathrm{C} .12$ was obtained as colorless crystals.

Yield: $0.13 \mathrm{~g}, 27 \% . \mathrm{M}=381.24 \mathrm{~g} / \mathrm{mol}$

${ }^{1} \mathrm{H}$ NMR (500.13 MHz, $\left.\mathrm{CD}_{2} \mathrm{Cl}_{2}\right): \quad \delta(\mathrm{ppm}) 8.45\left(\mathrm{~d},{ }^{3} \mathrm{~J}_{\mathrm{H}-\mathrm{H}}=5.0 \mathrm{~Hz}, 2 \mathrm{H}, \mathrm{H}_{\mathrm{f}}\right), 7.65-7.61$ $\left(\mathrm{m}, 4 \mathrm{H}, \mathrm{m}-\mathrm{Ph}, \mathrm{H}_{\mathrm{d}}\right), 7.50-7.47(\mathrm{~m}, 1 \mathrm{H}, \mathrm{p}-\mathrm{Ph}), 7.41-$ $7.39(\mathrm{~m}, 2 \mathrm{H}, \mathrm{o}-\mathrm{Ph}), 7.32-7.30\left(\mathrm{~m}, 2 \mathrm{H}, \mathrm{H}_{\mathrm{c}}\right), 7.21-$ $7.18\left(\mathrm{~m}, 2 \mathrm{H}, \mathrm{H}_{\mathrm{e}}\right), 4.03(\mathrm{br}, 2 \mathrm{H}, \mathrm{NH}), 3.82\left(\mathrm{dd},{ }^{2} \mathrm{~J}_{\mathrm{H}-\mathrm{H}}=\right.$ $\left.14.5 \mathrm{~Hz},{ }^{2} J_{\mathrm{P}-\mathrm{H}}=14.5 \mathrm{~Hz}, 2 \mathrm{H}, \mathrm{H}_{\mathrm{a}}\right), 3.75\left(\mathrm{dd},{ }^{2} J_{\mathrm{H}-\mathrm{H}}=\right.$ $14.5 \mathrm{~Hz},{ }^{2} J_{\mathrm{P}-\mathrm{H}}=14.5 \mathrm{~Hz}, 2 \mathrm{H}, \mathrm{H}_{\mathrm{a}}$ ).

${ }^{13} \mathrm{C}$ NMR (125.77 MHz, $\left.\mathrm{CD}_{2} \mathrm{Cl}_{2}\right): \quad \delta(\mathrm{ppm}) 153.0\left(\mathrm{~d},{ }^{2} \mathrm{~J}_{\mathrm{C}-\mathrm{P}}=7.8 \mathrm{~Hz}, \mathrm{C}_{\mathrm{b}}\right), 148.7\left(\mathrm{~s}, \mathrm{C}_{\mathrm{f}}\right)$, $137.7\left(\mathrm{~s}, \mathrm{C}_{\mathrm{d}}\right), 132.2(\mathrm{~s}, \mathrm{p}-\mathrm{Ph}), 131.7\left(\mathrm{~d},{ }^{1} \mathrm{~J}_{\mathrm{C}-\mathrm{P}}=\right.$ $97.2 \mathrm{~Hz}, i-\mathrm{Ph}), 131.3\left(\mathrm{~d},{ }^{3} J_{\mathrm{C}-\mathrm{P}}=9.0 \mathrm{~Hz}, m-\mathrm{Ph}\right), 128.7$ $\left(d,{ }^{2} J_{C-P}=11.7 \mathrm{~Hz}, o-P h\right), 125.6\left(d,{ }^{3} J_{C-P}=3.9 \mathrm{~Hz}\right.$, $\left.C_{c}\right), 122.5\left(s, C_{e}\right), 40.4\left(d,{ }^{1} J_{C-P}=61.5 \mathrm{~Hz}, C_{a}\right)$.

${ }^{31}$ P NMR (202.46 MHz, $\left.\mathrm{CD}_{2} \mathrm{Cl}_{2}\right): \quad \delta(\mathrm{ppm}) 33.74(\mathrm{~s})$.

${ }^{15} \mathrm{~N}$ NMR (30.41 MHz, $\left.\mathrm{CD}_{2} \mathrm{Cl}_{2}\right): \quad \delta(\mathrm{ppm})-298.9(\mathrm{Py}-\mathrm{N})$.

Anal. Calcd for $\mathrm{C}_{18} \mathrm{H}_{18} \mathrm{Cl}_{2}$ NOP: $\quad$ C, 62.71; $\mathrm{H}, 5.26 ; \mathrm{N}, 8.13$. Found: $\mathrm{C}, 64.67 ; \mathrm{H}, 5.84$; $\mathrm{N}, 7.71$. 


\subsubsection{Synthesis of $\left[\mathrm{PhP}(\mathrm{S})\left(\mathrm{CH}_{2} \mathrm{Py}\right)_{2}\right] \cdot \mathrm{HCl}(13)$}

$\mathrm{PhP}\left(\mathrm{CH}_{2} \mathrm{Py}\right)_{2}$ (1) $(0.35 \mathrm{~g}, 1.19 \mathrm{mmol})$ was dissolved in $15 \mathrm{~mL}$ toluene and a toluene solution $(10 \mathrm{~mL})$ of sulfur $(0.04 \mathrm{~g}, 1.19 \mathrm{mmol})$ was added dropwise at $-15^{\circ} \mathrm{C}$. The yellow reaction mixture was stirred for two days at room temperature. After filtration the volume of the solution was reduced and THF was added. Colorless<smiles>S=P(Cc1ccccn1)(Cc1ccccn1)c1ccccn1</smiles>
crystals of 13 were obtained at $-20^{\circ} \mathrm{C}$ after two weeks.

Yield: $0.07 \mathrm{~g}, 16 \% . \mathrm{M}=360.85 \mathrm{~g} / \mathrm{mol}$

${ }^{1} \mathrm{H}$ NMR (300.13 MHz, $\left.\mathrm{CD}_{2} \mathrm{Cl}_{2}\right): \quad \delta(\mathrm{ppm}) 11.23(\mathrm{br}, 1 \mathrm{H}, \mathrm{NH}), 8.44\left(\mathrm{~d},{ }^{3} \mathrm{~J}_{\mathrm{H}-\mathrm{H}}=4.9 \mathrm{~Hz}\right.$, $\left.2 \mathrm{H}, \mathrm{H}_{\mathrm{f}}\right), 8.05-7.97(\mathrm{~m}, 2 \mathrm{H}, m-\mathrm{Ph}), 7.79$ (ddd, ${ }^{3} \mathrm{~J}_{\mathrm{H}-}$ $\left.\mathrm{H}=7.8 \mathrm{~Hz},{ }^{3} \mathrm{~J}_{\mathrm{H}-\mathrm{H}}=7.8 \mathrm{~Hz},{ }^{4} J_{\mathrm{H}-\mathrm{H}}=1.3 \mathrm{~Hz}, 2 \mathrm{H}, \mathrm{H}_{\mathrm{d}}\right)$, 7.55-7.44 (m, 5H, o-Ph, $\left.p-\mathrm{Ph}, \mathrm{H}_{\mathrm{c}}\right), 7.36-7.32(\mathrm{~m}$, $\left.2 \mathrm{H}, \mathrm{H}_{\mathrm{e}}\right), 4.30\left(\mathrm{dd},{ }^{2} \mathrm{~J}_{\mathrm{H}-\mathrm{H}}=13.9 \mathrm{~Hz},{ }^{2} \mathrm{~J}_{\mathrm{P}-\mathrm{H}}=13.9 \mathrm{~Hz}\right.$, $\left.2 \mathrm{H}, \mathrm{H}_{\mathrm{a}}\right), 4.05\left(\mathrm{dd},{ }^{2} \mathrm{~J}_{\mathrm{H}-\mathrm{H}}=13.9 \mathrm{~Hz},{ }^{2} \mathrm{~J}_{\mathrm{P}-\mathrm{H}}=13.9 \mathrm{~Hz}\right.$, $\left.2 \mathrm{H}, \mathrm{H}_{\mathrm{a}}\right)$.

${ }^{13} \mathrm{C}$ NMR (75.48 MHz, $\left.\mathrm{CD}_{2} \mathrm{Cl}_{2}\right): \quad \delta(\mathrm{ppm}) 151.7\left(\mathrm{~d},{ }^{2} \mathrm{~J}_{\mathrm{C}-\mathrm{P}}=7.6 \mathrm{~Hz}, \mathrm{C}_{\mathrm{b}}\right), 146.5\left(\mathrm{~d},{ }^{4} \mathrm{~J}_{\mathrm{C}-\mathrm{P}}\right.$ $\left.=1.8 \mathrm{~Hz}, \mathrm{C}_{\mathrm{f}}\right), 139.3\left(\mathrm{~d},{ }^{4} J_{\mathrm{C}-\mathrm{P}}=2.3 \mathrm{~Hz}, \mathrm{C}_{\mathrm{d}}\right), 132.5(\mathrm{~d}$, $\left.{ }^{4} J_{C-P}=3.0 \mathrm{~Hz}, p-\mathrm{Ph}\right), 132.2\left(\mathrm{~d},{ }^{3} J_{\mathrm{C}-\mathrm{P}}=10.4 \mathrm{~Hz}, \mathrm{~m}-\right.$ $\mathrm{Ph}), 130.0\left(\mathrm{~d},{ }^{1} J_{\mathrm{C}-\mathrm{P}}=78.0 \mathrm{~Hz}, i-\mathrm{Ph}\right), 128.9\left(\mathrm{~d},{ }^{2} J_{\mathrm{C}-\mathrm{P}}=\right.$ $12.3 \mathrm{~Hz}, o-P h), 126.9\left(\mathrm{~d},{ }^{3} \mathrm{~J}_{\mathrm{C}-\mathrm{P}}=4.4 \mathrm{~Hz}, \mathrm{C}_{\mathrm{c}}\right.$ ), 123.4 $\left(d,{ }^{5} J_{C-P}=2.8 \mathrm{~Hz}, C_{e}\right), 41.9\left(d,{ }^{1} J_{C-P}=47.0 \mathrm{~Hz}, C_{a}\right)$.

${ }^{31}$ P NMR (121.50 MHz, $\left.\mathrm{CD}_{2} \mathrm{Cl}_{2}\right): \quad \delta(\mathrm{ppm}) 44.64(\mathrm{~s})$.

Anal. Calcd for $\mathrm{C}_{18} \mathrm{H}_{18} \mathrm{CIN}_{2} \mathrm{PS}: \quad$ C, 59.91; $\mathrm{H}, 5.03 ; \mathrm{N}, 7.76 ; \mathrm{S}, 8.89$. Found: $\mathrm{C}, 59.40$; $H, 5.07 ; N, 8.01 ; S, 8.63$. 


\subsubsection{Synthesis of $\left[\mathrm{PhP}(\mathrm{Se})\left(\mathrm{CH}_{2} \mathrm{Py}\right)_{2}\right] \cdot \mathrm{HCl}(14)$}

$\mathrm{PhP}\left(\mathrm{CH}_{2} \mathrm{Py}\right)_{2}$ (1) $(0.33 \mathrm{~g}, 1.13 \mathrm{mmol})$ was dissolved in $20 \mathrm{~mL}$ toluene and added dropwise to a toluene suspension $(10 \mathrm{~mL})$ of selenium $(0.09 \mathrm{~g}, 1.13 \mathrm{mmol})$ at $-15{ }^{\circ} \mathrm{C}$. The pale green reaction mixture was stirred for two days at room temperature. After filtration the volume of the solution was reduced. Colorless crystals

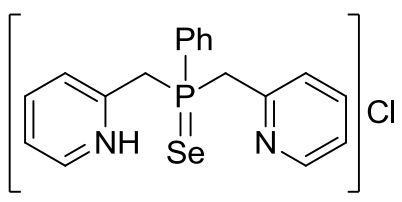
of 14 were obtained at room temperature after one day.

Yield: $0.09 \mathrm{~g}, 19 \% . \mathrm{M}=407.74 \mathrm{~g} / \mathrm{mol}$

${ }^{1} \mathrm{H}$ NMR (300.13 MHz, $\left.\mathrm{CD}_{2} \mathrm{Cl}_{2}\right): \quad \delta(\mathrm{ppm}) 13.89(\mathrm{br}, 1 \mathrm{H}, \mathrm{NH}), 8.45\left(\mathrm{~d},{ }^{3} \mathrm{~J}_{\mathrm{H}-\mathrm{H}}=4.4 \mathrm{~Hz}\right.$, $\left.2 \mathrm{H}, \mathrm{H}_{\mathrm{f}}\right), 8.15-8.08(\mathrm{~m}, 2 \mathrm{H}, m-\mathrm{Ph}), 7.85\left(\mathrm{dd},{ }^{3} \mathrm{~J}_{\mathrm{H}-}\right.$ $\left.\mathrm{H}=4.1 \mathrm{~Hz},{ }^{3} \mathrm{~J}_{\mathrm{H}-\mathrm{H}}=4.1 \mathrm{~Hz}, 2 \mathrm{H}, \mathrm{H}_{\mathrm{d}}\right), 7.56-7.47(\mathrm{~m}$, $\left.5 \mathrm{H}, o-\mathrm{Ph}, p-\mathrm{Ph}, \mathrm{H}_{\mathrm{c}}\right), 7.39-7.32\left(\mathrm{~m}, 2 \mathrm{H}, \mathrm{H}_{\mathrm{e}}\right), 4.59$ $\left(\mathrm{dd},{ }^{2} J_{\mathrm{H}-\mathrm{H}}=14.0 \mathrm{~Hz},{ }^{2} J_{\mathrm{P}-\mathrm{H}}=14.0 \mathrm{~Hz}, 2 \mathrm{H}, \mathrm{H}_{\mathrm{a}}\right), 4.25$ (dd, ${ }^{2} J_{\mathrm{H}-\mathrm{H}}=14.0 \mathrm{~Hz},{ }^{2} \mathrm{~J}_{\mathrm{P}-\mathrm{H}}=14.0 \mathrm{~Hz}, 2 \mathrm{H}, \mathrm{H}_{\mathrm{a}}$ ).

${ }^{13} \mathrm{C}$ NMR (75.48 MHz, $\left.\mathrm{CD}_{2} \mathrm{Cl}_{2}\right): \quad \delta(\mathrm{ppm}) 151.2\left(\mathrm{~d},{ }^{2} \mathrm{~J}_{\mathrm{C}-\mathrm{P}}=7.2 \mathrm{~Hz}, \mathrm{C}_{\mathrm{b}}\right), 145.8\left(\mathrm{~d},{ }^{4} \mathrm{~J}_{\mathrm{C}-\mathrm{p}}\right.$ $\left.=1.5 \mathrm{~Hz}, \mathrm{C}_{\mathrm{f}}\right), 140.0\left(\mathrm{~d},{ }^{4} J_{\mathrm{C}-\mathrm{P}}=2.4 \mathrm{~Hz}, \mathrm{C}_{\mathrm{d}}\right), 133.0(\mathrm{~d}$, $\left.{ }^{3} J_{C-P}=10.6 \mathrm{~Hz}, m-\mathrm{Ph}\right), 132.7\left(\mathrm{~d},{ }^{4} J_{\mathrm{C}-\mathrm{P}}=3.2 \mathrm{~Hz}, p-\right.$ $\mathrm{Ph}), 129.0\left(\mathrm{~d},{ }^{2} J_{\mathrm{C}-\mathrm{P}}=12.3 \mathrm{~Hz}, \mathrm{o}-\mathrm{Ph}\right), 128.1\left(\mathrm{~d},{ }^{1} \mathrm{~J}_{\mathrm{C}-\mathrm{P}}=\right.$ $69.0 \mathrm{~Hz}, i-\mathrm{Ph}), 127.2\left(\mathrm{~d},{ }^{3} J_{\mathrm{C}-\mathrm{P}}=4.3 \mathrm{~Hz}, \mathrm{C}_{\mathrm{c}}\right.$ ), 123.8 (d, $\left.{ }^{5} J_{C-P}=2.9 \mathrm{~Hz}, C_{e}\right), 40.9\left(d,{ }^{1} J_{C-P}=39.0 \mathrm{~Hz}, C_{a}\right)$.

${ }^{31} \mathrm{P}$ NMR (121.50 MHz, $\left.\mathrm{CD}_{2} \mathrm{Cl}_{2}\right): \quad \delta(\mathrm{ppm}) 36.80$ (s, satellites $\left.{ }^{1} \mathrm{~J}_{\mathrm{P}-\mathrm{Se}}=756 \mathrm{~Hz}\right)$.

${ }^{15} \mathrm{~N}$ NMR (30.42 MHz, $\left.\mathrm{CD}_{2} \mathrm{Cl}_{2}\right): \quad \delta(\mathrm{ppm})-108.1(\mathrm{Py}-\mathrm{N})$.

Anal. Calcd for $\mathrm{C}_{18} \mathrm{H}_{18} \mathrm{ClN}_{2}$ PSe: $\quad$ C, 53.02; $\mathrm{H}, 4.45 ; \mathrm{N}, 6.87$. Found: $\mathrm{C}, 51.95 ; \mathrm{H}, 4.61$; N, 6.79 . 


\subsubsection{Synthesis of $\left[(T H F)_{4} \mathrm{Li}_{2}\{\mathrm{C}(\mathrm{H}) \mathrm{Py}\}_{2} \mathrm{P}(\mathrm{O}) \mathrm{Ph}\right](17)$}

A $1.9 \mathrm{M} n$ BuLi solution in nhexane $(4.05 \mathrm{~mL}, 7.52 \mathrm{mmol})$ was added dropwise to a solution of $\mathrm{PhP}\left(\mathrm{CH}_{2} \mathrm{Py}\right)_{2}$ (1) $(1.00 \mathrm{~g}, 3.42 \mathrm{mmol})$ in THF $(10 \mathrm{~mL})$ at $-20^{\circ} \mathrm{C}$ and stirred for one day at room temperature. The volume of the deep red solution was reduced, layered with nhexane and stored for one week at $-20^{\circ} \mathrm{C}$. Exposure to air results in the formation of the lithium complex 17 as yellow crystals.

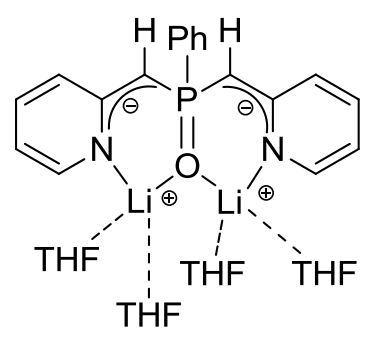

Yield: $0.8 \mathrm{~g}, 38 \% . \mathrm{M}=608.62 \mathrm{~g} / \mathrm{mol}$

${ }^{1}$ H NMR (500.13 MHz, THF-d 8 ): $\quad \delta(p p m) 7.98(\mathrm{br}, 2 \mathrm{H}, \mathrm{Ph}), 7.17\left(\mathrm{br}, 2 \mathrm{H}, \mathrm{H}_{\mathrm{f}}\right), 7.06$ (br, 3H, Ph), $6.44\left(\mathrm{br}, 2 \mathrm{H}, \mathrm{H}_{\mathrm{d}}\right), 5.97\left(\mathrm{br}, 2 \mathrm{H}, \mathrm{H}_{\mathrm{c}}\right)$, $5.38\left(\mathrm{br}, 2 \mathrm{H}, \mathrm{H}_{\mathrm{e}}\right), 3.64-3.61(\mathrm{~m}, 8 \mathrm{H}, \mathrm{THF}), 3.10-$ $3.06\left(m, 2 H, H_{a}\right), 1.79-1.76(m, 8 H, T H F)$.

${ }^{13} \mathrm{C}$ NMR (125.77 MHz, THF-d $\left.\mathrm{d}_{8}\right): \quad \delta(\mathrm{ppm}) 167.0\left(\mathrm{~s}, \mathrm{C}_{\mathrm{b}}\right), 147.5\left(\mathrm{~s}, \mathrm{C}_{\mathrm{f}}\right), 133.0\left(\mathrm{~s}, \mathrm{C}_{\mathrm{d}}\right)$, 130.8 (s, Ph), 127.9-127.3 (m, Ph), $118.1\left(\mathrm{~s}, \mathrm{C}_{\mathrm{c}}\right)$, $102.3\left(\mathrm{~s}, \mathrm{C}_{\mathrm{e}}\right), 68.2(\mathrm{~s}, \mathrm{THF}), 64.5-63.4\left(\mathrm{~m}, \mathrm{C}_{\mathrm{a}}\right), 26.4$ (s, THF).

${ }^{7}$ Li NMR (194.37 MHz, THF-d d : $\quad \delta(p p m) 0.50$ (s).

${ }^{31}$ P NMR (202.46 MHz, THF-d $\left.d_{8}\right): \quad \delta(p p m) 33.64(\mathrm{~s})$.

Anal. Calcd for $\mathrm{C}_{37} \mathrm{H}_{47} \mathrm{Li}_{2} \mathrm{~N}_{2} \mathrm{O}_{5} \mathrm{P}: \quad \mathrm{C}, 67.10 ; \mathrm{H}, 7.78 ; \mathrm{N}, 4.60$. Found: $\mathrm{C}, 63.42 ; \mathrm{H}, 6.46$; N, 5.87 . 


\subsubsection{3 $\left[\mathrm{PhP}\left(\mathrm{CH}_{2} \mathrm{Py}\right)_{2}\right] \mathrm{H}_{2} \mathrm{O}\left[\mathrm{B}\left(\mathrm{C}_{6} \mathrm{~F}_{5}\right)_{3}\right](18)$}

$\mathrm{PhP}\left(\mathrm{CH}_{2} \mathrm{Py}\right)_{2}(1)(0.51 \mathrm{~g}, 1.00 \mathrm{mmol})$ and $\mathrm{B}\left(\mathrm{C}_{6} \mathrm{~F}_{5}\right)_{3}(0.30 \mathrm{~g}$, $1.00 \mathrm{mmol})$ were dissolved in DCM $(8 \mathrm{~mL})$ and stirred over night at room temperature. Afterwards the solvent was removed in vacuum. The resulting white product was resolved in toluene and stored at $-20^{\circ} \mathrm{C}$. After one day colorless crystals of $\mathbf{1 8}$ were obtained.

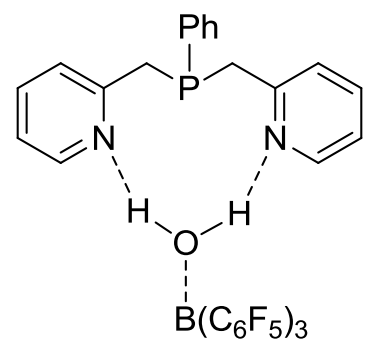

Yield: $0.38 \mathrm{~g}, 46 \% . \mathrm{M}=822.32 \mathrm{~g} / \mathrm{mol}$ 



\section{Crystallographic Section}

\subsection{Crystal Application}

The crystals were taken from the mother liquor using standard Schlenk techniques and placed in perfluorinated polyether oil on a microscope slide. An appropriately sized crystal of high quality was selected under a polarization microscope (for detection of twinning and the presence of satellites) with help of the X-TEMP2 cooling device. ${ }^{[81]}$ It was mounted on a glass fiber glued to the magnetic pin of the goniometer head in a way that it was completely coated with the perfluorinated polyether oil. ${ }^{\left[{ }^{82]}\right.}$ Oil and crystal were shocked-cooled in the cold gas stream of an open flow nitrogen cooling device attached to the diffractometer. The amorphous frozen oil served as glue and protected the sensitive compounds along with the nitrogen gas stream from moisture and oxygen.

\subsection{Data Collection and Processing}

All compounds were measured on a Bruker D8 Goniometer platform, equipped with an APEX // CCD X-ray detector. The compounds were measured using either an Incoatec microfocus source with mirror optics ${ }^{[83]}$ or on a rotating anode turbo X-ray source. Both are equipped with an APEX // CCD detector, mounted on a three-circle $D 8$ goniometer, and mirrors as monochromator optics, which supplies very intense and brilliant MoK $_{\alpha}$ radiation $(\lambda=0.71073 \AA$ ). All crystals were centered optically using a video camera after being placed on the diffractometer.

Data collection was controlled with the APEX2 package. ${ }^{[84]}$ A test run (matrix scan) was recorded prior to each experiment to check the crystal quality, to get a rough estimate of the cell parameters, and to determine the optimum exposure time. All scans of the data collections were performed in an $\omega$-scan mode with a step-width of $0.3^{\circ}$ or $0.5^{\circ}$ at fixed $\varphi$-angles.

The determination of the unit cells and orientation matrices were performed with the tools supplied in the APEX2 package. ${ }^{\left[{ }^{84]}\right.}$ The collected frames were integrated with SAINT ${ }^{[85]}$ using the $3 d$ profiling method described by Kabsch. ${ }^{[86]}$ All data sets were 
corrected for absorption and scaled using SADABS ${ }^{[87]}$ or TWINABS. ${ }^{[88]} X$ PREP ${ }^{[89]}$ was used to determine the space group prior to the absorption correction, as this is crucial for a correct treatment. SADABS and TWINABS refine an empirical model function by symmetry-equivalent reflections. Setup of the files for structure solution and refinement was performed with XPREP.

\subsection{Structure Solution and Refinement}

The structures were solved with direct methods or Patterson superposition procedure using SHELXS. ${ }^{[90]}$ Data were merged according to the determined symmetry with SHELXL. ${ }^{\left[{ }^{90]}\right.}$ All refinements were performed on $F^{2}$ with SHELXL. If not stated otherwise, the hydrogen atoms of the compounds were refined isotropically on calculated positions using a riding model. The positions were geometrically optimized and the $U_{\text {iso }}$ were constrained to $1.2 U_{\text {eq }}$ of the pivot atom or $1.5 U_{\text {eq }}$ of the methyl carbon atom. The position of certain hydrogen atoms (e.g. $\mathrm{OH}$ groups) were found with difference Fourier analysis of the rest electron density. If not stated otherwise, the hydrogen bond lengths were restrained to a sensible value and the $U_{\text {iso }}$ were constrained as mentioned above. In all refinements the function $M\left(p_{i}, k\right)$ (Eq. 7-1) was minimized using the weights $w_{H}$ defined in Eq. 7-2.

Eq. 7-1.

$$
M\left(p_{i}, k\right)=\sum_{H} w_{H}\left[k\left|F_{\text {obs }}(H)\right|^{2}-\left|F_{\text {calc }}(H)\right|^{2}\right]^{2}=\min
$$

Eq. 7-2.

$$
W_{\mathrm{H}}^{-1}=\sigma_{H}^{2} F_{\mathrm{obs}}^{2}+(g 1 \cdot P)^{2}+g 2 \cdot P \quad \text { with } \quad P=\left(\frac{F_{\mathrm{obs}}^{2}+2 F_{\mathrm{calc}}^{2}}{3}\right)
$$

The results of the refinements were verified by comparison of the calculated and the observed structure factors. Commonly used criteria are the residuals $R 1$ (Eq. 7-3) and $w R 2$ (Eq. 7-4). The $W R 2$ is more significant, because the model is refined against $F^{2}$.

$\begin{array}{ll}\text { Eq. 7-3. } & R 1=\frac{\sum_{H} w_{H}\left(\left|F_{\mathrm{obs}}\right|-\left|F_{\mathrm{calc}}\right|\right)}{\sum_{H} w_{H}\left|F_{\mathrm{obs}}\right|} \\ \text { Eq. 7-4. } & w R 2=\frac{\sum_{H} w_{H}\left(\left|F_{\mathrm{obs}}\right|^{2}-\left|F_{\mathrm{calc}}\right|^{2}\right)^{2}}{\sum_{H} w_{H}\left|F_{\mathrm{obs}}\right|^{4}}\end{array}$ 
Additionally, the goodness of fit (GoF, S), a figure or merit showing the relation between deviation of $F_{\text {calc }}$ from $F_{\text {obs }}$ and the over-determination of refined parameters is calculated (Eq. 7-5).

$$
\text { Eq. 7-5. } \quad S=\sqrt{\frac{\sum\left(w_{H}\left(F_{\mathrm{obs}}^{2}-F_{\mathrm{calc}}^{2}\right)^{2}\right)}{(n-p)}}
$$

The residual densities from difference Fourier analysis should be low. Due to the model restrictions the residuals are normally found in the bonding regions. Higher residuals for heavy scatterers are acceptable as they arise mainly from absorption effects and Fourier truncation errors due to the limited recorded resolution range. The highest peak and deepest hole from difference Fourier analysis are listed in the crystallographic tables.

Additionally, the orientation, size and ellipticity of the ADPs show the quality of the model. Ideally, the ADPs should be oriented perpendicular to the bonds, be equal in size and show little ellipticity. All graphics were generated and plotted with the XShell program at the $50 \%$ probability level.

\subsection{Treatment of Disorder}

Structures containing disordered fragments were refined using constraints and restraints. The geometries of chemically equivalent but crystallographically independent fragments can be fitted to each other by distance restraints. Especially the 1,2 distances (bond lengths) and 1,3 distances (bond angles) are set to be equal within their effective standard deviations. This is helpful for refining disordered positions as the averaging of equivalent fragments implements chemical information and stabilizes the refinement.

Restraints affecting the anisotropic displacement parameters are often essential for the anisotropic refinement of disordered atomic positions. The rigid bond restraints (DELU in SHELXL) ${ }^{[91]}$ fit the components of the anisotropic displacement parameters along the bonds within esd's. Similarity restraints (SIMU in SHELXL) ${ }^{[91]}$ adjust the ADPs of neighboring atoms within a certain radius to be equal according to their esd's. 


\subsection{Crystallographic Details}

\subsubsection{Di-2-picolylphenylphosphane (1)}

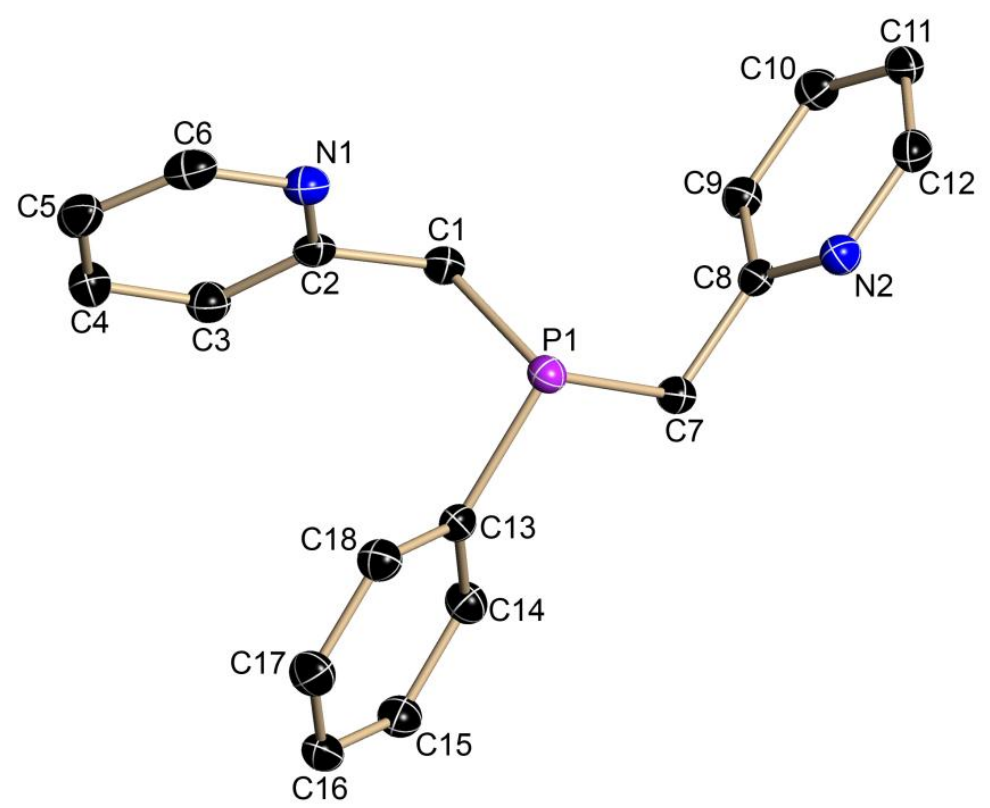

Figure 7-1. Asymmetric unit of di-2-picolylphenylphosphane (1). The anisotropic displacement parameters are depicted at the $50 \%$ probability level. The hydrogen atoms are omitted for clarity.

Table 7-1. Crystallographic data for di-2-picolylphenylphosphane (1).

\begin{tabular}{ll|ll}
\hline CCDC no. & 779983 & & \\
Empirical formula & $\mathrm{C}_{18} \mathrm{H}_{17} \mathrm{~N}_{2} \mathrm{P}$ & $\mu\left[\mathrm{mm}^{-1}\right]$ & 0.179 \\
Formula weight $[\mathrm{g} / \mathrm{mol}]$ & 292.31 & $\mathrm{~F}(000)$ & 616 \\
Temperature $[\mathrm{K}]$ & $100(2)$ & $\Theta$ range $\left[^{\circ}\right]$ & 2.32 to 26.37 \\
Wavelength $[\mathrm{pm}]$ & 71.073 & Reflections collected & 36407 \\
Crystal system & Monoclinic & Independent reflections & 3032 \\
Space group & $P 2_{1} / c$ & Completeness to $\Theta_{\text {max }}$ & $99.9 \%$ \\
$a[\mathrm{pm}]$ & $1610.84(12)$ & Absorption correction & Empirical \\
$b[\mathrm{pm}]$ & $553.16(4)$ & Max. / min. transmission & $0.7454 / 0.6974$ \\
$c[\mathrm{pm}]$ & $1794.25(14)$ & Restraints / parameters & $0 / 190$ \\
$\beta\left[^{\circ}\right]$ & $111.4860(10)$ & GoF & 1.056 \\
Volume $\left[\mathrm{nm}^{3}\right]$ & $1.48767(19)$ & $R 1 / w R 2(\mathrm{I}>2 \sigma(\mathrm{I}))$ & $0.0293 / 0.0722$ \\
$\mathrm{Z}$ & 4 & $R 1 / w R 2$ (all data) & $0.0338 / 0.0743$ \\
$\rho_{\text {calc }}\left[\mathrm{Mg} / \mathrm{m}^{3}\right]$ & 1.305 & Diff. peak and hole $\left[\mathrm{e} \AA^{-3}\right]$ & 0.294 and -0.268 \\
\hline
\end{tabular}




\subsection{2 $\quad\left[\mathrm{PhP}\left(\mathrm{CH}_{2} \mathrm{Py}\right)_{2} \mathrm{LiCl}\right]_{2}(2)$}

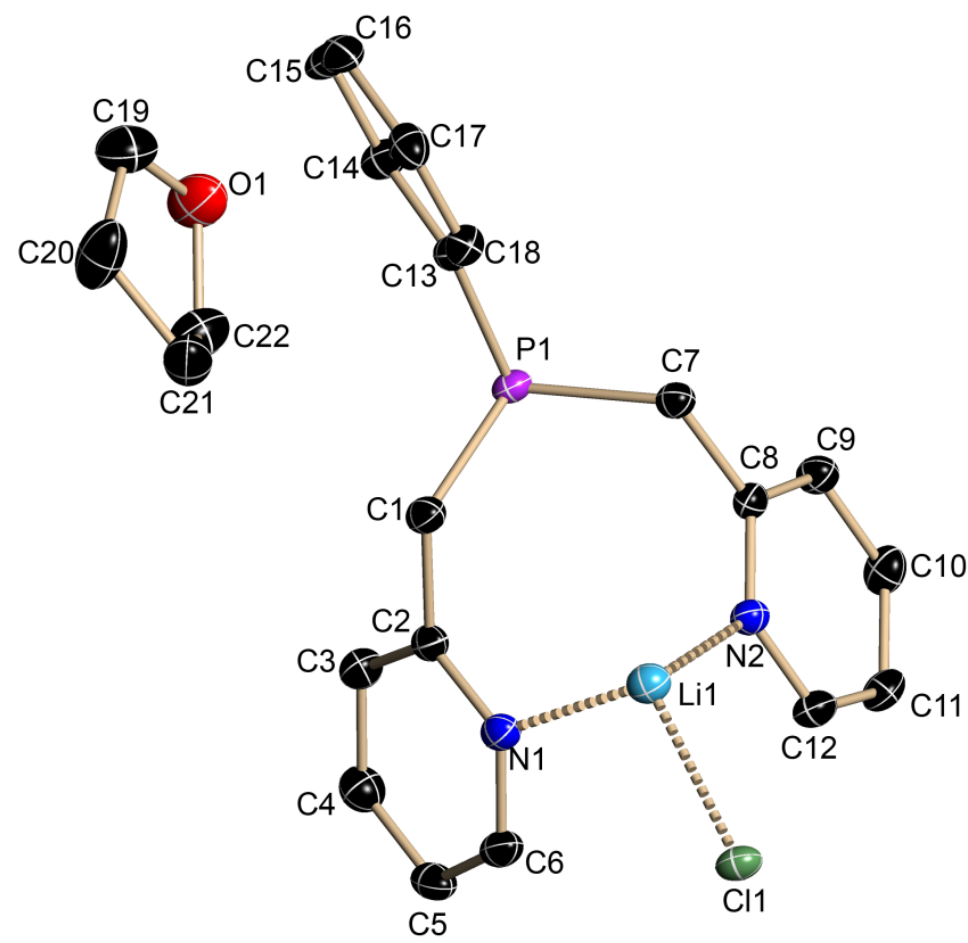

Figure 7-2. Asymmetric unit of $\left[\mathrm{PhP}\left(\mathrm{CH}_{2} \mathrm{Py}\right)_{2} \mathrm{LiCl}\right]_{2}$ (2). The anisotropic displacement parameters are depicted at the $50 \%$ probability level. The hydrogen atoms are omitted for clarity.

Table 7-2. Crystallographic data for $\left[\mathrm{PhP}\left(\mathrm{CH}_{2} \mathrm{Py}\right)_{2} \mathrm{LiCl}\right]_{2}(2)$.

\begin{tabular}{|c|c|c|c|}
\hline Identification code & 10144 & & \\
\hline Empirical formula & $\mathrm{C}_{44} \mathrm{H}_{50} \mathrm{Cl}_{2} \mathrm{Li}_{2} \mathrm{~N}_{4} \mathrm{O}_{2} \mathrm{P}_{2}$ & $\mu\left[\mathrm{mm}^{-1}\right]$ & 0.273 \\
\hline Formula weight $[\mathrm{g} / \mathrm{mol}]$ & 813.60 & $F(000)$ & 856 \\
\hline Temperature $[\mathrm{K}]$ & $100(2)$ & $\Theta$ range $\left[{ }^{\circ}\right]$ & 1.52 to 25.35 \\
\hline Wavelength [pm] & 71.073 & Reflections collected & 49528 \\
\hline Crystal system & Monoclinic & Independent reflections & 3842 \\
\hline Space group & $P 2_{1} / c$ & Completeness to $\Theta_{\max }$ & $100.0 \%$ \\
\hline$a[\mathrm{pm}]$ & $1340.8(2)$ & Absorption correction & Semi-empirical \\
\hline$b[\mathrm{pm}]$ & $966.7(2)$ & Max. / min. transmission & $1.0000 / 0.9690$ \\
\hline$c[\mathrm{pm}]$ & $1619.0(3)$ & Restraints / parameters & $0 / 253$ \\
\hline$\beta\left[^{\circ}\right]$ & $93.48(2)$ & GoF & 1.057 \\
\hline Volume $\left[\mathrm{nm}^{3}\right]$ & $2.0946(7)$ & $R 1 / w R 2(I>2 \sigma(I))$ & $0.0303 / 0.0748$ \\
\hline Z & 2 & $R 1 / w R 2$ (all data) & $0.0359 / 0.0785$ \\
\hline$\rho_{\text {calc }}\left[\mathrm{Mg} / \mathrm{m}^{3}\right]$ & 1.290 & Diff. peak and hole $\left[\mathrm{e} \AA^{-3}\right]$ & 0.303 and -0.253 \\
\hline
\end{tabular}




\subsection{3 $\left[\left(\mathrm{Et}_{2} \mathrm{O}\right)_{3} \mathrm{Li}_{2}\{\mathrm{C}(\mathrm{H}) \mathrm{Py}\}_{2} \mathrm{PPh}\right]_{2}(4)$}

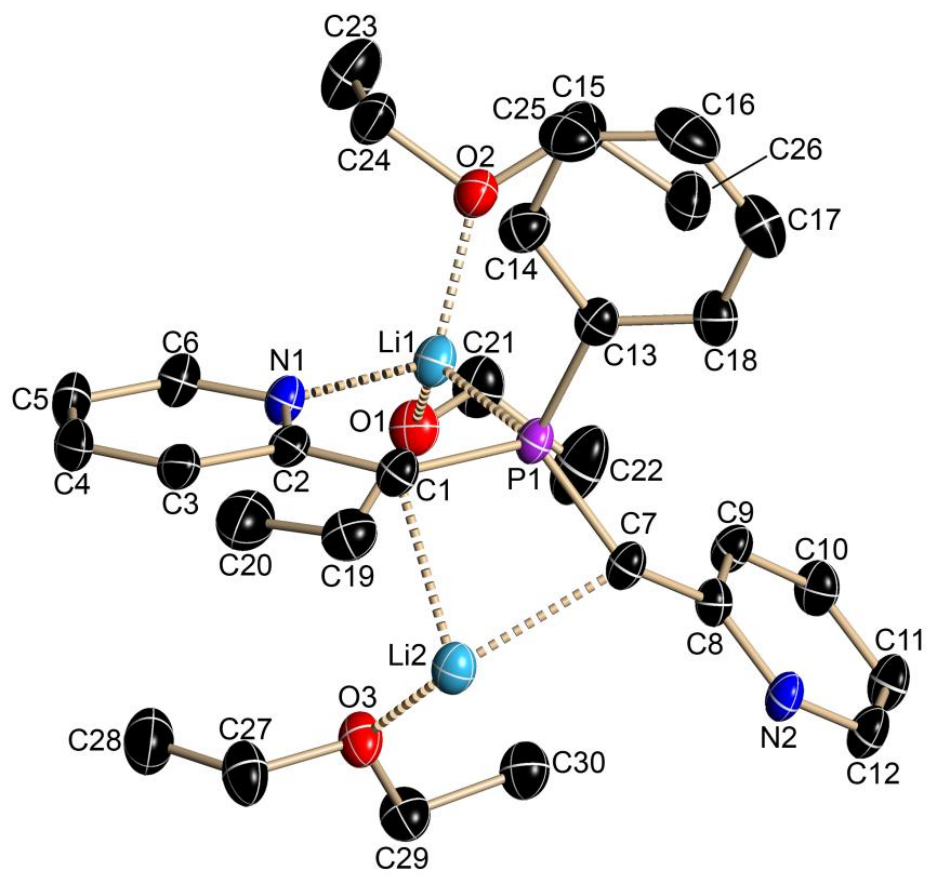

Figure 7-3. Asymmetric unit of $\left[\left(\mathrm{Et}_{2} \mathrm{O}\right)_{3} \mathrm{Li}_{2}\{\mathrm{C}(\mathrm{H}) \mathrm{Py}\}_{2} \mathrm{PPh}\right]_{2}(4)$. The anisotropic displacement parameters are depicted at the $50 \%$ probability level. The hydrogen atoms are omitted for clarity.

The positions of the hydrogen atoms bonded to $\mathrm{C} 1$ and $\mathrm{C} 7$ were taken from the difference map and refined with distance restraints.

Table 7-3. Crystallographic data for $\left[\left(\mathrm{Et}_{2} \mathrm{O}\right)_{3} \mathrm{Li}_{2}\{\mathrm{C}(\mathrm{H}) \mathrm{Py}\}_{2} \mathrm{PPh}\right]_{2}$ (4).

\begin{tabular}{|c|c|c|c|}
\hline CCDC no. & 779984 & & \\
\hline Empirical formula & $\mathrm{C}_{60} \mathrm{H}_{90} \mathrm{Li}_{4} \mathrm{~N}_{4} \mathrm{O}_{6} \mathrm{P}_{2}$ & $\rho_{\text {calc }}\left[\mathrm{Mg} / \mathrm{m}^{3}\right]$ & 1.124 \\
\hline Formula weight $[\mathrm{g} / \mathrm{mol}]$ & 1053.06 & $\mu\left[\mathrm{mm}^{-1}\right]$ & 0.119 \\
\hline Temperature $[\mathrm{K}]$ & $99(2)$ & $F(000)$ & 568 \\
\hline Wavelength [pm] & 71.073 & $\Theta$ range $\left[{ }^{\circ}\right]$ & 1.53 to 25.41 \\
\hline Crystal system & Triclinic & Reflections collected & 38224 \\
\hline Space group & $P \overline{1}$ & Independent reflections & 5706 \\
\hline$a[\mathrm{pm}]$ & $1007.15(10)$ & Completeness to $\Theta_{\max }$ & $99.7 \%$ \\
\hline$b[\mathrm{pm}]$ & $1225.96(12)$ & Absorption correction & Empirical \\
\hline$c[\mathrm{pm}]$ & $1379.79(13)$ & Max. / min. transmission & 0.7452 / 0.6459 \\
\hline$\alpha\left[^{\circ}\right]$ & $75.036(3)$ & Restraints / parameters & $3 / 355$ \\
\hline$\beta\left[^{\circ}\right]$ & $81.385(3)$ & GoF & 1.056 \\
\hline$\nu\left[^{\circ}\right]$ & $71.331(3)$ & $R 1 / w R 2(I>2 \sigma(I))$ & $0.0515 / 0.1335$ \\
\hline Volume $\left[\mathrm{nm}^{3}\right]$ & $1.5551(3)$ & $R 1$ / wR2 (all data) & $0.0712 / 0.1474$ \\
\hline Z & 1 & Diff. peak and hole $\left[\mathrm{e} \AA^{-3}\right]$ & 0.599 and -0.430 \\
\hline
\end{tabular}




\subsection{4 $\left[\left\{\left(\mathrm{Me}_{3} \mathrm{Si}\right)_{2} \mathrm{NSn}\right\}_{2}\{\mathrm{C}(\mathrm{H}) \mathrm{Py}\}_{2} \mathrm{PPh}\right](5)$}

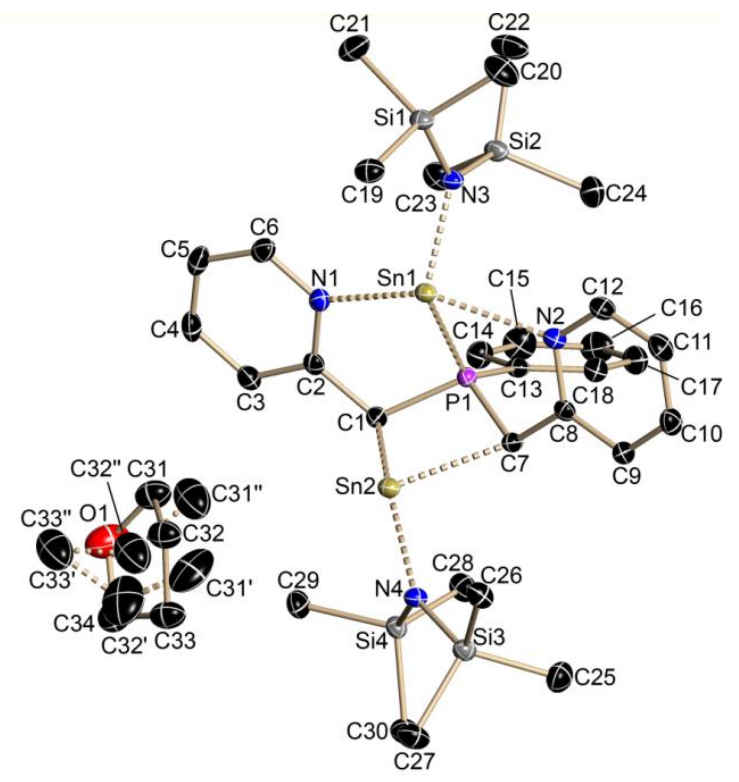

Figure 7-4. Asymmetric unit of $\left[\left\{\left(\mathrm{Me}_{3} \mathrm{Si}\right)_{2} \mathrm{NSn}\right\}_{2}\{\mathrm{C}(\mathrm{H}) \mathrm{Py}\}_{2} \mathrm{PPh}\right](5)$. The anisotropic displacement parameters are depicted at the $50 \%$ probability level. The hydrogen atoms are omitted for clarity.

The positions of the hydrogen atoms bonded to $\mathrm{C} 1$ and $\mathrm{C} 7$ were taken from the difference map and refined with distance restraints. Additionally, one noncoordinating THF molecule together with a hexane molecule is disordered on a special lattice position (inversion center) in a ratio of $0.80: 0.16: 0.04$.

Table 7-4. Crystallographic data for $\left.\left[\left(\mathrm{Me}_{3} \mathrm{Si}\right)_{2} \mathrm{NSn}\right\}_{2}\{\mathrm{C}(\mathrm{H}) \mathrm{Py}\}_{2} \mathrm{PPh}\right](\mathbf{5})$.

\begin{tabular}{ll|ll}
\hline CCDC no. & 779985 & & \\
Empirical formula & $\mathrm{C}_{33.8} \mathrm{H}_{58.8} \mathrm{~N}_{4} \mathrm{O}_{0.8} \mathrm{PSi}_{4} \mathrm{Sn}_{2}$ & $\rho_{\text {calc }}\left[\mathrm{Mg} / \mathrm{m}^{3}\right]$ & 1.436 \\
Formula weight $[\mathrm{g} / \mathrm{mol}]$ & 914.90 & $\mu\left[\mathrm{mm}^{-1}\right]$ & 1.362 \\
Temperature $[\mathrm{K}]$ & $100(2)$ & $\mathrm{F}(000)$ & 934 \\
Wavelength $[\mathrm{pm}]$ & 71.073 & $\Theta$ range $\left[^{\circ}\right]$ & 1.61 to 27.10 \\
Crystal system & Triclinic & Reflections collected & 46392 \\
Space group & $P \overline{1}$ & Independent reflections & 9329 \\
$a[\mathrm{pm}]$ & $1025.30(13)$ & Completeness to $\Theta_{\text {max }}$ & $99.9 \%$ \\
$b[\mathrm{pm}]$ & $1456.30(19)$ & Absorption correction & Empirical \\
$c[\mathrm{pm}]$ & $1654.7(3)$ & Max. / min. transmission & $0.4305 / 0.3881$ \\
$\alpha\left[^{\circ}\right]$ & $111.731(3)$ & Restraints / parameters & $46 / 471$ \\
$\beta\left[^{\circ}\right]$ & $97.660(3)$ & GoF & 1.028 \\
$\gamma\left[^{\circ}\right]$ & $106.814(2)$ & $R 1 / w R 2$ (I>2 $\sigma(\mathrm{I}))$ & $0.0192 / 0.0409$ \\
$\left.V^{\circ}\right)$ & $R 1 / w R 2$ (all data) & $0.0251 / 0.0430$ \\
$\mathrm{Z}$ & $2.1152(6)$ & Diff. peak and hole [e $\left.\AA^{-3}\right]$ & 0.395 and -0.293 \\
\hline
\end{tabular}




\subsection{5 [(PMDETA)Li\{C(H)Py\}P(CH $\left.\left.\mathrm{CH}_{2} \mathrm{Py}\right) \mathrm{Ph}\right](7)$}

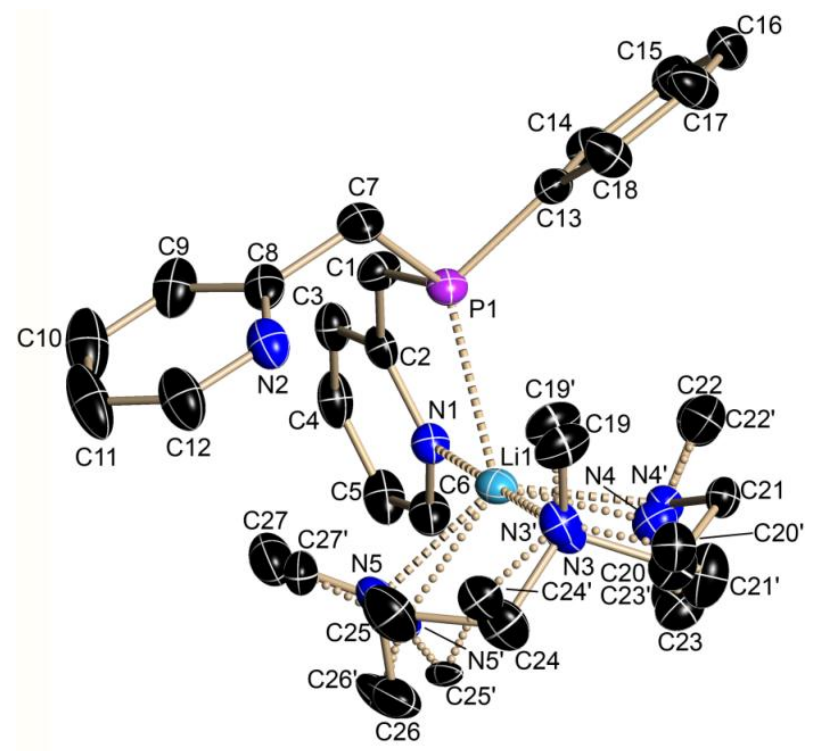

Figure 7-5. Asymmetric unit of [(PMDETA)Li $\left.\{\mathrm{C}(\mathrm{H}) \mathrm{Py}\} \mathrm{P}\left(\mathrm{CH}_{2} \mathrm{Py}\right) \mathrm{Ph}\right](\mathbf{7})$. The anisotropic displacement parameters are depicted at the $50 \%$ probability level. The hydrogen atoms are omitted for clarity.

The whole coordinating PMDETA molecule is disordered in a ratio of $0.76: 0.24$.

Table 7-5. Crystallographic data for [(PMDETA)Li\{C(H)Py\}P(CH $\left.\left.\mathrm{CH}_{2} \mathrm{Py}\right) \mathrm{Ph}\right](\mathbf{7})$.

\begin{tabular}{ll|ll}
\hline Identification code & $\mathrm{IO} 115$ & Abs. structure parameter & $0.06(7)$ \\
Empirical formula & $\mathrm{C}_{27} \mathrm{H}_{39} \mathrm{LiN}_{5} \mathrm{P}$ & $\mu\left[\mathrm{mm}^{-1}\right]$ & 0.123 \\
Formula weight $[\mathrm{g} / \mathrm{mol}]$ & 471.54 & $\mathrm{~F}(000)$ & 1016 \\
Temperature $[\mathrm{K}]$ & $100(2)$ & $\Theta$ range $\left[^{\circ}\right]$ & 1.94 to 26.47 \\
Wavelength $[\mathrm{pm}]$ & 71.073 & Reflections collected & 16390 \\
Crystal system & Monoclinic & Independent reflections & 5664 \\
Space group & $C c$ & Completeness to $\Theta_{\text {max }}$ & $99.9 \%$ \\
$a[\mathrm{pm}]$ & $954.4(3)$ & Absorption correction & Empirical \\
$b[\mathrm{pm}]$ & $2101.5(7)$ & Max. / min. transmission & $1.0000 / 0.8906$ \\
$c[\mathrm{pm}]$ & $1389.4(5)$ & Restraints / parameters & $495 / 421$ \\
$\beta\left[^{\circ}\right]$ & $98.85(2)$ & GoF & 1.034 \\
Volume $\left[\mathrm{nm}^{3}\right]$ & $2.7535(16)$ & $R 1 / w R 2(\mathrm{I}>2 \sigma(\mathrm{I}))$ & $0.0358 / 0.0830$ \\
$\mathrm{Z}$ & 4 & $R 1 / w R 2$ (all data) & $0.0415 / 0.0859$ \\
$\rho_{\text {calc }}\left[\mathrm{Mg} / \mathrm{m}^{3}\right]$ & 1.137 & Diff. peak and hole $\left[\mathrm{e} \AA^{-3}\right]$ & 0.190 and -0.179 \\
\hline
\end{tabular}




\subsection{6 $\quad\left[\left(\mathrm{PyCH}_{2}\right) \mathrm{PhP}\{\mathrm{C}(\mathrm{H}) \mathrm{Py}\} \mathrm{Na}\left(\mathrm{Et}_{2} \mathrm{O}\right)\right]_{2}(8)$}

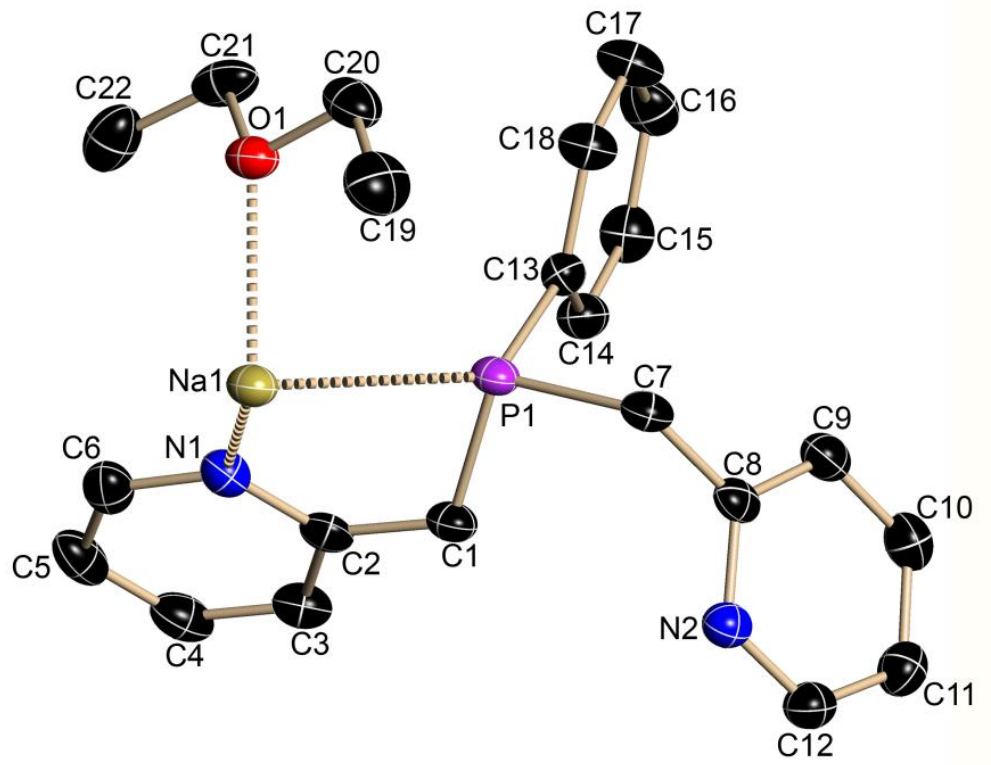

Figure 7-6. Asymmetric unit of $\left.\left[\left(\mathrm{PyCH}_{2}\right) \mathrm{PhP}\{\mathrm{C}(\mathrm{H}) \mathrm{Py}\} \mathrm{Na}_{(\mathrm{Et}} \mathrm{O}\right)\right]_{2}(\mathbf{8})$. The anisotropic displacement parameters are depicted at the $50 \%$ probability level. The hydrogen atoms are omitted for clarity.

The positions of the hydrogen atoms bonded to $\mathrm{C} 1$ and $\mathrm{C} 7$ were taken from the difference map and refined freely.

Table 7-6. Crystallographic data for $\left[\left(\mathrm{PyCH}_{2}\right) \mathrm{PhP}\{\mathrm{C}(\mathrm{H}) \mathrm{Py}\} \mathrm{Na}\left(\mathrm{Et}_{2} \mathrm{O}\right)\right]_{2}(\mathbf{8})$.

\begin{tabular}{ll|ll}
\hline Identification code & IOFE7 & & \\
Empirical formula & $\mathrm{C}_{44} \mathrm{H}_{52} \mathrm{~N}_{4} \mathrm{Na}_{2} \mathrm{O}_{2} \mathrm{P}_{2}$ & $\rho_{\text {calc }}\left[\mathrm{Mg} / \mathrm{m}^{3}\right]$ & 1.247 \\
Formula weight $[\mathrm{g} / \mathrm{mol}]$ & 776.82 & $\mu\left[\mathrm{mm}^{-1}\right]$ & 0.168 \\
Temperature $[\mathrm{K}]$ & $100(2)$ & $\mathrm{F}(000)$ & 412 \\
Wavelength [pm] & 71.073 & $\Theta$ range $\left[^{\circ}\right]$ & 1.99 to 25.39 \\
Crystal system & Triclinic & Reflections collected & 19103 \\
Space group & $P \overline{1}$ & Independent reflections & 3796 \\
$a[\mathrm{pm}]$ & $1054.75(14)$ & Completeness to $\Theta_{\text {max }}$ & $99.9 \%$ \\
$b[\mathrm{pm}]$ & $1076.66(14)$ & Absorption correction & Empirical \\
$c[\mathrm{pm}]$ & $1157.04(15)$ & Max. / min. transmission & $1.0000 / 0.8584$ \\
$\alpha\left[^{\circ}\right]$ & $64.188(2)$ & Restraints / parameters & $0 / 258$ \\
$\beta\left[^{\circ}\right]$ & $69.127(2)$ & GoF & 1.103 \\
$\gamma\left[^{\circ}\right]$ & $63.126(2)$ & $R 1 / w R 2$ (I>2 $\sigma(\mathrm{I}))$ & $0.0488 / 0.1159$ \\
$\left.V^{\circ}\right)$ & $R 1 / w R 2$ (all data) & $0.0668 / 0.1254$ \\
$\mathrm{Z}$ & $1.0341(2)$ & Diff. peak and hole [e $\left.\AA^{-3}\right]$ & 0.449 and -0.352 \\
\hline
\end{tabular}




\subsection{7 $\left[\left(\mathrm{Me}_{2} \mathrm{SiO}\right)_{5} \mathrm{OKLi}\right]_{4}(9)$}

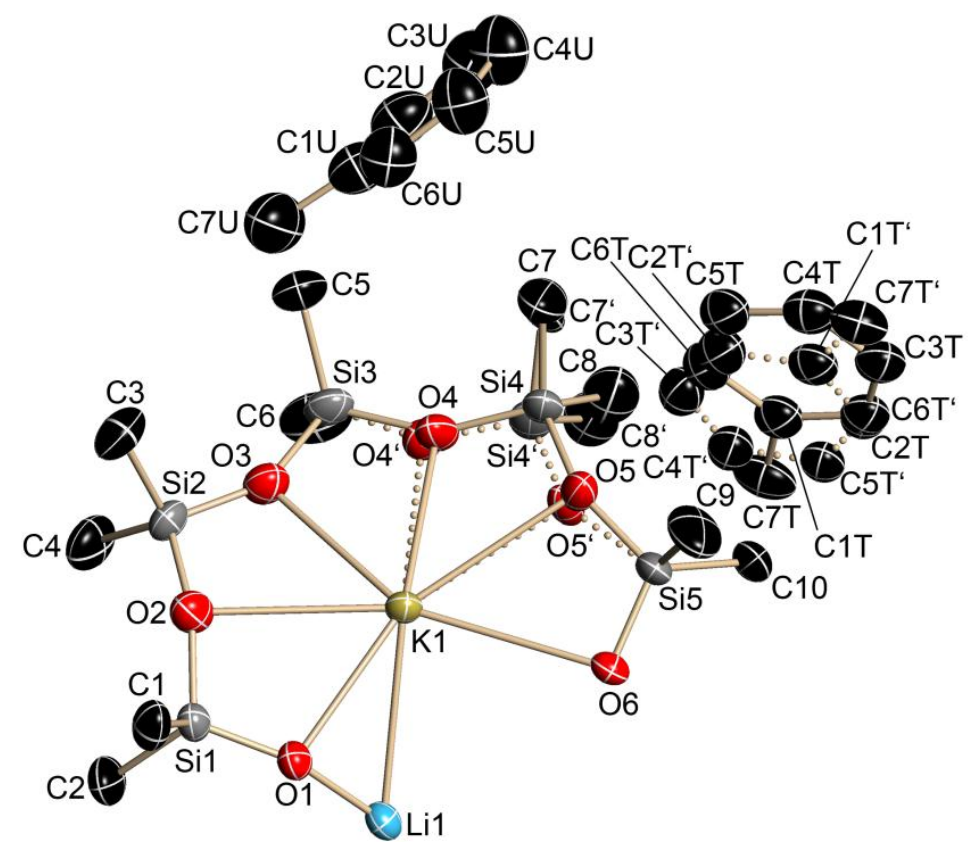

Figure 7-7. Asymmetric unit of $\left[\left(\mathrm{Me}_{2} \mathrm{SiO}\right)_{5} \mathrm{OKLi}\right]_{4}(9)$. The anisotropic displacement parameters are depicted at the $50 \%$ probability level. The hydrogen atoms are omitted for clarity.

The measured crystal is a racemic twin (BASF 0.08). One non-coordinating toluene molecule (39\%) and a OSi $\left(\mathrm{CH}_{3}\right)_{2} \mathrm{O}$ unit of the siloxane ligand (71 \%) are disordered.

Table 7-7. Crystallographic data for $\left[\left(\mathrm{Me}_{2} \mathrm{SiO}\right)_{5} \mathrm{OKLi}\right]_{4}(9)$.

\begin{tabular}{|c|c|c|c|}
\hline Identification code & 10111 & Abs. structure parameter & $-0.02(3)$ \\
\hline Empirical formula & $\mathrm{C}_{61} \mathrm{H}_{144} \mathrm{~K}_{4} \mathrm{Li}_{4} \mathrm{O}_{24} \mathrm{Si}_{20}$ & $\rho_{\text {calc }}\left[\mathrm{Mg} / \mathrm{m}^{3}\right]$ & 1.181 \\
\hline Formula weight $[\mathrm{g} / \mathrm{mol}]$ & 2007.72 & $\mu\left[\mathrm{mm}^{-1}\right]$ & 0.424 \\
\hline Temperature $[\mathrm{K}]$ & $100(2)$ & $F(000)$ & 2140 \\
\hline Wavelength [pm] & 71.073 & $\Theta$ range $\left[{ }^{\circ}\right]$ & 1.61 to 25.37 \\
\hline Crystal system & Tetragonal & Reflections collected & 29758 \\
\hline Space group & $1 \overline{4}$ & Independent reflections & 5155 \\
\hline$a[\mathrm{pm}]$ & $1410.0(2)$ & Completeness to $\Theta_{\max }$ & $99.8 \%$ \\
\hline$b[\mathrm{pm}]$ & $1410.0(2)$ & Absorption correction & Empirical \\
\hline$c[\mathrm{pm}]$ & $2839.9(4)$ & Max. / min. transmission & $1.0000 / 0.9070$ \\
\hline$\alpha\left[^{\circ}\right]$ & 90 & Restraints / parameters & $757 / 453$ \\
\hline$\beta\left[^{\circ}\right]$ & 90 & GoF & 1.036 \\
\hline$\gamma\left[^{\circ}\right]$ & 90 & $R 1 / w R 2(1>2 \sigma(I))$ & $0.0233 / 0.0531$ \\
\hline Volume $\left[\mathrm{nm}^{3}\right]$ & $5.6460(14)$ & $R 1 / w R 2$ (all data) & $0.0258 / 0.0542$ \\
\hline Z & 2 & Diff. peak and hole $\left[\mathrm{e} \AA^{-3}\right]$ & 0.155 and -0.121 \\
\hline
\end{tabular}




\subsection{8 $\quad\left[\left(\mathrm{Ph}_{2} \mathrm{PCH}_{2} \mathrm{Py}\right) \mathrm{PdCl}_{2}\right](11)$}

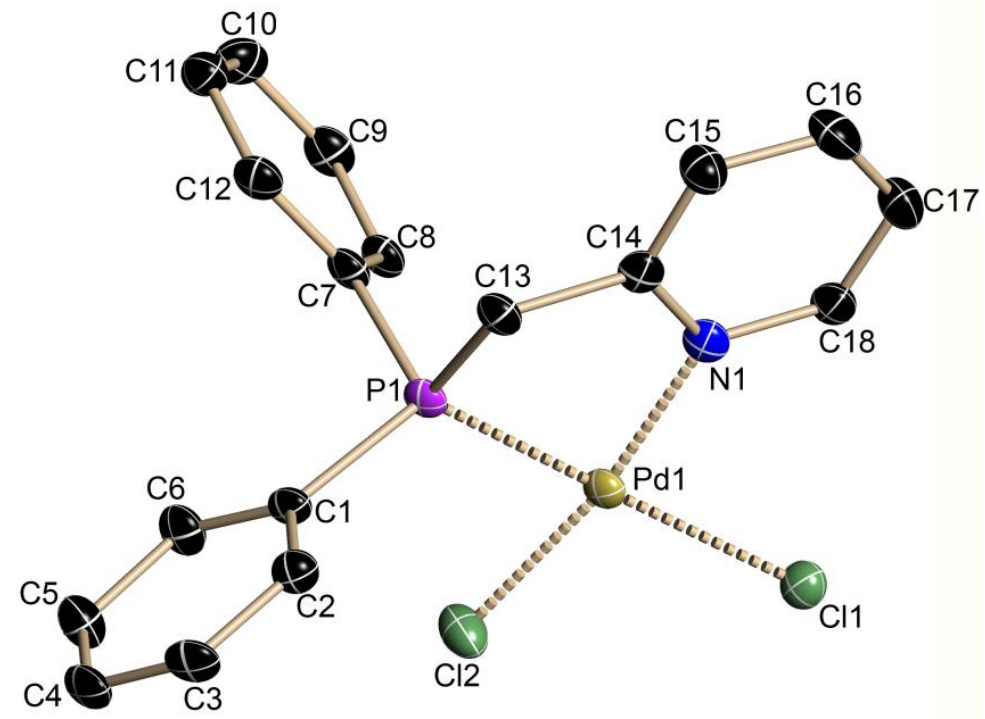

Figure 7-8. Asymmetric unit of [( $\left.\left.\mathrm{Ph}_{2} \mathrm{PCH}_{2} \mathrm{Py}\right) \mathrm{PdCl}_{2}\right]$ (11). The anisotropic displacement parameters are depicted at the $50 \%$ probability level. The hydrogen atoms are omitted for clarity.

Table 7-8. Crystallographic data for $\left[\left(\mathrm{Ph}_{2} \mathrm{PCH}_{2} \mathrm{Py}\right) \mathrm{PdCl}_{2}\right](\mathbf{1 1})$.

\begin{tabular}{|c|c|c|c|}
\hline Identification code & IOPh2PPicPdCl2 & & \\
\hline Empirical formula & $\mathrm{C}_{18} \mathrm{H}_{16} \mathrm{Cl}_{2} \mathrm{NPPd}$ & $\mu\left[\mathrm{mm}^{-1}\right]$ & 1.426 \\
\hline Formula weight $[\mathrm{g} / \mathrm{mol}]$ & 454.59 & $F(000)$ & 904 \\
\hline Temperature $[\mathrm{K}]$ & $99(2)$ & $\Theta$ range $\left[{ }^{\circ}\right]$ & 2.71 to 25.34 \\
\hline Wavelength [pm] & 71.073 & Reflections collected & 43451 \\
\hline Crystal system & Monoclinic & Independent reflections & 3257 \\
\hline Space group & $P 2_{1} / c$ & Completeness to $\Theta_{\max }$ & $99.7 \%$ \\
\hline$a[\mathrm{pm}]$ & $1315.2(3)$ & Absorption correction & Empirical \\
\hline$b[\mathrm{pm}]$ & $846.47(19)$ & Max. / min. transmission & $0.4288 / 0.3220$ \\
\hline$c[\mathrm{pm}]$ & $1636.5(4)$ & Restraints / parameters & $0 / 208$ \\
\hline$\beta\left[^{\circ}\right]$ & $101.546(3)$ & GoF & 1.056 \\
\hline Volume $\left[\mathrm{nm}^{3}\right]$ & $1.7849(7)$ & $R 1 / w R 2(I>2 \sigma(I))$ & $0.0319 / 0.0745$ \\
\hline Z & 4 & $R 1 / w R 2$ (all data) & $0.0424 / 0.0793$ \\
\hline$\rho_{\text {calc }}\left[\mathrm{Mg} / \mathrm{m}^{3}\right]$ & 1.692 & Diff. peak and hole $\left[\mathrm{e} \AA^{-3}\right]$ & 0.773 and -1.116 \\
\hline
\end{tabular}




\subsection{9 $\quad\left[\mathrm{PhP}(\mathrm{O})\left(\mathrm{CH}_{2} \mathrm{Py}\right)_{2}\right] \cdot 2 \mathrm{HCl}(12)$}

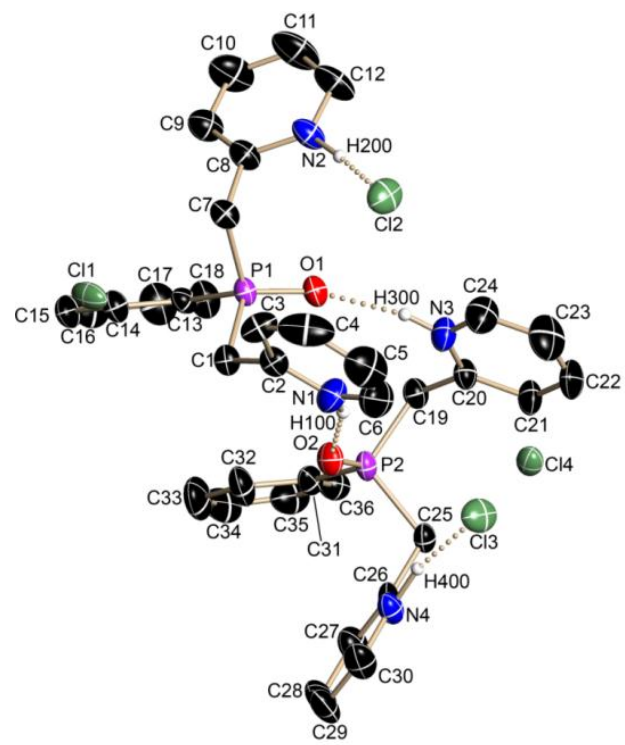

Figure 7-9. Asymmetric unit of $\left[\mathrm{PhP}(\mathrm{O})\left(\mathrm{CH}_{2} \mathrm{Py}\right)_{2}\right] \cdot 2 \mathrm{HCl}$ (12). The anisotropic displacement parameters are depicted at the $50 \%$ probability level. The hydrogen atoms are omitted for clarity.

The contributions of the extremely disordered non-coordinating solvent molecules to the scattering factors were removed with SQUEEZE. ${ }^{\left[{ }^{92]}\right.}$ Additionally, the positions of the hydrogen atoms $\mathrm{H} 100, \mathrm{H} 200, \mathrm{H} 300$ and $\mathrm{H} 400$, respectively, which are bonded to the nitrogen atoms, were taken from the difference map and refined with distance restraints. The measured crystal is a racemic twin (BASF 0.14).

Table 7-9. Crystallographic data for $\left[\mathrm{PhP}(\mathrm{O})\left(\mathrm{CH}_{2} \mathrm{Py}\right)_{2}\right] \cdot 2 \mathrm{HCl}(\mathbf{1 2})$.

\begin{tabular}{ll|ll}
\hline Identification code & $\mathrm{IO} 121$ & Abs. structure parameter & $0.14(5)$ \\
Empirical formula & $\mathrm{C}_{18} \mathrm{H}_{19} \mathrm{Cl}_{2} \mathrm{~N}_{2} \mathrm{OP}$ & $\mu\left[\mathrm{mm}^{-1}\right]$ & 0.344 \\
Formula weight $[\mathrm{g} / \mathrm{mol}]$ & 381.22 & $\mathrm{~F}(000)$ & 792 \\
Temperature $[\mathrm{K}]$ & $100(2)$ & $\Theta$ range $\left[^{\circ}\right]$ & 1.80 to 25.37 \\
Wavelength $[\mathrm{pm}]$ & 71.073 & Reflections collected & 46075 \\
Crystal system & Monoclinic & Independent reflections & 8757 \\
Space group & $P 2_{1}$ & Completeness to $\Theta_{\text {max }}$ & $99.8 \%$ \\
$a[\mathrm{pm}]$ & $1040.3(2)$ & Absorption correction & Empirical \\
$b[\mathrm{pm}]$ & $2030.5(3)$ & Max. / min. transmission & $1.0000 / 0.9489$ \\
$c[\mathrm{pm}]$ & $1181.7(2)$ & Restraints / parameters & $3 / 446$ \\
$\beta\left[{ }^{\circ}\right]$ & $106.84(2)$ & GoF & 1.032 \\
Volume $\left[\mathrm{nm}^{3}\right]$ & $2.3891(7)$ & $R 1 / w R 2$ (I>2 $\sigma(\mathrm{I}))$ & $0.0395 / 0.0937$ \\
$Z$ & 4 & $R 1 / w R 2$ (all data) & $0.0449 / 0.0959$ \\
$\rho_{\text {calc }}\left[\mathrm{Mg} / \mathrm{m}^{3}\right]$ & 1.060 & Diff. peak and hole $\left[\mathrm{e} \AA^{-3}\right]$ & 0.362 and -0.211 \\
\hline
\end{tabular}




\subsubsection{0 $\left[\mathrm{PhP}(\mathrm{S})\left(\mathrm{CH}_{2} \mathrm{Py}\right)_{2}\right] \cdot \mathrm{HCl}(13)$}

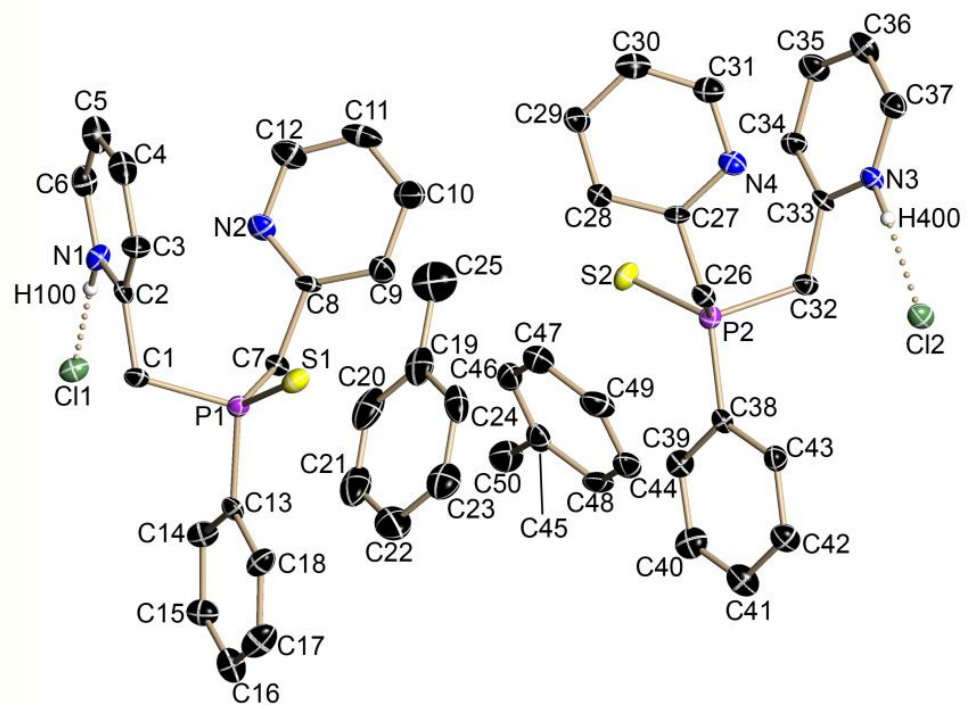

Figure 7-10. Asymmetric unit of $\left[\mathrm{PhP}(\mathrm{S})\left(\mathrm{CH}_{2} \mathrm{Py}\right)_{2}\right] \cdot \mathrm{HCl}(\mathbf{1 3})$. The anisotropic displacement parameters are depicted at the $50 \%$ probability level. The hydrogen atoms are omitted for clarity.

The positions of the hydrogen atoms $\mathrm{H} 100$ and $\mathrm{H} 400$, respectively, which are bonded to the nitrogen atoms, were taken from the difference map and refined freely.

Table 7-10. Crystallographic data for $\left[\mathrm{PhP}(\mathrm{S})\left(\mathrm{CH}_{2} \mathrm{Py}\right)_{2}\right] \cdot \mathrm{HCl}(\mathbf{1 3})$.

\begin{tabular}{ll|ll}
\hline Identification code & IO123S & & \\
Empirical formula & $\mathrm{C}_{25} \mathrm{H}_{26} \mathrm{ClN}_{2} \mathrm{PS}$ & $\mu\left[\mathrm{mm}^{-1}\right]$ & 0.334 \\
Formula weight $[\mathrm{g} / \mathrm{mol}]$ & 452.96 & $\mathrm{~F}(000)$ & 1904 \\
Temperature $[\mathrm{K}]$ & $100(2)$ & $\Theta$ range $\left[^{\circ}\right]$ & 1.37 to 25.42 \\
Wavelength $[\mathrm{pm}]$ & 71.073 & Reflections collected & 44116 \\
Crystal system & Monoclinic & Independent reflections & 8624 \\
Space group & $P 2_{1} / \mathrm{c}$ & Completeness to $\Theta_{\text {max }}$ & $99.7 \%$ \\
$a[\mathrm{pm}]$ & $3058.1(4)$ & Absorption correction & Empirical \\
$b[\mathrm{pm}]$ & $903.79(12)$ & Max. / min. transmission & $1.0000 / 0.9265$ \\
$c[\mathrm{pm}]$ & $1754.7(2)$ & Restraints / parameters & $0 / 549$ \\
$\beta\left[{ }^{\circ}\right]$ & $104.350(4)$ & GoF & 1.008 \\
Volume $\left[\mathrm{nm}^{3}\right]$ & $4.6985(10)$ & $R 1 / w R 2$ (I>2 $\sigma(\mathrm{I}))$ & $0.0502 / 0.0890$ \\
$\mathrm{Z}$ & 8 & $R 1 / w R 2$ (all data) & $0.1044 / 0.1053$ \\
$\rho_{\text {calc }}\left[\mathrm{Mg} / \mathrm{m}^{3}\right]$ & 1.281 & Diff. peak and hole $\left[\mathrm{e} \AA^{-3}\right]$ & 0.357 and -0.353 \\
\hline
\end{tabular}




\subsubsection{1 $\left[\mathrm{PhP}(\mathrm{Se})\left(\mathrm{CH}_{2} \mathrm{Py}\right)_{2}\right] \cdot \mathrm{HCl}(14)$}

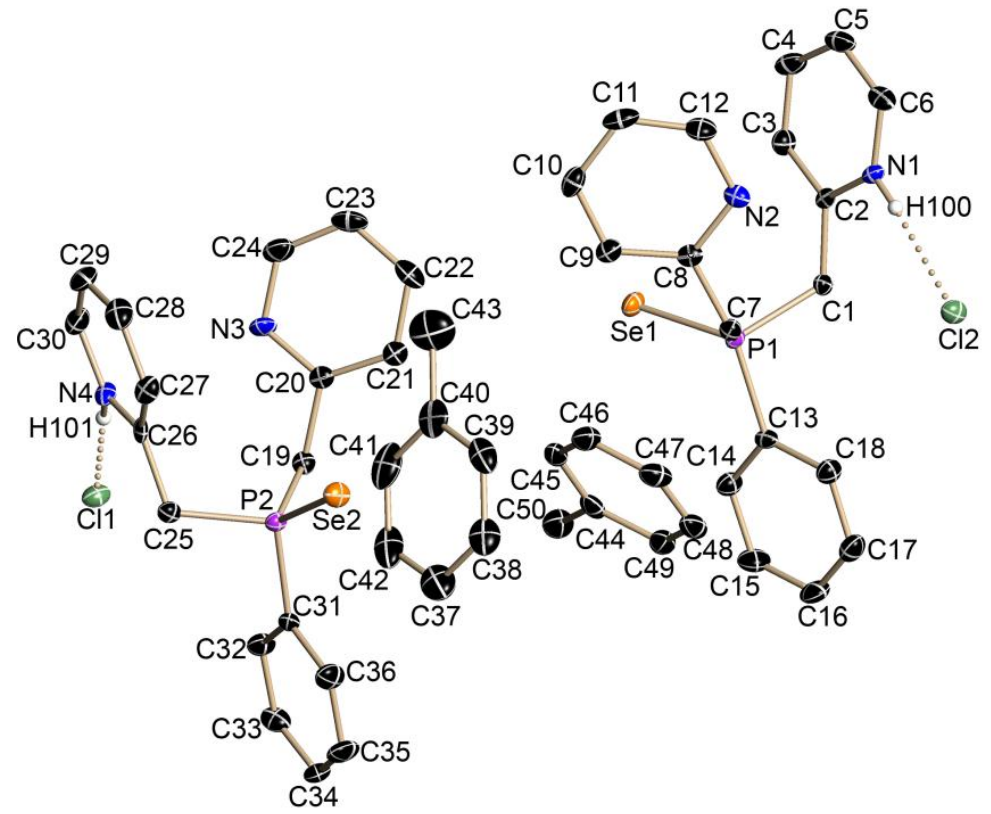

Figure 7-11. Asymmetric unit of $\left[\mathrm{PhP}(\mathrm{Se})\left(\mathrm{CH}_{2} \mathrm{Py}\right)_{2}\right] \cdot \mathrm{HCl}$ (14). The anisotropic displacement parameters are depicted at the $50 \%$ probability level. The hydrogen atoms are omitted for clarity.

The positions of the hydrogen atoms $\mathrm{H} 100$ and $\mathrm{H} 101$, respectively, which are bonded to the nitrogen atoms, were taken from the difference map and refined freely.

Table 7-11. Crystallographic data for $\left[\mathrm{PhP}(\mathrm{Se})\left(\mathrm{CH}_{2} \mathrm{Py}\right)_{2}\right] \cdot \mathrm{HCl}(\mathbf{1 4})$.

\begin{tabular}{ll|ll}
\hline Identification code & IO124Se & & \\
Empirical formula & $\mathrm{C}_{25} \mathrm{H}_{26} \mathrm{ClN}_{2} \mathrm{PSe}$ & $\mu\left[\mathrm{mm}^{-1}\right]$ & 1.773 \\
Formula weight $[\mathrm{g} / \mathrm{mol}]$ & 499.86 & $\mathrm{~F}(000)$ & 2048 \\
Temperature $[\mathrm{K}]$ & $100(2)$ & $\Theta$ range $\left[^{\circ}\right]$ & 1.37 to 25.42 \\
Wavelength $[\mathrm{pm}]$ & 71.073 & Reflections collected & 105313 \\
Crystal system & Monoclinic & Independent reflections & 8748 \\
Space group & $P{ }_{1} / c$ & Completeness to $\Theta_{\text {max }}$ & $99.8 \%$ \\
$a[\mathrm{pm}]$ & $3073.3(3)$ & Absorption correction & Empirical \\
$b[\mathrm{pm}]$ & $908.28(9)$ & Max. / min. transmission & $1.0000 / 0.8560$ \\
$c[\mathrm{pm}]$ & $1762.93(18)$ & Restraints / parameters & $0 / 549$ \\
$\beta\left[^{\circ}\right]$ & $104.848(2)$ & GoF & 1.117 \\
Volume $\left[\mathrm{nm}^{3}\right]$ & $4.7568(8)$ & $R 1 / w R 2(\mathrm{I}>2 \sigma(\mathrm{I}))$ & $0.0545 / 0.0831$ \\
$\mathrm{Z}$ & 8 & $R 1 / w R 2$ (all data) & $0.0814 / 0.0889$ \\
$\rho_{\text {calc }}\left[\mathrm{Mg} / \mathrm{m}^{3}\right]$ & 1.396 & Diff. peak and hole $\left[\mathrm{e} \AA^{-3}\right]$ & 0.735 and -0.629 \\
\hline
\end{tabular}




\subsubsection{2 $\left[\mathrm{PhP}\left(\mathrm{CH}_{2} \mathrm{Py}\right)_{2}\right] \cdot \mathrm{HCl}(15)$}

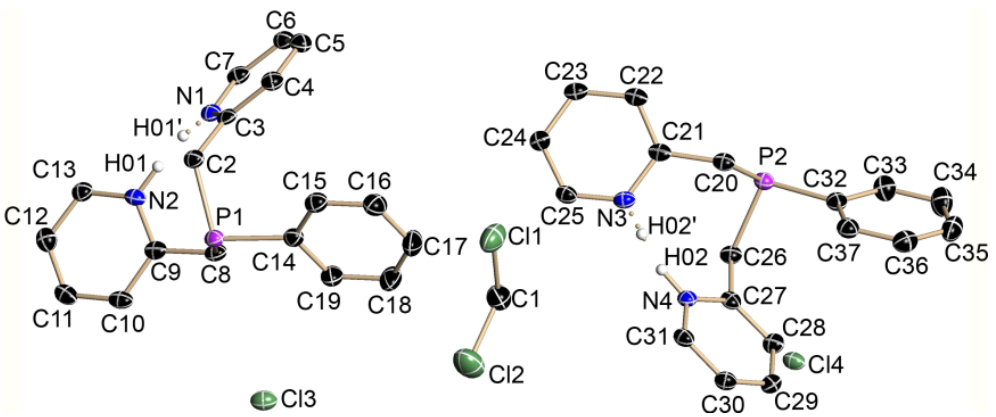

Figure 7-12. Asymmetric unit of $\left[\mathrm{PhP}\left(\mathrm{CH}_{2} \mathrm{Py}\right)_{2}\right] \cdot \mathrm{HCl}(15)$. The anisotropic displacement parameters are depicted at the $50 \%$ probability level. The hydrogen atoms are omitted for clarity.

The positions of the hydrogen atoms $\mathrm{HO}$ and $\mathrm{HO2}$ bonded to the nitrogen atoms were taken from the difference map and refined with distance restraints, additionally this hydrogen atoms are disordered (58 \% and $66 \%$ ).

Table 7-12. Crystallographic data for $\left[\mathrm{PhP}\left(\mathrm{CH}_{2} \mathrm{Py}\right)_{2}\right] \cdot \mathrm{HCl}(\mathbf{1 5})$.

\begin{tabular}{ll|ll}
\hline Identification code & $\mathrm{IO} 0$ & & \\
Empirical formula & $\mathrm{C}_{37} \mathrm{H}_{38} \mathrm{Cl}_{4} \mathrm{~N}_{4} \mathrm{P}_{2}$ & $\rho_{\text {calc }}\left[\mathrm{Mg} / \mathrm{m}^{3}\right]$ & 1.370 \\
Formula weight $[\mathrm{g} / \mathrm{mol}]$ & 742.45 & $\mu\left[\mathrm{mm}^{-1}\right]$ & 0.451 \\
Temperature $[\mathrm{K}]$ & $100(2)$ & $\mathrm{F}(000)$ & 772 \\
Wavelength $[\mathrm{pm}]$ & 71.073 & $\Theta$ range $\left[^{\circ}\right]$ & 1.72 to 25.29 \\
Crystal system & Triclinic & Reflections collected & 34392 \\
Space group & $P \overline{1}$ & Independent reflections & 6519 \\
$a[\mathrm{pm}]$ & $906.47(10)$ & Completeness to $\Theta_{\max }$ & $99.4 \%$ \\
$b[\mathrm{pm}]$ & $927.52(10)$ & Absorption correction & Empirical \\
$c[\mathrm{pm}]$ & $2412.8(3)$ & Max. / min. transmission & $0.7452 / 0.6493$ \\
$\alpha\left[^{\circ}\right]$ & $81.1040(10)$ & Restraints / parameters & $4 / 438$ \\
$\beta\left[^{\circ}\right]$ & $80.2360(10)$ & GoF & 1.221 \\
$\nu\left[^{\circ}\right]$ & $64.6900(10)$ & $R 1 / w R 2(\mathrm{I}>2 \sigma(\mathrm{I}))$ & $0.0436 / 0.0985$ \\
$\left.V^{\circ}\right)$ & $R 1 / w R 2$ (all data) & $0.0481 / 0.1000$ \\
$\mathrm{Z}$ & $1.7996(3)$ & Diff. peak and hole $\left[\mathrm{e} \AA^{-3}\right]$ & 0.470 and -0.423 \\
\hline
\end{tabular}




\subsubsection{3 $\left[\mathrm{Ph}_{2} \mathrm{P}(\mathrm{O})\left(\mathrm{CH}_{2} \mathrm{Py}\right)\right](16)$}

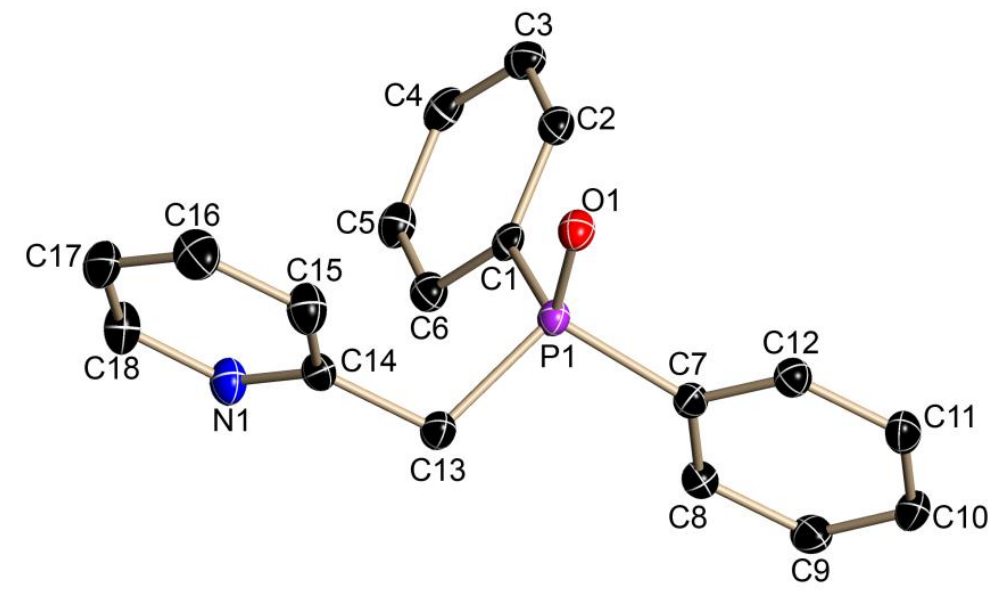

Figure 7-13. Asymmetric unit of $\left[\mathrm{Ph}_{2} \mathrm{P}(\mathrm{O})\left(\mathrm{CH}_{2} \mathrm{Py}\right)\right](\mathbf{1 6})$. The anisotropic displacement parameters are depicted at the $50 \%$ probability level. The hydrogen atoms are omitted for clarity.

Table 7-13. Crystallographic data for $\left[\mathrm{Ph}_{2} \mathrm{P}(\mathrm{O})\left(\mathrm{CH}_{2} \mathrm{Py}\right)\right](\mathbf{1 6})$.

\begin{tabular}{ll|ll}
\hline Identification code & $\mathrm{IO} 3$ & & \\
Empirical formula & $\mathrm{C}_{18} \mathrm{H}_{16} \mathrm{NOP}$ & $\rho_{\text {calc }}\left[\mathrm{Mg} / \mathrm{m}^{3}\right]$ & 1.333 \\
Formula weight $[\mathrm{g} / \mathrm{mol}]$ & 293.29 & $\mu\left[\mathrm{mm}^{-1}\right]$ & 0.186 \\
Temperature $[\mathrm{K}]$ & $100(2)$ & $\mathrm{F}(000)$ & 308 \\
Wavelength $[\mathrm{pm}]$ & 71.073 & $\Theta$ range $\left[^{\circ}\right]$ & 1.30 to 25.47 \\
Crystal system & Triclinic & Reflections collected & 15748 \\
Space group & $P \overline{1}$ & Independent reflections & 2691 \\
$a[\mathrm{pm}]$ & $585.14(6)$ & Completeness to $\Theta_{\text {max }}$ & $99.9 \%$ \\
$b[\mathrm{pm}]$ & $828.30(8)$ & Absorption correction & Empirical \\
$c[\mathrm{pm}]$ & $1613.34(16)$ & Max. $/$ min. transmission & $0.7452 / 0.6886$ \\
$\alpha\left[^{\circ}\right]$ & $100.1390(10)$ & Restraints / parameters & $0 / 190$ \\
$\beta\left[^{\circ}\right]$ & $95.8140(10)$ & GoF & 1.061 \\
$\gamma\left[^{\circ}\right]$ & $105.9980(10)$ & $R 1 / w R 2(\mathrm{I}>2 \sigma(\mathrm{I}))$ & $0.0306 / 0.0814$ \\
$\left.V^{\circ}\right)$ & $R 1 / w R 2$ (all data) & $0.0346 / 0.0837$ \\
$Z$ & $0.73059(13)$ & Diff. peak and hole $\left[\mathrm{e} \AA^{-3}{ }^{-3}\right]$ & 0.379 and -0.329 \\
\hline
\end{tabular}




\subsubsection{4 [(THF $\left.)_{4} \mathrm{Li}_{2}\{\mathrm{C}(\mathrm{H}) \mathrm{Py}\}_{2} \mathrm{P}(\mathrm{O}) \mathrm{Ph}\right](17)$}

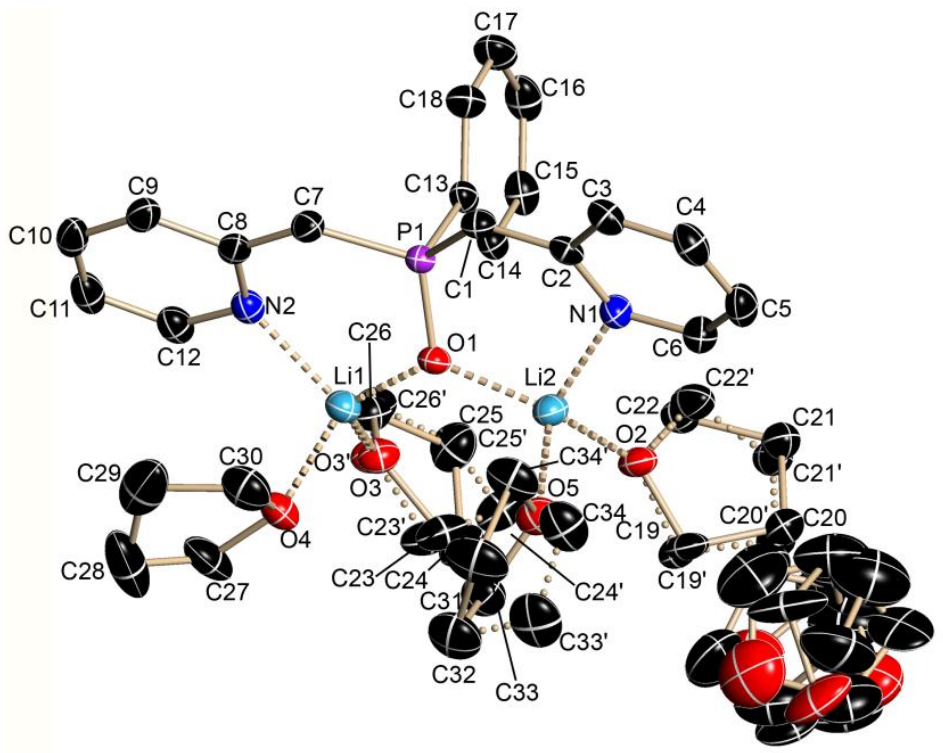

Figure 7-14. Asymmetric unit of [(THF) $\left.{ }_{4} \mathrm{Li}_{2}\{\mathrm{C}(\mathrm{H}) \mathrm{Py}\}_{2} \mathrm{P}(\mathrm{O}) \mathrm{Ph}\right](\mathbf{1 7})$. The anisotropic displacement parameters are depicted at the $50 \%$ probability level. The hydrogen atoms are omitted for clarity.

The positions of the hydrogen atoms bonded to $\mathrm{C} 1$ and $\mathrm{C} 7$ were taken from the difference map and refined with distance restraints. Additionally three coordinating and one non-coordinating THF molecule are completely disordered.

Table 7-14. Crystallographic data for [(THF $\left.)_{4} \mathrm{Li}_{2}\{\mathrm{C}(\mathrm{H}) \mathrm{Py}\}_{2} \mathrm{P}(\mathrm{O}) \mathrm{Ph}\right](\mathbf{1 7})$.

\begin{tabular}{|c|c|c|c|}
\hline Identification code & 1089 & & \\
\hline Empirical formula & $\mathrm{C}_{38} \mathrm{H}_{55} \mathrm{Li}_{2} \mathrm{~N}_{2} \mathrm{O}_{6} \mathrm{P}$ & $\mu\left[\mathrm{mm}^{-1}\right]$ & 0.120 \\
\hline Formula weight $[\mathrm{g} / \mathrm{mol}]$ & 680.69 & $F(000)$ & 1464 \\
\hline Temperature $[\mathrm{K}]$ & $100(2)$ & $\Theta$ range $\left[{ }^{\circ}\right]$ & 1.42 to 25.35 \\
\hline Wavelength [pm] & 71.073 & Reflections collected & 171741 \\
\hline Crystal system & Monoclinic & Independent reflections & 6832 \\
\hline Space group & $P 2_{1} / c$ & Completeness to $\Theta_{\max }$ & $99.9 \%$ \\
\hline$a[\mathrm{pm}]$ & $966.2(2)$ & Absorption correction & Empirical \\
\hline$b[\mathrm{pm}]$ & $1349.8(2)$ & Max. / min. transmission & $1.0000 / 0.9462$ \\
\hline$c[\mathrm{pm}]$ & $2879.2(3)$ & Restraints / parameters & $1430 / 691$ \\
\hline$\beta\left[^{\circ}\right]$ & $95.99(2)$ & GoF & 1.048 \\
\hline Volume $\left[\mathrm{nm}^{3}\right]$ & $3.7345(10)$ & $R 1 / w R 2(I>2 \sigma(I))$ & 0.0407 / 0.0987 \\
\hline Z & 4 & $R 1 / w R 2$ (all data) & $0.0523 / 0.1065$ \\
\hline$\rho_{\text {calc }}\left[\mathrm{Mg} / \mathrm{m}^{3}\right]$ & 1.211 & Diff. peak and hole $\left[\mathrm{e} \AA^{-3}\right]$ & 0.266 and -0.309 \\
\hline
\end{tabular}




\subsubsection{5 $\left[\mathrm{PhP}\left(\mathrm{CH}_{2} \mathrm{Py}\right)_{2}\right] \mathrm{H}_{2} \mathrm{O}\left[\mathrm{B}\left(\mathrm{C}_{6} \mathrm{~F}_{5}\right)_{3}\right](18)$}

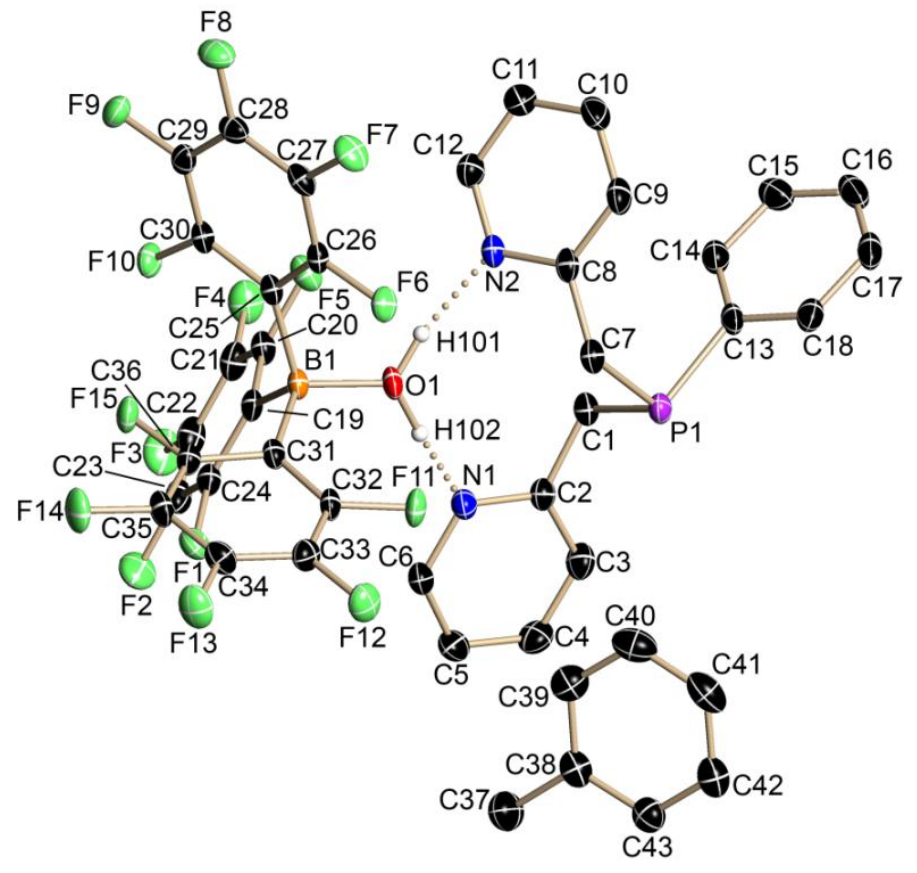

Figure 7-15. Asymmetric unit of $\left[\mathrm{PhP}\left(\mathrm{CH}_{2} \mathrm{Py}\right)_{2}\right] \mathrm{H}_{2} \mathrm{O}\left[\mathrm{B}\left(\mathrm{C}_{6} \mathrm{~F}_{5}\right)_{3}\right]$ (18). The anisotropic displacement parameters are depicted at the $50 \%$ probability level. The hydrogen atoms are omitted for clarity.

The positions of the hydrogen atoms $\mathrm{H} 101$ and $\mathrm{H} 102$ of the water molecule were taken from the difference map and refined freely.

Table 7-15. Crystallographic data for $\left[\mathrm{PhP}\left(\mathrm{CH}_{2} \mathrm{Py}\right)_{2}\right] \mathrm{H}_{2} \mathrm{O}\left[\mathrm{B}\left(\mathrm{C}_{6} \mathrm{~F}_{5}\right)_{3}\right](\mathbf{1 8})$.

\begin{tabular}{|c|c|c|c|}
\hline Identification code & IOFE1 & & \\
\hline Empirical formula & $\mathrm{C}_{43} \mathrm{H}_{27} \mathrm{BF}_{15} \mathrm{~N}_{2} \mathrm{OP}$ & $\rho_{\text {calc }}\left[\mathrm{Mg} / \mathrm{m}^{3}\right]$ & 1.541 \\
\hline Formula weight $[\mathrm{g} / \mathrm{mol}]$ & 914.45 & $\mu\left[\mathrm{mm}^{-1}\right]$ & 0.180 \\
\hline Temperature $[\mathrm{K}]$ & $100(2)$ & $F(000)$ & 924 \\
\hline Wavelength [pm] & 71.073 & $\Theta$ range $\left[{ }^{\circ}\right]$ & 1.64 to 26.37 \\
\hline Crystal system & Triclinic & Reflections collected & 50350 \\
\hline Space group & $P \overline{1}$ & Independent reflections & 8036 \\
\hline$a[\mathrm{pm}]$ & 1209.33(9) & Completeness to $\Theta_{\max }$ & $99.9 \%$ \\
\hline$b[\mathrm{pm}]$ & $1332.34(10)$ & Absorption correction & Empirical \\
\hline$c[\mathrm{pm}]$ & $1439.53(11)$ & Max. / min. transmission & $1.0000 / 0.8878$ \\
\hline$\alpha\left[^{\circ}\right]$ & $108.8040(10)$ & Restraints / parameters & $0 / 575$ \\
\hline$\beta\left[^{\circ}\right]$ & $114.0080(10)$ & GoF & 1.029 \\
\hline$\gamma\left[^{\circ}\right]$ & $91.7520(10)$ & $R 1 / w R 2(I>2 \sigma(I))$ & $0.0415 / 0.1008$ \\
\hline Volume $\left[\mathrm{nm}^{3}\right]$ & $1.9703(3)$ & $R 1$ / wR2 (all data) & $0.0546 / 0.1081$ \\
\hline Z & 2 & Diff. peak and hole $\left[\mathrm{e} \AA^{-3}\right]$ & 0.697 and -0.397 \\
\hline
\end{tabular}




\subsubsection{6 $\left[\mathrm{Ph}_{2} \mathrm{P}\left(\mathrm{CH}_{2} \mathrm{Py}\right)\left(\mathrm{NH}_{2}\right)\right] \mathrm{Cl}$}

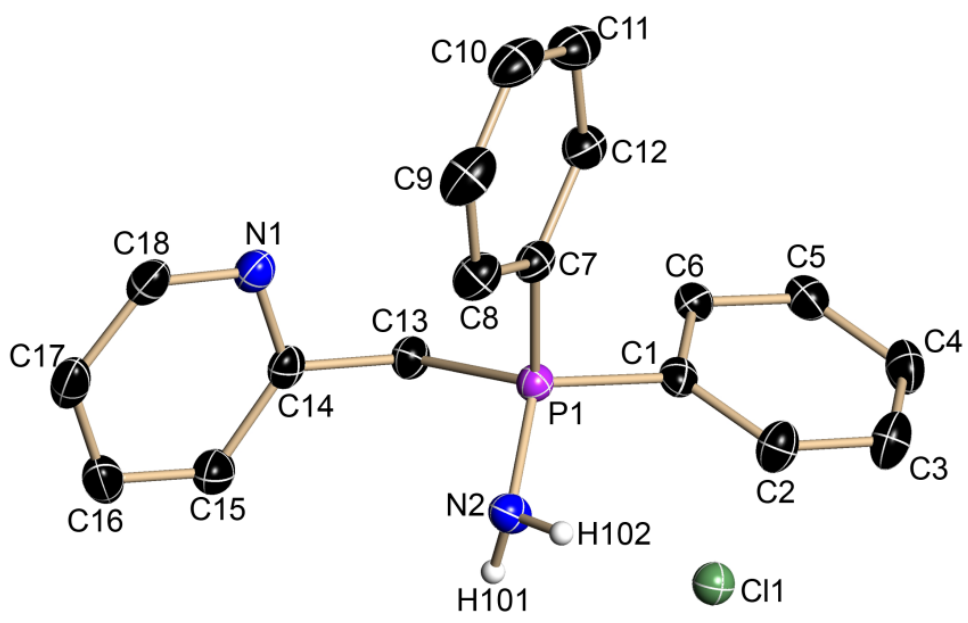

Figure 7-16. Asymmetric unit of $\left[\mathrm{Ph}_{2} \mathrm{P}\left(\mathrm{CH}_{2} \mathrm{Py}\right)\left(\mathrm{NH}_{2}\right)\right] \mathrm{Cl}$. The anisotropic displacement parameters are depicted at the $50 \%$ probability level. The hydrogen atoms are omitted for clarity.

The positions of the hydrogen atoms $\mathrm{H} 101$ and $\mathrm{H} 102$ of the amine moiety were taken from the difference map and refined with distance restraints.

Table 7-16. Crystallographic data for $\left[\mathrm{Ph}_{2} \mathrm{P}\left(\mathrm{CH}_{2} \mathrm{Py}\right)\left(\mathrm{NH}_{2}\right)\right] \mathrm{Cl}$.

\begin{tabular}{ll|ll}
\hline Identification code & $\mathrm{IO} 25$ & & \\
Empirical formula & $\mathrm{C}_{18} \mathrm{H}_{18} \mathrm{ClN}_{2} \mathrm{P}$ & $\mu\left[\mathrm{mm}^{-1}\right]$ & 0.328 \\
Formula weight $[\mathrm{g} / \mathrm{mol}]$ & 328.76 & $\mathrm{~F}(000)$ & 688 \\
Temperature $[\mathrm{K}]$ & $100(2)$ & $\Theta$ range $\left[^{\circ}\right]$ & 2.07 to 25.40 \\
Wavelength $[\mathrm{pm}]$ & 71.073 & Reflections collected & 22301 \\
Crystal system & Monoclinic & Independent reflections & 3023 \\
Space group & $P 2_{1} / n$ & Completeness to $\Theta_{\text {max }}$ & $99.8 \%$ \\
$a[\mathrm{pm}]$ & $1036.23(10)$ & Absorption correction & Empirical \\
$b[\mathrm{pm}]$ & $885.14(9)$ & Max. / min. transmission & 0.7452 and 0.6648 \\
$c[\mathrm{pm}]$ & $1843.01(18)$ & Restraints / parameters & $2 / 205$ \\
$\beta\left[^{\circ}\right]$ & $103.5710(10)$ & GoF & 1.068 \\
Volume $\left[\mathrm{nm}^{3}\right]$ & $1.6432(3)$ & $R 1 / w R 2$ (I>2 $\sigma(\mathrm{I}))$ & $0.0315 / 0.0716$ \\
$\mathrm{Z}$ & 4 & $R 1 / w R 2$ (all data) & $0.0388 / 0.0748$ \\
$\rho_{\text {calc }}\left[\mathrm{Mg} / \mathrm{m}^{3}\right]$ & 1.329 & Diff. peak and hole $\left[\mathrm{e} \AA^{-3}\right]$ & 0.279 and -0.281 \\
\hline
\end{tabular}




\subsubsection{7 $\left[\mathrm{Ph}_{2} \mathrm{PCH}_{2} \mathrm{Py}\right] \cdot \mathrm{HI}$}

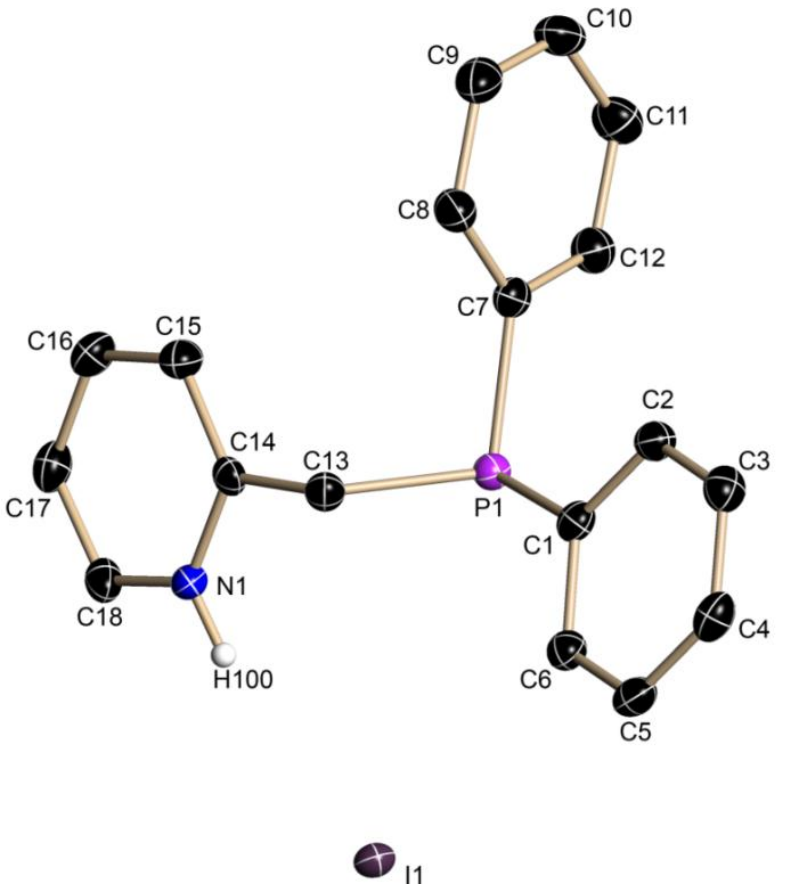

Figure 7-17. Asymmetric unit of $\left[\mathrm{Ph}_{2} \mathrm{PCH}_{2} \mathrm{Py}\right] \cdot \mathrm{HI}$. The anisotropic displacement parameters are depicted at the $50 \%$ probability level. The hydrogen atoms are omitted for clarity.

The position of the hydrogen atoms $\mathrm{H} 100$ at the nitrogen atom was taken from the difference map and refined with distance restraints.

Table 7-17. Crystallographic data for $\left[\mathrm{Ph}_{2} \mathrm{PCH}_{2} \mathrm{Py}\right] \cdot \mathrm{HI}$.

\begin{tabular}{|c|c|c|c|}
\hline Identification code & 1063 & & \\
\hline Empirical formula & $\mathrm{C}_{18} \mathrm{H}_{17} \mathrm{INP}$ & $\rho_{\text {calc }}\left[\mathrm{Mg} / \mathrm{m}^{3}\right]$ & 1.599 \\
\hline Formula weight $[\mathrm{g} / \mathrm{mol}]$ & 405.20 & $\mu\left[\mathrm{mm}^{-1}\right]$ & 1.991 \\
\hline Temperature $[\mathrm{K}]$ & $100(2)$ & $F(000)$ & 400 \\
\hline Wavelength [pm] & 71.073 & $\Theta$ range $\left[{ }^{\circ}\right]$ & 1.49 to 25.35 \\
\hline Crystal system & Triclinic & Reflections collected & 9724 \\
\hline Space group & $P \overline{1}$ & Independent reflections & 3072 \\
\hline$a[\mathrm{pm}]$ & $805.42(10)$ & Completeness to $\Theta_{\max }$ & $99.5 \%$ \\
\hline$b[\mathrm{pm}]$ & $806.19(10)$ & Absorption correction & Empirical \\
\hline$c[\mathrm{pm}]$ & $1391.04(17)$ & Max. / min. transmission & 0.7454 / 0.7031 \\
\hline$\alpha\left[^{\circ}\right]$ & $79.707(2)$ & Restraints / parameters & $1 / 193$ \\
\hline$\beta\left[^{\circ}\right]$ & $85.210(2)$ & GoF & 1.049 \\
\hline$\nu\left[^{\circ}\right]$ & $71.3380(10)$ & $R 1 / w R 2(I>2 \sigma(I))$ & 0.0169 / 0.0396 \\
\hline Volume $\left[\mathrm{nm}^{3}\right]$ & $0.84164(18)$ & $R 1 / w R 2$ (all data) & 0.0189 / 0.0401 \\
\hline Z & 2 & Diff. peak and hole $\left[\mathrm{e} \AA^{-3}\right]$ & 0.461 and -0.241 \\
\hline
\end{tabular}




\subsection{Crystallographic Cooperation}

During this PhD thesis service X-ray measurements were done for Dipl.-Chem. Julia Matussek and Dipl.-Chem. Christian Maaß of our own work group, Dipl.-Chem. Simone Dietz $^{[93]}$ and Dipl.-Chem. Tim Hungerland ${ }^{[94]}$ (both work group Prof. Dr. Dr. h.c. L. F. Tietze), Dr. Sankaranarayana P. Sarish ${ }^{[95]}$ and Dr. Anukul Jana ${ }^{[96]}$ (work group Prof. Dr. Dr. h.c. mult. H. W. Roesky) and Dr. Monika Heinz (work group Jun.Prof. Dr. C. Schulzke).

\subsubsection{Structures measured for Dipl.-Chem. Julia Matussek}
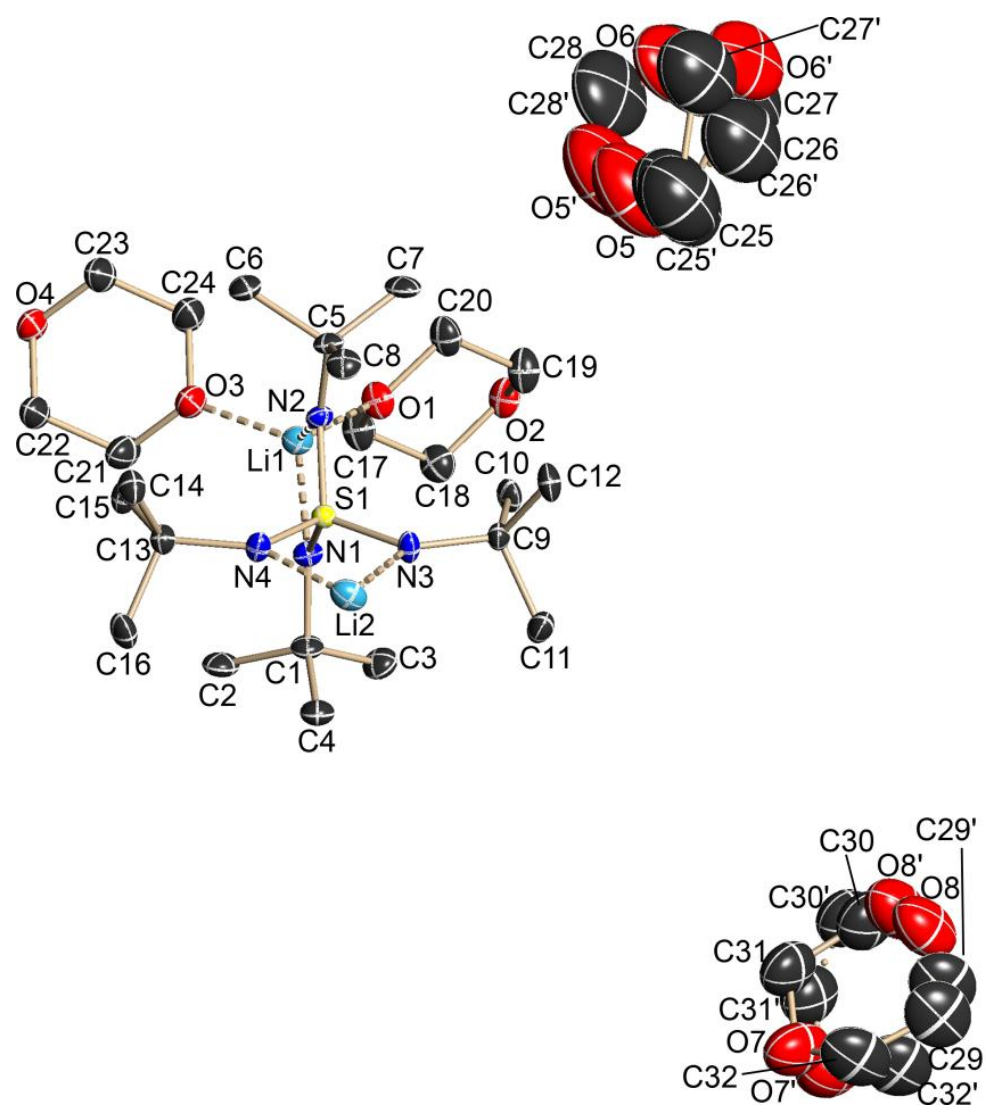

Figure 7-18. Asymmetric unit of [(1,4-dioxane $\left.)_{2} \mathrm{Li}_{2} \mathrm{~S}(\mathrm{NtBu})_{4}\right] \cdot(1,4-\text { dioxane })_{2}$. The anisotropic displacement parameters are depicted at the $50 \%$ probability level. The hydrogen atoms are omitted for clarity.

The non-coordinating 1,4-dioxane molecules are completely disordered. 
Table 7-18. Crystallographic data for [(1,4-dioxane $\left.)_{2} \mathrm{Li}_{2} \mathrm{~S}(\mathrm{~N} t \mathrm{Bu})_{4}\right] \cdot(1,4-\text { dioxane })_{2}$.

\begin{tabular}{ll|ll}
\hline Identification code & IOJM26 & Abs. structure parameter & not determined \\
Empirical formula & $\mathrm{C}_{32} \mathrm{H}_{68} \mathrm{Li}_{2} \mathrm{~N}_{4} \mathrm{O}_{8} \mathrm{~S}$ & $\rho_{\text {calc }}\left[\mathrm{Mg} / \mathrm{m}^{3}\right]$ & 1.068 \\
Formula weight $[\mathrm{g} / \mathrm{mol}]$ & 682.78 & $\mu\left[\mathrm{mm}^{-1}\right]$ & 0.122 \\
Temperature $[\mathrm{K}]$ & $100(2)$ & $\mathrm{F}(000)$ & 1462 \\
Wavelength $[\mathrm{pm}]$ & 71.073 & $\Theta$ range $\left[^{\circ}\right]$ & 1.94 to 25.38 \\
Crystal system & Tetragonal & Reflections collected & 36400 \\
Space group & $P 4_{3}$ & Independent reflections & 3875 \\
$a[\mathrm{pm}]$ & $1051.5(2)$ & Completeness to $\Theta_{\text {max }}$ & $99.9 \%$ \\
$b[\mathrm{pm}]$ & $1051.5(2)$ & Absorption correction & Empirical \\
$c[\mathrm{pm}]$ & $3753.5(7)$ & Max. / min. transmission & $1.0000 / 0.9263$ \\
$\alpha\left[^{\circ}\right]$ & 90 & Restraints / parameters & $219 / 512$ \\
$\beta\left[^{\circ}\right]$ & 90 & GoF & 1.039 \\
$\gamma\left[^{\circ}\right]$ & $R 1 / w R 2$ (I>2 $\sigma(\mathrm{I}))$ & $0.0601 / 0.1441$ \\
Volume $\left[\mathrm{nm}^{3}\right]$ & 90 & $R 1 / w R 2$ (all data) & $0.0711 / 0.1517$ \\
$Z$ & $4.1499(14)$ & Diff. peak and hole $\left[\mathrm{e} \AA^{-3}\right]$ & 0.512 and -0.404 \\
\hline
\end{tabular}

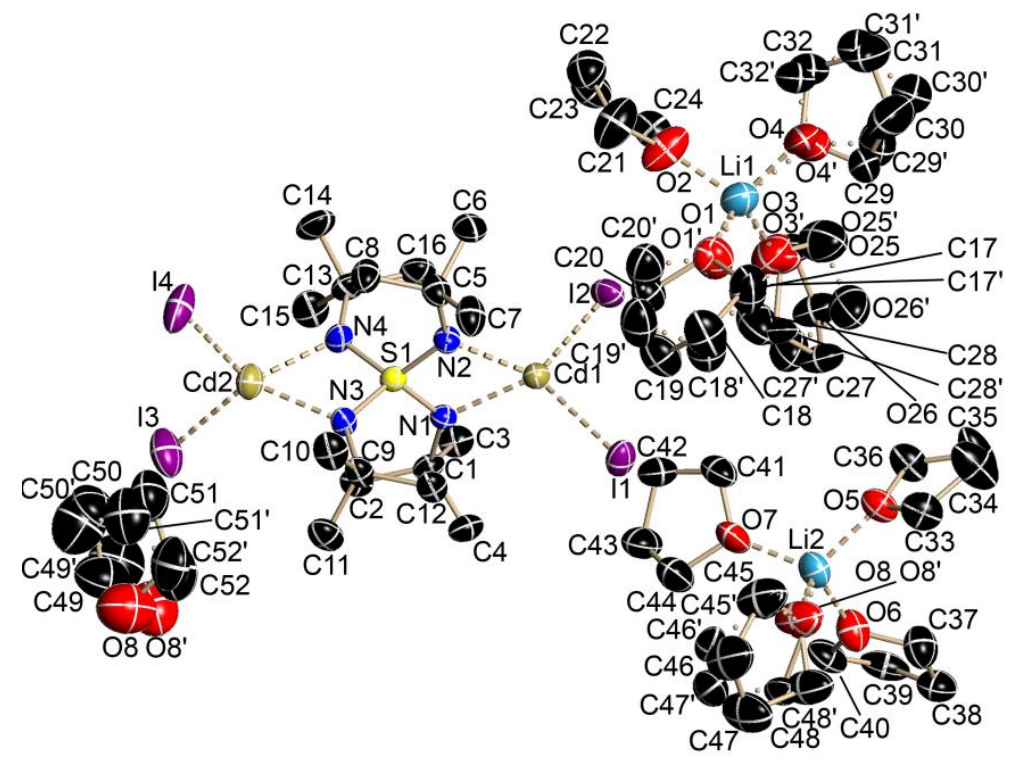

Figure 7-19. Asymmetric unit of $\left[\left(\mathrm{I}_{2} \mathrm{Cd}\right)_{2} \mathrm{~S}(\mathrm{NtBu})_{4}\right]\left[\mathrm{Li}(\mathrm{THF})_{4}\right]_{2} \cdot \mathrm{THF}$. The anisotropic displacement parameters are depicted at the $50 \%$ probability level. The hydrogen atoms are omitted for clarity.

Three coordinating THF molecules at Li1, one at Li2 and the non-coordinating solvent molecule are disordered. 
Table 7-19. Crystallographic data for $\left[\left(\mathrm{I}_{2} \mathrm{Cd}\right)_{2} \mathrm{~S}(\mathrm{NtBu})_{4}\right]\left[\mathrm{Li}(\mathrm{THF})_{4}\right]_{2} \cdot \mathrm{THF}$.

\begin{tabular}{|c|c|c|c|}
\hline Identification code & IOJM38 & & \\
\hline Empirical formula & $\mathrm{C}_{52} \mathrm{H}_{108} \mathrm{Cd}_{2} \mathrm{I}_{4} \mathrm{Li}_{2} \mathrm{~N}_{4} \mathrm{O}_{9} \mathrm{~S}$ & $\mu\left[\mathrm{mm}^{-1}\right]$ & 2.440 \\
\hline Formula weight $[\mathrm{g} / \mathrm{mol}]$ & 1711.76 & $F(000)$ & 3400 \\
\hline Temperature $[\mathrm{K}]$ & $100(2)$ & $\Theta$ range $\left[{ }^{\circ}\right]$ & 1.35 to 25.35 \\
\hline Wavelength [pm] & 71.073 & Reflections collected & 290887 \\
\hline Crystal system & Monoclinic & Independent reflections & 12857 \\
\hline Space group & $P 2_{1} / c$ & Completeness to $\Theta_{\max }$ & $100.0 \%$ \\
\hline$a[\mathrm{pm}]$ & $1542.77(12)$ & Absorption correction & Empirical \\
\hline$b[\mathrm{pm}]$ & $2244.17(18)$ & Max. / min. transmission & 0.8867 / 0.7303 \\
\hline$c[\mathrm{pm}]$ & $2086.90(17)$ & Restraints / parameters & $400 / 813$ \\
\hline$\beta\left[^{\circ}\right]$ & $103.5590(10)$ & GoF & 1.080 \\
\hline Volume $\left[\mathrm{nm}^{3}\right]$ & $7.0240(10)$ & $R 1 / w R 2(1>2 \sigma(I))$ & $0.0522 / 0.1166$ \\
\hline Z & 4 & $R 1 / w R 2$ (all data) & $0.0726 / 0.1310$ \\
\hline$\rho_{\text {calc }}\left[\mathrm{Mg} / \mathrm{m}^{3}\right]$ & 1.619 & Diff. peak and hole $\left[\mathrm{e}^{-3}{ }^{-3}\right]$ & 2.025 and -1.959 \\
\hline
\end{tabular}




\subsubsection{Structures measured for Dipl.-Chem. Christian Maaß}

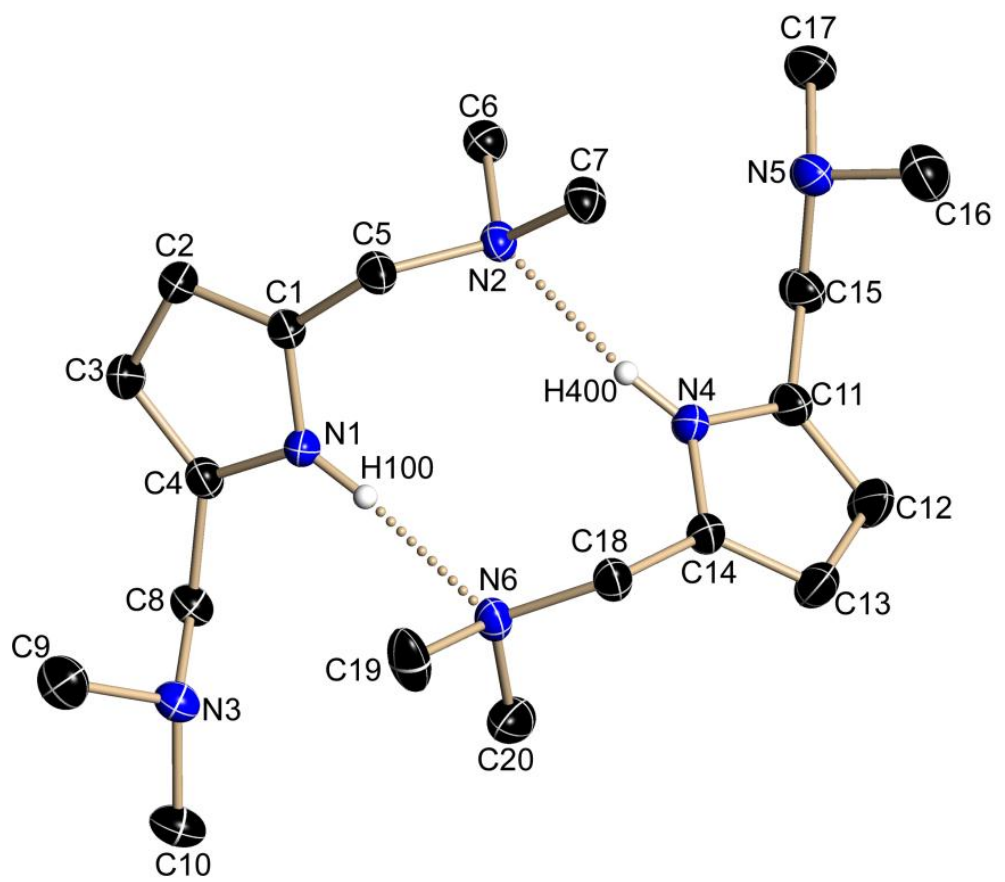

Figure 7-20. Asymmetric unit of $\left[2,5-\left(\mathrm{CH}_{2} \mathrm{NMe}_{2}\right) \mathrm{C}_{4} \mathrm{H}_{4} \mathrm{NH}\right]_{2}$. The anisotropic displacement parameters are depicted at the $50 \%$ probability level. The hydrogen atoms are omitted for clarity.

The positions of the hydrogen atoms $\mathrm{H} 100$ and $\mathrm{H} 400$ at the pyrrole rings were taken from the difference map and refined with distance restraints.

Table 7-20. Crystallographic data for $\left[2,5-\left(\mathrm{CH}_{2} \mathrm{NMe}_{2}\right) \mathrm{C}_{4} \mathrm{H}_{4} \mathrm{NH}\right]_{2}$.

\begin{tabular}{ll|ll}
\hline Identification code & IOCMPyNMe2 & & \\
Empirical formula & $\mathrm{C}_{20} \mathrm{H}_{38} \mathrm{~N}_{6}$ & $\mu\left[\mathrm{mm}^{-1}\right]$ & 0.065 \\
Formula weight $[\mathrm{g} / \mathrm{mol}]$ & 362.56 & $\mathrm{~F}(000)$ & 800 \\
Temperature $[\mathrm{K}]$ & $100(2)$ & $\Theta$ range $\left[^{\circ}\right]$ & 1.83 to 27.10 \\
Wavelength [pm] & 71.073 & Reflections collected & 41284 \\
Crystal system & Monoclinic & Independent reflections & 5007 \\
Space group & $P 2_{1} / n$ & Completeness to $\Theta_{\text {max }}$ & $99.5 \%$ \\
$a[\mathrm{pm}]$ & $975.38(9)$ & Absorption correction & Empirical \\
$b[\mathrm{pm}]$ & $1049.00(9)$ & Max. / min. transmission & $0.7456 / 0.7112$ \\
$c[\mathrm{pm}]$ & $2244.1(2)$ & Restraints / parameters & $2 / 249$ \\
$\beta\left[{ }^{\circ}\right]$ & $98.2250(10)$ & GoF & 1.041 \\
Volume $\left[\mathrm{nm}^{3}\right]$ & $2.2725(4)$ & $R 1 / w R 2$ (I>2 $\sigma(\mathrm{I}))$ & $0.0395 / 0.1016$ \\
$\mathrm{Z}$ & 4 & $R 1 / w R 2$ (all data) & $0.0449 / 0.1055$ \\
$\rho_{\text {calc }}\left[\mathrm{Mg} / \mathrm{m}^{3}\right]$ & 1.060 & Diff. peak and hole $\left[\mathrm{e} \AA^{-3}\right]$ & 0.255 and -0.179 \\
\hline
\end{tabular}




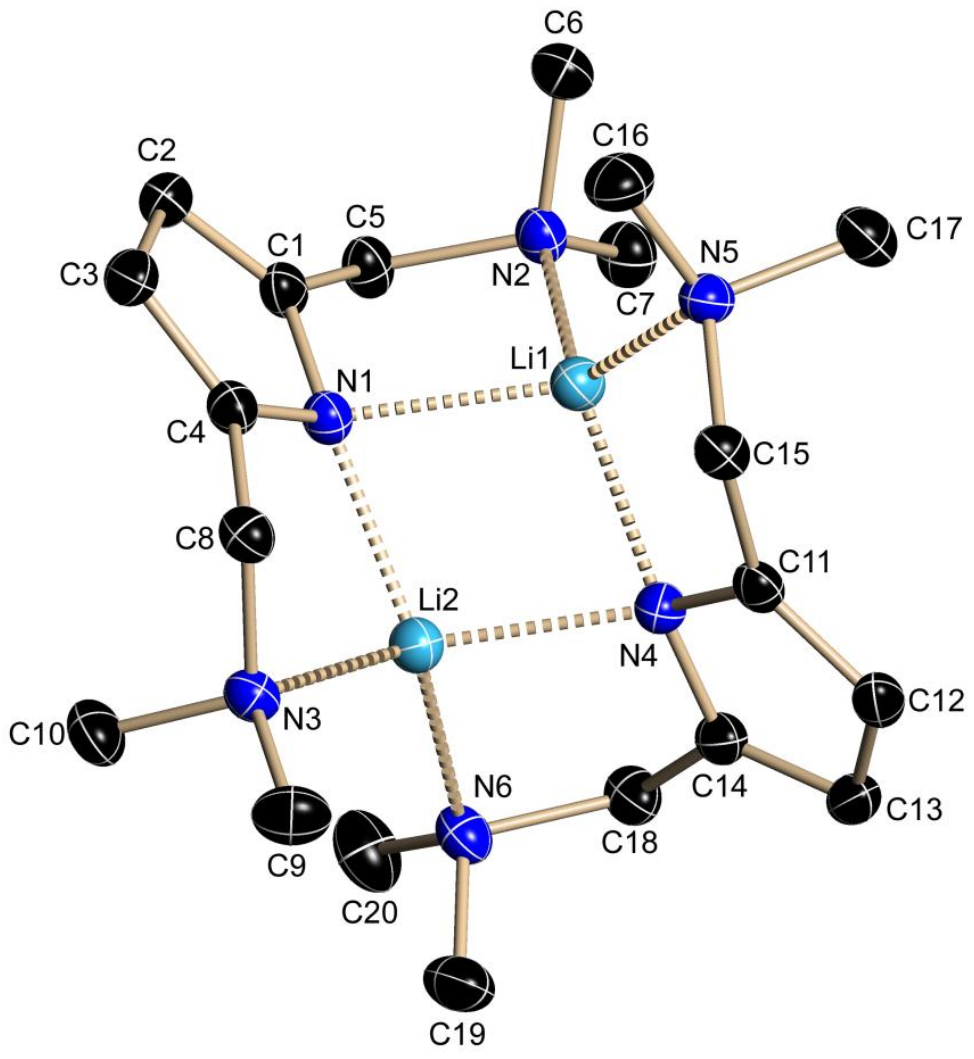

Figure 7-21. Asymmetric unit of $\left[2,5-\left(\mathrm{CH}_{2} \mathrm{NMe}_{2}\right) \mathrm{C}_{4} \mathrm{H}_{4} \mathrm{NLi}\right]_{2}$. The anisotropic displacement parameters are depicted at the $50 \%$ probability level. The hydrogen atoms are omitted for clarity.

This crystal structure was already measured by P.-C. Kuo et al. at room temperature. ${ }^{[97]}$

Table 7-21. Crystallographic data for $\left[2,5-\left(\mathrm{CH}_{2} \mathrm{NMe}_{2}\right) \mathrm{C}_{4} \mathrm{H}_{4} \mathrm{NLi}\right]_{2}$.

\begin{tabular}{|c|c|c|c|}
\hline Identification code & IOCMPyNMe2Li & & \\
\hline Empirical formula & $\mathrm{C}_{20} \mathrm{H}_{36} \mathrm{Li}_{2} \mathrm{~N}_{6}$ & $\mu\left[\mathrm{mm}^{-1}\right]$ & 0.065 \\
\hline Formula weight $[\mathrm{g} / \mathrm{mol}]$ & 374.43 & $F(000)$ & 816 \\
\hline Temperature $[\mathrm{K}]$ & $100(2)$ & $\Theta$ range $\left[{ }^{\circ}\right]$ & 1.60 to 26.73 \\
\hline Wavelength [pm] & 71.073 & Reflections collected & 59523 \\
\hline Crystal system & Monoclinic & Independent reflections & 4908 \\
\hline Space group & $P 2_{1} / c$ & Completeness to $\Theta_{\max }$ & $99.7 \%$ \\
\hline$a[\mathrm{pm}]$ & $1279.46(11)$ & Absorption correction & Empirical \\
\hline$b[\mathrm{pm}]$ & $970.89(8)$ & Max. / min. transmission & $0.7456 / 0.7027$ \\
\hline$c[\mathrm{pm}]$ & $1867.30(15)$ & Restraints / parameters & $0 / 261$ \\
\hline$\beta\left[^{\circ}\right]$ & $94.2520(10)$ & GoF & 1.064 \\
\hline Volume $\left[\mathrm{nm}^{3}\right]$ & $2.3132(3)$ & $R 1 / w R 2(I>2 \sigma(I))$ & $0.0376 / 0.1000$ \\
\hline Z & 4 & $R 1 / w R 2$ (all data) & $0.0426 / 0.1037$ \\
\hline$\rho_{\text {calc }}\left[\mathrm{Mg} / \mathrm{m}^{3}\right]$ & 1.075 & Diff. peak and hole $\left[\mathrm{e} \AA^{-3}\right]$ & 0.206 and -0.201 \\
\hline
\end{tabular}




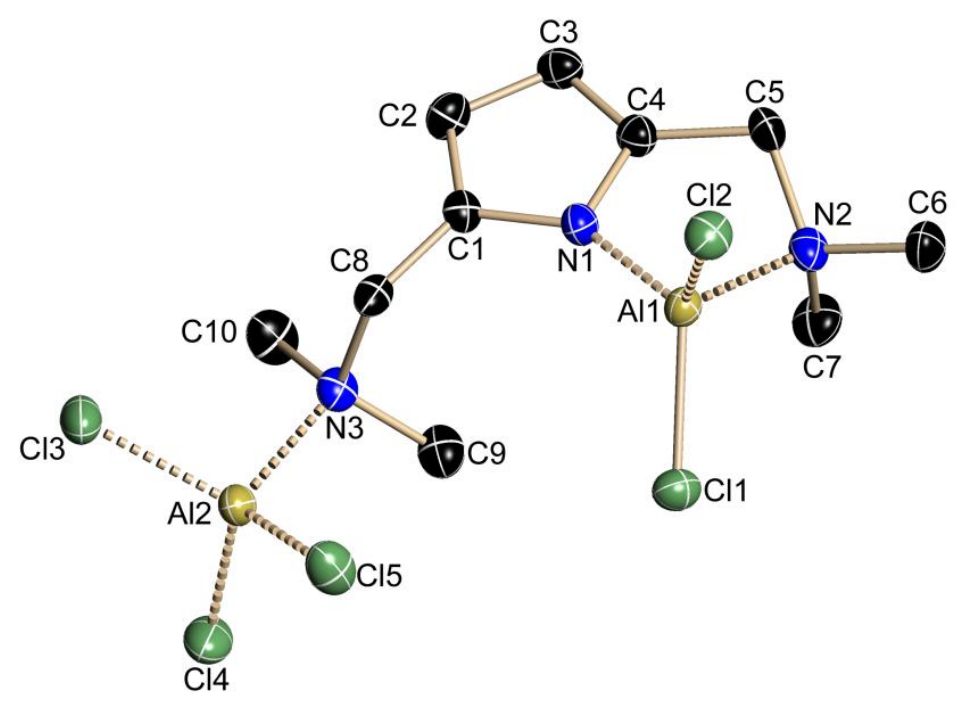

Figure 7-22. Asymmetric unit of [2,5-( $\left.\left.\mathrm{CH}_{2} \mathrm{NMe}_{2}\right) \mathrm{C}_{4} \mathrm{H}_{4} \mathrm{NAIMe}_{2}\right] \mathrm{AlMe}$. The anisotropic displacement parameters are depicted at the $50 \%$ probability level. The hydrogen atoms are omitted for clarity.

Table 7-22. Crystallographic data for $\left[2,5-\left(\mathrm{CH}_{2} \mathrm{NMe}_{2}\right) \mathrm{C}_{4} \mathrm{H}_{4} \mathrm{NAIMe}_{2}\right] \mathrm{AlMe}_{3}$.

\begin{tabular}{|c|c|c|c|}
\hline Identification code & IOCMR039 & & \\
\hline Empirical formula & $\mathrm{C}_{10} \mathrm{H}_{18} \mathrm{Al}_{2} \mathrm{Cl}_{5} \mathrm{~N}_{3}$ & $\mu\left[\mathrm{mm}^{-1}\right]$ & 0.854 \\
\hline Formula weight $[\mathrm{g} / \mathrm{mol}]$ & 411.48 & $F(000)$ & 840 \\
\hline Temperature $[\mathrm{K}]$ & $100(2)$ & $\Theta$ range $\left[{ }^{\circ}\right]$ & 1.85 to 22.97 \\
\hline Wavelength [pm] & 71.073 & Reflections collected & 27713 \\
\hline Crystal system & Monoclinic & Independent reflections & 2618 \\
\hline Space group & $P 2_{1} / c$ & Completeness to $\Theta_{\max }$ & $100.0 \%$ \\
\hline$a[\mathrm{pm}]$ & $1113.2(4)$ & Absorption correction & Empirical \\
\hline$b[\mathrm{pm}]$ & $1186.3(4)$ & Max. / min. transmission & 0.7449 / 0.6157 \\
\hline$c[\mathrm{pm}]$ & $1445.6(5)$ & Restraints / parameters & $0 / 185$ \\
\hline$\beta\left[^{\circ}\right]$ & $98.338(7)$ & GoF & 1.019 \\
\hline Volume $\left[\mathrm{nm}^{3}\right]$ & $1.8890(11)$ & $R 1 / w R 2(I>2 \sigma(I))$ & 0.0479 / 0.0990 \\
\hline Z & 4 & $R 1 / w R 2$ (all data) & 0.0849 / 0.1149 \\
\hline$\rho_{\text {calc }}\left[\mathrm{Mg} / \mathrm{m}^{3}\right]$ & 1.447 & Diff. peak and hole $\left[\mathrm{e} \AA^{-3}\right]$ & 0.479 and -0.350 \\
\hline
\end{tabular}




\subsubsection{Structures measured for Dipl.-Chem. Simone Dietz}

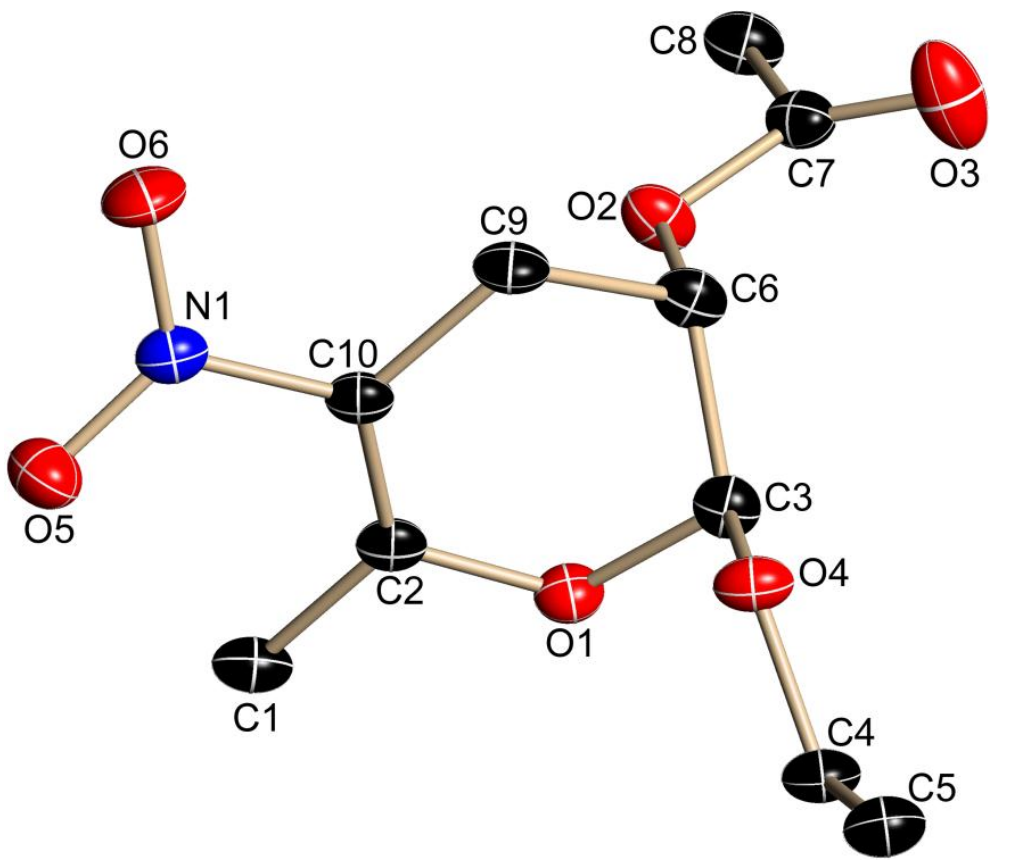

Figure 7-23. Asymmetric unit of rac-(2S,3S)-3-Acetoxy-2-ethoxy-6-methyl-5-nitro-3,4-dihydro-2H-pyran.

The anisotropic displacement parameters are depicted at the $50 \%$ probability level. The hydrogen atoms are omitted for clarity.

Table 7-23. Crystallographic data for rac-(2S,3S)-3-Acetoxy-2-ethoxy-6-methyl-5-nitro-3,4dihydro-2H-pyran.

\begin{tabular}{|c|c|c|c|}
\hline CCDC no. & 826507 & & \\
\hline Empirical formula & $\mathrm{C}_{10} \mathrm{H}_{15} \mathrm{NO}_{6}$ & $\mu\left[\mathrm{mm}^{-1}\right]$ & 0.116 \\
\hline Formula weight $[\mathrm{g} / \mathrm{mol}]$ & 245.23 & $F(000)$ & 520 \\
\hline Temperature $[\mathrm{K}]$ & $100(2)$ & $\Theta$ range $\left[{ }^{\circ}\right]$ & 1.74 to 25.37 \\
\hline Wavelength [pm] & 71.073 & Reflections collected & 18803 \\
\hline Crystal system & Monoclinic & Independent reflections & 2120 \\
\hline Space group & $P 2_{1} / c$ & Completeness to $\Theta_{\max }$ & $99.7 \%$ \\
\hline$a[\mathrm{pm}]$ & $1195.1(3)$ & Absorption correction & Empirical \\
\hline$b[\mathrm{pm}]$ & $993.0(2)$ & Max. / min. transmission & $1.0000 / 0.7324$ \\
\hline$c[\mathrm{pm}]$ & $1002.5(2)$ & Restraints / parameters & $0 / 157$ \\
\hline$\beta\left[^{\circ}\right]$ & $101.81(2)$ & GoF & 1.093 \\
\hline Volume $\left[\mathrm{nm}^{3}\right]$ & $1.1645(4)$ & $R 1 / w R 2(I>2 \sigma(I))$ & $0.0440 / 0.1052$ \\
\hline Z & 4 & $R 1 / w R 2$ (all data) & $0.0681 / 0.1225$ \\
\hline$\rho_{\text {calc }}\left[\mathrm{Mg} / \mathrm{m}^{3}\right]$ & 1.399 & Diff. peak and hole $\left[\mathrm{e} \AA^{-3}\right]$ & 0.283 and -0.309 \\
\hline
\end{tabular}




\subsubsection{Structures measured for Dipl.-Chem. Tim Hungerland}

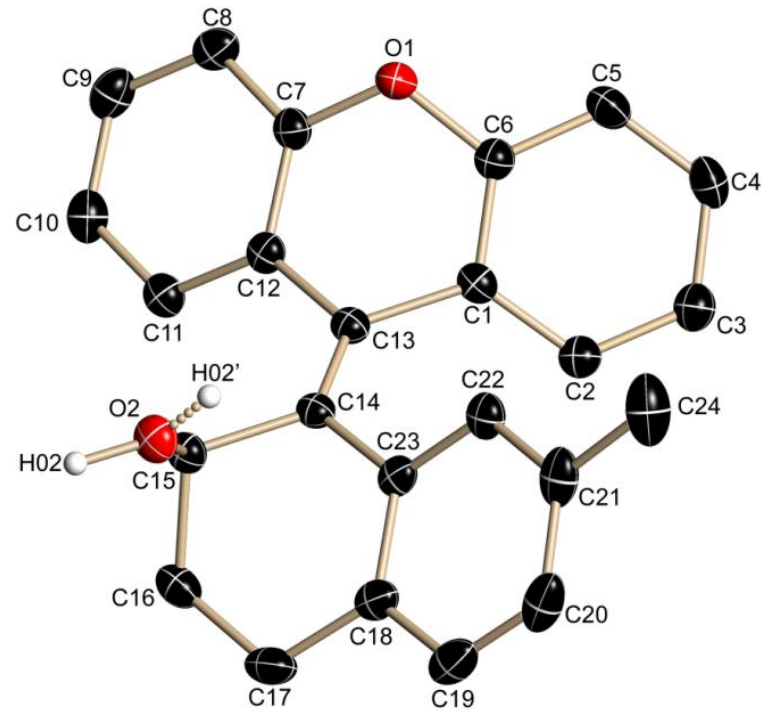

Figure 7-24. Asymmetric unit of rac-7-Methyl-1-(9H-xanthen-9-ylidene)-1,2,3,4-tetrahydronaphthalen-2ol. The anisotropic displacement parameters are depicted at the $50 \%$ probability level. The hydrogen atoms are omitted for clarity.

The position of the hydrogen atom $\mathrm{HO} 2$ at the $\mathrm{OH}$ group was taken from the difference map and refined with distance restraints, additionally this hydrogen atom is disordered (ratio $0.58: 0.42$ ). The hydrogen atoms of the methyl group C24 were refined with HFIX 123.

Table 7-24. Crystallographic data for rac-7-Methyl-1-(9H-xanthen-9-ylidene)-1,2,3,4-tetrahydronaphthalen-2-ol.

\begin{tabular}{ll|ll}
\hline CCDC no. & 826455 & & \\
Empirical formula & $\mathrm{C}_{24} \mathrm{H}_{20} \mathrm{O}_{2}$ & $\mu\left[\mathrm{mm}^{-1}\right]$ & 0.082 \\
Formula weight $[\mathrm{g} / \mathrm{mol}]$ & 340.40 & $\mathrm{~F}(000)$ & 720 \\
Temperature $[\mathrm{K}]$ & $100(2)$ & $\Theta$ range $\left[^{\circ}\right]$ & 1.22 to 26.46 \\
Wavelength $[\mathrm{pm}]$ & 71.073 & Reflections collected & 23358 \\
Crystal system & Monoclinic & Independent reflections & 3545 \\
Space group & $P 2 / c$ & Completeness to $\Theta_{\max }$ & $99.7 \%$ \\
$a[\mathrm{pm}]$ & $1740.5(9)$ & Absorption correction & Empirical \\
$b[\mathrm{pm}]$ & $624.0(4)$ & Max. / min. transmission & $1.0000 / 0.8908$ \\
$c[\mathrm{pm}]$ & $1656.9(9)$ & Restraints / parameters & $1 / 245$ \\
$\beta\left[^{\circ}\right]$ & $106.89(2)$ & GoF & 1.080 \\
Volume $\left[\mathrm{nm}^{3}\right]$ & $1.7219(17)$ & $R 1 / w R 2(\mathrm{I}>2 \sigma(\mathrm{I}))$ & $0.0478 / 0.1309$ \\
$\mathrm{Z}$ & 4 & $R 1 / w R 2($ all data) & $0.0569 / 0.1371$ \\
$\rho_{\text {calc }}\left[\mathrm{Mg} / \mathrm{m}^{3}\right]$ & 1.313 & Diff. peak and hole $\left[\mathrm{e} \AA^{-3}\right]$ & 0.294 and -0.216 \\
\hline
\end{tabular}




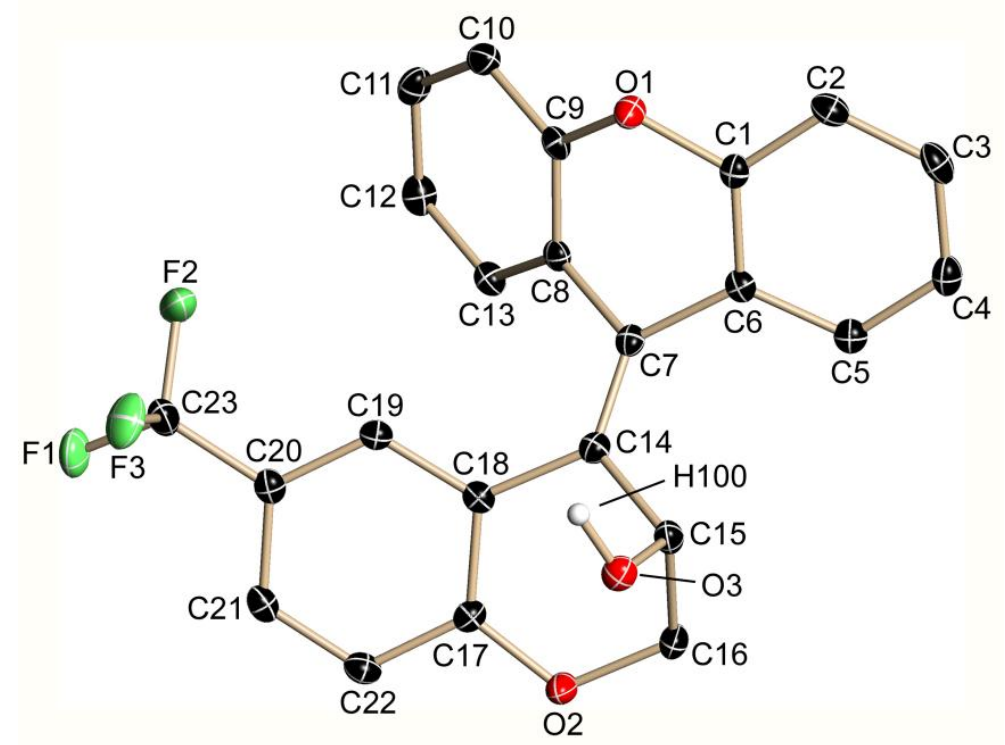

Figure 7-25. Asymmetric unit of rac-6-(Trifluoromethyl)-4-(9H-xanthen-9-ylidene)chroman-3-ol. The anisotropic displacement parameters are depicted at the $50 \%$ probability level. The hydrogen atoms are omitted for clarity.

The position of the hydrogen atom $\mathrm{H} 100$ at the $\mathrm{OH}$ group was taken from the difference map and refined freely.

Table 7-25. Crystallographic data for rac-6-(Trifluoromethyl)-4-(9H-xanthen-9-ylidene)chroman-3-ol.

\begin{tabular}{ll|ll}
\hline CCDC no. & 826454 & & \\
Empirical formula & $\mathrm{C}_{23} \mathrm{H}_{15} \mathrm{~F}_{3} \mathrm{O}_{3}$ & $\mu\left[\mathrm{mm}^{-1}\right]$ & 0.122 \\
Formula weight $[\mathrm{g} / \mathrm{mol}]$ & 396.35 & $\mathrm{~F}(000)$ & 816 \\
Temperature $[\mathrm{K}]$ & $100(2)$ & $\Theta$ range $\left[^{\circ}\right]$ & 2.03 to 26.40 \\
Wavelength $[\mathrm{pm}]$ & 71.073 & Reflections collected & 24574 \\
Crystal system & Monoclinic & Independent reflections & 3542 \\
Space group & $P 2_{1} / n$ & Completeness to $\Theta_{\text {max }}$ & $99.7 \%$ \\
$a[\mathrm{pm}]$ & $1262.0(2)$ & Absorption correction & Empirical \\
$b[\mathrm{pm}]$ & $945.3(2)$ & Max. / min. transmission & $1.0000 / 0.9196$ \\
$c[\mathrm{pm}]$ & $1458.9(3)$ & Restraints / parameters & $0 / 266$ \\
$\beta\left[{ }^{\circ}\right]$ & $96.09(2)$ & GoF & 1.038 \\
Volume $\left[\mathrm{nm}^{3}\right]$ & $1.7306(6)$ & $R 1 / w R 2(\mathrm{I} 2 \sigma(\mathrm{I}))$ & $0.0376 / 0.0879$ \\
$\mathrm{Z}$ & 4 & $R 1 / w R 2$ (all data) & $0.0492 / 0.0937$ \\
$\rho_{\text {calc }}\left[\mathrm{Mg} / \mathrm{m}^{3}\right]$ & 1.521 & Diff. peak and hole $\left[\mathrm{e} \AA^{-3}\right]$ & 0.279 and -0.252 \\
\hline
\end{tabular}




\subsubsection{Structures measured for Dr. Sankaranarayana P. Sarish}

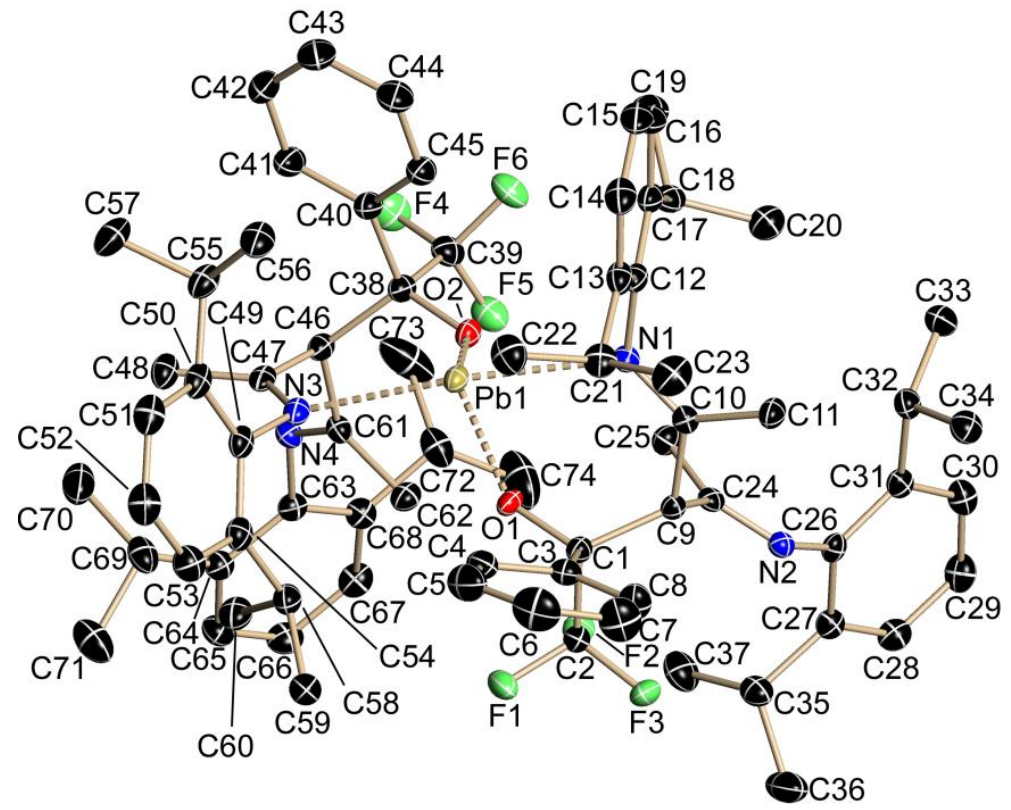

Figure 7-26. Asymmetric unit of $\left[\mathrm{CH}\left(\mathrm{CPhCF}_{3} \mathrm{O}\right)-\left\{\mathrm{C}(\mathrm{Me})\left(=2,6-{ }^{i} \mathrm{Pr}_{2} \mathrm{C}_{6} \mathrm{H}_{3} \mathrm{~N}\right)\right\}_{2}\right] \mathrm{Pb}$. The anisotropic displacement parameters are depicted at the $50 \%$ probability level. The hydrogen atoms are omitted for clarity.

The contributions of the extremely disordered non-coordinating THF molecules to the scattering factors were removed with SQUEEZE. ${ }^{[92]}$

Table 7-26. Crystallographic data for $\left[\mathrm{CH}\left(\mathrm{CPhCF}_{3} \mathrm{O}\right)-\left\{\mathrm{C}(\mathrm{Me})\left(=2,6-{ }^{i} \mathrm{Pr}_{2} \mathrm{C}_{6} \mathrm{H}_{3} \mathrm{~N}\right)\right\}_{2}\right] \mathrm{Pb}$.

\begin{tabular}{ll|ll}
\hline CCDC no. & 808035 & & \\
Empirical formula & $\mathrm{C}_{74} \mathrm{H}_{92} \mathrm{~F}_{6} \mathrm{~N}_{4} \mathrm{O}_{2} \mathrm{~Pb}$ & $\mu\left[\mathrm{mm}^{-1}\right]$ & 2.316 \\
Formula weight $[\mathrm{g} / \mathrm{mol}]$ & 1390.71 & $\mathrm{~F}(000)$ & 2864 \\
Temperature $[\mathrm{K}]$ & $100(2)$ & $\Theta$ range $\left[^{\circ}\right]$ & 1.35 to 26.02 \\
Wavelength $[\mathrm{pm}]$ & 71.073 & Reflections collected & 166483 \\
Crystal system & Monoclinic & Independent reflections & 14728 \\
Space group & $P 2_{1} / \mathrm{c}$ & Completeness to $\Theta_{\max }$ & $100.0 \%$ \\
$a[\mathrm{pm}]$ & $1570.60(15)$ & Absorption correction & Empirical \\
$b[\mathrm{pm}]$ & $1890.00(18)$ & Max. / min. transmission & $0.7921 / 0.6482$ \\
$c[\mathrm{pm}]$ & $2633.6(3)$ & Restraints / parameters & $0 / 804$ \\
$\beta\left[^{\circ}\right]$ & $107.0930(10)$ & GoF & 1.063 \\
Volume $\left[\mathrm{nm}^{3}\right]$ & $7.4723(12)$ & $R 1 / w R 2(\mathrm{I}>2 \sigma(\mathrm{I}))$ & $0.0208 / 0.0522$ \\
$\mathrm{Z}$ & 4 & $R 1 / w R 2($ all data) & $0.0260 / 0.0543$ \\
$\rho_{\text {calc }}\left[\mathrm{Mg} / \mathrm{m}^{3}\right]$ & 1.236 & Diff. peak and hole $\left[\mathrm{e} \AA^{-3}\right]$ & 0.717 and -1.197 \\
\hline
\end{tabular}




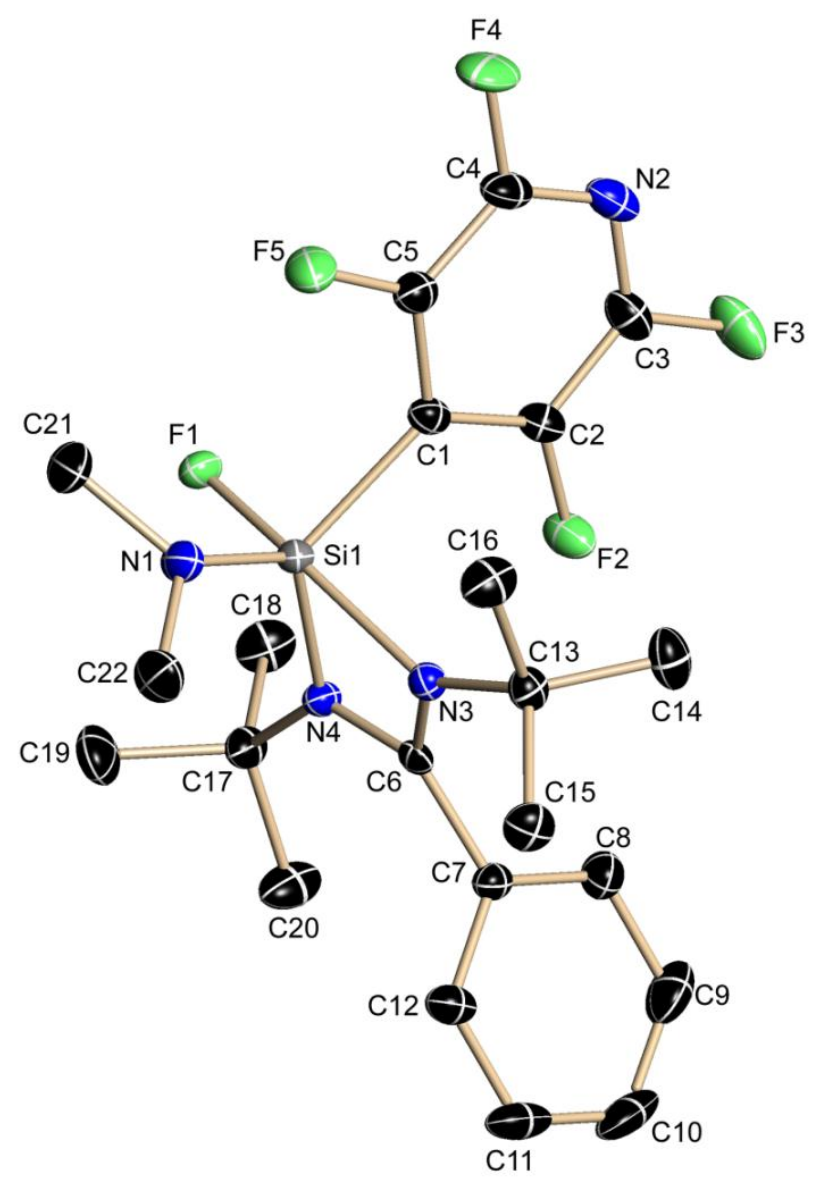

Figure 7-27. Asymmetric unit of $\mathrm{PhC}(\mathrm{NtBu})_{2} \mathrm{Si}(\mathrm{F})\left(\mathrm{NMe}_{2}\right)\left(\mathrm{C}_{4} \mathrm{NF}_{4}\right)$. The anisotropic displacement parameters are depicted at the $50 \%$ probability level. The hydrogen atoms are omitted for clarity.

Table 7-27. Crystallographic data for $\mathrm{PhC}(\mathrm{NtBu})_{2} \mathrm{Si}(\mathrm{F})\left(\mathrm{NMe}_{2}\right)\left(\mathrm{C}_{4} \mathrm{NF}_{4}\right)$.

\begin{tabular}{ll|ll}
\hline Identification code & IOSS97 & & \\
Empirical formula & $\mathrm{C}_{22} \mathrm{H}_{29} \mathrm{~F}_{5} \mathrm{~N}_{4} \mathrm{Si}$ & $\rho_{\text {calc }}\left[\mathrm{Mg} / \mathrm{m}^{3}\right]$ & 1.332 \\
Formula weight $[\mathrm{g} / \mathrm{mol}]$ & 472.58 & $\mu\left[\mathrm{mm}^{-1}\right]$ & 0.156 \\
Temperature $[\mathrm{K}]$ & $100(2)$ & $\mathrm{F}(000)$ & 496 \\
Wavelength $[\mathrm{pm}]$ & 71.073 & $\Theta$ range $\left[^{\circ}\right]$ & 1.47 to 27.88 \\
Crystal system & Triclinic & Reflections collected & 33255 \\
Space group & $P \overline{1}$ & Independent reflections & 5620 \\
$a[\mathrm{pm}]$ & $925.64(7)$ & Completeness to $\Theta_{\text {max }}$ & $99.9 \%$ \\
$b[\mathrm{pm}]$ & $1020.25(8)$ & Absorption correction & Empirical \\
$c[\mathrm{pm}]$ & $1391.13(10)$ & Max. / min. transmission & $0.9847 / 0.94987$ \\
$\alpha\left[^{\circ}\right]$ & $93.4800(10)$ & Restraints / parameters & $0 / 297$ \\
$\beta\left[^{\circ}\right]$ & $92.2830(10)$ & GoF & 1.039 \\
$\gamma\left[^{\circ}\right]$ & $115.6770(10)$ & $R 1 / w R 2(\mathrm{I}) 2 \sigma(\mathrm{I}))$ & $0.0357 / 0.0876$ \\
$\left.V^{\circ}\right)$ & $R 1 / w R 2$ (all data) & $0.0445 / 0.0927$ \\
$Z$ & $1.17865(15)$ & Diff. peak and hole $\left[\mathrm{e} \AA^{-3}\right]$ & 0.320 and -0.273 \\
\hline
\end{tabular}




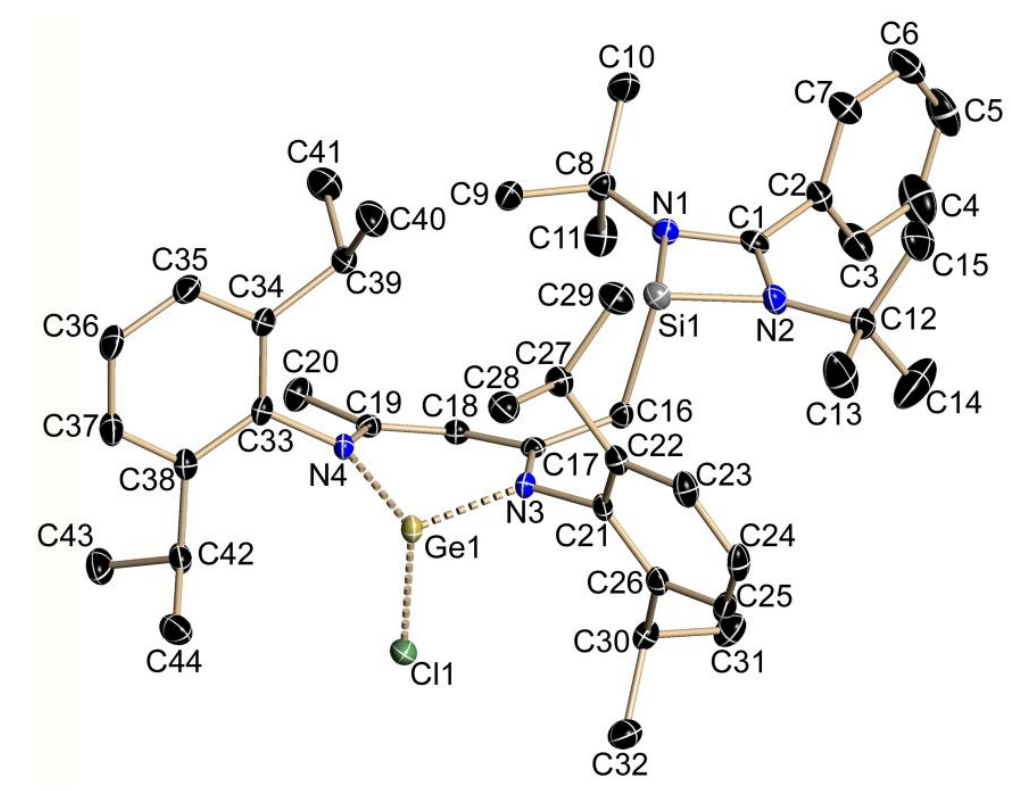

Figure 7-28. Asymmetric unit of $\mathrm{PhC}(\mathrm{NtBu})_{2} \mathrm{Si}\left[\mathrm{CH}\left\{\left(\mathrm{CCH}_{2}\right)(\mathrm{CMe})\left(2,6-\mathrm{Pr}_{2} \mathrm{C}_{6} \mathrm{H}_{3} \mathrm{~N}\right)_{2}\right\}\right] \mathrm{GeCl}$. The anisotropic displacement parameters are depicted at the $50 \%$ probability level. The hydrogen atoms are omitted for clarity.

The positions of the hydrogen atoms bonded to C16 were taken from the difference map and refined freely.

Table 7-28. Crystallographic data for $\mathrm{PhC}(\mathrm{NtBu})_{2} \mathrm{Si}\left[\mathrm{CH}\left\{\left(\mathrm{CCH}_{2}\right)(\mathrm{CMe})\left(2,6-{ }^{i} \mathrm{Pr}_{2} \mathrm{C}_{6} \mathrm{H}_{3} \mathrm{~N}\right)_{2}\right\}\right] \mathrm{GeCl}$.

\begin{tabular}{ll|ll}
\hline CCDC no. & 819683 & & \\
Empirical formula & $\mathrm{C}_{44} \mathrm{H}_{63} \mathrm{ClGeN}_{4} \mathrm{Si}$ & $\mu\left[\mathrm{mm}^{-1}\right]$ & 0.831 \\
Formula weight [g/mol] & 784.11 & $\mathrm{~F}(000)$ & 1672 \\
Temperature $[\mathrm{K}]$ & $99(2)$ & $\Theta$ range $\left[^{\circ}\right]$ & 1.66 to 26.73 \\
Wavelength $[\mathrm{pm}]$ & 71.073 & Reflections collected & 96322 \\
Crystal system & Monoclinic & Independent reflections & 9189 \\
Space group & $P 2{ }_{1} / n$ & Completeness to $\Theta_{\text {max }}$ & $100.0 \%$ \\
$a[\mathrm{pm}]$ & $1318.15(10)$ & Absorption correction & Empirical \\
$b[\mathrm{pm}]$ & $2247.98(17)$ & Max. / min. transmission & $1.0000 / 0.9093$ \\
$c[\mathrm{pm}]$ & $1522.20(11)$ & Restraints / parameters & $0 / 487$ \\
$\beta\left[^{\circ}\right]$ & $106.3880(10)$ & GoF & 1.047 \\
Volume $\left[\mathrm{nm}^{3}\right]$ & $4.3273(6)$ & $R 1 / w R 2(\mathrm{I}>2 \sigma(\mathrm{I}))$ & $0.0318 / 0.0673$ \\
$\mathrm{Z}$ & 4 & $R 1 / w R 2$ (all data) & $0.0453 / 0.0722$ \\
$\rho_{\text {calc }}\left[\mathrm{Mg} / \mathrm{m}^{3}\right]$ & 1.204 & Diff. peak and hole $\left[\mathrm{e} \AA^{-3}\right]$ & 0.571 and -0.313 \\
\hline
\end{tabular}




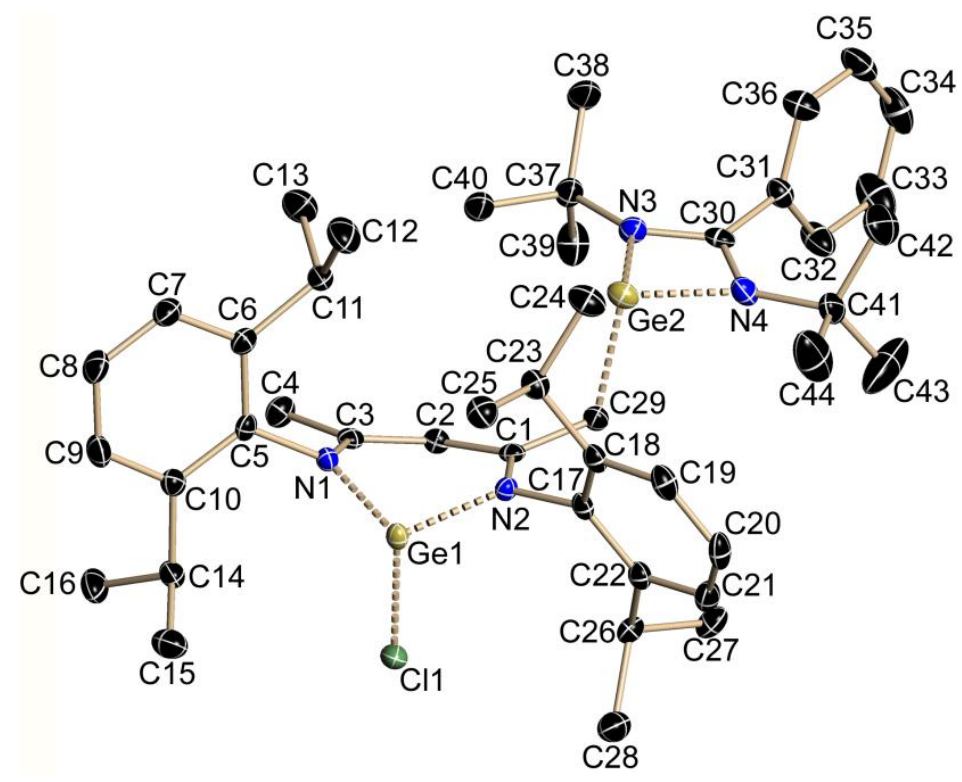

Figure 7-29. Asymmetric unit of $\mathrm{PhC}(\mathrm{NtBu})_{2} \mathrm{Ge}\left[\mathrm{CH}\left\{\left(\mathrm{CCH}_{2}\right)(\mathrm{CMe})\left(2,6-{ }^{i} \mathrm{Pr}_{2} \mathrm{C}_{6} \mathrm{H}_{3} \mathrm{~N}\right)_{2}\right\}\right] \mathrm{GeCl}$. The anisotropic displacement parameters are depicted at the $50 \%$ probability level. The hydrogen atoms are omitted for clarity.

Table 7-29. Crystallographic data for PhC(NtBu$)_{2} \mathrm{Ge}\left[\mathrm{CH}\left\{\left(\mathrm{CCH}_{2}\right)(\mathrm{CMe})\left(2,6-{ }^{i} \mathrm{Pr}_{2} \mathrm{C}_{6} \mathrm{H}_{3} \mathrm{~N}\right)_{2}\right\}\right] \mathrm{GeCl}$.

\begin{tabular}{|c|c|c|c|}
\hline CCDC no. & 819684 & & \\
\hline Empirical formula & $\mathrm{C}_{44} \mathrm{H}_{63} \mathrm{ClGe}_{2} \mathrm{~N}_{4}$ & $\mu\left[\mathrm{mm}^{-1}\right]$ & 1.476 \\
\hline Formula weight $[\mathrm{g} / \mathrm{mol}]$ & 828.61 & $F(000)$ & 1744 \\
\hline Temperature $[\mathrm{K}]$ & $100(2)$ & $\Theta$ range $\left[{ }^{\circ}\right]$ & 1.66 to 25.35 \\
\hline Wavelength [pm] & 71.073 & Reflections collected & 90869 \\
\hline Crystal system & Monoclinic & Independent reflections & 7962 \\
\hline Space group & $P 2_{1} / n$ & Completeness to $\Theta_{\max }$ & $100.0 \%$ \\
\hline$a[\mathrm{pm}]$ & $1320.7(2)$ & Absorption correction & Empirical \\
\hline$b[\mathrm{pm}]$ & $2251.5(3)$ & Max. / min. transmission & $0.93 / 0.820074$ \\
\hline$c[\mathrm{pm}]$ & $1527.3(2)$ & Restraints / parameters & $0 / 475$ \\
\hline$\beta\left[^{\circ}\right]$ & $106.601(2)$ & GoF & 1.038 \\
\hline Volume $\left[\mathrm{nm}^{3}\right]$ & $4.3524(11)$ & $R 1 / w R 2(I>2 \sigma(I))$ & $0.0325 / 0.0642$ \\
\hline Z & 4 & $R 1 / w R 2$ (all data) & 0.0459 / 0.0690 \\
\hline$\rho_{\text {calc }}\left[\mathrm{Mg} / \mathrm{m}^{3}\right]$ & 1.265 & Diff. peak and hole $\left[\mathrm{e}^{-3}\right]$ & 0.710 and -0.474 \\
\hline
\end{tabular}




\subsubsection{Structures measured for Dr. Anukul Jana}

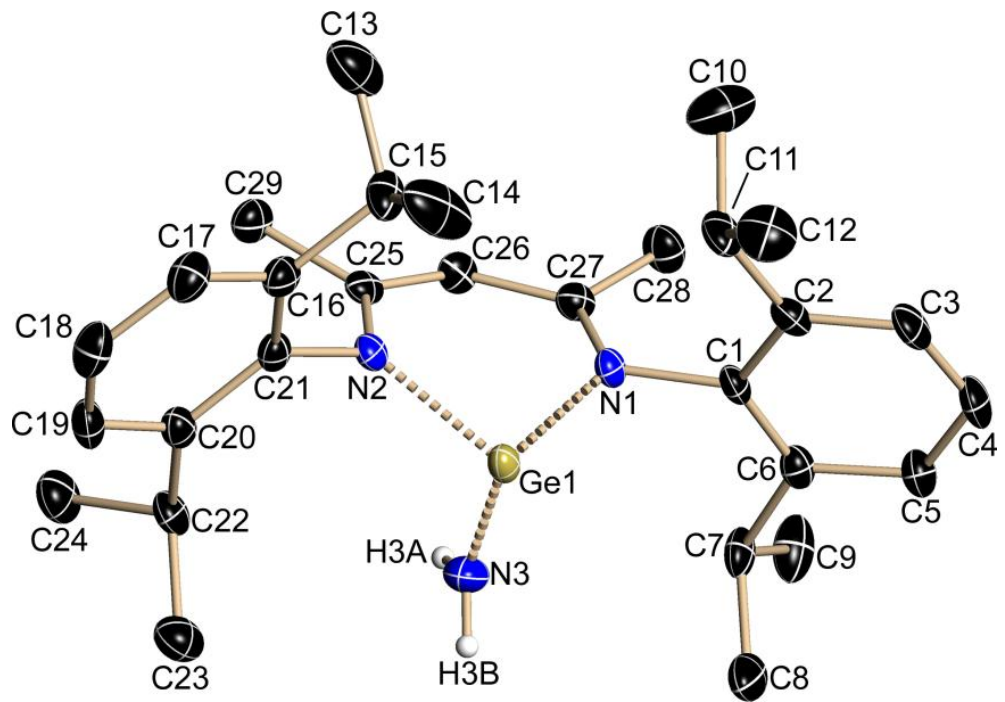

Figure 7-30. Asymmetric unit of $\left[\mathrm{CH}\left\{(\mathrm{CMe})\left(2,6-{ }^{i} \mathrm{Pr}_{2} \mathrm{C}_{6} \mathrm{H}_{3} \mathrm{~N}\right)\right\}_{2}\right] \mathrm{GeNH}_{2}$. The anisotropic displacement parameters are depicted at the $50 \%$ probability level. The hydrogen atoms are omitted for clarity.

The positions of the hydrogen atoms $\mathrm{H} 3 \mathrm{~A}$ and $\mathrm{H} 3 \mathrm{~B}$ at the amine nitrogen atom N3 were taken from the difference map and refined with distance restraints.

Table 7-30. Crystallographic data for $\left[\mathrm{CH}\left\{(\mathrm{CMe})\left(2,6-{ }^{i} \mathrm{Pr}_{2} \mathrm{C}_{6} \mathrm{H}_{3} \mathrm{~N}\right)\right\}_{2}\right] \mathrm{GeNH}_{2}$.

\begin{tabular}{ll|ll}
\hline CCDC no. & 705305 & & \\
Empirical formula & $\mathrm{C}_{29} \mathrm{H}_{43} \mathrm{GeN}_{3}$ & $\mu\left[\mathrm{mm}^{-1}\right]$ & 1.131 \\
Formula weight $[\mathrm{g} / \mathrm{mol}]$ & 506.25 & $\mathrm{~F}(000)$ & 2160 \\
Temperature $[\mathrm{K}]$ & $100(2)$ & $\Theta$ range $\left[^{\circ}\right]$ & 1.57 to 25.38 \\
Wavelength [pm] & 71.073 & Reflections collected & 25829 \\
Crystal system & Monoclinic & Independent reflections & 5069 \\
Space group & $C 2 / \mathrm{c}$ & Completeness to $\Theta_{\text {max }}$ & $99.5 \%$ \\
$a[\mathrm{pm}]$ & $2490.2(5)$ & Absorption correction & Empirical \\
$b[\mathrm{pm}]$ & $1516.7(3)$ & Max. / min. transmission & $0.970 / 0.746$ \\
$c[\mathrm{pm}]$ & $1467.2(3)$ & Restraints / parameters & $3 / 316$ \\
$\beta\left[{ }^{\circ}\right]$ & $95.261(3)$ & GoF & 1.074 \\
Volume $\left[\mathrm{nm}^{3}\right]$ & $5.5180(18)$ & $R 1 / w R 2$ (I>2 $\sigma(\mathrm{I}))$ & $0.0385 / 0.1005$ \\
$\mathrm{Z}$ & 8 & $R 1 / w R 2$ (all data) & $0.0498 / 0.1048$ \\
$\rho_{\text {calc }}\left[\mathrm{Mg} / \mathrm{m}^{3}\right]$ & 1.219 & Diff. peak and hole $\left[\mathrm{e} \AA^{-3}\right]$ & 0.609 and -0.799 \\
\hline
\end{tabular}




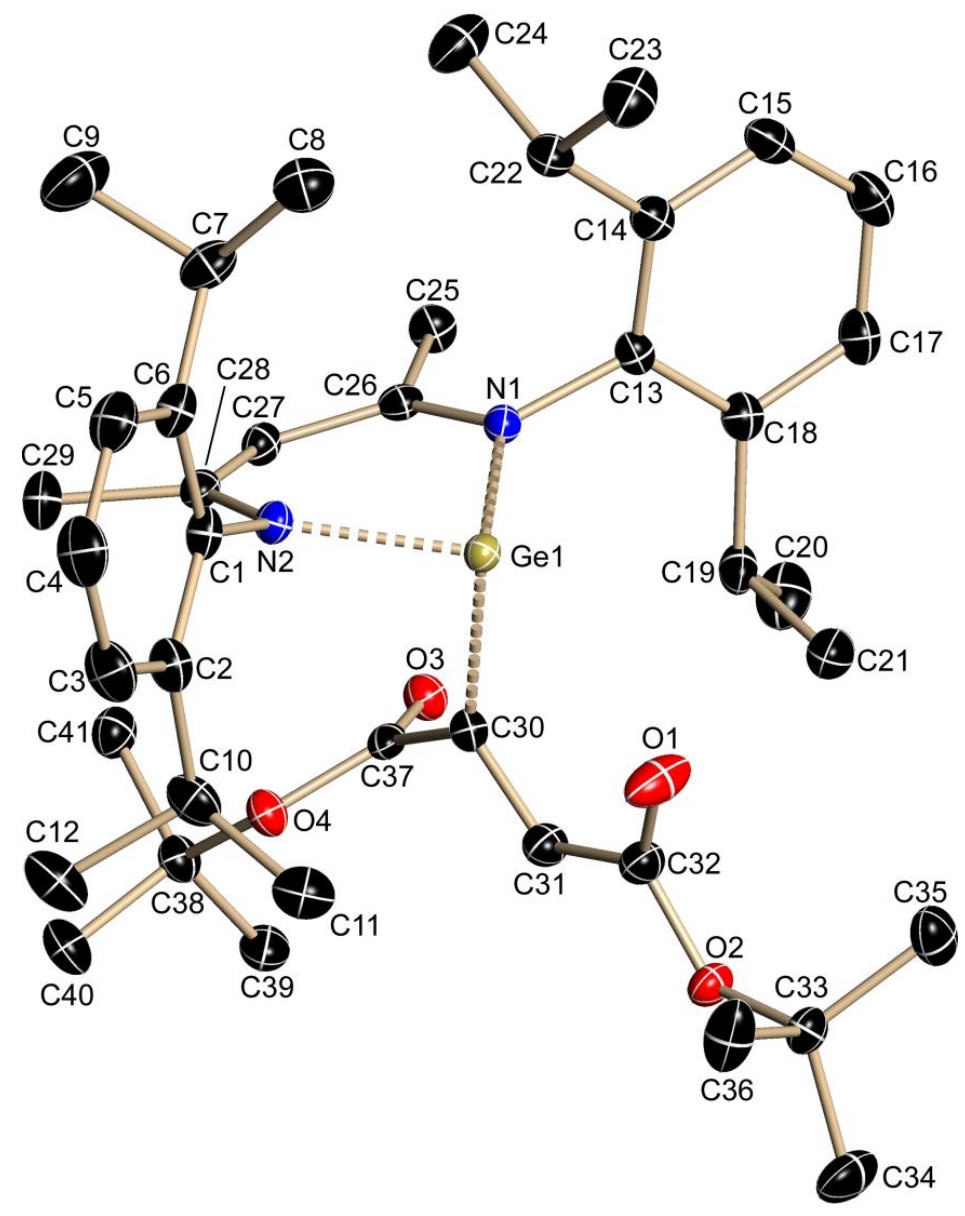

Figure 7-31. Asymmetric unit of $\left[\mathrm{CH}\left\{(\mathrm{CMe})\left(2,6-{ }^{i} \mathrm{Pr}_{2} \mathrm{C}_{6} \mathrm{H}_{3} \mathrm{~N}\right)\right\}_{2}\right] \mathrm{Ge}\left(\mathrm{C}_{2} \mathrm{HCO}_{2} t \mathrm{Bu}\right)\left(\mathrm{CO}_{2} t \mathrm{Bu}\right)$. The anisotropic displacement parameters are depicted at the $50 \%$ probability level. The hydrogen atoms are omitted for clarity.

Table 7-31. Crystallographic data for $\left[\mathrm{CH}\left\{(\mathrm{CMe})\left(2,6-{ }^{i} \mathrm{Pr}_{2} \mathrm{C}_{6} \mathrm{H}_{3} \mathrm{~N}\right)\right\}_{2}\right] \mathrm{Ge}\left(\mathrm{C}_{2} \mathrm{HCO}_{2} t \mathrm{Bu}\right)\left(\mathrm{CO}_{2} t \mathrm{Bu}\right)$.

\begin{tabular}{|c|c|c|c|}
\hline CCDC no. & 706624 & & \\
\hline Empirical formula & $\mathrm{C}_{41} \mathrm{H}_{60} \mathrm{GeN}_{2} \mathrm{O}_{4}$ & $\mu\left[\mathrm{mm}^{-1}\right]$ & 0.823 \\
\hline Formula weight $[\mathrm{g} / \mathrm{mol}]$ & 717.50 & $F(000)$ & 1536 \\
\hline Temperature $[\mathrm{K}]$ & $100(2)$ & $\Theta$ range $\left[{ }^{\circ}\right]$ & 1.57 to 26.37 \\
\hline Wavelength [pm] & 71.073 & Reflections collected & 63793 \\
\hline Crystal system & Monoclinic & Independent reflections & 8000 \\
\hline Space group & $P 2_{1} / \mathrm{n}$ & Completeness to $\Theta_{\max }$ & $99.9 \%$ \\
\hline$a[\mathrm{pm}]$ & $1157.88(19)$ & Absorption correction & Empirical \\
\hline$b[\mathrm{pm}]$ & $1755.9(3)$ & Max. / min. transmission & $0.4299 / 0.3808$ \\
\hline$c[\mathrm{pm}]$ & $1977.8(3)$ & Restraints / parameters & $0 / 449$ \\
\hline$\beta\left[^{\circ}\right]$ & $103.221(2)$ & GoF & 1.047 \\
\hline Volume $\left[\mathrm{nm}^{3}\right]$ & $3.9145(11)$ & $R 1 / w R 2(I>2 \sigma(I))$ & $0.0279 / 0.0666$ \\
\hline Z & 4 & $R 1 / w R 2$ (all data) & $0.0339 / 0.0689$ \\
\hline$\rho_{\text {calc }}\left[\mathrm{Mg} / \mathrm{m}^{3}\right]$ & 1.217 & Diff. peak and hole $\left[\mathrm{e} \AA^{-3}\right]$ & 0.297 and -0.330 \\
\hline
\end{tabular}




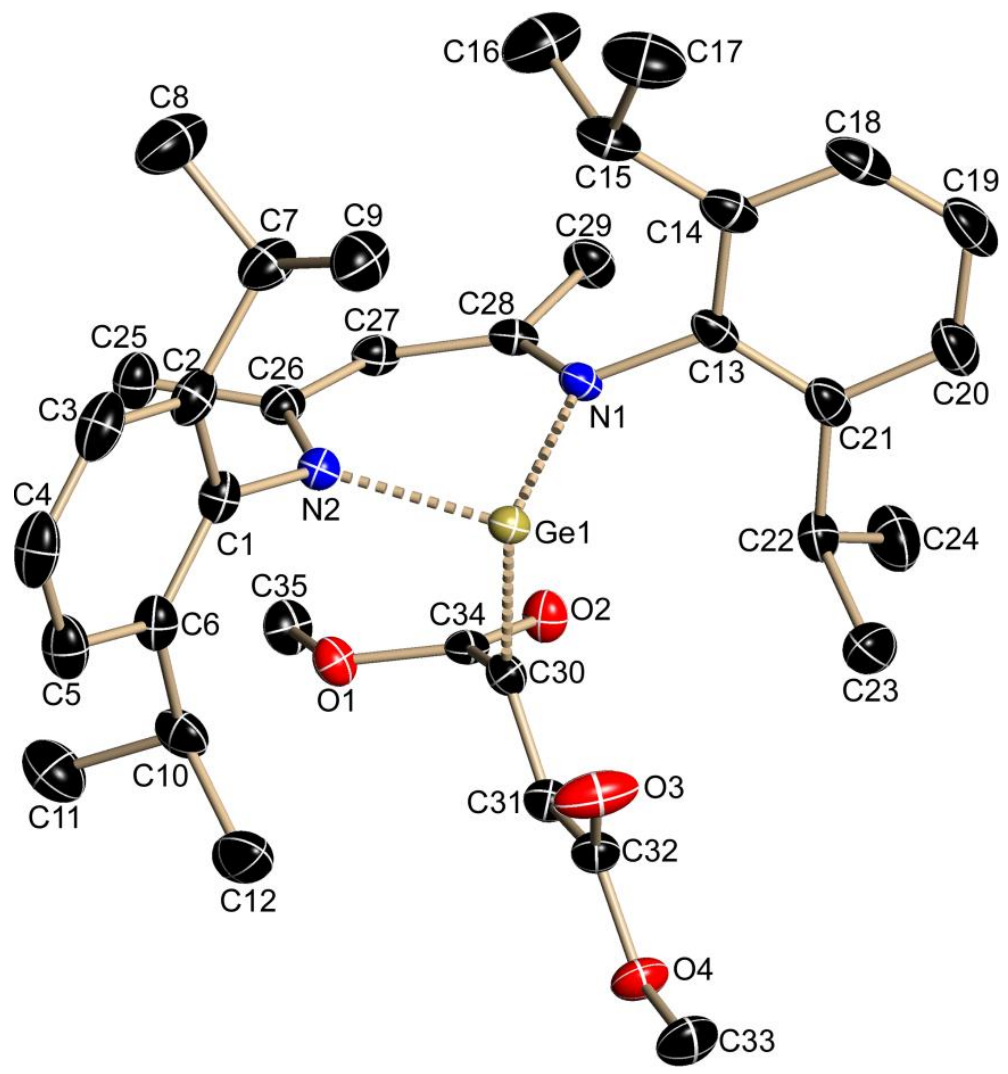

Figure 7-32. Asymmetric unit of $\left[\mathrm{CH}\left\{(\mathrm{CMe})\left(2,6-{ }^{i} \mathrm{Pr}_{2} \mathrm{C}_{6} \mathrm{H}_{3} \mathrm{~N}\right)\right\}_{2}\right] \mathrm{Ge}\left(\mathrm{C}_{2} \mathrm{HCO}_{2} \mathrm{Me}\right)\left(\mathrm{CO}_{2} \mathrm{Me}\right)$. The anisotropic displacement parameters are depicted at the $50 \%$ probability level. The hydrogen atoms are omitted for clarity.

Table 7-32. Crystallographic data for $\left[\mathrm{CH}\left\{(\mathrm{CMe})\left(2,6-{ }^{i} \mathrm{Pr}_{2} \mathrm{C}_{6} \mathrm{H}_{3} \mathrm{~N}\right)\right\}_{2}\right] \mathrm{Ge}\left(\mathrm{C}_{2} \mathrm{HCO}_{2} \mathrm{Me}\right)\left(\mathrm{CO}_{2} \mathrm{Me}\right)$.

\begin{tabular}{ll|ll}
\hline CCDC no. & 706623 & & \\
Empirical formula & $\mathrm{C}_{35} \mathrm{H}_{48} \mathrm{GeN}_{2} \mathrm{O}_{4}$ & $\mu\left[\mathrm{mm}^{-1}\right]$ & 0.929 \\
Formula weight [g/mol] & 633.34 & $\mathrm{~F}(000)$ & 1344 \\
Temperature $[\mathrm{K}]$ & $100(2)$ & $\Theta$ range $\left[^{\circ}\right]$ & 2.21 to 26.37 \\
Wavelength $[\mathrm{pm}]$ & 71.073 & Reflections collected & 55980 \\
Crystal system & Monoclinic & Independent reflections & 7008 \\
Space group & $P 2{ }_{1} / \mathrm{n}$ & Completeness to $\Theta_{\text {max }}$ & $99.9 \%$ \\
$a[\mathrm{pm}]$ & $1201.06(19)$ & Absorption correction & Empirical \\
$b[\mathrm{pm}]$ & $1501.0(2)$ & Max. / min. transmission & $0.4299 / 0.3914$ \\
$c[\mathrm{pm}]$ & $1963.5(3)$ & Restraints / parameters & $0 / 391$ \\
$\beta\left[^{\circ}\right]$ & $103.980(2)$ & GoF & 1.023 \\
Volume $\left[\mathrm{nm}{ }^{3}\right]$ & $3.4349(9)$ & $R 1 / w R 2(\mathrm{I}>2 \sigma(\mathrm{I}))$ & $0.0264 / 0.0649$ \\
$\mathrm{Z}$ & 4 & $R 1 / w R 2$ (all data) & $0.0306 / 0.0668$ \\
$\rho_{\text {calc }}\left[\mathrm{Mg} / \mathrm{m}^{3}\right]$ & 1.225 & Diff. peak and hole $\left[\mathrm{e} \AA^{-3}\right]$ & 0.320 and -0.344 \\
\hline
\end{tabular}




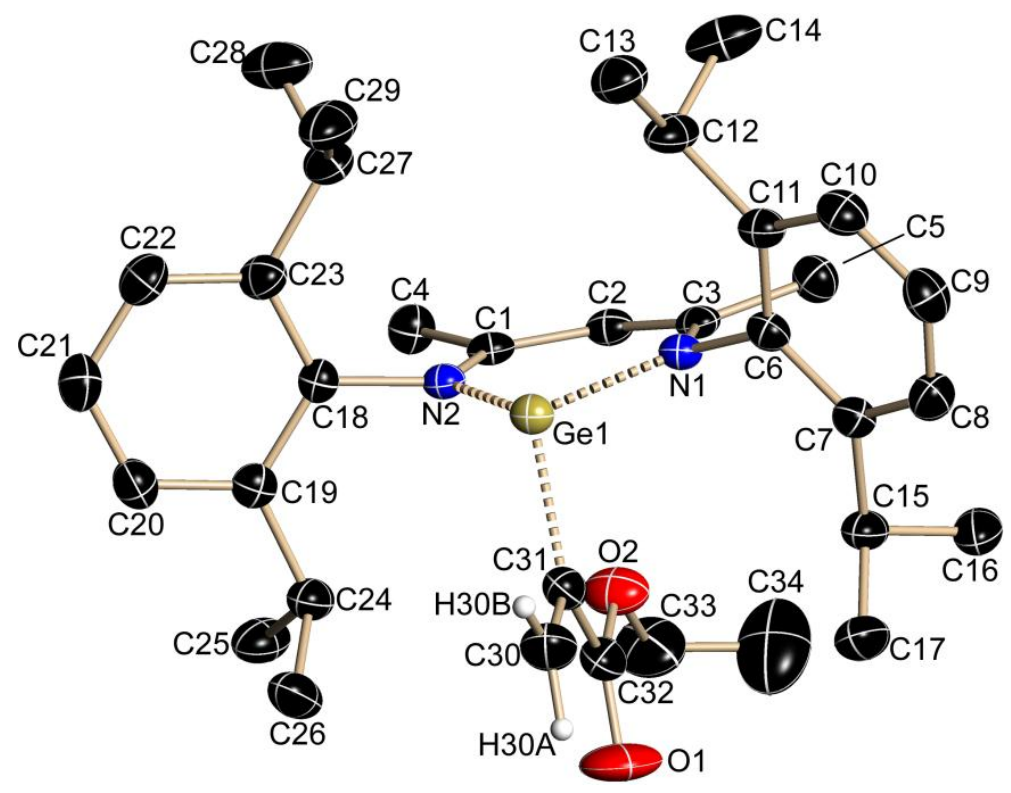

Figure 7-33. Asymmetric unit of $\left[\mathrm{CH}\left\{(\mathrm{CMe})\left(2,6-{ }^{i} \mathrm{Pr}_{2} \mathrm{C}_{6} \mathrm{H}_{3} \mathrm{~N}\right)\right\}_{2}\right] \mathrm{Ge}\left(\mathrm{C}_{2} \mathrm{H}_{2}\right)\left(\mathrm{CO}_{2} \mathrm{Et}\right)$. The anisotropic displacement parameters are depicted at the $50 \%$ probability level. The hydrogen atoms are omitted for clarity.

Table 7-33. Crystallographic data for $\left[\mathrm{CH}\left\{(\mathrm{CMe})\left(2,6-{ }^{j} \mathrm{Pr}_{2} \mathrm{C}_{6} \mathrm{H}_{3} \mathrm{~N}\right)\right\}_{2}\right] \mathrm{Ge}\left(\mathrm{C}_{2} \mathrm{H}_{2}\right)\left(\mathrm{CO}_{2} \mathrm{Et}\right)$.

\begin{tabular}{ll|ll}
\hline CCDC no. & 706622 & & \\
Empirical formula & $\mathrm{C}_{34} \mathrm{H}_{48} \mathrm{GeN}_{2} \mathrm{O}_{2}$ & $\mu\left[\mathrm{mm}^{-1}\right]$ & 0.978 \\
Formula weight $[\mathrm{g} / \mathrm{mol}]$ & 589.33 & $\mathrm{~F}(000)$ & 1256 \\
Temperature $[\mathrm{K}]$ & $100(2)$ & $\Theta$ range $\left[^{\circ}\right]$ & 2.52 to 25.03 \\
Wavelength $[\mathrm{pm}]$ & 71.073 & Reflections collected & 29205 \\
Crystal system & Monoclinic & Independent reflections & 5716 \\
Space group & $P 2_{1} / \mathrm{c}$ & Completeness to $\Theta_{\text {max }}$ & $99.9 \%$ \\
$a[\mathrm{pm}]$ & $1199.17(19)$ & Absorption correction & Empirical \\
$b[\mathrm{pm}]$ & $2041.7(3)$ & Max. / min. transmission & $0.4288 / 0.3351$ \\
$c[\mathrm{pm}]$ & $1379.7(2)$ & Restraints / parameters & $0 / 363$ \\
$\beta\left[^{\circ}\right]$ & $106.896(3)$ & GoF & 1.068 \\
Volume $\left[\mathrm{nm}^{3}\right]$ & $3.2323(9)$ & $R 1 / w R 2$ (I>2 $\sigma(\mathrm{I}))$ & $0.0401 / 0.1042$ \\
$\mathrm{Z}$ & 4 & $R 1 / w R 2$ (all data) & $0.0535 / 0.1094$ \\
$\rho_{\text {calc }}\left[\mathrm{Mg} / \mathrm{m}^{3}\right]$ & 1.211 & Diff. peak and hole $\left[\mathrm{e} \AA^{-3}\right]$ & 0.777 and -0.481 \\
\hline
\end{tabular}




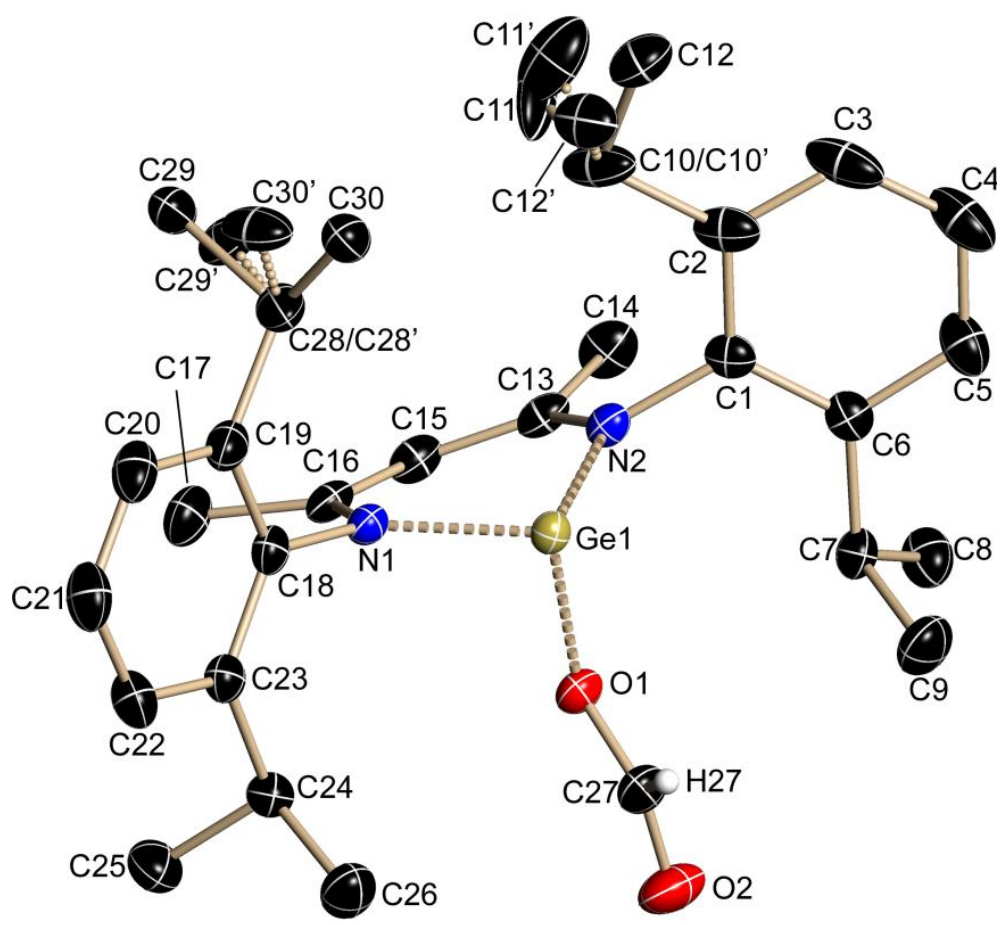

Figure 7-34. Asymmetric unit of $\left[\mathrm{CH}\left\{(\mathrm{CMe})\left(2,6-{ }^{i} \mathrm{Pr}_{2} \mathrm{C}_{6} \mathrm{H}_{3} \mathrm{~N}\right)\right\}_{2}\right] \mathrm{GeOC}(\mathrm{O}) \mathrm{H}$. The anisotropic displacement parameters are depicted at the $50 \%$ probability level. The hydrogen atoms are omitted for clarity.

Two of the iso-propyl groups are disordered (32\% and $42 \%$ ) and the crystal is a racemic twin (BASF 0.55).

Table 7-34. Crystallographic data for $\left[\mathrm{CH}\left\{(\mathrm{CMe})\left(2,6{ }^{i} \mathrm{Pr}_{2} \mathrm{C}_{6} \mathrm{H}_{3} \mathrm{~N}\right)\right\}_{2}\right] \mathrm{GeOC}(\mathrm{O}) \mathrm{H}$.

\begin{tabular}{|c|c|c|c|}
\hline CCDC no. & 706621 & & \\
\hline Empirical formula & $\mathrm{C}_{30} \mathrm{H}_{42} \mathrm{GeN}_{2} \mathrm{O}_{2}$ & $\rho_{\text {calc }}\left[\mathrm{Mg} / \mathrm{m}^{3}\right]$ & 1.266 \\
\hline Formula weight $[\mathrm{g} / \mathrm{mol}]$ & 535.25 & $\mu\left[\mathrm{mm}^{-1}\right]$ & 1.119 \\
\hline Temperature $[\mathrm{K}]$ & $100(2)$ & $F(000)$ & 568 \\
\hline Wavelength [pm] & 71.073 & $\Theta$ range $\left[{ }^{\circ}\right]$ & 1.40 to 26.02 \\
\hline Crystal system & Triclinic & Reflections collected & 26322 \\
\hline Space group & $P \overline{1}$ & Independent reflections & 5494 \\
\hline$a[\mathrm{pm}]$ & $874.49(12)$ & Completeness to $\Theta_{\max }$ & $99.3 \%$ \\
\hline$b[\mathrm{pm}]$ & $1170.58(16)$ & Absorption correction & Empirical \\
\hline$c[\mathrm{pm}]$ & $1497.0(2)$ & Max. / min. transmission & $0.4299 / 0.3968$ \\
\hline$\alpha\left[^{\circ}\right]$ & $98.446(2)$ & Restraints / parameters & $6 / 369$ \\
\hline$\beta\left[^{\circ}\right]$ & $96.896(2)$ & GoF & 1.136 \\
\hline$\gamma\left[{ }^{\circ}\right]$ & $109.595(2)$ & $R 1 / w R 2(1>2 \sigma(I))$ & $0.0342 / 0.0870$ \\
\hline Volume $\left[\mathrm{nm}^{3}\right]$ & $1.4042(3)$ & $R 1 / w R 2$ (all data) & $0.0353 / 0.0877$ \\
\hline Z & 2 & Diff. peak and hole $\left[\mathrm{e}^{-3}{ }^{-3}\right]$ & 0.680 and -0.449 \\
\hline
\end{tabular}




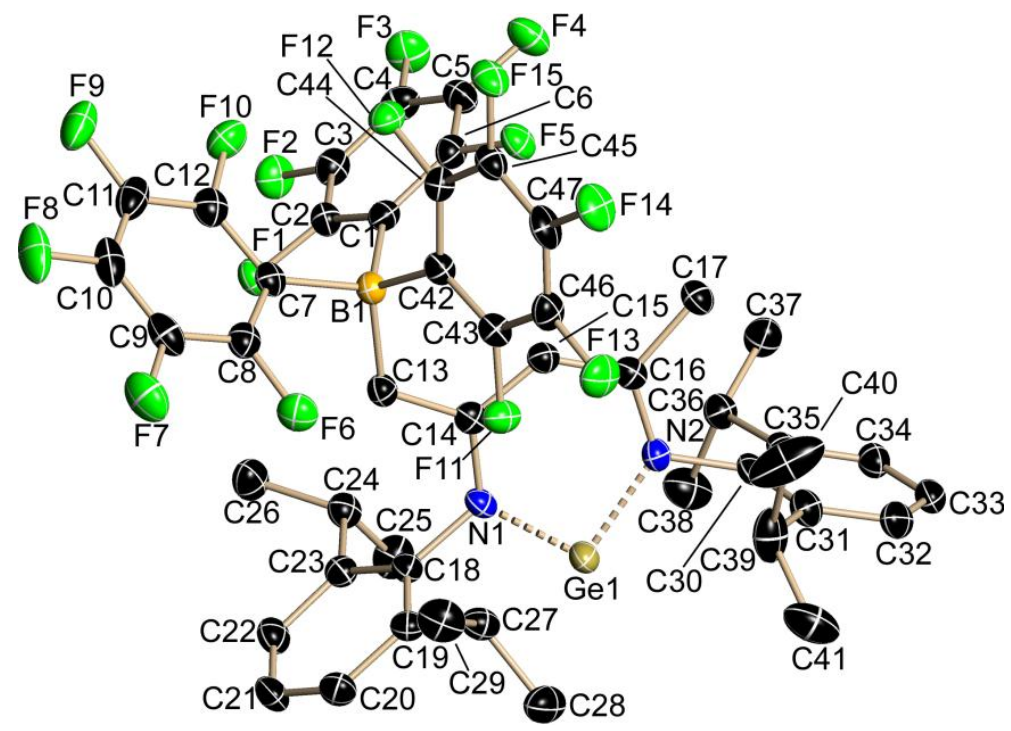

Figure 7-35. Asymmetric unit of $\left[\left\{\mathrm{B}\left(\mathrm{C}_{6} \mathrm{~F}_{5}\right)_{3}\right\} \mathrm{CH}\left\{\left(\mathrm{CCH}_{2}\right)(\mathrm{CMe})\left(2,6-{ }^{i} \mathrm{Pr}_{2} \mathrm{C}_{6} \mathrm{H}_{3} \mathrm{~N}\right)_{2}\right\} \mathrm{Ge}\right]$. The anisotropic displacement parameters are depicted at the $50 \%$ probability level. The hydrogen atoms are omitted for clarity.

Table 7-35. Crystallographic data for $\left[\left\{\mathrm{B}\left(\mathrm{C}_{6} \mathrm{~F}_{5}\right)_{3}\right\} \mathrm{CH}\left\{\left(\mathrm{CCH}_{2}\right)(\mathrm{CMe})\left(2,6-{ }^{i} \mathrm{Pr}_{2} \mathrm{C}_{6} \mathrm{H}_{3} \mathrm{~N}\right)_{2}\right\} \mathrm{Ge}\right]$.

\begin{tabular}{ll|ll}
\hline CCDC no. & 720891 & & \\
Empirical formula & $\mathrm{C}_{47} \mathrm{H}_{40} \mathrm{BF}_{15} \mathrm{GeN}_{2}$ & $\rho_{\text {calc }}\left[\mathrm{Mg} / \mathrm{m}^{3}\right]$ & 1.505 \\
Formula weight $[\mathrm{g} / \mathrm{mol}]$ & 1001.21 & $\mu\left[\mathrm{mm}^{-1}\right]$ & 0.794 \\
Temperature $[\mathrm{K}]$ & $100(2)$ & $\mathrm{F}(000)$ & 1016 \\
Wavelength $[\mathrm{pm}]$ & 71.073 & $\Theta$ range $\left[^{\circ}\right]$ & 1.69 to 25.39 \\
Crystal system & Triclinic & Reflections collected & 43135 \\
Space group & $P \overline{1}$ & Independent reflections & 8111 \\
$a[\mathrm{pm}]$ & $1216.90(13)$ & Completeness to $\Theta_{\text {max }}$ & $99.8 \%$ \\
$b[\mathrm{pm}]$ & $1371.36(15)$ & Absorption correction & Empirical \\
$c[\mathrm{pm}]$ & $1504.04(16)$ & Max. / min. transmission & $0.8958 / 0.7919$ \\
$\alpha\left[^{\circ}\right]$ & $109.9890(10)$ & Restraints / parameters & $0 / 604$ \\
$\beta\left[^{\circ}\right]$ & $91.1810(10)$ & GoF & 1.085 \\
$\nu\left[^{\circ}\right]$ & $108.7890(10)$ & $R 1 / w R 2$ (I>2 $\sigma(\mathrm{I}))$ & $0.0385 / 0.0953$ \\
$\left.V^{\circ}\right)$ & $R 1 / w R 2$ (all data) & $0.0527 / 0.0998$ \\
$\mathrm{Z}$ & $2.2088(4)$ & Diff. peak and hole [e $\left.\AA^{-3}\right]$ & 0.391 and -0.656 \\
\hline
\end{tabular}




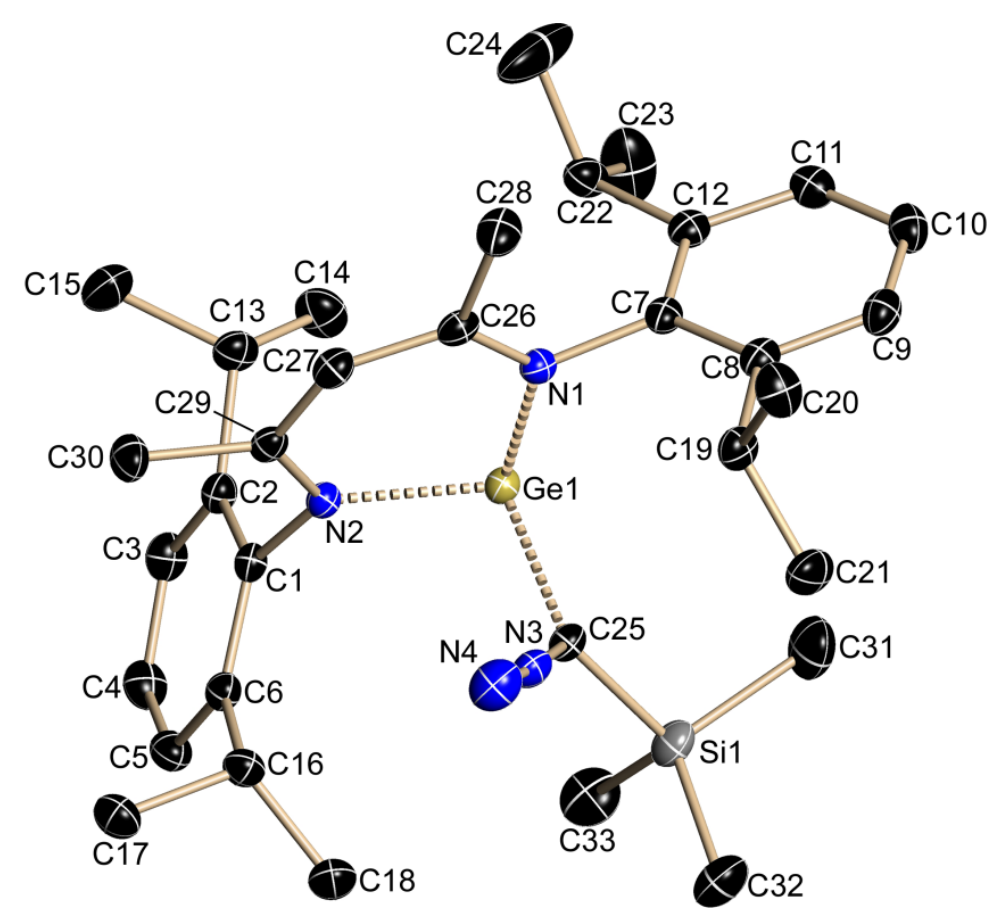

Figure 7-36. Asymmetric unit of $\left[\mathrm{CH}\left\{(\mathrm{CMe})\left(2,6-{ }^{i} \mathrm{Pr}_{2} \mathrm{C}_{6} \mathrm{H}_{3} \mathrm{~N}\right)\right\}_{2}\right] \mathrm{GeC}\left(\mathrm{N}_{2}\right) \mathrm{SiMe}_{3}$. The anisotropic displacement parameters are depicted at the $50 \%$ probability level. The hydrogen atoms are omitted for clarity.

Table 7-36. Crystallographic data for $\left[\mathrm{CH}\left\{(\mathrm{CMe})\left(2,6-{ }^{i} \mathrm{Pr}_{2} \mathrm{C}_{6} \mathrm{H}_{3} \mathrm{~N}\right)\right\}_{2}\right] \mathrm{GeC}\left(\mathrm{N}_{2}\right) \mathrm{SiMe}_{3}$.

\begin{tabular}{|c|c|c|c|}
\hline CCDC no. & 734212 & & \\
\hline Empirical formula & $\mathrm{C}_{33} \mathrm{H}_{50} \mathrm{GeN}_{4} \mathrm{Si}$ & $\rho_{\text {calc }}\left[\mathrm{Mg} / \mathrm{m}^{3}\right]$ & 1.209 \\
\hline Formula weight $[\mathrm{g} / \mathrm{mol}]$ & 603.45 & $\mu\left[\mathrm{mm}^{-1}\right]$ & 0.987 \\
\hline Temperature $[\mathrm{K}]$ & $100(2)$ & $F(000)$ & 644 \\
\hline Wavelength [pm] & 71.073 & $\Theta$ range $\left[{ }^{\circ}\right]$ & 1.91 to 26.74 \\
\hline Crystal system & Triclinic & Reflections collected & 40967 \\
\hline Space group & $P \overline{1}$ & Independent reflections & 7047 \\
\hline$a[\mathrm{pm}]$ & $1074.32(4)$ & Completeness to $\Theta_{\max }$ & $99.9 \%$ \\
\hline$b[\mathrm{pm}]$ & $1200.91(5)$ & Absorption correction & Empirical \\
\hline$c[\mathrm{pm}]$ & $1450.66(6)$ & Max. / min. transmission & $0.4299 / 0.4068$ \\
\hline$\alpha\left[^{\circ}\right]$ & $106.9280(10)$ & Restraints / parameters & $0 / 365$ \\
\hline$\beta\left[^{\circ}\right]$ & $94.2460(10)$ & GoF & 1.053 \\
\hline$\gamma\left[^{\circ}\right]$ & $109.4780(10)$ & $R 1 / w R 2(I>2 \sigma(I))$ & $0.0258 / 0.0677$ \\
\hline Volume $\left[\mathrm{nm}^{3}\right]$ & $1.65736(12)$ & $R 1$ / wR2 (all data) & $0.0273 / 0.0685$ \\
\hline Z & 2 & Diff. peak and hole $\left[\mathrm{e} \AA^{-3}\right]$ & 1.378 and -0.287 \\
\hline
\end{tabular}




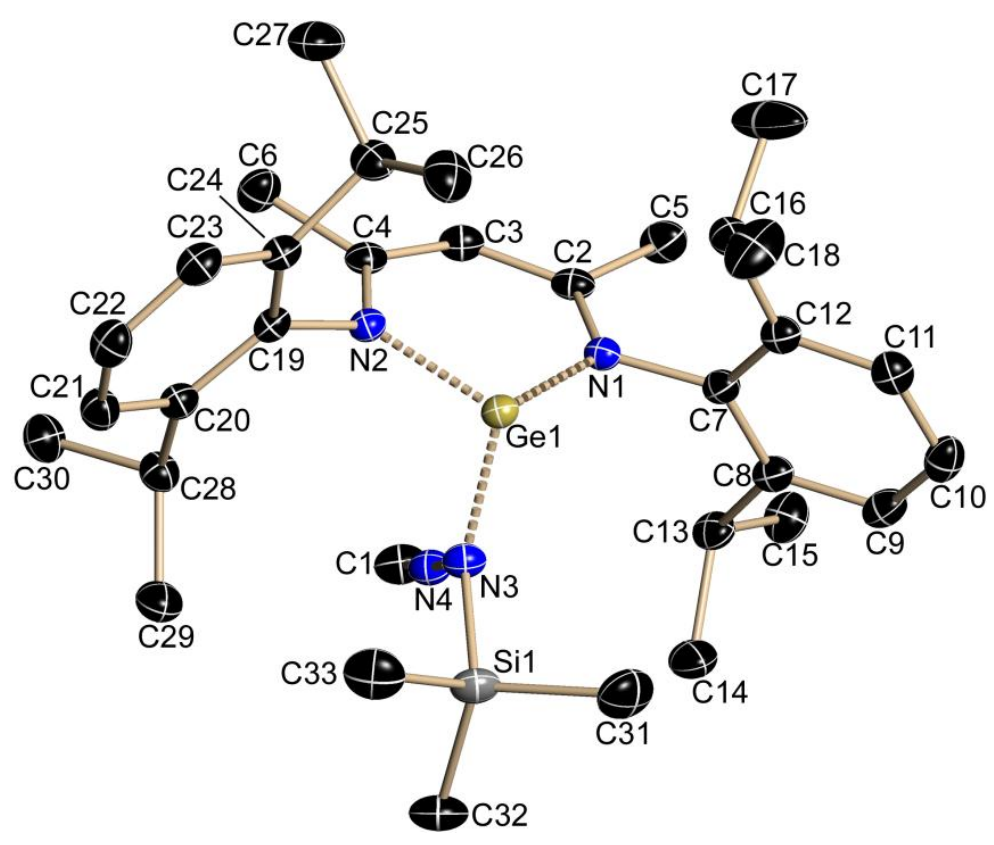

Figure 7-37. Asymmetric unit of $\left[\mathrm{CH}\left\{(\mathrm{CMe})\left(2,6-{ }^{i} \mathrm{Pr}_{2} \mathrm{C}_{6} \mathrm{H}_{3} \mathrm{~N}\right)\right\}_{2}\right] \mathrm{GeN}\left(\mathrm{SiMe}_{3}\right) \mathrm{NC}$. The anisotropic displacement parameters are depicted at the $50 \%$ probability level. The hydrogen atoms are omitted for clarity.

Table 7-37. Crystallographic data for $\left[\mathrm{CH}\left\{(\mathrm{CMe})\left(2,6{ }^{i} \mathrm{Pr}_{2} \mathrm{C}_{6} \mathrm{H}_{3} \mathrm{~N}\right)\right\}_{2}\right] \mathrm{GeN}\left(\mathrm{SiMe}_{3}\right) \mathrm{NC}$.

\begin{tabular}{|c|c|c|c|}
\hline CCDC no. & 728257 & & \\
\hline Empirical formula & $\mathrm{C}_{33} \mathrm{H}_{50} \mathrm{GeN}_{4} \mathrm{Si}$ & $\rho_{\text {calc }}\left[\mathrm{Mg} / \mathrm{m}^{3}\right]$ & 1.207 \\
\hline Formula weight $[\mathrm{g} / \mathrm{mol}]$ & 603.45 & $\mu\left[\mathrm{mm}^{-1}\right]$ & 0.985 \\
\hline Temperature $[\mathrm{K}]$ & $100(2)$ & $F(000)$ & 644 \\
\hline Wavelength [pm] & 71.073 & $\Theta$ range $\left[{ }^{\circ}\right]$ & 1.50 to 25.35 \\
\hline Crystal system & Triclinic & Reflections collected & 24779 \\
\hline Space group & $P \overline{1}$ & Independent reflections & 6039 \\
\hline$a[\mathrm{pm}]$ & $1077.8(3)$ & Completeness to $\Theta_{\max }$ & $99.4 \%$ \\
\hline$b[\mathrm{pm}]$ & $1204.0(4)$ & Absorption correction & Empirical \\
\hline$c[\mathrm{pm}]$ & $1444.5(4)$ & Max. / min. transmission & $0.95008 / 0.76466$ \\
\hline$\alpha\left[^{\circ}\right]$ & $107.113(3)$ & Restraints / parameters & $0 / 365$ \\
\hline$\beta\left[^{\circ}\right]$ & $94.231(4)$ & GoF & 1.063 \\
\hline$\gamma\left[^{\circ}\right]$ & $109.254(3)$ & $R 1 / w R 2(I>2 \sigma(I))$ & $0.0311 / 0.0869$ \\
\hline Volume $\left[\mathrm{nm}^{3}\right]$ & $1.6607(8)$ & $R 1$ / wR2 (all data) & $0.0331 / 0.0880$ \\
\hline Z & 2 & Diff. peak and hole $\left[\mathrm{e} \AA^{-3}\right]$ & 0.900 and -0.221 \\
\hline
\end{tabular}




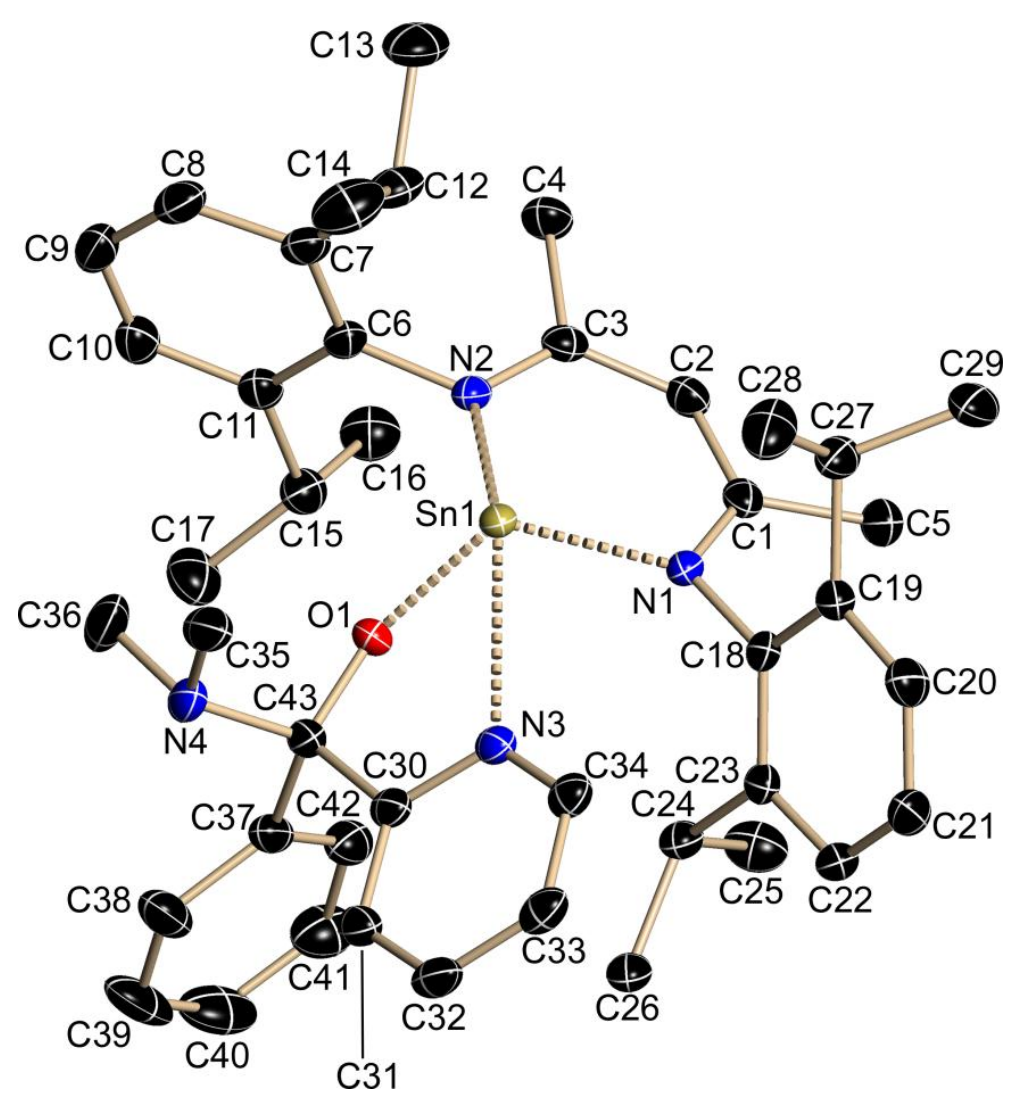

Figure 7-38. Asymmetric unit of $\left[\mathrm{CH}\left\{(\mathrm{CMe})\left(2,6-{ }^{i} \mathrm{Pr}_{2} \mathrm{C}_{6} \mathrm{H}_{3} \mathrm{~N}\right)\right\}_{2}\right] \mathrm{SnOCPh}(2-\mathrm{Py}) \mathrm{NMe}_{2}$. The anisotropic displacement parameters are depicted at the $50 \%$ probability level. The hydrogen atoms are omitted for clarity.

Table 7-38. Crystallographic data for $\left[\mathrm{CH}\left\{(\mathrm{CMe})\left(2,6-{ }^{i} \mathrm{Pr}_{2} \mathrm{C}_{6} \mathrm{H}_{3} \mathrm{~N}\right)\right\}_{2}\right] \mathrm{SnOCPh}(2-\mathrm{Py}) \mathrm{NMe}_{2}$.

\begin{tabular}{ll|ll}
\hline CCDC no. & 743154 & & \\
Empirical formula & $\mathrm{C}_{43} \mathrm{H}_{56} \mathrm{~N}_{4} \mathrm{OSn}$ & $\rho_{\text {calc }}\left[\mathrm{Mg} / \mathrm{m}^{3}\right]$ & 1.296 \\
Formula weight $[\mathrm{g} / \mathrm{mol}]$ & 763.61 & $\mu\left[\mathrm{mm}^{-1}\right]$ & 0.690 \\
Temperature $[\mathrm{K}]$ & $100(2)$ & $\mathrm{F}(000)$ & 800 \\
Wavelength [pm] & 71.073 & $\Theta$ range $\left[^{\circ}\right]$ & 2.08 to 26.02 \\
Crystal system & Triclinic & Reflections collected & 42763 \\
Space group & $P \overline{1}$ & Independent reflections & 7688 \\
$a[\mathrm{pm}]$ & $1100.83(9)$ & Completeness to $\Theta_{\text {max }}$ & $99.8 \%$ \\
$b[\mathrm{pm}]$ & $1188.19(10)$ & Absorption correction & Empirical \\
$c[\mathrm{pm}]$ & $1697.1(2)$ & Max. / min. transmission & $0.4299 / 0.3895$ \\
$\alpha\left[^{\circ}\right]$ & $96.9270(10)$ & Restraints / parameters & $0 / 454$ \\
$\beta\left[^{\circ}\right]$ & $101.1180(10)$ & GoF & 1.066 \\
$\gamma\left[^{\circ}\right]$ & $113.0550(10)$ & $R 1 / w R 2$ (I>2 $\sigma(\mathrm{I}))$ & $0.0200 / 0.0474$ \\
$V^{\circ}$ olume $\left[\mathrm{nm}^{3}\right]$ & $1.9563(3)$ & $R 1 / w R 2$ (all data) & $0.0232 / 0.0484$ \\
$Z$ & 2 & Diff. peak and hole [e $\left.\AA^{-3}\right]$ & 0.326 and -0.250 \\
\hline
\end{tabular}




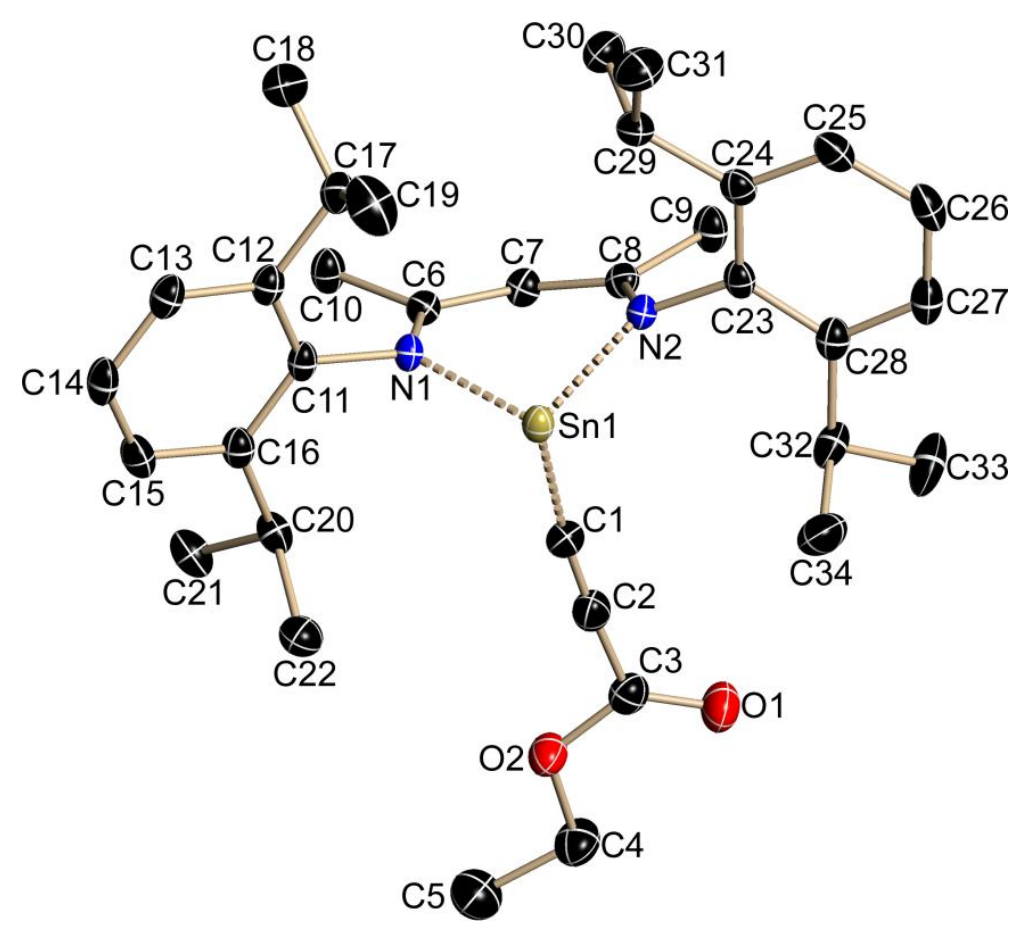

Figure 7-39. Asymmetric unit of $\left[\mathrm{CH}\left\{(\mathrm{CMe})\left(2,6-{ }^{i} \mathrm{Pr}_{2} \mathrm{C}_{6} \mathrm{H}_{3} \mathrm{~N}\right)\right\}_{2}\right] \mathrm{SnCCCO}_{2}$ Et. The anisotropic displacement parameters are depicted at the $50 \%$ probability level. The hydrogen atoms are omitted for clarity.

Table 7-39. Crystallographic data for $\left[\mathrm{CH}\left\{(\mathrm{CMe})\left(2,6-{ }^{i} \mathrm{Pr}_{2} \mathrm{C}_{6} \mathrm{H}_{3} \mathrm{~N}\right)\right\}_{2}\right] \mathrm{SnCCCO}_{2} \mathrm{Et}$.

\begin{tabular}{ll|ll}
\hline CCDC no. & 743155 & & \\
Empirical formula & $\mathrm{C}_{34} \mathrm{H}_{46} \mathrm{~N}_{2} \mathrm{O}_{2} \mathrm{Sn}$ & $\mu\left[\mathrm{mm}^{-1}\right]$ & 0.819 \\
Formula weight $[\mathrm{g} / \mathrm{mol}]$ & 633.42 & $\mathrm{~F}(000)$ & 1320 \\
Temperature $[\mathrm{K}]$ & $100(2)$ & $\Theta$ range $\left[^{\circ}\right]$ & 1.90 to 26.73 \\
Wavelength $[\mathrm{pm}]$ & 71.073 & Reflections collected & 60564 \\
Crystal system & Monoclinic & Independent reflections & 6864 \\
Space group & $P 2_{1} / \mathrm{n}$ & Completeness to $\Theta_{\text {max }}$ & $100.0 \%$ \\
$a[\mathrm{pm}]$ & $1277.7(2)$ & Absorption correction & Empirical \\
$b[\mathrm{pm}]$ & $1991.1(4)$ & Max. / min. transmission & $0.4305 / 0.3889$ \\
$c[\mathrm{pm}]$ & $1318.6(2)$ & Restraints / parameters & $0 / 363$ \\
$\beta\left[^{\circ}\right]$ & $104.998(2)$ & GoF & 1.068 \\
Volume $\left[\mathrm{nm}^{3}\right]$ & $3.2402(10)$ & $R 1 / w R 2$ (I>2 $\sigma(\mathrm{l}))$ & $0.0249 / 0.0564$ \\
$\mathrm{Z}$ & 4 & $R 1 / w R 2$ (all data) & $0.0307 / 0.0592$ \\
$\rho_{\text {calc }}\left[\mathrm{Mg} / \mathrm{m}^{3}\right]$ & 1.298 & Diff. peak and hole $\left[\mathrm{e} \AA^{-3}\right]$ & 0.942 and -0.706 \\
\hline
\end{tabular}




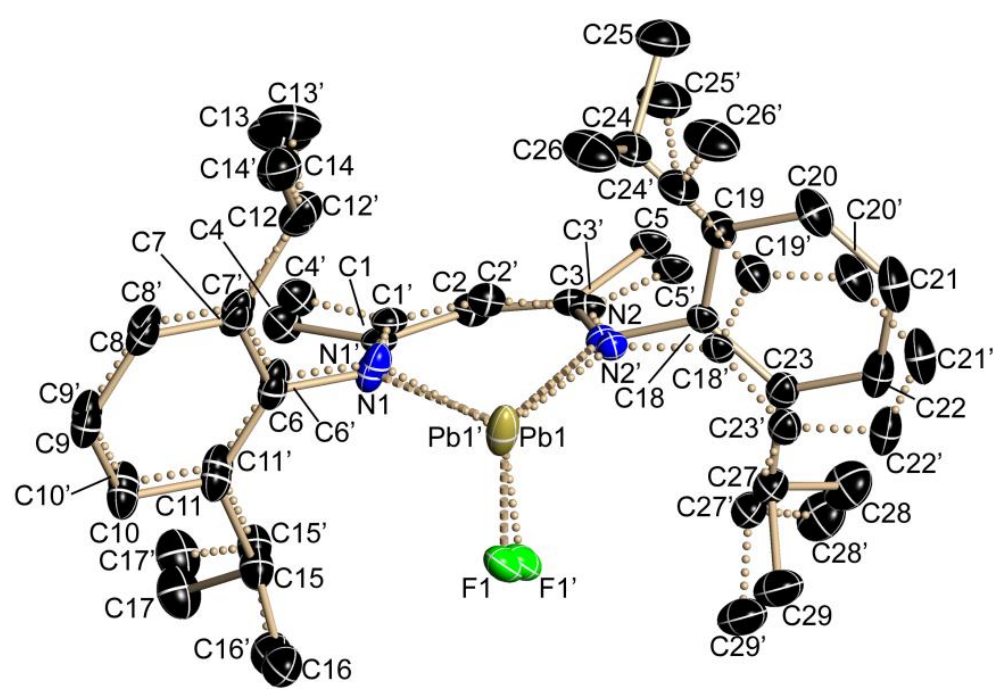

Figure 7-40. Asymmetric unit of $\left[\mathrm{CH}\left\{(\mathrm{CMe})\left(2,6-{ }^{i} \mathrm{Pr}_{2} \mathrm{C}_{6} \mathrm{H}_{3} \mathrm{~N}\right)\right\}_{2}\right] \mathrm{PbF}$. The anisotropic displacement parameters are depicted at the $50 \%$ probability level. The hydrogen atoms are omitted for clarity.

The whole molecule is disordered (ratio 0.56:0.44). Disordered moieties were refined using bond length, rigid bond, similarity, and ADP-restraints.

Table 7-40. Crystallographic data for $\left[\mathrm{CH}\left\{(\mathrm{CMe})\left(2,6-{ }^{i} \mathrm{Pr}_{2} \mathrm{C}_{6} \mathrm{H}_{3} \mathrm{~N}\right)\right\}_{2}\right] \mathrm{PbF}$.

\begin{tabular}{ll|ll}
\hline CCDC no. & 808034 & & \\
Empirical formula & $\mathrm{C}_{29} \mathrm{H}_{41} \mathrm{FN}_{2} \mathrm{~Pb}$ & $\mu\left[\mathrm{mm}^{-1}\right]$ & 6.006 \\
Formula weight $[\mathrm{g} / \mathrm{mol}]$ & 643.84 & $\mathrm{~F}(000)$ & 1280 \\
Temperature $[\mathrm{K}]$ & $100(2)$ & $\Theta$ range $\left[^{\circ}\right]$ & 2.0 to 30.6 \\
Wavelength $[\mathrm{pm}]$ & 71.073 & Reflections collected & 90262 \\
Crystal system & Monoclinic & Independent reflections & 8667 \\
Space group & $P 2_{1} / \mathrm{n}$ & Completeness to $\Theta_{\text {max }}$ & $99.7 \%$ \\
$a[\mathrm{pm}]$ & $1176.97(16)$ & Absorption correction & Numerical \\
$b[\mathrm{pm}]$ & $2046.5(3)$ & Max. / min. transmission & $0.7589 / 0.5022$ \\
$c[\mathrm{pm}]$ & $1177.27(16)$ & Restraints / parameters & $715 / 350$ \\
$\beta\left[^{\circ}\right]$ & $95.906(2)$ & GoF & 1.058 \\
Volume $\left[\mathrm{nm}^{3}\right]$ & $2.8206(7)$ & $R 1 / w R 2$ (I>2 $\sigma(\mathrm{I}))$ & $0.0210 / 0.0491$ \\
$\mathrm{Z}$ & 4 & $R 1 / w R 2$ (all data) & $0.0256 / 0.0503$ \\
$\rho_{\text {calc }}\left[\mathrm{Mg} / \mathrm{m}^{3}\right]$ & 1.516 & Diff. peak and hole $\left[\mathrm{e} \AA^{-3}\right]$ & 3.121 and -1.411 \\
\hline
\end{tabular}




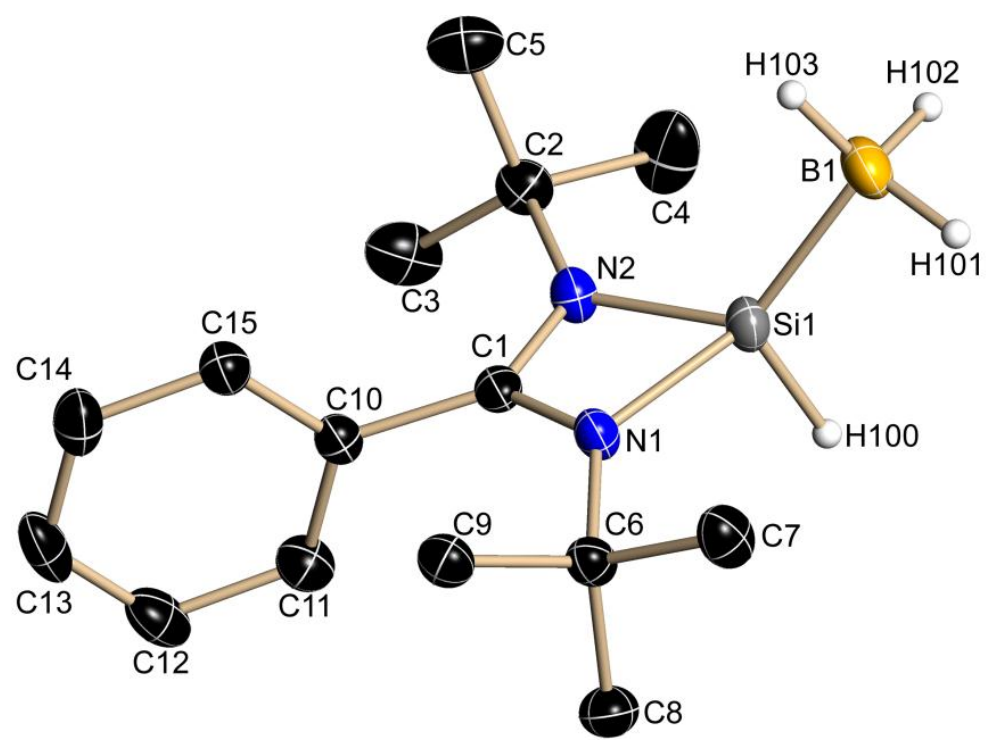

Figure 7-41. Asymmetric unit of $\mathrm{PhC}(\mathrm{NtBu})_{2} \mathrm{Si}(\mathrm{H}) \mathrm{BH}_{3}$. The anisotropic displacement parameters are depicted at the $50 \%$ probability level. The hydrogen atoms are omitted for clarity.

The positions of the hydrogen atoms $\mathrm{H} 100$ at the silicon atom Si1 and H101, H102 and $\mathrm{H} 103$ at the boron atom B1 were taken from difference map and refined freely.

Table 7-41. Crystallographic data for $\mathrm{PhC}(\mathrm{NtBu})_{2} \mathrm{Si}(\mathrm{H}) \mathrm{BH}_{3}$.

\begin{tabular}{ll|ll}
\hline CCDC no. & 778885 & Abs. structure parameter & $0.01(10)$ \\
Empirical formula & $\mathrm{C}_{15} \mathrm{H}_{27} \mathrm{BN}_{2} \mathrm{Si}$ & $\rho_{\text {calc }}\left[\mathrm{Mg} / \mathrm{m}^{3}\right]$ & 1.081 \\
Formula weight $[\mathrm{g} / \mathrm{mol}]$ & 274.29 & $\mu\left[\mathrm{mm}^{-1}\right]$ & 0.129 \\
Temperature $[\mathrm{K}]$ & $100(2)$ & $\mathrm{F}(000)$ & 600 \\
Wavelength $[\mathrm{pm}]$ & 71.073 & $\Theta$ range $\left[^{\circ}\right]$ & 2.12 to 26.73 \\
Crystal system & Orthorhombic & Reflections collected & 24712 \\
Space group & $P 2{ }_{1} 2{ }_{1} 2_{1}$ & Independent reflections & 3575 \\
$a[\mathrm{pm}]$ & $851.74(14)$ & Completeness to $\Theta_{\text {max }}$ & $100.0 \%$ \\
$b[\mathrm{pm}]$ & $1157.91(18)$ & Absorption correction & Empirical \\
$c[\mathrm{pm}]$ & $1708.2(3)$ & Max. $/$ min. transmission & $0.9841 / 0.9417$ \\
$\alpha\left[^{\circ}\right]$ & 90 & Restraints / parameters & $0 / 194$ \\
$\beta\left[^{\circ}\right]$ & 90 & GoF & 1.107 \\
$\gamma\left[^{\circ}\right]$ & 90 & $R 1 / w R 2$ (I>2 $\sigma(\mathrm{I}))$ & $0.0286 / 0.0728$ \\
Volume $\left[\mathrm{nm}^{3}\right]$ & $1.6847(5)$ & $R 1 / w R 2$ (all data) & $0.0304 / 0.0735$ \\
$Z$ & 4 & Diff. peak and hole $\left[\mathrm{e} \AA^{-3}\right]$ & 0.209 and -0.158 \\
\hline
\end{tabular}




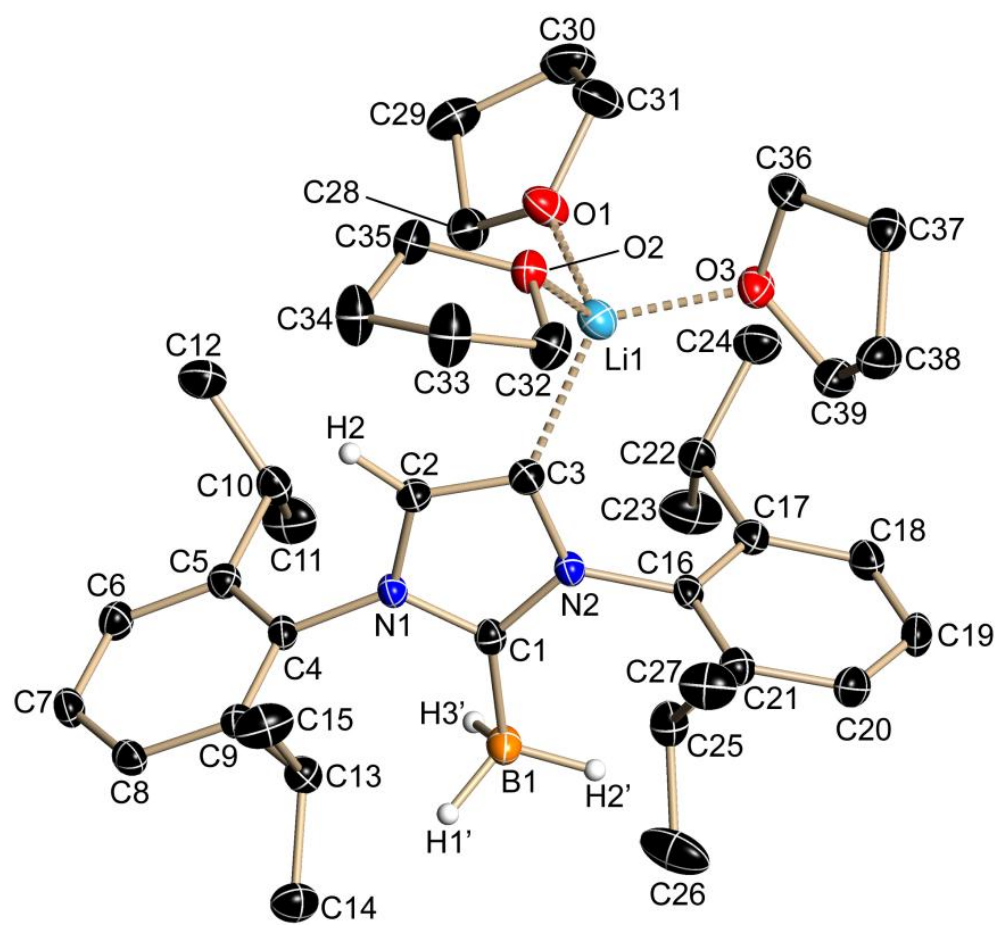

Figure 7-42. Asymmetric unit of [: $\left.\mathrm{C}\left\{\left[\mathrm{N}\left(2,6-{ }^{i} \mathrm{Pr}_{2} \mathrm{C}_{6} \mathrm{H}_{3}\right)\right]_{2} \mathrm{CHCLi}(\mathrm{THF})_{3}\right\} \mathrm{BH}_{3}\right]$. The anisotropic displacement parameters are depicted at the 50 \% probability level. The hydrogen atoms are omitted for clarity.

The positions of the hydrogen atoms $\mathrm{H} 2$ at the carbon atom $\mathrm{C} 2$ and $\mathrm{H}^{\prime}, \mathrm{H}^{\prime}$ and $\mathrm{H}^{\prime}$ at the boron atom B1 were taken from difference map and refined with distance restraints.

Table 7-42. Crystallographic data for $\left[: \mathrm{C}\left\{\left[\mathrm{N}\left(2,6-{ }^{-} \mathrm{Pr}_{2} \mathrm{C}_{6} \mathrm{H}_{3}\right)\right]_{2} \mathrm{CHCLi}(\mathrm{THF})_{3}\right\} \mathrm{BH}_{3}\right]$.

\begin{tabular}{|c|c|c|c|}
\hline CCDC no. & 826662 & & \\
\hline Empirical formula & $\mathrm{C}_{39} \mathrm{H}_{62} \mathrm{BLiN}_{2} \mathrm{O}_{3}$ & $\rho_{\text {calc }}\left[\mathrm{Mg} / \mathrm{m}^{3}\right]$ & 1.091 \\
\hline Formula weight $[\mathrm{g} / \mathrm{mol}]$ & 624.66 & $\mu\left[\mathrm{mm}^{-1}\right]$ & 0.067 \\
\hline Temperature $[\mathrm{K}]$ & $101(2)$ & $F(000)$ & 684 \\
\hline Wavelength [pm] & 71.073 & $\Theta$ range $\left[{ }^{\circ}\right]$ & 1.14 to 25.39 \\
\hline Crystal system & Triclinic & Reflections collected & 40602 \\
\hline Space group & $P \overline{1}$ & Independent reflections & 6982 \\
\hline$a[\mathrm{pm}]$ & $1036.9(2)$ & Completeness to $\Theta_{\max }$ & $99.8 \%$ \\
\hline$b[\mathrm{pm}]$ & $1096.5(2)$ & Absorption correction & Empirical \\
\hline$c[\mathrm{pm}]$ & $1873.1(3)$ & Max. / min. transmission & $0.7452 / 0.7174$ \\
\hline$\alpha\left[^{\circ}\right]$ & $73.74(2)$ & Restraints / parameters & $3 / 436$ \\
\hline$\beta\left[^{\circ}\right]$ & $89.37(3)$ & GoF & 1.040 \\
\hline$\gamma\left[{ }^{\circ}\right]$ & $69.21(2)$ & $R 1 / w R 2(I>2 \sigma(I))$ & $0.0387 / 0.0910$ \\
\hline Volume $\left[\mathrm{nm}^{3}\right]$ & $1.9020(6)$ & $R 1 / w R 2$ (all data) & $0.0471 / 0.0960$ \\
\hline Z & 2 & Diff. peak and hole $\left[\mathrm{e} \AA^{-3}\right]$ & 0.242 and -0.219 \\
\hline
\end{tabular}




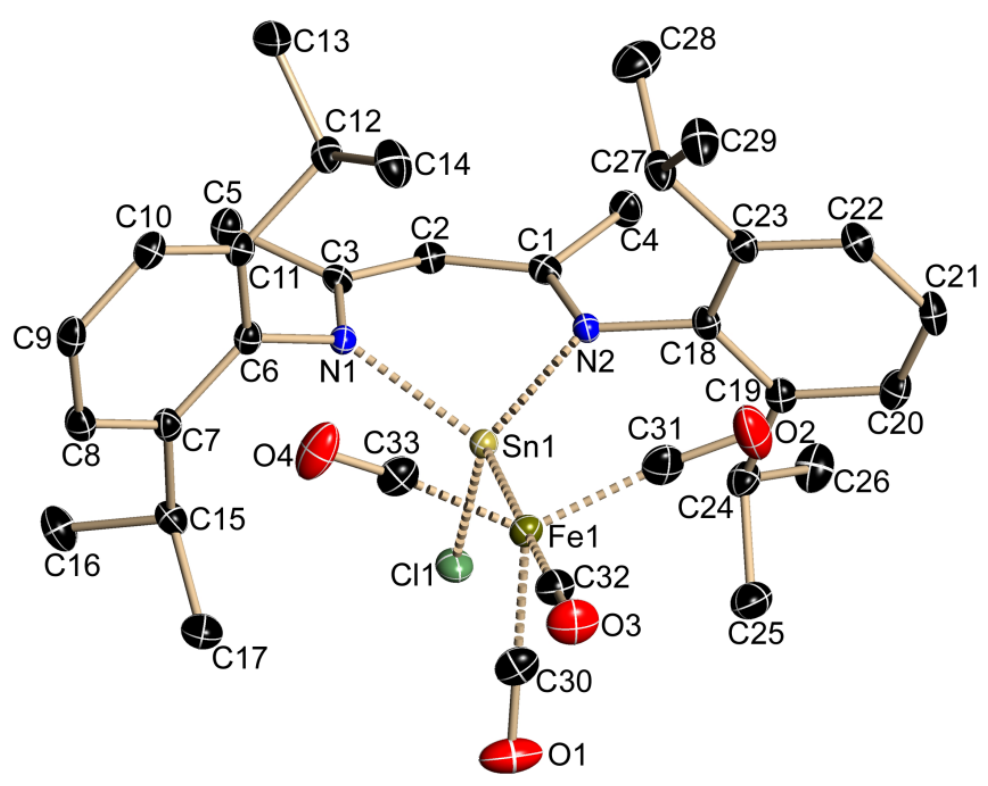

Figure 7-43. Asymmetric unit of $\left[\mathrm{CH}\left\{\mathrm{CMe}\left(2,6-{ }^{i} \mathrm{Pr}_{2} \mathrm{C}_{6} \mathrm{H}_{3} \mathrm{~N}\right)\right\}_{2}\right] \mathrm{Sn}(\mathrm{Cl}) \mathrm{Fe}(\mathrm{CO})_{4}$. The anisotropic displacement parameters are depicted at the $50 \%$ probability level. The hydrogen atoms are omitted for clarity.

The position of the hydrogen atom bonded to carbon atom C2 was taken from difference map and refined with distance restraints.

Table 7-43. Crystallographic data for $\left[\mathrm{CH}\left\{\mathrm{CMe}\left(2,6-{ }^{i} \mathrm{Pr}_{2} \mathrm{C}_{6} \mathrm{H}_{3} \mathrm{~N}\right)\right\}_{2}\right] \mathrm{Sn}(\mathrm{Cl}) \mathrm{Fe}(\mathrm{CO})_{4}$.

\begin{tabular}{ll|ll}
\hline CCDC no. & 827732 & & \\
Empirical formula & $\mathrm{C}_{33} \mathrm{H}_{41} \mathrm{ClFeN}_{2} \mathrm{O}_{4} \mathrm{Sn}$ & $\mu\left[\mathrm{mm}^{-1}\right]$ & 1.325 \\
Formula weight $[\mathrm{g} / \mathrm{mol}]$ & 739.67 & $\mathrm{~F}(000)$ & 1512 \\
Temperature $[\mathrm{K}]$ & $100(2)$ & $\Theta$ range $\left[^{\circ}\right]$ & 2.33 to 26.37 \\
Wavelength $[\mathrm{pm}]$ & 71.073 & Reflections collected & 37372 \\
Crystal system & Monoclinic & Independent reflections & 6697 \\
Space group & $P 2_{1} / \mathrm{n}$ & Completeness to $\Theta_{\text {max }}$ & $99.9 \%$ \\
$a[\mathrm{pm}]$ & $1008.11(13)$ & Absorption correction & Empirical \\
$b[\mathrm{pm}]$ & $2011.2(3)$ & Max. / min. transmission & $0.4305 / 0.3753$ \\
$c[\mathrm{pm}]$ & $1675.6(2)$ & Restraints / parameters & $1 / 392$ \\
$\beta\left[^{\circ}\right]$ & $105.284(2)$ & GoF & 1.026 \\
Volume $\left[\mathrm{nm}^{3}\right]$ & $3.2772(7)$ & $R 1 / w R 2$ (I>2 $\sigma(\mathrm{I}))$ & $0.0233 / 0.0516$ \\
$\mathrm{Z}$ & 4 & $R 1 / w R 2$ (all data) & $0.0328 / 0.0564$ \\
$\rho_{\text {calc }}\left[\mathrm{Mg} / \mathrm{m}^{3}\right]$ & 1.499 & Diff. peak and hole [e $\left.\AA^{-3}\right]$ & 0.414 and -0.349 \\
\hline
\end{tabular}




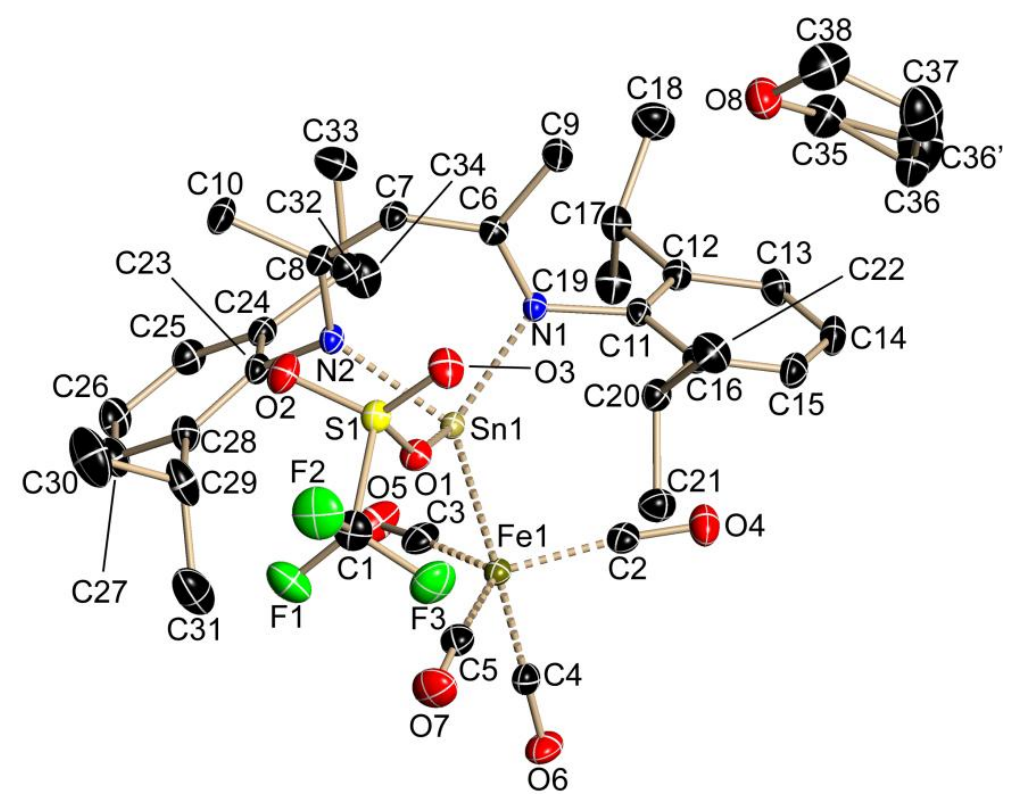

Figure 7-44. Asymmetric unit of $\left[\mathrm{CH}\left\{\mathrm{CMe}\left(2,6-{ }^{i} \mathrm{Pr}_{2} \mathrm{C}_{6} \mathrm{H}_{3} \mathrm{~N}\right)\right\}_{2}\right] \mathrm{Sn}(\mathrm{OTf}) \mathrm{Fe}(\mathrm{CO})_{4}$. The anisotropic displacement parameters are depicted at the $50 \%$ probability level. The hydrogen atoms are omitted for clarity.

The position of the hydrogen atom bonded to the carbon atom C7 was taken from difference map and refined with distance restraints. Carbon atom C36 of the THF moiety is disordered (ratio $0.76: 0.24$ ).

Table 7-44. Crystallographic data for $\left[\mathrm{CH}\left\{\mathrm{CMe}\left(2,6-{ }^{\mathrm{i}} \mathrm{Pr}_{2} \mathrm{C}_{6} \mathrm{H}_{3} \mathrm{~N}\right)\right\}_{2}\right] \mathrm{Sn}(\mathrm{OTf}) \mathrm{Fe}(\mathrm{CO})_{4}$.

\begin{tabular}{ll|ll}
\hline CCDC no. & 827731 & & \\
Empirical formula & $\mathrm{C}_{38} \mathrm{H}_{49} \mathrm{~F}_{3} \mathrm{FeN}_{2} \mathrm{O}_{8} \mathrm{SSn}$ & $\rho_{\text {calc }}\left[\mathrm{Mg} / \mathrm{m}^{3}\right]$ & 1.495 \\
Formula weight $[\mathrm{g} / \mathrm{mol}]$ & 925.39 & $\mu\left[\mathrm{mm}^{-1}\right]$ & 1.075 \\
Temperature $[\mathrm{K}]$ & $100(2)$ & $\mathrm{F}(000)$ & 948 \\
Wavelength $[\mathrm{pm}]$ & 71.073 & $\Theta$ range $\left[^{\circ}\right]$ & 1.24 to 27.10 \\
Crystal system & Triclinic & Reflections collected & 53534 \\
Space group & $P \overline{1}$ & Independent reflections & 9084 \\
$a[\mathrm{pm}]$ & $1099.5(2)$ & Completeness to $\Theta_{\text {max }}$ & $100.0 \%$ \\
$b[\mathrm{pm}]$ & $1192.3(2)$ & Absorption correction & Semi-empirical \\
$c[\mathrm{pm}]$ & $1763.6(3)$ & Max. / min. transmission & $0.4305 / 0.3957$ \\
$\alpha\left[^{\circ}\right]$ & $105.48(2)$ & Restraints / parameters & $7 / 511$ \\
$\beta\left[^{\circ}\right]$ & $98.40(3)$ & GoF & 1.056 \\
$\gamma\left[^{\circ}\right]$ & $107.72(2)$ & $R 1 / w R 2$ (I>2 $\sigma(\mathrm{I}))$ & $0.0173 / 0.0448$ \\
$\left.V^{\circ}\right)$ & $R 1 / w R 2$ (all data) & $0.0183 / 0.0454$ \\
$Z$ & $2.0563(6)$ & Diff. peak and hole [e $\left.\AA^{-3}\right]$ & 0.575 and -0.404 \\
\hline
\end{tabular}




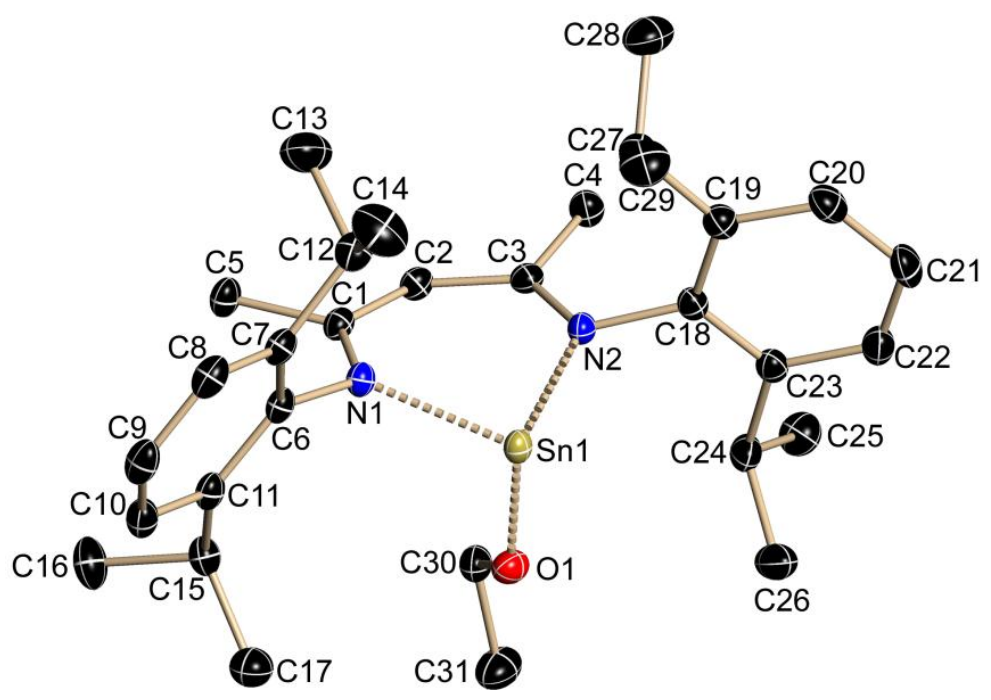

Figure 7-45. Asymmetric unit of $\left[\mathrm{CH}\left\{\mathrm{CMe}\left(2,6-{ }^{i} \mathrm{Pr}_{2} \mathrm{C}_{6} \mathrm{H}_{3} \mathrm{~N}\right)\right\}_{2}\right] \mathrm{SnOEt}$. The anisotropic displacement parameters are depicted at the $50 \%$ probability level. The hydrogen atoms are omitted for clarity.

Table 7-45. Crystallographic data for $\left[\mathrm{CH}\left\{\mathrm{CMe}\left(2,6-{ }^{i} \mathrm{Pr}_{2} \mathrm{C}_{6} \mathrm{H}_{3} \mathrm{~N}\right)\right\}_{2}\right]$ SnOEt.

\begin{tabular}{|c|c|c|c|}
\hline Identification code & IOAJ62 & & \\
\hline Empirical formula & $\mathrm{C}_{31} \mathrm{H}_{46} \mathrm{~N}_{2} \mathrm{OSn}$ & $\mu\left[\mathrm{mm}^{-1}\right]$ & 0.882 \\
\hline Formula weight $[\mathrm{g} / \mathrm{mol}]$ & 581.39 & $F(000)$ & 1216 \\
\hline Temperature $[\mathrm{K}]$ & $100(2)$ & $\Theta$ range $\left[{ }^{\circ}\right]$ & 2.48 to 26.75 \\
\hline Wavelength [pm] & 71.073 & Reflections collected & 54299 \\
\hline Crystal system & Monoclinic & Independent reflections & 6322 \\
\hline Space group & $P 2_{1} / c$ & Completeness to $\Theta_{\max }$ & $99.9 \%$ \\
\hline$a[\mathrm{pm}]$ & 2201.16(18) & Absorption correction & Empirical \\
\hline$b[\mathrm{pm}]$ & $1192.61(10)$ & Max. / min. transmission & 0.4299 / 0.3831 \\
\hline$c[\mathrm{pm}]$ & $1151.73(10)$ & Restraints / parameters & $0 / 327$ \\
\hline$\beta\left[^{\circ}\right]$ & $100.0070(10)$ & GoF & 1.045 \\
\hline Volume $\left[\mathrm{nm}^{3}\right]$ & $2.9774(4)$ & $R 1 / w R 2(I>2 \sigma(I))$ & $0.0207 / 0.0536$ \\
\hline $\mathrm{Z}$ & 4 & $R 1 / w R 2$ (all data) & $0.0227 / 0.0546$ \\
\hline$\rho_{\text {calc }}\left[\mathrm{Mg} / \mathrm{m}^{3}\right]$ & 1.297 & Diff. peak and hole $\left[\mathrm{e} \AA^{-3}\right]$ & 0.716 and -0.604 \\
\hline
\end{tabular}




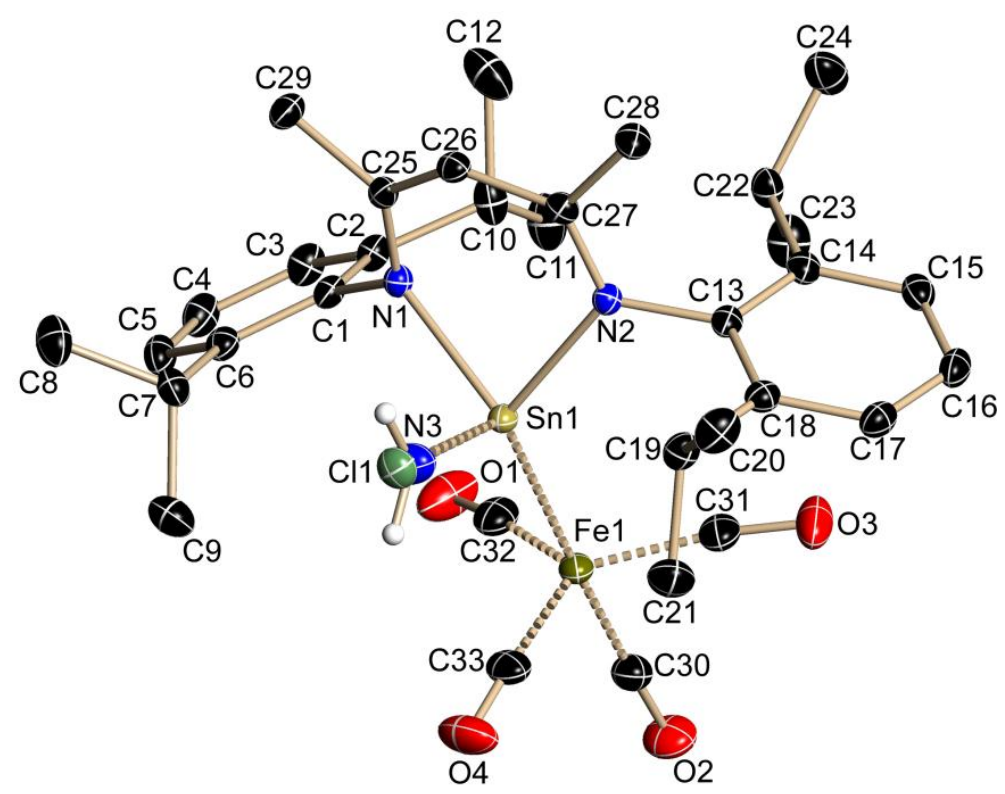

Figure 7-46. Asymmetric unit of $\left[\mathrm{CH}\left\{\mathrm{CMe}\left(2,6-{ }^{i} \mathrm{Pr}_{2} \mathrm{C}_{6} \mathrm{H}_{3} \mathrm{~N}\right)\right\}_{2}\right] \mathrm{Sn}\left(\mathrm{Cl} / \mathrm{NH}_{2}\right) \mathrm{Fe}(\mathrm{CO})_{4}$. The anisotropic displacement parameters are depicted at the $50 \%$ probability level. The hydrogen atoms are omitted for clarity.

The amine moiety (N3) is disordered with a chlorine atom in a ratio $0.75: 0.25$. The positions of the hydrogen atoms bonded to the amine nitrogen atom and C26 were taken from difference map and refined with distance restraints.

Table 7-46. Crystallographic data for $\left[\mathrm{CH}\left\{\mathrm{CMe}\left(2,6{ }^{i} \mathrm{Pr}_{2} \mathrm{C}_{6} \mathrm{H}_{3} \mathrm{~N}\right)\right\}_{2}\right] \mathrm{Sn}\left(\mathrm{Cl} / \mathrm{NH}_{2}\right) \mathrm{Fe}(\mathrm{CO})_{4}$.

\begin{tabular}{|c|c|c|c|}
\hline Identification code & IOAJ65 & & \\
\hline Empirical formula & $\mathrm{C}_{33} \mathrm{H}_{42.5} \mathrm{Cl}_{0.3} \mathrm{FeN}_{2.7} \mathrm{O}_{4} \mathrm{Sn}$ & $\mu\left[\mathrm{mm}^{-1}\right]$ & 1.272 \\
\hline Formula weight $[\mathrm{g} / \mathrm{mol}]$ & 725.20 & $F(000)$ & 1488 \\
\hline Temperature $[\mathrm{K}]$ & $100(2)$ & $\Theta$ range $\left[{ }^{\circ}\right]$ & 2.33 to 26.37 \\
\hline Wavelength [pm] & 71.073 & Reflections collected & 43841 \\
\hline Crystal system & Monoclinic & Independent reflections & 6665 \\
\hline Space group & $P 2_{1} / n$ & Completeness to $\Theta_{\max }$ & $99.9 \%$ \\
\hline$a[\mathrm{pm}]$ & $1004.23(19)$ & Absorption correction & Empirical \\
\hline$b[\mathrm{pm}]$ & $2010.6(4)$ & Max. / min. transmission & $0.4305 / 0.3794$ \\
\hline$c[\mathrm{pm}]$ & $1673.3(3)$ & Restraints / parameters & $4 / 408$ \\
\hline$\beta\left[^{\circ}\right]$ & $105.321(2)$ & GoF & 1.024 \\
\hline Volume $\left[\mathrm{nm}^{3}\right]$ & $3.2585(11)$ & $R 1 / w R 2(1>2 \sigma(I))$ & $0.0189 / 0.0476$ \\
\hline Z & 4 & $R 1 / w R 2$ (all data) & 0.0234 / 0.0499 \\
\hline$\rho_{\text {calc }}\left[\mathrm{Mg} / \mathrm{m}^{3}\right]$ & 1.478 & Diff. peak and hole $\left[\mathrm{e} \AA^{-3}\right]$ & 0.390 and -0.317 \\
\hline
\end{tabular}




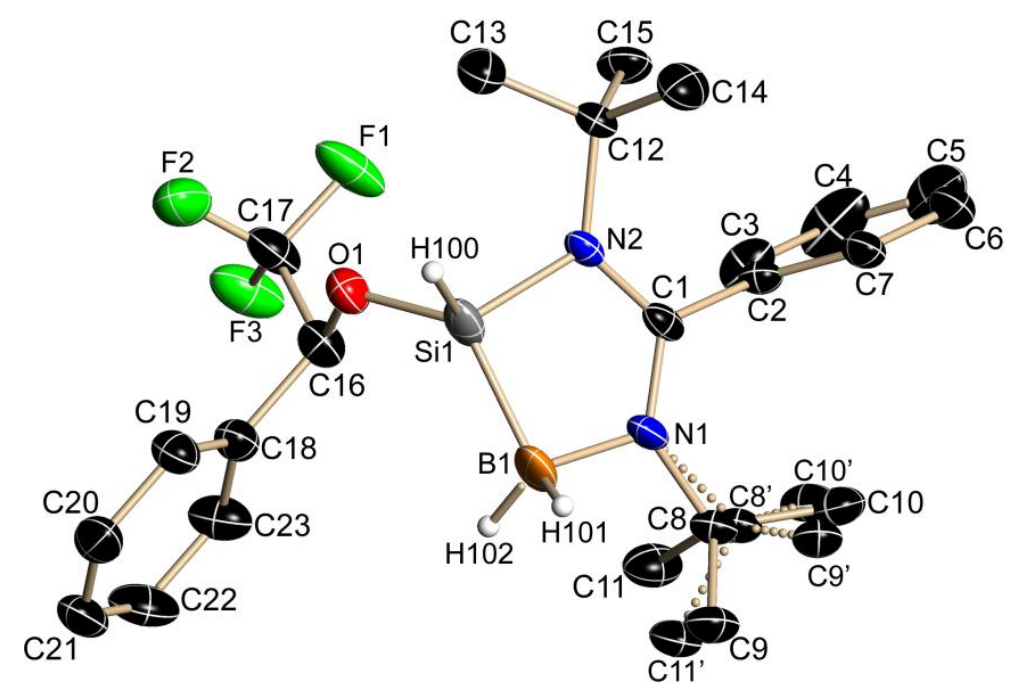

Figure 7-47. Asymmetric unit of $\mathrm{PhC}(\mathrm{NtBu})_{2} \mathrm{BH}_{2} \mathrm{Si}(\mathrm{H}) \mathrm{OCF}_{3} \mathrm{Bn}$. The anisotropic displacement parameters are depicted at the $50 \%$ probability level. The hydrogen atoms are omitted for clarity.

The positions of the hydrogen atoms $\mathrm{H} 100$ at $\mathrm{Si} 1$ and $\mathrm{H} 101$ and $\mathrm{H} 102$ at $\mathrm{B} 1$ were taken from difference map and refined with distance restraints. The tbutyl moiety at $\mathrm{N} 1$ is disordered (ratio $0.62: 0.38$ ).

Table 7-47. Crystallographic data for $\mathrm{PhC}(\mathrm{NtBu})_{2} \mathrm{BH}_{2} \mathrm{Si}(\mathrm{H}) \mathrm{OCF}_{3} \mathrm{Bn}$.

\begin{tabular}{|c|c|c|c|}
\hline Identification code & IOAJ78 & & \\
\hline Empirical formula & $\mathrm{C}_{23} \mathrm{H}_{32} \mathrm{BF}_{3} \mathrm{~N}_{2} \mathrm{OSi}$ & $\rho_{\text {calc }}\left[\mathrm{Mg} / \mathrm{m}^{3}\right]$ & 1.262 \\
\hline Formula weight $[\mathrm{g} / \mathrm{mol}]$ & 448.41 & $\mu\left[\mathrm{mm}^{-1}\right]$ & 0.140 \\
\hline Temperature $[\mathrm{K}]$ & $100(2)$ & $F(000)$ & 476 \\
\hline Wavelength [pm] & 71.073 & $\Theta$ range $\left[{ }^{\circ}\right]$ & 1.78 to 23.62 \\
\hline Crystal system & Triclinic & Reflections collected & 28910 \\
\hline Space group & $P \overline{1}$ & Independent reflections & 3530 \\
\hline$a[\mathrm{pm}]$ & $910.36(8)$ & Completeness to $\Theta_{\max }$ & $99.8 \%$ \\
\hline$b[\mathrm{pm}]$ & 1175.39(11) & Absorption correction & Empirical \\
\hline$c[\mathrm{pm}]$ & 1199.37(11) & Max. / min. transmission & 0.7449 / 0.6788 \\
\hline$\alpha\left[^{\circ}\right]$ & $101.596(3)$ & Restraints / parameters & $18 / 330$ \\
\hline$\beta\left[^{\circ}\right]$ & $109.250(3)$ & GoF & 1.097 \\
\hline$\nu\left[^{\circ}\right]$ & $91.843(3)$ & $R 1 / w R 2(I>2 \sigma(I))$ & $0.0475 / 0.1133$ \\
\hline Volume $\left[\mathrm{nm}^{3}\right]$ & $1.18013(19)$ & $R 1 / w R 2$ (all data) & $0.0581 / 0.1190$ \\
\hline Z & 2 & Diff. peak and hole $\left[\mathrm{e}^{-3}\right]$ & 0.410 and -0.363 \\
\hline
\end{tabular}




\subsubsection{Structure measured for Dr. Monika Heinz}
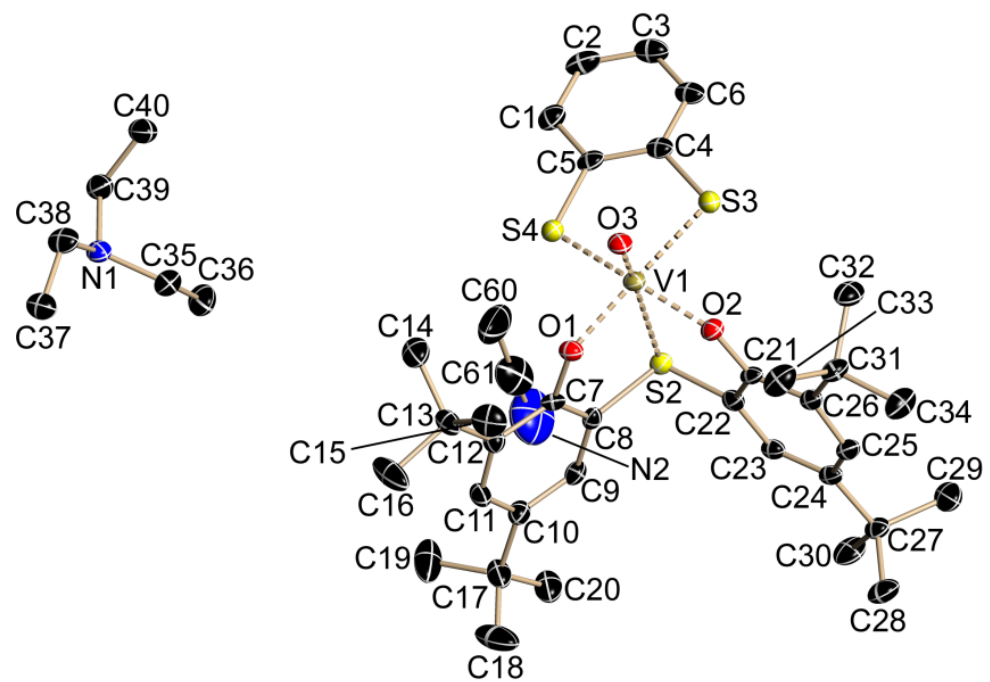

Figure 7-48. Asymmetric unit of $\left(2,4-{ }^{i} \mathrm{PrC}_{6} \mathrm{H}_{2} \mathrm{O}\right){ }_{2} \mathrm{SV}(\mathrm{O})\left(\mathrm{S}_{2} \mathrm{C}_{6} \mathrm{H}_{4}\right)\left(\mathrm{NEt}_{3}\right)\left(\mathrm{CH}_{3} \mathrm{CN}\right)$. The anisotropic displacement parameters are depicted at the $50 \%$ probability level. The hydrogen atoms are omitted for clarity.

Table 7-48. Crystallographic data for $\left(2,4-{ }^{i} \mathrm{PrC}_{6} \mathrm{H}_{2} \mathrm{O}\right)_{2} \mathrm{SV}(\mathrm{O})\left(\mathrm{S}_{2} \mathrm{C}_{6} \mathrm{H}_{4}\right)\left(\mathrm{NEt}_{3}\right)\left(\mathrm{CH}_{3} \mathrm{CN}\right)$.

\begin{tabular}{ll|ll}
\hline Identification code & IOPFSO09 & & \\
Empirical formula & $\mathrm{C}_{42} \mathrm{H}_{63} \mathrm{~N}_{2} \mathrm{O}_{3} \mathrm{~S}_{3} \mathrm{~V}$ & $\rho_{\text {calc }}\left[\mathrm{Mg} / \mathrm{m}^{3}\right]$ & 1.210 \\
Formula weight $[\mathrm{g} / \mathrm{mol}]$ & 791.06 & $\mu\left[\mathrm{mm}^{-1}\right]$ & 0.410 \\
Temperature $[\mathrm{K}]$ & $105(2)$ & $\mathrm{F}(000)$ & 848 \\
Wavelength $[\mathrm{pm}]$ & 71.073 & $\Theta$ range $\left[^{\circ}\right]$ & 1.31 to 25.36 \\
Crystal system & Triclinic & Reflections collected & 20740 \\
Space group & $P \overline{1}$ & Independent reflections & 7905 \\
$a[\mathrm{pm}]$ & $1054.54(12)$ & Completeness to $\Theta_{\text {max }}$ & $99.3 \%$ \\
$b[\mathrm{pm}]$ & $1398.65(15)$ & Absorption correction & Empirical \\
$c[\mathrm{pm}]$ & $1631.38(18)$ & Max. / min. transmission & $0.4288 / 0.3231$ \\
$\alpha\left[^{\circ}\right]$ & $102.268(2)$ & Restraints / parameters & $0 / 476$ \\
$\beta\left[^{\circ}\right]$ & $97.565(2)$ & GoF & 1.017 \\
$\gamma\left[^{\circ}\right]$ & $108.878(2)$ & $R 1 / w R 2$ (I>2 $\sigma(\mathrm{I}))$ & $0.0497 / 0.0893$ \\
Volume $\left[\mathrm{nm}^{3}\right]$ & $2.1719(4)$ & $R 1 / w R 2$ (all data) & $0.0869 / 0.0971$ \\
$Z$ & 2 & Diff. peak and hole [e $\left.\AA^{-3}\right]$ & 0.408 and -0.381 \\
\hline
\end{tabular}




\section{REFERENCES}

[1] B. Cornils, W. A. Herrmann, M. Muhler, C.-H. Wong, Catalysis from A to Z: A Concise Encyclopedia, Wiley-VCH, Weinheim, 2007.

[2] C. Janiak, T. M. Klapötke, H.-J. Meyer, Moderne Anorganische Chemie (E. Riedel), Walter de Gruyter, Berlin / New York, 1999.

[3] a) J. A. Osborn, F. H. Jardine, J. F. Young, G. Wilkinson, J. Chem. Soc. A 1966, 1711-1732; b) D. Evans, G. Yagupsky, G. Wilkinson, J. Chem. Soc. A 1968, 2660-2665; c) S. S. Bath, L. Vaska, J. Am. Chem. Soc. 1963, 85, 3500-3501.

[4] a) W. A. Herrmann, C. W. Kohlpaintner, H. Bahrmann, W. Konkol, J. Mol. Catal. 1992, 73, 191201; b) H. Chen, Y. Li, R. Li, P. Cheng, X. Li, J. Mol. Catal. A 2003, 198, 1-7; c) H. Bahrmann, W. A. Herrmann, C. Kohlpaintner, R. Manetsberger (Hoechst), DE 4220267, 1993.

[5] a) C. G. Arena, F. Nicolo, D. Drommi, G. Bruno, F. Faraone, J. Chem. Soc., Chem. Commun. 1994, 2251-2252; b) C. Basoli, C. Botteghi, M. A. Cabras, G. Chelucci, M. Marchetti, J. Organomet. Chem. 1995, 488, C20-C22; c) K. Nozaki, N. Sakai, T. Nanno, T. Higashijima, S. Mano, T. Horiuchi, H. Takaya, J. Am. Chem. Soc. 1997, 119, 4413-4423; d) I. Arribas, S. Vargas, M. Rubio, A. Suárez, C. Domene, E. Álvarez, A. Pizzano, Organometallics 2010, 29, 5791-5804.

[6] a) T. K. Panda, P. W. Roesky, Chem. Soc. Rev. 2009, 38, 2782-2804; b) K. Kutlescha, T. Irrgang, R. Kempe, Adv. Synth. Catal. 2010, 352, 3126-3130; c) M. Simona, Coord. Chem. Rev. 2009, 253, 1793-1832; d) G. P. C. M. Dekker, A. Buijs, C. J. Elsevier, K. Vrieze, P. W. N. M. Van Leeuwen, W. J. J. Smeets, A. L. Spek, Y. F. Wang, C. H. Stam, Organometallics 1992, 11, 1937-1948.

[7] a) J. Pfeiffer, G. Kickelbick, U. Schubert, Organometallics 1999, 19, 62-71; b) O. Kühl, P. Lönnecke, Inorg. Chem. 2002, 41, 4315-4317; c) R. Romeo, Luigi M. Scolaro, Maria R. Plutino, A. Romeo, F. Nicolo', Alessandro D. Zotto, Eur. J. Inorg. Chem. 2002, 2002, 629-638; d) T. Cantat, B. L. Scott, D. E. Morris, J. L. Kiplinger, Inorg. Chem. 2009, 48, 2114-2127; e) L. J. Hounjet, M. Bierenstiel, M. J. Ferguson, R. McDonald, M. Cowie, Dalton Trans. 2009, 4213-4226; f) A. R. Shaffer, J. A. R. Schmidt, Organometallics 2009, 28, 2494-2504; g) M. Jiménez-Tenorio, M. C. Puerta, P. Valerga, S. Moncho, G. Ujaque, A. Lledós, Inorg. Chem. 2010, 49, 6035-6057; h) I. Hyder, M. Jiménez-Tenorio, M. C. Puerta, P. Valerga, Organometallics 2011, 30, 726-737.

[8] J. C. Jeffrey, T. B. Rauchfuss, Inorg. Chem. 1979, 18, 2658-2666.

[9] a) R. G. Pearson, J. Am. Chem. Soc. 1963, 85, 3533-3539; b) R. G. Parr, R. G. Pearson, J. Am. Chem. Soc. 1983, 105, 7512-7516.

[10] P. Braunstein, F. Naud, Angew. Chem. 2001, 113, 702-722; Angew. Chem. Int. Ed. 2001, 40, 680700.

[11] I. Objartel, H. Ott, D. Stalke, Z. Anorg. Allg. Chem. 2008, 634, 2373-2379.

[12] E. Poverenov, M. Gandelman, L. J. W. Shimon, H. Rozenberg, Y. Ben-David, D. Milstein, Chem. Eur. J. 2004, 10, 4673-4684.

[13] a) M. Veith, S. Weidner, K. Kunze, D. Käfer, J. Hans, V. Huch, Coord. Chem. Rev. 1994, 137, $297-$ 322; b) T. Stey, D. Stalke, Z. Anorg. Allg. Chem. 2005, 651, 2931-2936; c) T. Stey, J. Henn, D. Stalke, Chem. Commun. 2007, 413-415; d) I. Kuzu, I. Krummenacher, J. Meyer, F. Armbruster, F. Breher, Dalton Trans. 2008, 5836-5865; e) J. J. Weigand, K.-O. Feldmann, A. K. C. Echterhoff, A. W. Ehlers, K. Lammertsma, Angew. Chem. 2010, 122, 6314-6317; Angew. Chem. Int. Ed. 2010, 49, 6178-6181; f) I. Objartel, N. A. Pott, M. John, D. Stalke, Organometallics 2010, 29, 56705675; g) M. M. Meinholz, S. K. Pandey, S. M. Deuerlein, D. Stalke, Dalton Trans. 2011, 40, 16621671; h) L. Mahalakshmi, D. Stalke in Structure and Bonding - Group 13 Chemistry I, (Ed.: Springer Verlag, Heidelberg, 2002, pp. 85-115.

[14] a) F. Baier, Z. Fei, H. Gornitzka, A. Murso, S. Neufeld, M. Pfeiffer, I. Rüdenauer, A. Steiner, T. Stey, D. Stalke, J. Organomet. Chem. 2002, 661, 111-127; b) T. Stey, M. Pfeiffer, J. Henn, S. K. Pandey, D. Stalke, Chem. Eur. J. 2007, 13, 3636-3642.

[15] a) R. M. Silva, C. Gwengo, S. V. Lindeman, M. D. Smith, J. R. Gardinier, Inorg. Chem. 2006, 45, 10998-11007; b) J. R. Gardinier, R. M. Silva, C. Gwengo, S. V. Lindeman, Chem. Commun. 2007, 1524-1526; c) F. Armbruster, I. Fernández, F. Breher, Dalton Trans. 2009, 5612-5626; d) S. Trofimenko, Chem. Rev. 1993, 93, 943-980. 
[16] a) J. A. Casares, P. Espinet, J. M. Martín-Alvarez, V. Santos, Inorg. Chem. 2004, 43, 189-197; b) J. A. Casares, P. Espinet, J. M. Martín-Álvarez, V. Santos, Inorg. Chem. 2006, 45, 6628-6636; c) C. Kling, D. Leusser, T. Stey, D. Stalke, Organometallics 2011, 30, 2461-2463.

[17] M. Viciano, M. Sanaú, E. Peris, Organometallics 2007, 26, 6050-6054.

[18] D. M. Khramov, E. L. Rosen, V. M. Lynch, C. W. Bielawski, Angew. Chem. 2008, 120, 2299-2302; Angew. Chem. Int. Ed. 2008, 47, 2267-2270.

[19] a) P. K. Byers, N. Carr, F. G. A. Stone, J. Chem. Soc., Dalton Trans. 1990, 3701-3708; b) P. K. Byers, F. G. A. Stone, J. Chem. Soc., Dalton Trans. 1991, 93-99; c) C. Kling, PhD Thesis, Germany (Göttingen), 2010.

[20] E. Lindner, H. Rauleder, W. Hiller, Z. Naturforsch. 1983, 38b, 417-425.

[21] E. Lindner, H. Rauleder, P. Wegner, Z. Naturforsch. 1984, 39b, 1224-1229.

[22] A. Kermagoret, F. Tomicki, P. Braunstein, Dalton Trans. 2008, 22, 2901-3016.

[23] a) K. K. Klausmeyer, F. Hung, Acta Crystallogr., Sect. E. 2006, 62, m2415-m2416; b) K. K. Klausmeyer, A. Renz, F. Hung-Low, Eur. J. Inorg. Chem. 2009, 20, 2994-3002; c) S. Liu, R. Peloso, P. Braunstein, Dalton Trans. 2010, 39, 2563-2572; d) S. Liu, R. Peloso, R. Pattacini, P. Braunstein, Dalton Trans. 2010, 39, 7881-7883; e) S. Liu, R. Pattacini, P. Braunstein, Organometallics 2011, 30, 3549-3558.

[24] C. Kling, Diploma Thesis, Germany (Göttingen), 2006.

[25] N. A. Pott, Examensarbeit, Germany (Göttingen), 2009.

[26] D. Stalke Chem. Eur. J. 2011, 17, 9264-9278.

[27] G. M. Sheldrick, SHELXL in SHELXTL v2008/4, Madison, 2008.

[28] R. F. W. Bader, Atoms in Molecules - A Quantum Theory, Oxford University Press, New York, 1990.

[29] a) A. Volkov, P. Macchi, L. J. Farrugia, C. Gatti, P. R. Mallinson, T. Richter, T. Koritsanszky, XD2006, A Computer Program Package for Multipole Refinement, Topological Analysis of Charge Densities and Evaluation of Intermolecular Energies from Experimental or Theoretical Structure Factors, 2006; b) The multipole modeling was done by Dr. Dirk Leusser of our working group; private communication.

[30] Z. Su, P. Coppens, Acta Crystallogr. 1998, A54, 646-652.

[31] a) S. Deuerlein, D. Leusser, U. Flierler, H. Ott, D. Stalke, Organometallics 2008, 27, 2306-2315; b) H. Ott, U. Pieper, D. Leusser, U. Flierler, J. Henn, D. Stalke, Angew. Chem. 2009, 121, 3022-3026; Angew. Chem. Int. Ed. 2009, 48, 2978-2982; c) J. Hey, D. Leusser, D. Kratzert, J. Dieterich, R. A. Mata, D. Stalke, Angew. Chem. Int. Ed. 2011, in preparation; d) H. Ott, C. Däschlein, D. Leusser, D. Schildbach, T. Seibel, D. Stalke, C. Strohmann, J. Am. Chem. Soc. 2008, 130, 11901-11911; e) D. Kratzert, D. Leusser, D. Stern, J. Meyer, F. Breher, D. Stalke Chem. Commun. 2011, 47, 2931 2933.

[32] C. B. Hübschle, B. Dittrich, J. Appl. Crystallogr. 2011, 44, 238-240.

[33] a) N. Kocher, D. Leusser, A. Murso, D. Stalke, Chem. Eur. J. 2004, 10, 3622-3631; b) A. Murso, D. Stalke, Dalton Trans. 2004, 2563-2569; c) A. Murso, M. Straka, M. Kaupp, R. Bertermann, D. Stalke, Organometallics 2005, 24, 3576-3578.

[34] a) W.-P. Leung, Z.-X. Wang, H.-W. Li, Q.-C. Yang, T. C. W. Mak, J. Am. Chem. Soc. 2001, 123, 8123-8124; b) W.-P. Leung, Q. W.-Y. Ip, S.-Y. Wong, T. C. W. Mak, Organometallics 2003, 22, 4604-4609; c) W.-H. Leung, Q.-F. Zhang, X.-Y. Yi, Coord. Chem. Rev. 2007, 251, 2266-2279.

[35] P. Rademacher, Strukturen organischer Moleküle, VCH, New York, 1987.

[36] a) A. Steiner, D. Stalke, J. Chem. Soc., Chem. Commun. 1993, 444-446; b) J. Henn, K. Meindl, A. Oechsner, G. Schwab, T. Koritsanszky, D. Stalke, Angew. Chem. 2010, 122, 2472-2476; Angew. Chem. Int. Ed. 2010, 49, 2422-2426.

[37] Cambridge Structural Database, release 5.31, 2009.

[38] a) A. Murso, D. Stalke, Eur. J. Inorg. Chem. 2004, 4272-4277; b) H. Gornitzka, D. Stalke, Eur. J. Inorg. Chem. 1998, 311-317.

[39] a) D. Seebach, R. Hässig, J. Gabriel, Helv. Chim. Acta 1983, 66, 308-337; b) J. F. McGarrity, C. A. Ogle, Z. Brich, H.-R. Loosli, J. Am. Chem. Soc. 1985, 107, 1810-1815; c) W. Bauer, W. R. Winchester, P. v. R. Schleyer, Organometallics 1987, 6, 2371-2379; d) M. A. Nichols, P. G. Williard, J. Am. Chem. Soc. 1993, 115, 1568-1572; e) T. Tatic, K. Meindl, J. Henn, S. K. Pandey, D. Stalke, Chem. Commun. 2010, 46, 4562-4564.

[40] C. D. Broaddus, J. Org. Chem. 1970, 35, 10-15. 
[41] T. Kottke, D. Stalke, Angew. Chem. 1993, 105, 619-621; Angew. Chem. Int. Ed. Engl. 1993, 32, 580-582.

[42] T. Tatic, H. Ott, D. Stalke, Eur. J. Inorg. Chem. 2008, 3765-3768.

[43] a) L. Lochmann, J. Pospísil, D. Lím, Tetrahedron Lett. 1966, 2, 257-262; b) M. Schlosser, J. Organomet. Chem. 1967, 8, 9-16.

[44] M. Schlosser, J. Hartmann, Angew. Chem. 1973, 85, 544-545; Angew. Chem. Int. Ed. Engl. 1973, 12, 508-509.

[45] M. Schlosser, Pure Appl. Chem. 1988, 60, 1627-1634.

[46] Cambridge Structural Database, release 5.32, 2010.

[47] a) L. Lochmann, J. Trekoval, Collect. Czech. Chem. Commun. 1988, 53, 76-96; b) L. Lochmann, Eur. J. Inorg. Chem. 2000, 1115-1126.

[48] a) F. M. Mackenzie, R. E. Mulvey, W. Clegg, L. Horsburgh, J. Am. Chem. Soc. 1996, 118, 47214722; b) W. Clegg, S. T. Liddle, A. M. Drummond, R. E. Mulvey, A. Robertson, Chem. Commun. 1999, 1569-1570; c) A. R. Kennedy, J. G. MacLellan, R. E. Mulvey, A. Robertson, J. Chem. Soc., Dalton Trans. 2000, 4112-4116; d) D. R. Armstrong, W. Clegg, A. M. Drummond, S. T. Liddle, R. E. Mulvey, J. Am. Chem. Soc. 2000, 122, 11117-11124; e) P. C. Andrews, J. G. MacLellan, R. E. Mulvey, P. J. Nichols, J. Chem. Soc., Dalton Trans. 2002, 1651-1655.

[49] A. R. Kennedy, J. G. MacLellan, R. E. Mulvey, Angew. Chem. 2001, 113, 3345-3347; Angew. Chem. Int. Ed. 2001, 40, 3245-3247.

[50] a) M. R. Churchill, C. H. Lake, S.-H. L. Chao, O. T. Beachley, J. Chem. Soc., Chem. Commun. 1993, 1577-1578; b) A. Decken, J. Passmore, X. Wang, Angew. Chem. 2006, 118, 2839-2843; Angew. Chem. Int. Ed. 2006, 45, 2773-2777.

[51] E. Weiss, E. A. C. Lucken, J. Organomet. Chem. 1964, 2, 197-205

[52] a) W. Hess, J. Treutwein, G. Hilt, Synthesis 2008, 22, 3537-3562; b) M. Zhang, Appl. Organometal. Chem. 2010, 24, 269-284; c) C.-L. Sun, B.-J. Li, Z.-J. Shi, Chem. Rev. 2010, 111, 1293-1314.

[53] B. Li, Z.-H. Wu, Y.-F. Gu, C.-L. Sun, B.-Q. Wang, Z.-J. Shi, Angew. Chem. 2011, 123, 1141-1145; Angew. Chem. Int. Ed. 2011, 50, 1109-1113.

[54] C. J. Moody, Angew. Chem. 2007, 119, 9308-9310; Angew. Chem. Int. Ed. 2007, 46, 9148-9150.

[55] P. E. Sues, A. J. Lough, R. H. Morris, Organometallics 2011, 30, 4418-4431.

[56] I. P. Beletskaya, A. V. Cheprakov, Chem. Rev. 2000, 100, 3009-3066.

[57] K. C. Nicolaou, P. G. Bulger, D. Sarlah, Angew. Chem. 2005, 117, 4487-4487; Angew. Chem. Int. Ed. 2005, 44, 4442-4489.

[58] A. Suzuki, Angew. Chem. 2011, 123, 6854-6869; Angew. Chem. Int. Ed. 2011, 50, 6722-6737.

[59] J. Wiedermann, K. Mereiter, K. Kirchner, J. Mol. Catal. A 2006, 257, 67-72.

[60] P. A. Aguirre, C. A. Lagos, S. A. Moya, C. Zuniga, C. Vera-Oyarce, E. Sola, G. Peris, J. C. Bayon, Dalton Trans. 2007, 5419-5426.

[61] a) M. A. Giardello, V. P. Conticello, L. Brard, M. R. Gagne, T. J. Marks, J. Am. Chem. Soc. 1994, 116, 10241-10254; b) Y. Li, T. J. Marks, J. Am. Chem. Soc. 1998, 120, 1757-1771; c) V. M. Arredondo, F. E. McDonald, T. J. Marks, Organometallics 1999, 18, 1949-1960.

[62] M. R. Douglass, T. J. Marks, J. Am. Chem. Soc. 2000, 122, 1824-1825.

[63] A. Zulys, T. K. Panda, M. T. Gamer, P. W. Roesky, Chem. Commun. 2004, 2584-2585.

[64] M. D. Fryzuk, P. Yu, B. O. Patrick, Can. J. Chem. 2001, 79, 1194-1200.

[65] M. D. Fryzuk, L. Jafarpour, F. M. Kerton, J. B. Love, B. O. Patrick, S. J. Rettig, Organometallics 2001, 20, 1387-1396.

[66] L. Douce, L. J. Charbonnière, M. Cesario, R. Ziessel, New J. Chem. 2001, 25, 1024-1030.

[67] M. Montalti, L. Prodi, N. Zaccheroni, L. Charbonnière, L. Douce, R. Ziessel, J. Am. Chem. Soc. 2001, 123, 12694-12695.

[68] L. J. Charbonnière, R. Ziessel, M. Montalti, L. Prodi, N. Zaccheroni, C. Boehme, G. Wipff, J. Am. Chem. Soc. 2002, 124, 7779-7788.

[69] T. Steiner, Angew. Chem. 2002, 114, 50-80; Angew. Chem. Int. Ed. 2002, 41, 48-78.

[70] F. Hung-Low, K. K. Klausmeyer, Polyhedron 2010, 29, 1676-1686.

[71] K. K. Klausmeyer, F. Hung, Acta Crystallogr., Sect. E. 2006, 62, 05560-05562.

[72] D. W. Stephan, Dalton Trans. 2009, 3129-3136.

[73] D. W. Stephan, Org. Biomol. Chem. 2008, 6, 1535-1539. 
[74] P. Spies, G. Erker, G. Kehr, K. Bergander, R. Frohlich, S. Grimme, D. W. Stephan, Chem. Commun. 2007, 5072-5074.

[75] D. W. Stephan, G. Erker, Angew. Chem. 2010, 122, 50-81; Angew. Chem. Int. Ed. 2010, 49, 4676.

[76] D. W. Stephan, S. Greenberg, T. W. Graham, P. Chase, J. J. Hastie, S. J. Geier, J. M. Farrell, C. C. Brown, Z. M. Heiden, G. C. Welch, M. Ullrich, Inorg. Chem. 2011, published online.

[77] a) H. Braunschweig, C. Kollann, K. W. Klinkhammer, Eur. J. Inorg. Chem. 1999, 1999, 1523-1529; b) H. Braunschweig, C. von Koblinski, M. Neugebauer, U. Englert, X. Zheng, J. Organomet. Chem. 2001, 619, 305-312; c) M. Yamashita, K. Kamura, Y. Yamamoto, K.-y. Akiba, Chem. Eur. J. 2002 8, 2976-2979; d) Pamela J. Shapiro, F. Jiang, X. Jin, B. Twamley, Jasson T. Patton, Arnold L. Rheingold, Eur. J. Inorg. Chem. 2004, 3370-3378; e) C. Mazet, V. Köhler, A. Pfaltz, Angew. Chem. 2005, 117, 4966-4969; Angew. Chem. Int. Ed. 2005, 44, 4888-4891; f) V. Köhler, C. Mazet, A. Toussaint, K. Kulicke, D. Häussinger, M. Neuburger, S. Schaffner, S. Kaiser, A. Pfaltz, Chem. Eur. J. 2008, 14, 8530-8539.

[78] W. Schlenk, A. Thal, Ber. Dtsch. Chem. Ges. 1913, 46, 2840-2854.

[79] M. J. S. Gynane, D. H. Harris, M. F. Lappert, P. P. Power, P. Rivière, M. Rivière-Baudet, J. Chem. Soc., Dalton Trans. 1977, 2004-2009.

[80] R. K. Harris, E. D. Becker, S. M. Cabral de Menezes, R. Goodfellow, P. Granger, Pure Appl. Chem. 2001, 73, 1795-1818.

[81] a) T. Kottke, D. Stalke, J. Appl. Crystallogr. 1993, 26, 615-619; b) D. Stalke, Chem. Soc. Rev. 1998, 27, 171-178.

[82] H. Hope, Acta Crystallogr., Sect. B. 1988, 44, 22-26.

[83] T. Schulz, K. Meindl, D. Leusser, D. Stern, J. Graf, C. Michaelsen, M. Ruf, G. M. Sheldrick, D. Stalke, J. Appl. Crystallogr. 2009, 42, 885-891.

[84] Bruker APEX v2011.4-1, Madison, 2011.

[85] Bruker SAINT v7.68A, Madison, 2009.

[86] W. Kabsch, J. Appl. Crystallogr. 1988, 21, 916-924.

[87] G. M. Sheldrick, SADABS 2008/2, Göttingen, 2008.

[88] G. M. Sheldrick, TWINABS v1.05 in Bruker APEX v2.1-0, Madison, 2005.

[89] G. M. Sheldrick, XPREP Version 2005/2 for Windows, Madison, 2005.

[90] G. M. Sheldrick, Acta Crystallogr., Sect. A. 2008, 64, 112-122.

[91] P. Müller, R. Herbst-Irmer, A. L. Spek, T. R. Schneider, M. R. Sawaya, in Crystal Structure Refinement - A Crystallographer's Guide to SHELXL, Vol. 8 (Ed.: P. Müller), Oxford University Press, Oxford (England), 2006,

[92] P. van der Sluis, A. L. Spek, Acta Crystallogr. 1990, A46, 194-201.

[93] L. F. Tietze, S. Dietz, N. Böhnke, M. A. Düfert, I. Objartel, D. Stalke, Eur. J. Org. Chem. 2011, published online.

[94] L. F. Tietze, T. Hungerland, M. A. Düfert, I. Objartel, D. Stalke, Chem. Eur. J. 2011, accepted.

[95] S. P. Sarish, S. S. Sakya, H. W. Roesky, I. Objartel, D. Stalke, Chem. Commun. 2011, 47, 72067208.

[96] a) A. Jana, I. Objartel, H. W. Roesky, D. Stalke, Inorg. Chem. 2009, 48, 798-800; b) A. Jana, D. Ghoshal, H. W. Roesky, I. Objartel, G. Schwab, D. Stalke, J. Am. Chem. Soc. 2009, 131, 12881293; c) A. Jana, I. Objartel, H. W. Roesky, D. Stalke, Inorg. Chem. 2009, 48, 7645-7649; d) A. Jana, I. Objartel, H. W. Roesky, D. Stalke, Dalton Trans. 2010, 39, 4647-4650; e) A. Jana, S. P. Sarish, H. W. Roesky, D. Leusser, I. Objartel, D. Stalke, Chem. Commun. 2011, 47, 5434-5436; f) A. Jana, D. Leusser, I. Objartel, H. W. Roesky, D. Stalke, Dalton Trans. 2011, 40, 5458-5463; g) A. Jana, R. Azhakar, G. Tavčar, H. W. Roesky, I. Objartel, D. Stalke, Eur. J. Inorg. Chem. 2011, 36863689; h) A. Jana, R. Azhakar, H. W. Roesky, I. Objartel, D. Stalke, Z. Anorg. Allg. Chem. 2011, published online.

[97] P.-C. Kuo, J.-C. Chang, W.-Y. Lee, H. M. Lee, J.-H. Huang, J. Organomet. Chem. 2005, 690, 41684174. 


\section{Curriculum Vitae}

\section{Persönliche Daten}

$\begin{array}{ll}\text { Name } & \text { Ina Objartel } \\ \text { Geburtstag } & 31.12 .1982 \\ \text { Geburtsort } & \text { Kiel } \\ \text { Staatsangehörigkeit } & \text { Deutsch } \\ \text { Familienstand } & \text { Ledig, keine Kinder }\end{array}$

\section{Schulische Bildung}

9/1989-7/1993 Grundschule Raisdorf

8/1993 - 6/1995 Orientierungsstufe: Schule am Wildfang Gronau (Leine)

8/1995-6/2002 Gymnasium Alfeld

6/2002 Schulabschluss: Abitur

(Abiturfächer: Chemie, Geschichte, Deutsch und Biologie)

\section{Akademische Bildung}

10/2002 - 9/2007 Studium der Chemie (Abschluss Diplom) an der Georg-AugustUniversität Göttingen

$10 / 2004$ Diplomvorprüfung

4/2006 - 06/2006 Erasmus Studentin im Arbeitskreis von Prof. Dr. Alberto Brandi, Università degli Studi di Firenze, Florenz, Italien

12/2006 - 6/2007 Diplomarbeit im Arbeitskreis von Prof. Dr. Dietmar Stalke, Georg-August Universität Göttingen, Institut für Anorganische Chemie, „Phosphorzentrierte Januskopf-Liganden in der Metallkoordination" 9/2007 Diplomprüfung August-Universität Göttingen, Institut für Anorganische Chemie, „Design of Phosphorus Centered Janus Head Ligands" 


\section{Universitäre Tätigkeiten}

Seit $12 / 2006$

$10 / 2009-4 / 2011$

$11 / 2007-9 / 2010$
Betreuung von Praktika und Seminaren für Studierende mit Hauptoder Nebenfach Chemie

Leitung und Organisation des Begleitseminars zur Experimentalchemie-Vorlesung "Allgemeine und Anorganische Chemie"

Stellvertretende Sprecherin des JCF Göttingen

Mitgründung des JungChemikerForums (JCF) Göttingen am 07.11.07 (Organisation der Gesellschaft Deutscher Chemiker GDCh)

Organisation der fakultätsinternen Tagung ChemieForum, Göttingen, 04. Juli 2008

Organisation der fakultätsinternen Tagung ChemieForum, Göttingen, 03. Juli 2009

Organisation der internationalen Tagung JCF-Frühjahrssymposium, Göttingen, 17. - 20 März 2010

\section{Fremdsprachenkenntnisse}

Englisch Fließend in Wort und Schrift

Französisch Grundkenntnisse

Italienisch Grundkenntnisse

\section{Poster Präsentationen und Vorträge bei wissenschaftlichen Tagungen}

$9 / 2008$

$3 / 2010$

$11 / 2010$
Poster Präsentation - 11. Norddeutsches Doktorandenkolloquium der Anorganischen Chemie, Burg Warberg, 25. - 26. September 2008 Ina Objartel, Holger Ott, Dietmar Stalke „Temperatur-NMR- und Kristallstruktur-Analyse eines hemilabilen Zinn(II)-Komplexes" Poster Präsentation - 12. JCF-Frühjahrssymposium, Göttingen, 17. - 20 März 2010

Ina Objartel, Nils A. Pott, Dietmar Stalke „Site selective Janus Head ligands"

Vortrag - Center of Materials Crystallography - Second Workshop, Göttingen, 11. - 12. November 2010

"The Janus Head Ligand PhP( $\left.\mathrm{CH}_{2} \mathrm{Py}\right)_{2}$ " 


\section{Veröffentlichungen}

Ina Objartel, Holger Ott, Dietmar Stalke, Z. Anorg. Allg. Chem. 2008, 634, 2373-2379.

"Low-Temperature NMR and Crystal Structure Analyses of a Hemilabile Tin Complex"

Anukul Jana, Ina Objartel, Herbert W. Roesky, Dietmar Stalke, Inorg. Chem. 2009, 48, 798-800.

"Cleavage of a N-H Bond of Ammonia at Room Temperature by a Germylene"

Anukul Jana, Debajyoti Ghoshal, Herbert W. Roesky, Ina Objartel, Gerald Schwab, Dietmar Stalke, J. Am. Chem. Soc. 2009, 131, 1288-1293.

"A Germanium(II) Hydride as an Effective Reagent for Hydrogermylation Reactions"

Anukul Jana, Ina Objartel, Herbert W. Roesky, Dietmar Stalke, Inorg. Chem. 2009, 48, 76457649.

"Dehydrogenation of $\mathrm{LGeH}$ by a Lewis N-Heterocyclic Carbene Borane Pair under the Formation of L'Ge and its Reactions with $B\left(C_{6} F_{5}\right)_{3}$ and Trimethylsilyl Diazomethane: An Unprecedented Rearrangement of a Diazocompound to an Isonitrile"

Ina Objartel, Nils A. Pott, Michael John, Dietmar Stalke, Organometallics 2010, 29, 5670-5675. "Coordination Site Selective Janus Head Ligands"

Anukul Jana, Ina Objartel, Herbert W. Roesky, Dietmar Stalke, Dalton Trans. 2010, 39, 46474650.

"Reaction of $\beta$-diketiminate tin(II) dimethylamide $L S n N M e_{2}\left[\mathrm{~L}=\mathrm{HC}(\mathrm{CMeNAr})_{2} ; \mathrm{Ar}=2,6-\mathrm{iPr}_{2} \mathrm{C}_{6} \mathrm{H}_{3}\right]$ with ketones and alkynes"

Stefano Cicchi, Julia Revuelta, Ina Objartel, Armin de Meijere, Alberto Brandi, Synlett 2010, 13, 1939-1942.

"Switching the Reaction Mode of 4-Methoxycarbonyl-4-chloro-5-spirocyclopropaneisoxazolidines by N-Aryl Substitution"

Anukul Jana, Sankaranarayana P. Sarish, Herbert W. Roesky, Dirk Leusser, Ina Objartel, Dietmar Stalke, Chem. Commun. 2011, 47, 5434-5436.

"Pentafluoropyridine as a fluorinating reagent for preparing a hydrocarbon soluble $\beta$ -

diketiminatolead(II) monofluoride"

Anukul Jana, Dirk Leusser, Ina Objartel, Herbert W. Roesky, Dietmar Stalke, Dalton Trans. 2011, 40, 5458-5463.

"A stable silicon(II) monohydride" 
Sankaranarayana P. Sarish, Sakya S. Sen, Herbert W. Roesky, Ina Objartel, Dietmar Stalke, Chem. Commun. 2011, 47, 7206-7208.

"Elegant approach to spacer arranged silagermylene and bis(germylene) compounds"

Anukul Jana, Ramachandran Azhakar, Gašper Tavčar, Herbert W. Roesky, Ina Objartel, Dietmar Stalke, Eur. J. Inorg. Chem. 2011, 3686-3689.

"Anionic Abnormal N-Heterocyclic Carbene"

Lutz F. Tietze, Simone Dietz, Niels Böhnke, M. Alexander Düfert, Ina Objartel, Dietmar Stalke, Eur. J. Org. Chem. 2011, 6574-6580.

"Three component domino-Knoevenagel/hetero-Diels-Alder Reaction for the Synthesis of the Aminosugars 2-O-acetoxyforosamine and 2-O-acetoxy-ossamine: Experimental and Theoretical Results"

Anukul Jana, Ramachandran Azhakar, Herbert W. Roesky, Ina Objartel, Dietmar Stalke, Z. Anorg. Allg. Chem. 2011, 637, 1795-1799.

"Syntheses of Iron Carbonyl Complexes from N-Heterocyclic Stannylene Compounds"

Lutz F. Tietze, Tim Hungerland, M. Alexander Düfert, Ina Objartel, Dietmar Stalke, Chem. Eur. J. 2011, accepted.

"Synthese von tetrasubstituierten Alkenen durch Pd-katalysierte C-H Funktionalisierung" 